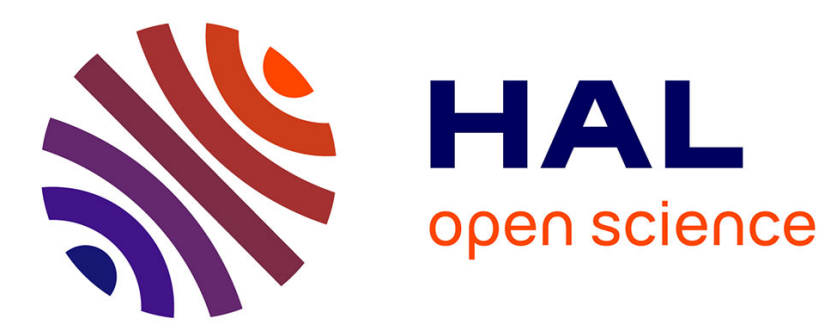

\title{
Migración en el Sur boliviano
}

\author{
Ceydric Martin
}

\section{To cite this version:}

Ceydric Martin. Migración en el Sur boliviano: Contrastes entre valles andinos tradicionales y áreas orientales de colonización. CONICET - IRD. CONICET - IRD, pp.206, 2012, 978-607-00-6141-7. hal-00844591

\section{HAL Id: hal-00844591 \\ https://hal.science/hal-00844591}

Submitted on 15 Jul 2013

HAL is a multi-disciplinary open access archive for the deposit and dissemination of scientific research documents, whether they are published or not. The documents may come from teaching and research institutions in France or abroad, or from public or private research centers.
L'archive ouverte pluridisciplinaire HAL, est destinée au dépôt et à la diffusion de documents scientifiques de niveau recherche, publiés ou non, émanant des établissements d'enseignement et de recherche français ou étrangers, des laboratoires publics ou privés. 


\section{MIGRACIÓN EN EL SUR BOLIVIANO}

CONTRASTES ENTRE VALLES ANDINOS TRADICIONALES Y ÁREAS DE COLONIZACIÓN ORIENTALES

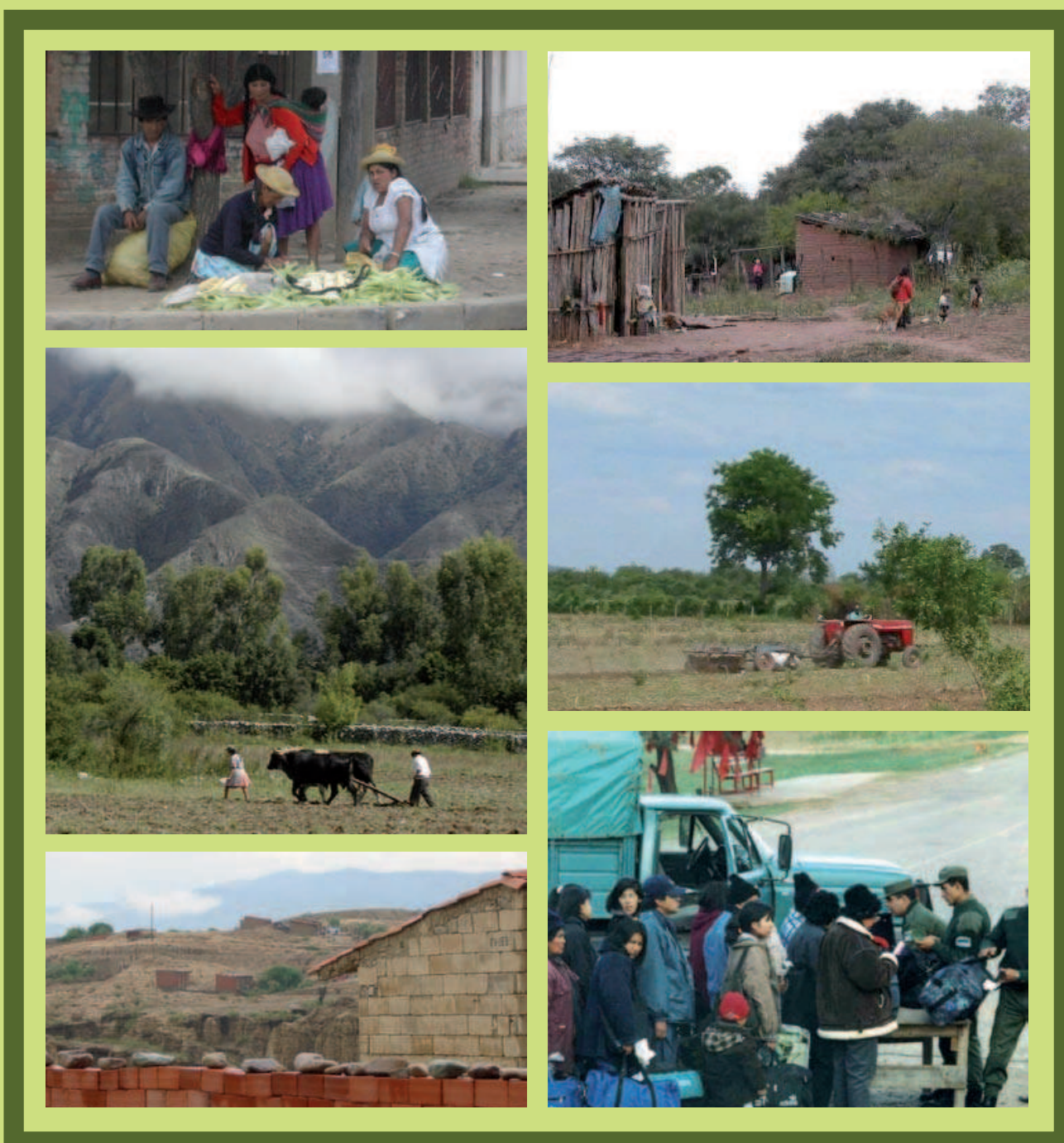

\section{CEYDRIC MARTIN}




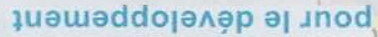

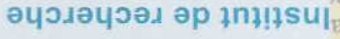

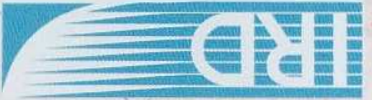

$\sin b \min 4$

VSONOTOI

BIIIOPIEO

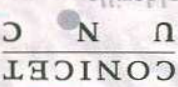
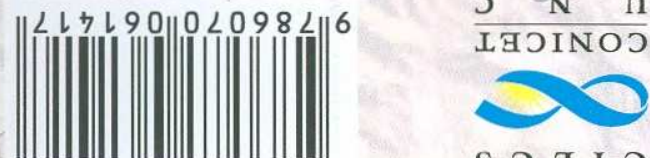

S ว

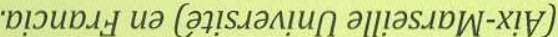

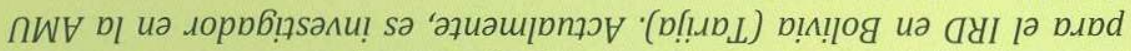

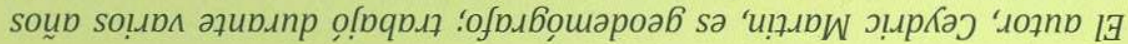

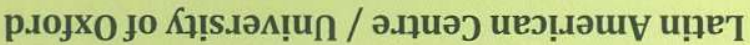 uołsə.Id pı̣ıed}

'еретрпзsә оэод ецәәу еІ

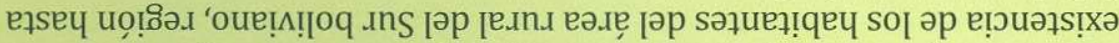

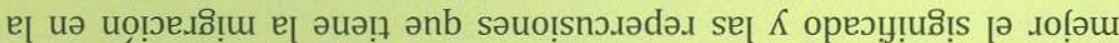

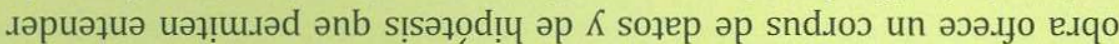

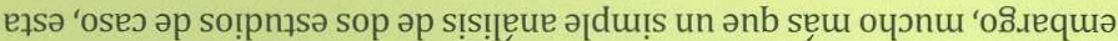

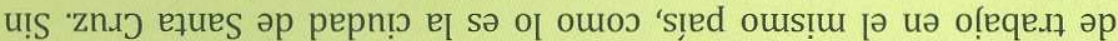

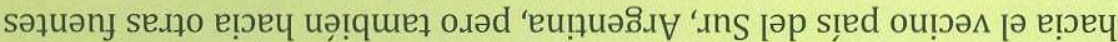

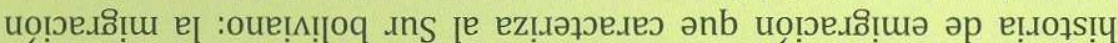
еві.е [

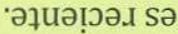
- -

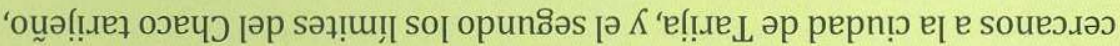

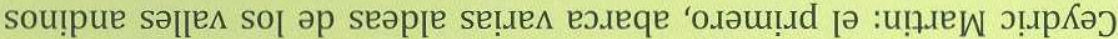

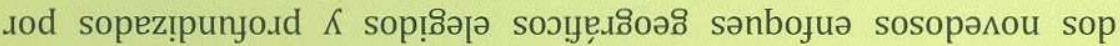
e әqәр әs иәши[о

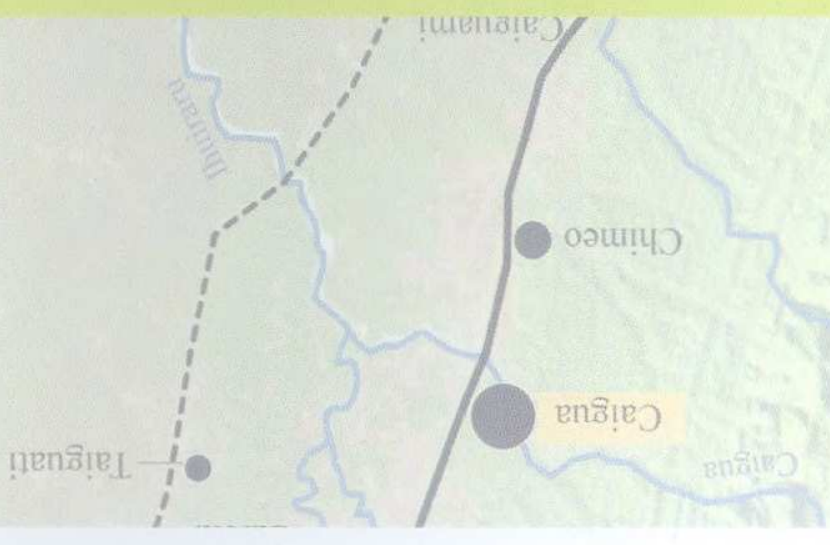





\section{MIGRACIÓN EN EL SUR BOLIVIANO}

CONTRASTES ENTRE VALLES ANDINOS TRADICIONALES Y ÁREAS ORIENTALES DE COLONIZACIÓN 



\title{
Migración en el Sur boliviano
}

\author{
Contrastes entre valles andinos tradicionales \\ y áreas orientales de colonización
}

CeYdric MARTIN

C I E C S
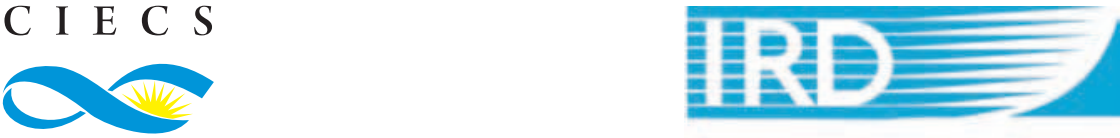

\begin{tabular}{lll} 
C O N I C E T \\
\hline $\mathbf{U} \quad \mathbf{N} \mathbf{C}$
\end{tabular}

Institut de recherche pour le développement 
Primera edición, 2012

(C) Ceydric Martin

Consejo Nacional de Investigaciones Científicas

y Tecnológicas, CONICET

Argentina

Presidente

Dr. Roberto Salvarezza

Universidad Nacional de Córdoba, UNC

Argentina

Rectora

Dra. Silvia Carolina Scotto

Centro de Investigaciones y Estudios sobre Cultura y Sociedad, CONICET-UNC

Argentina

Directora

Dra. Dora E. Celton

Institut de recherche pour le développement, IRD

France

Président

Michel Laurent

ISBN: 978-607-00-6141-7

Se prohíbe la reproducción por cualquier medio sin el consentimiento de los titulares de los derechos de la obra Impreso en México / Printed in Mexico 
$\begin{array}{ll}\text { PREFACIO } & 11\end{array}$

$\begin{array}{ll}\text { INTRODUCCIÓN } & 13\end{array}$

ALGUNAS PRECISIONES METODOLÓGICAS $\quad 19$

$\begin{array}{ll}\text { Entender la complejidad de las migraciones en Bolivia } & 19\end{array}$

El campo de análisis dinámicas del Occidente y del Oriente 25

\section{CAPÍTULO 1}

\section{OCCIDENTE: ÁMBITO CAMPESINO TRADICIONAL} Y EMIGRACIÓN AGRÍCOLA HACIA ARGENTINA

I. LÍMITES DE UNA ACTIVIDAD AGRÍCOLA HETEROGÉNEA 36

A. Adaptación al medio ambiente 38

$\begin{array}{ll}\text { Predominio agrícola } & 38\end{array}$

Preponderancia de las culturas tradicionales $\quad 40$

El acceso a los recursos hídricos, causa de desequilibrios $\quad 42$

Ganadería, actividad secundaria o de sustitución 44

B. Las dificultades del sector agrícola $\quad 49$

Oportunidades comerciales limitadas $\quad 49$

Fragmentación del minifundio $\quad 52$

Perspectivas limitadas $\quad 54$

Subempleo en el sector agrícola de la cuenca 55

II. IMPORTANCIA Y DIVERSIDAD DE LOS DESPLAZAMIENTOS DESDE EL VALLE 57

A. Movimientos estacionales de invierno para reducir el subempleo 58 Migraciones estacionales largas hacia Argentina $\quad 60$

Desplazamientos estacionales: una visión anual 66

B. Migraciones anteriores, otro indicador de diversificación de la actividad 70

$\begin{array}{ll}\text { Similitudes con las migraciones estacionales } & 72\end{array}$

$\begin{array}{ll}\text { Improbables migraciones de regreso } & 73\end{array}$ 
C. Dispersión de la descendencia, testimonio de las migraciones actuales $\quad 74$ Emigración masiva $\quad 75$

Inserción laboral favorable y repercusiones financieras $\quad 80$

Predominio de Argentina $\quad 83$

III. EVOLUCIÓN DE UN MODELO BASADO EN LOS DESPLAZAMIENTOS HACIA ARGENTINA 88

A. La lógica de desplazamientos masivos 88

Estrategias relacionadas con las necesidades específicas
de las comunidades

Adaptación a los cambios del mercado laboral agrícola argentino 90

B. Impacto del modelo migratorio y el futuro del valle 97

Regulación de la presión antrópica, principal efecto de la migración 97

Perspectivas: continuación de la migración y desarrollo

urbano de Tarija

99

\section{CAPÍTULO 2}

\section{ORIENTE: COLONIZACIÓN AGRÍCOLA Y EMIGRACIÓN HACIA LAS CIUDADES BOLIVIANAS}

I. INMIGRACIÓN Y AGRICULTURA, MOTORES DEL DESARROLLO 106

$\begin{array}{lr}\text { A. Atracción creciente } & 108\end{array}$

Tres ciclos de inmigración $\quad 109$

Ampliación del área de atracción $\quad 110$

B. Factores de una dinámica de valoración inédita 116

Inmigración de una población joven y activa 116

Poblamiento y contexto del desarrollo agrícola 118

II. LÍMITES ACtUALES DE LA COLONIZACIÓN AGRÍCOLA 123

$\begin{array}{ll}\text { A. Una comunidad estructurada por la agricultura } & 123\end{array}$

Ganadería, actividad extensa y marginal $\quad 125$

Agricultura diversificada de pequeñas explotaciones familiares $\quad 126$

Formación de un paisaje agrícola compuesto 130

B. Crisis en la tenencia de la tierra agrícola y atracción

por la pluriactividad 134

El acceso a la tierra, freno al crecimiento de Caigua 134

Rumbo a una diversificación de las actividades 139

III. SURGIMIENTO DE UNA EMIGRACIÓN HACIA LAS CIUDADES

$\begin{array}{ll}\text { A. ¿Partidas suscitadas por la crisis? } & 146\end{array}$

Migraciones anteriores: desplazamientos laborales de corta duración 146

La descendencia: retención o instalación fuera de la comunidad 150 
¿Retornos condicionados por la situación económica de los hogares?

B. Redistribución hacia las ciudades del Sureste boliviano

Descripción de los lugares de destino

Atracción de las ciudades del Oriente y movimientos

emergentes hacia el Occidente

CONCLUSIÓN: LAS DINÁMICAS RURALES DIFERENCIADAS

\section{Anexo metodológico}

1. ENTOL 2002 (CUENCA DE TOLOMOSA)

2. ENVIL 2002 (COMUNIDAD DE CAIGUA)

Bibliografía 



\section{Prefacio David Preston*}

Es notable el debate que se da en muchas revistas internacionales de ciencias sociales sobre los cambios en las áreas rurales, tanto en Europa, como en África y en el sur y sudeste de Asia, existiendo asimismo un cuerpo teórico importante. Cabe señalar que estos documentos frecuentemente no están basados sobre estudios cuantitativos a nivel de una muestra de hogares en las localidades que sirven de sustento para estos trabajos. Cualquier análisis cualitativo debe estar apoyado por el uso de los mejores datos cuantitativos posibles para poder examinar la importancia relativa, por ejemplo: la formación de capital humano, la situación económica del hogar e historias de migraciones anteriores.

Aunque es necesario reflexionar sobre lo que representa "lo rural" en esta época de transporte rápido y fácil (para ir al colegio o para buscar trabajo adicional) y de mejoras en las telecomunicaciones (llamadas por teléfono celular para vender a buen precio sus quesos), es imprescindible tener datos concretos para apoyar el análisis y una comprensión de las metas que tiene la gente de las áreas rurales hoy en día.

Los estudios sobre los cuales se basa este libro ofrecen algunas conclusiones para entender mejor ciertos componentes del papel de la migración en las estrategias de los individuos y sus hogares. Durante casi 20 años de trabajo en las áreas rurales de Tarija, (mayormente en los valles centrales alrededor de la capital, en el altiplano tarijeño y el valle de San Juan del Oro) he aprendido

* David Preston es investigador asociado del Latin American Centre de la University of Oxford $<$ www.lac.ox.ac.uk $>$. 
mucho de los intercambios con migrantes, al momento de volver de visita, con gente a punto de partir hacia la Argentina y con mujeres y hombres esperando una llamada telefónica de lejos para tener noticias de sus hijos, hermanos o hermanas. Pero la interpretación de tales conocimientos acumulados tiene poco valor sin una visión más profunda de migración a nivel de comunidad, tal como ofrece este estudio.

La relevancia de los resultados presentados en este volumen se debe a dos novedosos enfoques geográficos elegidos y profundizados por Ceydric Martin: el primero abarca varias aldeas de los valles andinos cercanos a la ciudad de Tarija, y el segundo los límites del Chaco tarijeño, en donde la historia de migración -que en este caso es de inmigración- es reciente.

Estos dos estudios tienen que leerse, y entenderse, en el marco de la larga historia de emigración que caracteriza al sur boliviano: la migración hacia el vecino país austral, Argentina, pero también hacia otras fuentes de trabajo en el mismo país, como lo es la ciudad de Santa Cruz. Sin embargo, mucho más que un simple análisis de dos estudios de caso, esta obra ofrece un corpus de datos y de hipótesis que permiten entender mejor el significado y las repercusiones que tiene la migración en la existencia de los habitantes del área rural del sur boliviano, región hasta la fecha poco estudiada.

Oxford, 15 de agosto de 2012 


\section{Introducción}

En Bolivia, la organización productiva de las zonas rurales occidentales (del Oeste del país) difiere tradicionalmente de la del Oriente (en el Este). ${ }^{2}$ En el Occidente, el campo (y sus tradiciones agrícolas) siempre fue marcado por una gran movilidad espacial de las poblaciones relacionadas con el modo de organización del espacio inca y preinca (Amilhat Szary, 2007). Sin embargo, bajo el dominio español - y de la misma manera que está sucediendo en el resto de América del Sur - las migraciones fueron limitadas, o estrechamente canalizadas, hacia sectores estratégicos como el de las minas. Los campesinos estaban arraigados a las haciendas de los propietarios por las deudas de peonaje y con otras instituciones (Simmons 1985, p. 285). Estas estrategias, motivadas por un sistema de producción que requería abundante mano de obra, ${ }^{3}$ continuaron después de la Independencia, para suministrar de alimentos a las personas que trabajaban en las minas de extracción de oro (hasta 1880) y de estaño (de 1880 a 1930). En cambio, en el Oriente, los pueblos autóctonos se caracterizaron tradicionalmente por un estilo de vida seminómada y combinaban actividades agrícolas con la pesca, la caza y la recolección (Steward 1948). La implantación de los misioneros en el siglo XIX trajo consigo el desarrollo de las actividades agrícolas y la sedentarización de poblaciones de forma excepcional sin que esto generara cambios mayores.

\footnotetext{
${ }^{2}$ En este libro, Oriente y Occidente se refieren a las regiones que conforman la bipartición de Bolivia [Cf. Martin, 2010 para una definición detallada de estos dos conjuntos].

${ }^{3}$ Según Alan Simmons (1985), cuando los españoles llegaron a América Central y a América del Sur a principios del siglo XVI, lo hicieron con un armamento superior, sin embargo su tecnología de producción era sencilla y basada en la capacidad de mano de obra (p. 294). Así, el aumento de la producción dependía más de la constitución de una importante capacidad de mano de obra que del crecimiento de las inversiones de capital en las máquinas (p. 293).
} 
Fue hasta mediados del siglo Xx que dos factores cuestionaron esta situación. Uno de carácter institucional que se inscribe en los principales cambios iniciados por la revolución nacional (1952): la reforma agraria. Reforma que marcó el fin del sistema de haciendas en el Occidente de Bolivia y el deseo de difundir las prácticas agrícolas en el Oriente del país, ilustrado por el desarrollo de la agroindustria ${ }^{4}$ la distribución de la tierra. El otro factor fue la transición demográfica, cuyo impacto sobre el volumen poblacional resultó brutal, lo que aumentó la presión antrópica sobre el uso del suelo en las zonas ya densamente pobladas, especialmente en los fértiles valles del Occidente. Estos dos factores, aunados a los importantes cambios en la economía boliviana (cierre de las minas, liberalización del mercado), tuvieron repercusiones en la distribución de la población rural del país (Mazurek \& Areghinio, 2006; Mazurek, 2007, y d'Andréa, 2007).

Por supuesto, de manera general, la dinámica poblacional de estas zonas rurales aún está marcada por el continuo crecimiento de la población (Quesnel, 2004, p. 57) e incluso en el caso de Bolivia se nota un cierto vigor demográfico del campo (Vignoli 2002). Sin embargo es un crecimiento bastante lento y con fuertes desigualdades espaciales tal como se refleja en el Sur boliviano, más particularmente en el departamento de Tarija (Martin, 2010). Por un lado, a pesar de un crecimiento natural importante, el incremento de la población rural del Occidente tarijeño es bajo, lo que hay que relacionar con una emigración constante. Por el otro, aunque pequeños y con claras muestras de agotamiento, hay dos frentes de expansión agrícola en el Oriente, alrededor de las ciudades de Bermejo y Villamontes. Empero, la información disponible sobre estas dinámicas del campo departamental es escasa y todavía quedan muchos cuestionamientos que trataremos aquí.

Antes que nada, uno puede preguntarse sobre el desarrollo de las actividades rurales. Conviene entender la historia de la colonización agrícola en la parte oriental del departamento de Tarija para identificar a los protagonistas de este nuevo dinamismo rural y las estrategias —individuales o colectivas, organizadas o espontáneas- que acompañan este repoblamiento, ${ }^{5}$ explorando la relación entre la inmigración y el desarrollo de las zonas de colo-

\footnotetext{
${ }^{4}$ Los recursos de las minas nacionalizadas tenían que financiar el desarrollo de una agroindustria de la cual la reforma agraria y la colonización agrícola del Oriente amazónico eran las bases productivas (Franqueville, 2000, p. 18).

${ }^{5}$ El término "repoblamiento" es más apropiado en este caso que "poblamiento", ya que las zonas de colonización agrícola estaban temporalmente habitadas por nómadas.
} 
nización. Al mismo tiempo no se puede descuidar el estudio de la crianza, actividad tradicional en el Oriente, para observar si ésta se realiza en zonas de colonización. También hay que evaluar el papel de la agricultura tarijeña (Occidente y Oriente) a la luz de las evoluciones actuales (desarrollo de los cultivos industriales, ${ }^{6}$ apertura de las fronteras), medir su importancia en las comunidades $^{7}$ rurales y cuestionar una posible selección de cultivos y sus objetivos (el autoconsumo, la venta o la adaptación a las limitaciones del medio ambiente). De manera general, debemos cuestionar los límites que sufren los sistemas de producción estudiados: ¿existe un desequilibrio entre

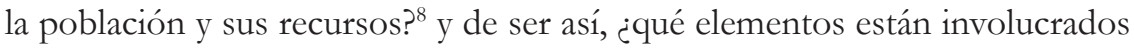
(crecimiento de la población, división de la tierra, erosión, falta de recursos hídricos)?, ¿es simplemente la coyuntura económica y el difícil acceso a los mercados? Básicamente se trata de comprender si la agricultura tradicional de Tarija es viable y, según los límites encontrados, interrogarse sobre las estrategias de adaptación implementadas. ¿Estamos asistiendo a una diversificación de las actividades? y, sobre todo, ¿cuál es el papel de la emigración en este proceso?

Porque las formas de emigración parecen numerosas y diversas en las zonas rurales de Bolivia y han sido poco estudiadas en la parte Occidental del país. Señalemos primero los trabajos de Miriam Vargas y de Jaime Barron (capítulos 5 y 6 de Zoomers, 1998) sobre los mecanismos de las migraciones temporal y definitiva. André Franqueville (2000) cita una encuesta realizada en el Potosí, en la que más de la mitad de los hogares de una comunidad declara una fuerza de trabajo estacional. Por su parte Geneviève Cortes (2004) señala que entre 54 y 73 por ciento de las familias estudiadas en los pueblos de los valles altos de Cochabamba tiene al menos un emigrante en el Chaparé. También conviene señalar el trabajo de Sophie Blanchard que ilustra la complejidad de las trayectorias migratorias del Occidente hacia el Oriente del país con casos que muestran su reversibilidad (2006). Nos preguntaremos sobre estas dinámicas en la parte occidental del departamento de Tarija, donde las prácticas migratorias fueron localmente estudiadas de manera cualitativa por David Preston y Samantha Punch en el Valle de Camacho (Preston, Macklin et al., 1997; Preston, 1999, y Punch, 2001) y por Alfonso Hinojosa y su equipo

\footnotetext{
${ }^{6}$ Ver Guibert \& Velut, 2011 sobre el tratamiento de tal fenómeno en América Latina.

${ }^{7}$ Entendemos por comunidad (término frecuentemente empleado en Bolivia) las localidades rurales.

${ }^{8}$ cf. Domenach \& Picouet, 1995, p. 113.
} 
(Valle de Tolomosa, Hinojosa Gordonova y Cortez Franco, 1999, e Hinojosa Gordonova, Pérez et al., 2000).

El objetivo será primero determinar las características específicas de las corrientes migratorias en el Occidente: su frecuencia (estacional, permanente, reversible) y sus destinos (ciudades o campos de otras regiones ecológicas), lo que podría significar que contribuye al poblamiento de las zonas de colonización del Oriente o una sobrerrepresentación sistemática de Argentina. Lo anterior porque, en el siglo XX, la emigración boliviana hacia el país vecino ha aumentado significativamente a causa de la expansión de los cultivos de caña de azúcar y de tabaco en las provincias septentrionales de Salta y Jujuy, que se encuentran justamente en la frontera con Tarija. También debemos preguntarnos si las salidas de los habitantes de los campos del Occidente se hacen hacia destinos emergentes (Estados Unidos, Israel, España). ${ }^{10}$ Finalmente, el análisis de la motivación de estos desplazamientos es esencial, especialmente para saber si dejar su ámbito rural se acompaña o no de un cambio sectorial de actividad.

En el Oriente, la migración hacia las zonas de colonización agrícola fue estudiada por Eastwood y Pollard desde los años ochenta (Eastwood y Pollards 1986), pero raros son los estudios que hablan de la emigración desde estas zonas, y aun menos en el Sur del país, donde los datos censales indican su existencia (Martin, 2010). De aquí surgen las preguntas anteriores en los mismos términos, y la comparación de estrategias migratorias, según las regiones de origen.

Por último, es una mirada general a la población de las zonas rurales del departamento que queremos tener, a través del estudio de las causas y consecuencias de la emigración. Esto implica la observación de la relación entre los sistemas agrarios y las estrategias de migración. ¿Las formas de emigración dependen de los hogares? ¿Coinciden con lógicas comunitarias? Podemos preguntarnos si — como lo evoca Cortes (2004)— desplazarse

\footnotetext{
${ }^{9}$ Ver Celton, 1995 para un relato histórico de tal corriente, y Bologna, 2010 para su desarrollo actual analizado con datos censales desde el lugar de destino.

${ }^{10}$ Geneviève Cortes ya evocaba estas corrientes en 2004 (Cortes 2004). Ver Baby-Collin, Cortes et al., 2009 para un relato más reciente de esta corriente hacia España, el capítulo de Mar Cebrián para un enfoque latinoamericano del fenómeno (Meichtry, Pellegrino et al., 2008), los trabajos editados por Godard \& Sandoval para un relato sobre la emigración de los Andes hacia España y Estados Unidos y el capítulo de Alfonso Hinojosa Gordonava en Mazurek, 2009 específicamente sobre la migración boliviana a España.
} 
permite ampliar su "espacio económico" en lugar de cambiarlo. Este tipo de cuestionamientos se integran a los hechos por Christophe Guilmoto y Frédéric Sandron (2003) quienes invitan a reconsiderar el papel de la migración: la extensión de zonas de vida sería una estrategia de diversificación de los ingresos del hogar, y entonces se permitiría la reproducción del grupo familiar y el comunitario. Para seguir esta lógica, y considerando a los mismos autores, también hay que tomar en cuenta los efectos de la migración (particularmente las remesas) para determinar si la emigración es un factor de desarrollo. Así se tocará el tema de la diversificación de los ingresos, y de la actividad rural, lo que nos permitirá interrogarnos sobre la existencia de una "nueva ruralidad"11 del Sur boliviano. De manera general, es también el impacto de estas dinámicas rurales diferenciadas sobre la recomposición del espacio rural regional que podremos interrogar (Hamelin 2007), cuestionándonos sobre las perspectivas de los modelos estudiados.

Para aclarar estos cambios en las zonas rurales, este libro se apoya en dos encuestas realizadas en Tolomosa (el valle) y Caigua (la comunidad) ${ }^{12}$ dos ejemplos que ilustran la diversidad del campo tarijeño [cf. Martin, 2010 y las precisiones metodológicas más abajo]. Después de haberlas tratado por separado, concluiremos con un enfoque comparativo. Comenzaremos con el modelo tradicional del Occidente, el de Tolomosa (Capítulo I). En el corazón templado y fértil de los valles centrales (principal espacio de producción del departamento), las comunidades de la cuenca de Tolomosa responden a problemáticas rurales del Oeste del Sur boliviano. Dos de ellas fueron estudiadas previamente por el sociólogo Alfonso Hinojosa, ${ }^{13}$ y son fuertemente estructuradas por una emigración rural modelada por diversas estrategias. Completamos aquí este trabajo con el análisis de los datos producidos y proponiendo una visión más amplia del valle. Por otra parte, el estudio de las nuevas dinámicas rurales del Oriente pasa a través de las concentraciones de población detectadas en el Piedemonte del Chaco (Martin, 2010). Así, abordaremos el nuevo modelo de Caigua (Capítulo II), comunidad afectada por la

\footnotetext{
${ }^{11}$ La intención aquí no es entrar en algún debate conceptual sobre la nueva ruralidad, lo que ha sido tratado últimamente por varios autores: de Grammont, 2004; Insua \& Correa, 2007; Kay, 2009; Martínez, 2010, y Sánchez Albarrán, 2011.

${ }^{12}$ Lastimosamente, esta diferencia en la escala se debe a cuestiones logísticas [cf. anexo metodológico].

${ }^{13}$ Dentro del marco de un estudio cualitativo (ver Hinojosa Gordonova \& Cortez Franco, 1999, e Hinojosa Gordonova, Pérez et al., 2000).
} 
reciente aparición (a partir de los años sesenta) de nuevas zonas de agricultura intensiva, que debían contribuir a la renovación demográfica de la zona. Entender la formación de la localidad y su desarrollo actual permitirá una nueva mirada sobre la colonización agrícola en el Sur boliviano. 


\section{Algunas precisiones metodológicas}

Tarija, pequeño departamento integrado a la diversidad física de Bolivia (Martin, 2010), es un terreno privilegiado para el estudio de los cambios demográficos del país, especialmente respecto a los movimientos migratorios. Sin embargo, los estudios sobre este tema son escasos, lo que nos condujo a desarrollar un programa de encuestas que explicaremos brevemente a continuación. Aprovecharemos la oportunidad para justificar las unidades de análisis elegidas y explicar los grandes ejes metodológicos que serán empleados. La metodología específica de cada una de las encuestas se encuentra al final de este libro.

\section{ENTENDER LA COMPLEJIDAD DE LAS MIGRACIONES EN BOLIVIA}

La comprensión del poblamiento y de la redistribución de la población pasa especialmente por un estudio de los movimientos migratorios, cuya importancia va en aumento desde los últimos cincuenta años en Bolivia. Pero la complejidad de estos movimientos se estudia generalmente sólo a través de análisis cualitativos puntuales o por medio de datos incompletos del censo.

LA FALTA DE ESTUDIOS Y DATOS SOBRE

MOVIMIENTOS DE POBLACIÓN

Faltan estudios y datos sobre los movimientos de población en Bolivia, tanto a escala nacional como internacional. El trabajo de Geneviève Cortes ${ }^{14}$

\footnotetext{
${ }^{14}$ Ver la selección siguiente de publicaciones de Geneviève Cortes sobre el tema: 2002a, 2002b, 2004.
} 
constituye una de las pocas investigaciones sobre las migraciones internas; ahí, revela la existencia de migraciones entre los diferentes niveles ecológicos del Cochabamba que permiten a las comunidades rurales andinas participar en el desarrollo del cultivo de la coca en el Chaparé (cuyas características físicas son similares a las de los valles subandinos del departamento de Tarija). Sin querer hacer una revisión bibliográfica completa, conviene también citar a otros autores a los cuales se hará referencia en esta obra: Víctor Vaca Flores (2004), Vargas Martin (2005), Sophie Blanchard (2006), Hubert Mazurek (2007). En cuanto a los valles tarijeños, ya señalamos los estudios cualitativos de David Preston y de Samantha Punch, sobre la emigración desde el valle de Camacho hacia Argentina (Preston, 1999, y Punch, 2001) y los trabajos de Alfonso Hinojosa que proponen una mirada del mismo fenómeno desde el valle vecino de Tolomosa (Hinojosa Gordonova \& Cortez Franco 1999, e Hinojosa Gordonova, Pérez et al., 2000).

En cuanto a los datos disponibles sobre la migraciones internas en Bolivia, se limitan a tres variables del censo de población llevado a cabo por el INE (Instituto Nacional de Estadística): lugar de nacimiento (aplica a todos), lugar de residencia cinco años antes (reservado para individuos mayores de cuatro años) y lugar de residencia habitual, lo que permite afinar las subpoblaciones estudiadas. ${ }^{15}$ Es a partir de estos datos que Melvy Vargas Bonilla desarrolló la primera evaluación de la migración interna en Bolivia (principalmente para el periodo 1996-2001, CODEPO, 2004), midiendo el movimiento de personas entre las regiones ecológicas (de acuerdo con la tripartición del INE), entre departamentos y municipios. La contribución de este trabajo para la comprensión de la redistribución de la población en Bolivia es innegable, ya que ilustra las grandes tendencias actuales: el crecimiento de las llanuras y la urbanización general. Además, mediante la combinación de las variables de género o educación con las de la migración, se pueden abordar con mayor precisión causas y consecuencias de la migración. Sin embargo, esto es apenas una aproximación general a un problema más complicado y los datos del censo sólo ofrecen una respuesta fragmentada.

En primer lugar, se puede señalar que permiten una visión parcial de los eventos migratorios dado que los intervalos temporales son demasiado espaciados; es decir, trabajar sobre el lugar de residencia cinco años antes de la

\footnotetext{
${ }^{15}$ Notar que el ultimo censo de población realizado por el INE el 21 de noviembre de 2012 tiene integrado un capitulo especifico sobre migración internacional que censó a las personas que salieron del hogar para ir a vivir a otro país.
} 
recolección de datos impide la detección de movimientos de corta duración (especialmente la migración estacional) y el lapso intercensal puede dejar un vasto periodo no cubierto. ${ }^{16}$ Además, la inclusión del lugar de nacimiento, del lugar de residencia de cinco años antes del censo, y del lugar de la vida actual no muestra la diversidad de las migraciones, a menudo más complejas. ${ }^{17}$ Por último, estudiar los movimientos de personas respecto a los datos producidos por las instituciones de estadística limita considerablemente las posibilidades de cruce de las variables. ¿Cómo entender las motivaciones de los migrantes limitándonos al estudio de los censos del INE? ¿Cómo abordar la relación crucial entre migraciones y actividades? Y en las zonas rurales, ¿`cómo podemos vincular la situación agraria y los desplazamientos? Por lo tanto, en Bolivia, los censos son sólo una herramienta de análisis parcial de los mecanismos y de los determinantes socioeconómicos en el trabajo de las migraciones.

\section{Las encuestas Frontarbol}

Estas faltas justifican la realización de encuestas adecuadas, con variables precisas y apropiadas para cada unidad de análisis. Sin embargo, en América del Sur, la tradición colonial de contar y, más recientemente, el establecimiento de las encuestas nacionales de hogares en todos los países de este continente, paradójicamente, ha limitado la extensión de las investigaciones de la migración (Domenach \& Picouet, 1995, p. 20).

En este sentido se puso en marcha el programa Frontarbol — gracias a la cooperación científica entre universidades Sudamericanas (UAJMS ${ }^{18}$ de Tarija y $\mathrm{UNC}^{19}$ de Córdoba) y centros de investigación franceses la (IRD ${ }^{20}$ y IFEA)—- ${ }^{21}$

\footnotetext{
${ }^{16}$ En el caso de Bolivia, no tenemos información respecto a los movimientos de población realizados entre 1976 y 1987, cinco años antes del censo de 1992.

${ }^{17}$ Por ejemplo, y según Luc Cambrézy en Veracruz (México), la falta de datos sobre el tema de la movilidad en las zonas rurales puede afectar su comprensión, el riesgo es centrarse en migraciones en formas masivas y también más caricaturescas: el éxodo rural. El peligro es entonces caer en una percepción reduccionista de los fenómenos migratorios que, justamente, no se limitan solamente a esta forma de movilidad (Cambrézy, 1996, p. 680).

${ }^{18}$ Universidad Autónoma Juan Misael Saracho, la universidad pública del departamento de Tarija.

${ }^{19}$ Universidad Nacional de Córdoba en Argentina.

${ }^{20}$ Institut recherche pour le développement (institución francesa que publica investigaciones especializadas sobre los países del Sur).

${ }^{21}$ Instituto Francés de Estudios Andinos (ente público de investigación, con base en Lima, que trabaja sobre Bolivia, Ecuador, Perú y Colombia).
} 
con el objetivo de generar y analizar datos sobre las migraciones en el departamento de Tarija. Así, diversos estudios se llevaron a cabo a escala departamental: Entar 2001 en la ciudad de Tarija, en septiembre de ese año; Entol 2002 en el valle de Tolomosa, al sur de la capital, en febrero de 2002; Enyac 2002 en la ciudad fronteriza de Yacuiba, en abril de ese año; Envil 2002 en la ciudad de Villamontes, la localidad rural de Caigua ubicada en el Piedemonte y de Caraparí, en los Valles Subandinos orientales en julio de 2002, y finalmente Enber 2005 en la ciudad de Bermejo, en mayo de ese año. Los principales resultados de esta gran empresa —2 604 hogares encuestados, más de 12000 personas en total - son presentados en el libro colectivo Movilidady procesos migratorios en el espacio de frontera argentino-boliviana dirigido por Hervé Domenach, Dora Celton, Hugo Arze y Philippe Hamelin (Domenach, Arze et al., 2007).

A diferencia de los censos INE, estas encuestas se aplicaron exclusivamente a miembros de hogares (no se incluyeron establecimientos colectivos como hospitales, cárceles, hoteles, etc.) y contabilizaron una población de derecho (que vive habitualmente en el hogar) y no de ley (presente durante la recolección de datos). El enfoque básico fue llevar a cabo una encuesta ${ }^{22}$ retrospectiva de los eventos migratorios (desde el nacimiento) y de las movilidades (en los últimos 12 meses) utilizando definiciones a priori: los lugares de migración son aquellos en los que el entrevistado vivió por lo menos seis meses continuos (fuera del lugar de nacimiento) y la movilidad con relación a cualquier desplazamiento que generó el paso de al menos una noche fuera de la localidad y de una duración total inferior a seis meses. Como parte de este estudio, se preguntó sobre las motivaciones de cada uno de los desplazamientos, lo que permitió distinguir movimientos activos y pasivos, y en esta última categoría, los viajes por motivos laborales y por educación. De manera complementaria, la situación en el tiempo del evento fue especificada por los años de llegada y de salida del lugar de la migración, o por el mes de principio de la movilidad más larga (en caso de desplazamientos múltiples hacia el mismo destino). Por último, se prestó especial atención a la hora de identificar los lugares de migración o de movilidad a distintas escalas: localidad, provincia, departamento y país. Se realizó lo mismo con el lugar de nacimiento de las personas encuestadas (dato esencial para el estudio de los movimientos de

\footnotetext{
${ }^{22}$ Visitar la página <www.frontarbol.com> para los cuestionarios completos.

${ }^{23} \mathrm{El}$ módulo que censa el lugar de origen de los padres del jefe de hogar fue introducido desde Entol 2002.
} 
población), y de los padres del jefe de hogar, ${ }^{23}$ lo que permitió atrasar una generación el estudio del lugar de origen. Además de estas preguntas específicas sobre los desplazamientos, se diseñaron otras más generales a nivel individual (edad, sexo, relación familiar, fecundidad) y familiar (electrodomésticos, condiciones de vivienda) [cf. www.frontarbol.com para ver los cuestionarios completos, Hamelin, Martin et al., 2007 para la metodología].

Es conveniente resaltar varias especificaciones de estos cuestionarios respecto a las encuestas habituales sobre migración. En primer lugar, sobre el enfoque económico, su estudio a nivel individual (por sector y categoría de empleo en caso de ocupación laboral) se complementó con un censo de las prácticas agrícolas y de crianza en los hogares, en zonas rurales pero también en zonas urbanas, a fin de captar posibles vínculos entre la ciudad y el campo y medir la importancia de estas prácticas a las afueras de la ciudad. Además, en la encuesta Envil 2002 se incluyó un módulo para identificar una eventual pluralidad de actividad en los hogares (o la diversificación de las fuentes de ingresos de los hogares). Por último — en esta misma encuesta— el módulo "instalación”, reservado a los no nativos, proporcionó valiosa información respecto a la actividad de los individuos en su lugar de origen y sobre las razones para la instalación y el trabajo realizado a la llegada en la localidad encuestada. ${ }^{24}$

En segundo lugar, un módulo especialmente innovador, "otros hijos del hogar" permitió estudiar el lugar de vida (para todas las encuestas) y la actividad (salvo en el caso de Entar) de la descendencia del jefe del hogar y de su pareja, información que consideramos relevante sobre la redistribución de la población desde las localidades encuestadas. ${ }^{25}$ En tercer lugar, se introdujeron, de forma esporádica, algunos módulos específicos de la situación de las localidades. Citaremos aquí dos ejemplos: el cuestionario Entol 2002 incluye un módulo sobre la frecuencia y las motivaciones de la movilidad cotidiana de los habitantes del valle hacia la ciudad vecina de Tarija. Y la importancia local del petróleo nos animó a introducir en Envil 2002 un módulo sobre la percepción del futuro y los proyectos de migración. ${ }^{26}$

\footnotetext{
${ }^{24}$ Este módulo no se presenta hasta la encuesta Enyac 2002.

${ }^{25}$ Notaremos la presencia de otro módulo innovador que trata la cuestión de las visitas (toda persona, no miembro del hogar, que se haya quedado al menos una noche en el hogar encuestado) y que permite estudiar las movilidades hacia la localidad censada. Para simplificar este módulo no está presente en el cuestionario de Envil 2002 [cf. anexo metodológico].

${ }^{26}$ Estos ejemplos no son exhaustivos: en Enyac 2002 se insertó un módulo sobre la movilidad cotidiana entre la ciudad fronteriza de Yacuiba y Argentina; Entol 2002 y Enyac 2002 incluyen
} 


\section{Presentación del departamento de Tarija y de su partición}

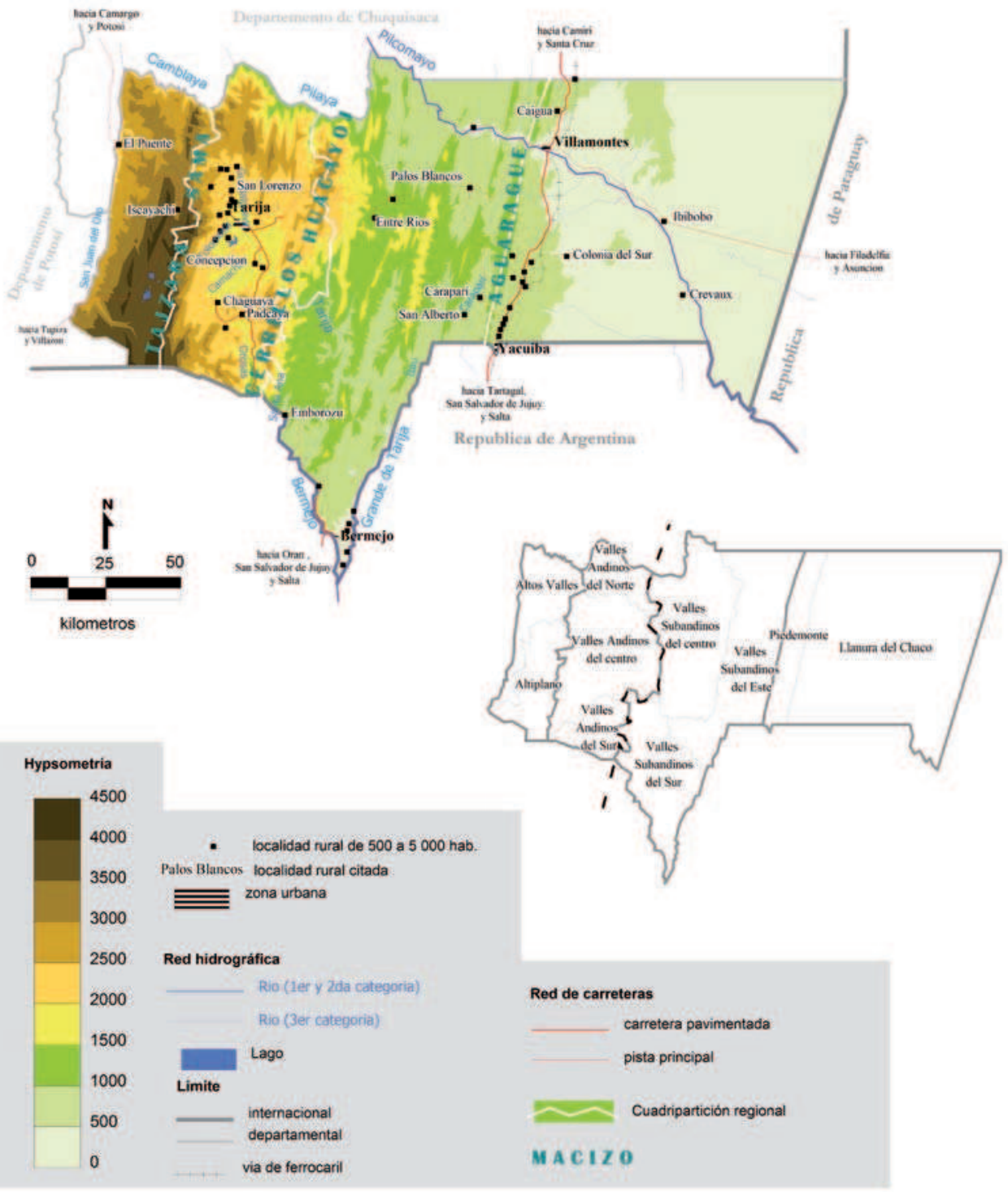

Fuente de datos : 7ONISIG (1999) INE (2001) 
Producto de estas encuestas en el departamento de Tarija tenemos ahora una base de datos consistente y de una riqueza importante, ${ }^{27}$ de la cual usaremos sólo una pequeña parte en este estudio.

\section{EL CAMPO DE ANÁLISIS: DINÁMICAS DEL OCCIDENTE Y DEL ORIENTE}

Restringiremos el campo de análisis a dos niveles. El primero, espacial, para seleccionar las unidades que serán estudiadas de acuerdo con la diversidad física del departamento de Tarija y sus dinámicas de poblamiento; el segundo, metodológico, presenta el enfoque para el análisis de las localidades seleccionadas, indicando datos y terminología utilizados en este trabajo.

\section{LA DIVISIÓN ESPACLAL DEL DEPARTAMENTO}

\section{DE TARIJA Y DE BOLIVIA}

Este trabajo esta basado en una división espacial del departamento, realizada por el autor en investigaciones anteriores, según criterios físicos y de ocupación del espacio. Incluye una división principal, entre el Occidente y el Oriente, a nivel nacional y departamental. Está completada por varias subdivisiones del departamento de Tarija que se presentarán brevemente abajo (ver Martin, 2010 para más detalles).

En el Oeste (Occidente) de Tarija, las Altas Montañas ${ }^{28}$ y los Valles Andinos tienen climas áridos o templados y constituyen el corazón histórico del poblamiento. Durante el reinado inca, se aprovechó el fondo de los Valles Andinos que tenían aventaje de ser fértiles y de servir de zona tapón para protegerse contra las tribus guerreras del Este. Durante la época de la Colonia, los valles cumplieron con la misma función y se consolidaron alrededor de la fundación de la ciudad de Tarija, lo cual permitió centralizar la

\footnotetext{
un módulo sobre las condiciones de trabajo en Argentina, restringido a las personas que declaran al menos una migración y/o una movilidad profesional en el país vecino; en el caso de Entar 2001, son las estrategias residenciales en las ciudades las que son objeto de una atención particular. Finalmente, señalaremos que todas las encuestas incluyen un módulo específico para la movilidad por razones de salud, identificando los desplazamientos relacionados con algún tratamiento médico en los últimos cinco años.

${ }^{27}$ Esta base de datos, pública, puede descargarse en formato SPSS en la página dedicada a este proyecto: <www.frontarbol.com>.

${ }^{28}$ Se emplearán mayúsculas para escribir el nombre de las regiones delimitadas.
} 
producción de las haciendas agrícolas destinadas al área minera de Potosí y proporcionar una base para las expediciones laboriosas en la zona oriental del departamento (Oriente). Este último conjunto está compuesto por los Valles Subandinos y por la Llanura del Chaco, ambos más cálidos y menos áridos. La fuerte resistencia de sus habitantes limitó los intereses de la Colonia y el Oriente tuvo hasta 1880 un papel pasivo de extensión exótica e inerte de un conjunto geográfico meramente andino (Roux, 2000).

Esta bipartición departamental tiene varias subdivisiones multiescalares que se detallan en el mapa — la decapartición integrada a la cuadripartición—, útil según el tipo de análisis que se quiera manejar. Respecto al nivel nacional, coincidimos con Nicolás d'Andréa (2004) en su crítica a los modelos de partición propuestos hasta ahora, en general en tres grupos (altiplano, valle y llanura) a los cuales atribuimos su falta de relevancia debido a las evoluciones recientes de Bolivia o a las elecciones de divisiones estadísticas muy amplias. Se optó aquí por una prolongación nacional de la bipartición Occidente/ Oriente utilizada para el departamento, e inspirada por Vidal de la Blache, quien tiene el mérito de plantear el problema de las relaciones entre Bolivia tradicional y su Far East (d'Andréa, 2004).

\section{ILUSTRAR LAS DINÁMICAS RURALES \\ DEL OCCIDENTE Y ORIENTE}

Existen dos tendencias muy marcadas en el Occidente tarijeño rural: la concentración de la población en los valles centrales y el papel desempeñado por la emigración, sobre todo hacia Argentina (Martin, 2010). Es a partir de la cuenca de Tolomosa, ubicada en los valles centrales alrededor de la ciudad de Tarija, en la cuenca histórica el poblamiento, que hemos optado por estudiar estos movimientos migratorios. Esta unidad de análisis es particularmente adecuada para el estudio de la emigración tradicional del campo occidental, y de algunos indicadores del censo 2001 del INE, bajo el supuesto de una fuerte emigración actual desde el valle. Por un lado, el estudio de la estructura por edad de la cuenca de Tolomosa muestra las grandes tendencias de un sistema migratorio particularmente exacerbado [cf. Fig. I-9 para la representación de la pirámide de edad de Tolomosa, cf. Martin, 2010 para aquellas de los otros valles del Occidente tarijeño). De esta manera, la salida de los jóvenes induce una clara ruptura a partir del rango de edad de 15-19 años, sobre todo en la población masculina; el envejecimiento de la población es más importante, y el déficit de niños pequeños es considerable 
(especialmente en los de 0-4 años). Por otro lado, la proporción de no nativos de Bolivia en el valle es particularmente sobresaliente. ${ }^{29}$ Un elemento adicional que justifica nuestra elección es la estructura de los asentamientos humanos de la cuenca de Tolomosa, pues parece corresponder a la observada a escala de los valles centrales, o a una mezcla de pequeñas comunidades aisladas (en el Sur del valle) y de localidades rurales mayores (más de 500 habitantes en 2001) bien conectadas a la red de carreteras que rodean la capital departamental. Finalmente, la ubicación del valle a lo largo de la cordillera de Sama implica una variedad de climas en la cuenca: las localidades ubicadas al pie de las montañas se benefician de un drenaje acuífero sostenible y de fuertes lluvias (más de $1200 \mathrm{~mm}$ por año), mientras que las comunidades lejanas a la línea de cresta están fuera del alcance de los ríos permanentes en zonas más áridas (menos de $900 \mathrm{~mm}$ de precipitación anual).

La combinación de estos factores condujo a la selección del valle de Tolomosa para la encuesta del Occidente rural del departamento de Tarija. En el marco de este trabajo, utilizaremos los datos recogidos para llevar a cabo un análisis del sistema agrario de las localidades encuestadas, más específicamente sobre la crisis rural andina mencionada anteriormente. Con los resultados de este análisis, buscaremos entender la diversidad de estrategias migratorias de los habitantes del valle. ${ }^{30}$ Prestaremos especial interés a la frecuencia de la emigración (distinguiremos la estacional de aquella de mayor duración), a las motivaciones y a los destinos. Este último punto revelará qué tanto Argentina constituye el único lugar de la emigración, o si el país vecino está en competencia con polos de atracción más cercanos (Tarija, por ejemplo) o al contrario más distantes (España, Estados Unidos).

Para estudiar la dinámica poblacional rural del Oriente tarijeño, se buscaron espacios con funciones demográficas receptivas y redistributivas, sin que estén ligadas a fenómenos obsoletos o coyunturales (comercio fronterizo, hidrocarburos). Se excluyeron del estudio las localidades rurales del triángulo de Bermejo, en los Valles Subandinos meridionales, que corresponden más a

\footnotetext{
${ }^{29}$ La proporción de personas nacidas fuera de Bolivia y residente en diferentes valles centrales (según el censo del INE de 2001) varía fuertemente de un valle del Occidente tarijeño a otro. Es así que encontramos que es muy baja en el caso de Nogal/Papa Chacra $(0,3 \%)$, del río Tarija $(0,6 \%)$, y de Santa Ana $(0,7 \%)$, en la media del Occidente rural tarijeño $(1,6 \%)$ por el valle de Guadalquivir $(1,8 \%)$ y particularmente fuerte en los valles de Camacho $(3,0 \%)$ y de Tolomosa $(3,2 \%)$ [Cf. Martin, 2010 para información más completa sobre este tema].

${ }^{30}$ Ver Martin, 2011 para un tratamiento sintético de estas estrategias.
} 
enfoques históricos (caña de azúcar, cf. Martin, 2010) y que están aislados del resto del departamento. ${ }^{31}$ Más al Norte, el estudio de los Valles Subandinos del centro se limitaría a analizar la emigración y el estancamiento de la población rural. Ahora bien, se pudieron detectar dinámicas demográficas mayores en el Este en los Valles Subandinos orientales, pero correspondientes a situaciones altamente coyunturales, relacionadas con las actividades esporádicas del gas. En la misma zona, el estudio llevado a cabo en la localidad de Caraparí hubiese podido servir como base de análisis, pero no de una dinámica rural actual, ya que corresponde a asentamientos no reciente. ${ }^{32}$ Por último, si las características de poblamiento de la llanura del Chaco son numerosas (bases militares, menonitas, indígenas establecidos recientemente) el peso demográfico de esta región del Oriente tarijeño la hace poco significativa.

Justamente este peso demográfico es uno de los criterios por los que se eligió el Piedemonte — cuya densidad rural es particularmente alta— ${ }^{33}$ como observatorio de la dinámica del poblamiento del campo oriental del departamento de Tarija. Además, su poblamiento está relacionado al crecimiento reciente de comunidades rurales ubicadas en uno de los ejes de comunicación más importante del departamento, que une Argentina y Santa Cruz, en una zona con potencial agrícola apenas explotado a mitad del siglo pasado y que fue posteriormente sujeto a una colonización. Y las investigaciones de hoy en día tienden a mostrar un límite actual en la extensión de estas nuevas comunidades (Martin, 2012), lo que refuerza su interés para estudiar las estrategias de adaptación desarrolladas y así observar en conjunto la inmigración reciente y la redistribución eventual del poblamiento. Pues bien, nos referimos a la localidad de Caigua, ubicada en el Piedemonte Norte, como la seleccionada

\footnotetext{
${ }^{31}$ Esta elección no resta interés a una zona portadora de una fuerte dinámica histórica del poblamiento rural y escenario de importantes migraciones temporales.

${ }^{32}$ Sin embargo, el estudio de Caraparí podría integrarse en futuras investigaciones. Por un lado, vinculando el crecimiento de esta localidad y la ciudad cercana de Yacuiba (a $30 \mathrm{~km}$, al otro lado del Aguaragüe); por el otro, un estudio específico sobre la influencia de los hidrocarburos sobre el poblamiento de Tarija deberá tomar en cuenta el desarrollo de esta pequeña ciudad de los Valles Subandinos orientales. De hecho, su proximidad con el pozo de San Alberto ha influido su desarrollo en los años sesenta. La evolución reciente del sector en la región (extensión del complejo de San Alberto, perforación de los pozos de Itaú) y los beneficios financieros sólo ampliarán esta relación (Martin, 2010). En este contexto, la realización en el futuro de una investigación suplementaria en la localidad de Caraparí podría resultar un estudio longitudinal muy interesante.

${ }^{33}$ En relación al resto en el departamento de Tarija [cf. Martin, 2010a para más detalles].
} 
por observar esta dinámica. Como se señaló con anterioridad, la instalación de sus primeros habitantes se remonta a mediados del siglo XX, y los últimos 50 años han estado marcados por la llegada de colonos, alentados por la redistribución de tierras de la reforma agraria de 1953, mismos que han desarrollado las actividades agrícolas.

\section{LA INESTABILIDAD DEL POBLAMIENTO EN EL CENTRO DEL MÉTODO ANALÍTICO}

Para comprender los principales mecanismos que controlan la distribución de la población actual de las zonas rurales del departamento de Tarija, proponemos estudiar los grandes flujos migratorios, pasados y presentes, y los polos de atracción que la estructuran. Para este fin, las unidades geográficas de Tolomosa y Caigua tendrán su análisis dividido en varias secciones que presentaremos brevemente a continuación, haciendo las precisiones conceptuales necesarias.

En un primer momento, centraremos nuestra atención en el entendimiento del poblamiento pasado de las zonas seleccionadas a fin de identificar el origen y el desarrollo de las localidades encuestadas; para lo cual relacionaremos informaciones de carácter histórico y demográfico (esta última proveniente del INE y de encuestas Frontarbol). Haremos también una revisión detallada de la inmigración reciente hacia la zona, a través del estudio de los lugares de origen, compuesto por los lugares de nacimiento (de origen) para los no nativos que vinieron directamente a instalarse en las localidades encuestadas; o bien, de los lugares de la última migración ${ }^{34}$ para quienes declaran otro lugar de vida precedente a la instalación. Entonces, podremos evaluar la relación entre los períodos de llegada y las zonas geográficas y caracterizar así, de mejor manera, la inmigración a través de variables con respecto a la motivación y la actividad.

En una segunda instancia la actividad actual en las localidades encuestadas será el punto de interés. En este estudio rural caracterizaremos, sobre todo, el sistema agrario: proporción de las actividades ganaderas y de agricultura, tipos de cultivo y ganado, tamaño de las parcelas, presencia o ausencia de riego. Para ello, la información recogida en el módulo agrícola será esencial, así como las observaciones de campo.

\footnotetext{
${ }^{34}$ Como se señaló anteriormente, con el término migración designamos un cambio de residencia de una duración superior o igual a seis meses.
} 
Por último, el enfoque de la redistribución de la población de las comunidades encuestadas es fundamental y complementario. Se abordará principalmente a partir de las migraciones anteriores; ${ }^{35}$ es decir, la migración que llevó a ir y regresar a la localidad encuestada, y con base en las migraciones actuales (las de los hijos que dejaron la ciudad). Para cada uno de estos tipos de migración, se relacionará la motivación de los desplazamientos con el destino, para aclarar la especificidad de los polos de atracción, mientras que la comparación de las migraciones anteriores y actuales arrojará una visión diacrónica de estas atracciones. De manera general, se favorecerá el estudio de la migración significativa en la distribución de la población en el espacio en lugar de la movilidad. ${ }^{36}$ Además, son las migraciones activas (formación, laboral) las que constituirán nuestro eje principal de análisis. Por último, este trabajo no se centra específicamente en los efectos de la migración, sin embargo nos ocuparemos de algunos como el del impacto sobre la estructura por edad o el de las remesas.

Organizado de tal manera, el trabajo propone un análisis sistemático de la inmigración y la emigración hacia y desde las unidades seleccionadas, permitiendo algunos puntos de comparación durante el estudio o en las conclusiones. Finalmente, señalando que este modelo tiene una variación en el caso del valle de Tolomosa, las edades de su poblamiento no justifican una sección dedicada a la formación de su espacio rural; en cambio, la riqueza de los desplazamientos de la zona ha validado dos secciones en la redistribución de los habitantes del valle.

\footnotetext{
${ }^{35}$ Nosotros preferimos este término para la migración de retorno, concepto que se ha utilizado principalmente a nivel internacional para estudiar los efectos del retorno de antiguos emigrantes a sus países de origen y que se basa en un periodo relativamente largo de estancia en el país de acogida (Domenach \& Picouet, 1995) que no corresponde, precisamente, al sentido que queremos darle.

${ }^{36}$ Como recordatorio, se trata de desplazamientos que significaron pasar al menos una noche fuera de la localidad y una duración total inferior a seis meses.
} 


\section{Capítulo 1 \\ Occidente: ámbito campesino tradicional y emigración agrícola hacia Argentina}

Al pie de la cordillera de Sama, en el suroeste de la ciudad de Tarija, se encuentra la cuenca ${ }^{1}$ del valle de Tolomosa cuyo fondo alcanza seis $\mathrm{km}$ de ancho en algunos lugares y se extiende sobre unos $20 \mathrm{~km}$ de largo. Los primeros vestigios conocidos de su población se remontan al periodo inca. La cuenca se encontraba entonces sobre uno de los caminos del Inca ${ }^{2}$ que conectaba el Altiplano con los Valles Andinos. ${ }^{3}$ Por lo que sabemos, la más importante transformación del poblamiento del valle data del inicio de la Colonia, cuando se produjo una mezcla entre los indígenas y los españoles que estaban a cargo de las haciendas, grandes explotaciones agrícolas constituían esencialmente el sistema productivo del valle. El fin de este modo de producción, ocurrido poco después de la reforma agraria de 1953, no tuvo un efecto importante en la inmigración hacia la cuenca, ya que la redistribución de la tierra se tradujo en la asignación de pequeñas parcelas que limitaron cualquier instalación nueva (Hinojosa, Pérez et al., 2000). Los primeros datos referentes a los pueblos del valle son los otorgados por el INE, ${ }^{4}$ mismos que refieren un crecimiento anual de $0,4 \%$ entre los censos de 1992 y $2001,{ }^{5}$ una cifra muy por debajo

\footnotetext{
${ }^{1}$ Término español que puede referirse a cuenca o valle. Aquí lo emplearemos para designar la cuenca del valle del río Tolomosa.

${ }^{2}$ Estos caminos fueron construidos por los incas para conectar las diferentes regiones ecológicas. En la cuenca de Tolomosa, el camino del Inca se termina en la comunidad de Pinos Sur, ubicada al suroeste del valle [cf. Mapa I-1].

${ }^{3}$ Ver el trabajo de Ana María Presta sobre los valles centrales de Tarija y su población en el siglo XVI (Presta 2001).

${ }^{4}$ Como recordatorio, el INE es el Instituto Nacional de Estadística de Bolivia.

${ }^{5}$ Según las divisiones estadísticas del INE, la cuenca está compuesta de dos cantones: Lazareto y Tolomosa. Ambos sumaban 7736 habitantes en 2001, repartidos en 18 localidades, sobre una superficie de $465 \mathrm{~km}^{2}$.
} 
del crecimiento natural (que es aproximadamente de 2,5\% anual). Es por eso que, al final del siglo xx, la cuenca de Tolomosa se inscribe plenamente en el proceso de despoblamiento de los Valles Andinos.

Un análisis breve de los datos de la encuesta Entol 2002 confirma que el valle no es un área de recepción, porque más de $90 \%$ de los jefes de hogar censados son nativos, una proporción similar a la de sus padres [cf. Tab. I-2 ${ }^{6}$ y la Figura. I-1]. El bajo crecimiento demográfico así como la inmigración insignificante (según el lugar de nacimiento) no justificaron dedicar una sección de este capítulo al reciente poblamiento del valle, de acuerdo con los lugares de origen o de procedencia; así que empezaremos por un estudio de la situación agraria en la cuenca (I), poniendo de relieve la diversidad de los patrones observados, ubicando las cinco comunidades seleccionadas según el marco de la encuesta Entol 2002. Lo anterior nos permitirá entender los principales ciclos del calendario agrícola del valle y los límites encontrados en el trabajo de la tierra, elementos que relacionaremos con los desplazamientos desde la cuenca, regresando periódicamente a la escala de las localidades para subrayar el vínculo entre el sistema productivo del valle y las migraciones (II). Se trata entonces de observar con mayor precisión la amplitud y las lógicas de las estrategias migratorias de los habitantes de las localidades rurales de los valles centrales, tema ampliamente discutido en Tarija, pero hasta ahora poco estudiado. ${ }^{7}$ Proponemos entonces una síntesis de los problemas actuales de los poblamientos en el valle, en particular mediante la identificación de los polos de atracción que implican los desplazamientos identificados y sugiriendo poner en perspectiva el modelo de estudio (III).

La encuesta Entol 2002 se aplicó en las comunidades de Pampa Redonda, San Andrés, Pinos Sur, Tolomosa Norte y Turumayo [cf. Mapa I-1]. Se sugiere consultar el anexo metodológico para obtener detalles sobre el proceso de recopilación de información (lista de personas involucradas en todas las fases de la investigación, cartografía de la dispersión de las viviendas de las localidades encuestadas, datos del sondeo y explicación general de la metodología utilizada). Los argumentos que permitieron la selección de las localidades a encuestar — de acuerdo con una elección razonada para ilustrar la diversidad del Valle de Tolomosa- se mencionarán en el transcurso de la primera sección de este capítulo.

\footnotetext{
${ }^{6}$ En todo el libro, estas referencias se refieren a tablas que pueden consultarse en la página del proyecto Frontarbol<www.frontarbol.com>, en la sección Publicaciones.

${ }^{7}$ Los trabajos de Hinojosa (2000) y de Punch (2001) permitieron, por primera vez, estudiar la emigración de los valles centrales. Su enfoque cualitativo complementa el uso de la encuesta Entol 2002.
} 
Fig. I-1: Entol 2002 - Lugar de nacimiento de los jefes de hogar y de sus padres

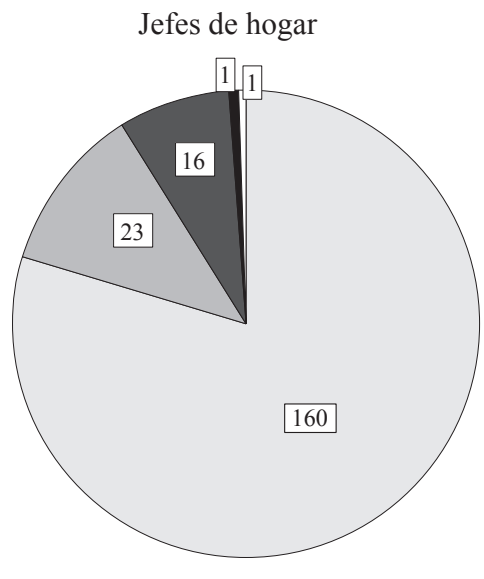

Madres del jefe de hogar

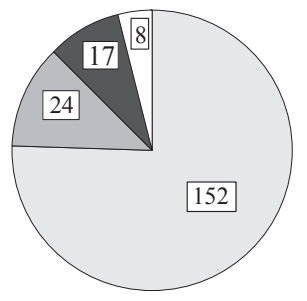

\section{Lugar de nacimiento:}

En la comunidad

En otra comunidad del valle de Tolomosa

En otro lugar de Bolivia

En Argentina

Sin respuesta

160 Cantidad

Padres del jefe de hogar

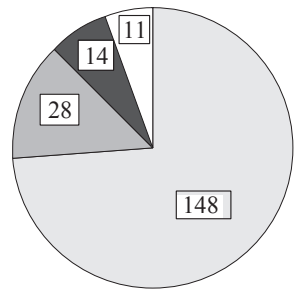

Nota: cada círculo representa 201 observaciones (total de los jefes de hogar encuestados y que viven en el valle de Tolomosa).

Cabe señalar que Entol 2002 encuestó 213 hogares y 1055 individuos pero es necesario aclarar dos puntos sobre el uso de estos datos:

1. La selección razonada de las comunidades encuestadas y las lógicas que determinan las muestras dentro de la comunidad permiten suponer la fiabilidad y representatividad de los resultados. Sin embargo, limites técnicos 


\section{Mapa I-1: Valle de Tolomosa - Localidades y vías de comunicacón}

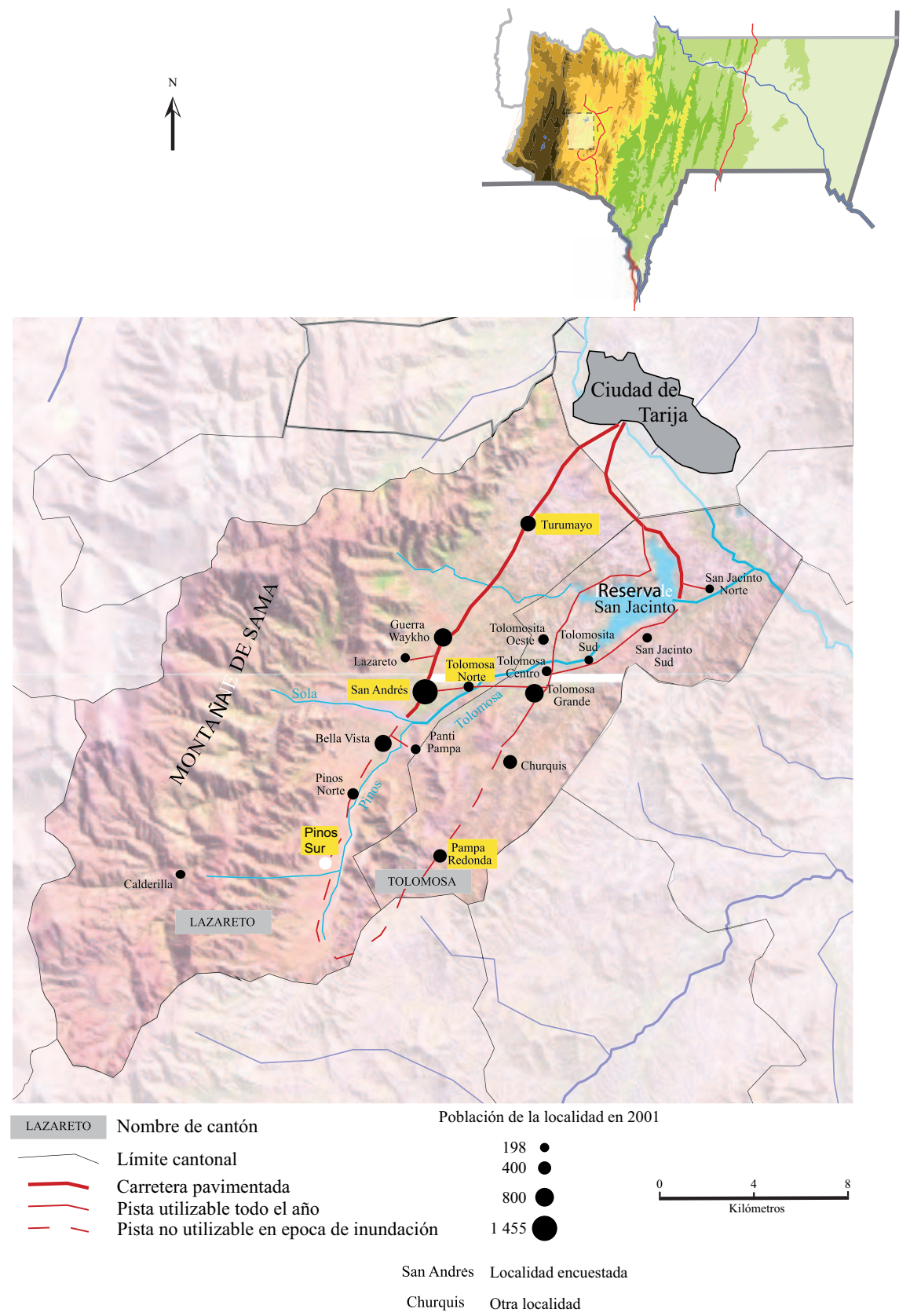

Nota: La sección Tarija-San Andrés no estaba pavimentada al momento de la encuesta

La construcción de un puente, en 2005, entre San Andrés y Pinos Sur, debe permitir que esta sección sea utilizable todo e Fuente: Datos y división cantonal del censo INE 2001 (INE 1999; 2002 b), Foto Satélite Landsat (julio 1996). 
— como la falta de registros del catastro- nos impiden extrapolar a nivel valle o comunidades. ${ }^{8}$

2. Con el fin de determinar la temporalidad de la residencia de los encuestados, hemos añadido una pregunta ${ }^{9}$ en este sentido, en el módulo 3 del cuestionario de Entol 2002 [cf. cuestionario A-4]. Así, identificamos a las personas para quienes la localidad registrada representa sólo un lugar temporal y nos limitamos a quienes no están de paseo. ${ }^{10}$

\section{LLEGADA DE LOS ESPAÑOLES, EL ÚNICO ACONTECIMIENTO DE UN POBLAMIENTO ANTIGUO}

Como se mencionó antes, el poblamiento de los valles centrales del departamento de Tarija se remonta al periodo inca (Martin, 2010). En el caso de la cuenca de Tolomosa, la presencia de un camino del Inca ${ }^{11}$ que conecta la parte alta del departamento con la cabeza del valle, confirma la importancia de la zona en esa época. Desde el comienzo de la Colonia, la implementación de un centro regional de Tarija marcó una nueva etapa en el poblamiento de los Valles Andinos, reforzada por la instalación de colonos a cargo de las hacien-

\footnotetext{
${ }^{8}$ Así es utilizando los efectivos encuestados y generalmente por localidad que realizaremos nuestro análisis. Sin embargo, en ocasiones trataremos los resultados en conjunto (sin distinguir las comunidades), especialmente si las cifras son numéricamente muy bajas o las diferencias entre las localidades poco significativas.

${ }^{9}$ La pregunta (con sus opciones de respuesta) fue la siguiente: "Reside en esta vivienda... ¿permanentemente?, ¿parte de la semana?, ¿los fines de semana?, ¿temporalmente?”.

${ }^{10}$ En doce hogares, el conjunto de individuos miembros de una casa (48 en total), declararon residir de manera provisional en la localidad encuestada. Se trata de familias enteras que vienen a pasar las fiestas de fin de año y que prolongan su estancia hasta el carnaval (principios de febrero), antes de regresar a sus lugares de emigración. La encuesta tuvo lugar al final del periodo estival y se capturó sólo una minoría de estos hogares (los que se habían demorado). Esta hipótesis ha sido confirmada por el importante número de casas cerradas durante la recolección de datos (particularmente Pampa Redonda) y por las entrevistas con residentes de varias localidades encuestadas. Con el fin de evitar trabajar con datos incompletos, no trataremos la subpoblación de los residentes no permanentes si eso concierne a todos los miembros de la familia. Por lo tanto nos concentraremos en los hogares restantes (201), que suman 1007 individuos. Es a esta subpoblación a la que nos referimos cuando mencionamos el total de los hogares o personas encuestadas. Los detalles de esta cifra, de acuerdo con las localidades encuestadas, se pueden observar en la Tabla I-I.

${ }^{11}$ A menudo los caminos del Inca son de piedra, fueron construidos para permitir la circulación dentro del imperio y su control.
} 
das. ${ }^{12}$ En el valle de Tolomosa la propiedad más importante es Pampa la villa del Rosario, propagación de la angostura (ranura situada al noroeste del valle y por donde fluyen las aguas de la cuenca) con relieves de la montaña de Sama. La producción agrícola se organiza alrededor del cultivo de maíz y trigo (y de tres molinos en permanente transformación), así como del de papa y algunas verduras. La crianza de animales, principalmente ganado bovino, es particularmente practicada sobre las tierras altas de la hacienda, suelo poco propicio para la agricultura. Este sistema de organización del espacio permaneció después de la Independencia boliviana y fue hasta la reforma agraria de 1952 (y su aplicación en 1964 en el caso del valle de Tolomosa), ${ }^{13}$ que los chacareros se encargaron de la gestión de tierras individuales. ¿Esta redistribución de tierras podía fomentar la llegada de nuevas poblaciones al valle? Según las observaciones de Hinojosa, la respuesta es no de manera significativa pues la reforma agraria implicó, sin duda, un aumento de recursos financieros de los habitantes de Tolomosa pero también una disminución de la productividad, así como una desaceleración en la expansión del cultivo (Hinojosa, 2000).

\section{LÍMITES DE UNA ACTIVIDAD AGRÍCOLA HETEROGÉNEA}

Al igual que los Valles Andinos, la cuenca de Tolomosa participó, durante la Colonia española, en la alimentación de las cuencas mineras altiplánicas. Este sistema, desarrollado por los propios españoles, se mantuvo durante la Independencia y no fue sino hasta después de la reforma agraria que la organización productiva del valle se perturbó, cuando los campesinos dispusieron de tierras propias que podían gestionar a su conveniencia. Por lo que sabemos, no existe estudio alguno sobre esta reestructuración del sistema agrario de la cuenca y si recientemente se han producido datos, estos no se consideran un objeto de aná-

\footnotetext{
${ }^{12}$ Las haciendas de la Colonia resultaban de la atribución por la Corona española de encomiendas en recompensa de actos de conquista. Los encomenderos eran, en otros términos, los maestros y recibían el derecho de controlar grandes extensiones de tierra así como a los indígenas que vivían en ellas. En el caso de los Valles Andinos, se crearon las grandes explotaciones agrícolas (de las haciendas). Las relaciones con el hacendero (propietario de la hacienda) o chacarero (campesino) podían tomar muchas formas, desde la esclavitud hasta el arrendamiento de la tierra en alquiler (Hinojosa, 2000). Notar que existían comunidades que no formaban parte de las haciendas en esta época.

${ }^{13}$ De hecho, si la redistribución de tierras se decidió en 1952, su aplicación se concretó solamente después de la creación de los sindicatos agrícolas y de un proceso judicial con el Consejo Nacional de la Reforma Agraria.
} 
lisis hecho a profundidad. Entonces será a través de la observación de grandes tendencias contemporáneas de la actividad agrícola de Tolomosa que comenzaremos nuestro análisis. Iniciaremos con un enfoque descriptivo del sistema productivo de la cuenca (A) antes de presentar una mirada más analítica sobre la evolución reciente y los límites actuales de este modelo de organización (B), requisito previo indispensable para estudiar los movimientos de la población.

Los datos empleados en esta sección se citan por una doble razón: situar las localidades encuestadas según Entol dentro de la pluralidad de las comunidades de la cuenca y, cuando los resultados son comparables, reflejar los cambios en el valle entre 1995 y 2002. Además en los datos del INE, nos apoyaremos en el conteo agrícola efectuado por la Codetar $^{14}$ en agosto de 1995 y citaremos los resultados obtenidos durante las encuestas preliminares del proyecto Zonisig ${ }^{15}$ realizado en el año 1999 [cf. Tab. I-3 a I-8 sobre los principales resultados de los trabajos de Codetar y Zonisig].

\section{COMUNIDADES DESIGUALMENTE CONECTADAS}

\section{A LA CAPITAL DEPARTAMENTAL}

El estudio de la ubicación geográfica de las comunidades en la cuenca reveló tres grandes conjuntos. El primero, las localidades cercanas a Tarija, al norte del valle; es decir, San Jacinto y Turumayo Norte (a seis km de la capital departamental). El centro de estas comunidades se encuentra en la parte baja de la cuenca (entre 1850 y $1900 \mathrm{~m}$ de altitud) y está muy bien conectado con la ciudad. Por ejemplo, para viajar de Tarija a Turumayo se requiere tomar el autobús que va a San Andrés y sólo toma unos minutos.

El segundo grupo, el más importante del valle, se sitúa alrededor de los ríos de Sola y Pinos Sur, afluentes de Tolomosa que alimentan la reserva de San Jacinto. Se integra por las localidades Huayco Guerra, Lazareto, San Andrés, San Jacinto del Sur y todas aquellas de Tolomosa. ${ }^{16}$ Los centros de

\footnotetext{
${ }^{14}$ La Codetar (Corporación Regional de Desarrollo de Tarija) es un organismo estatal que administra la planificación y ejecución de proyectos de desarrollo en Tarija. Su estudio de la cuenca de Tolomosa tenía por objetivo hacer un diagnóstico de la zona antes del establecimiento del proyecto control de la sedimentación de la reserva de San Jacinto.

${ }^{15}$ El objetivo del proyecto Zonisig era establecer cartografía del uso de la tierra en Tarija. Los resultados de las investigaciones preliminares realizadas en el marco de este proyecto se tomaron de manera indicativa.

${ }^{16}$ Entendemos por comunidades las de Tolomosa Norte, Tolomosa Centro, Tolomosa Grande, Tolomosita Sur y Tolomosita Oeste.
} 
estas comunidades se sitúan alrededor de $1950 \mathrm{~m}$ de altitud y están conectados todo el año a la ciudad de Tarija — los puentes fueron construidos para atravesar por el río principal- mediante un minibús que cruza regularmente (en el caso San Andrés, la frecuencia diurna se escalona entre 30 minutos y una hora) los $15 \mathrm{~km}$ (13 km en el caso de Tolomosa Norte y San Jacinto) para unirse a la capital departamental. Dos ejes permiten la ruta, uno oriental (pavimentado) y otro occidental (parcialmente pavimentado); ambos se unen a la altura de San Andrés por una pista transversal (consolidada) a lo largo de la cual se estableció Tolomosa Norte.

Finalmente, el tercer grupo de localidades se sitúa en las prolongaciones de estos dos ejes: Bella Vista, Pantipampa, Pinos Norte y Pinos Sur para el eje occidental; Churquis y Pampa Redonda para el eje oriental. Dichas comunidades están mucho más aisladas, lo cual puede explicarse por el mal estado de las pistas, por la ausencia de un puente sobre el río (intransitable durante las inundaciones) y la distancia geográfica (23 km para la comunidad de Pinos Sur, 25 para Pampa Redonda). Como resultado de ello, este grupo de localidades está conectado con Tarija una vez al día (menos en el caso de los Pinos al sur) y sólo fuera de los periodos de inundaciones. Por último, estas comunidades se ubican en la parte superior del valle, por lo general alrededor de 2000 metros (1 980 m para Pampa Redonda, 2100 para Pinos Sur), excepto Calderillas (situado a una altura de $3060 \mathrm{~m}$ de altitud), accesible sólo por el camino del Inca, a tres horas a pie en el oeste de Pinos Sur.

\section{A. ADAPTACIÓN AL MEDIO AMBIENTE}

El estudio sobre el sistema productivo del valle nos conducirá a aclarar dos puntos: la importancia de la agricultura y la ganadería dentro de las actividades de la cuenca y las diferencias existentes entre las localidades del valle. De esta manera esperamos detectar los principales modelos económicos del valle y considerar la heterogeneidad que ofrece el medio ambiente natural.

\section{Predominio agrícola}

En el censo INE 2001, de los 2894 activos de la cuenca — personas de siete años y más con una actividad laboral— $2252(77,8 \%)$ se encontraban relacionados con la agricultura y la ganadería. Los estudios de Zonisig sobre once comunidades del valle confirman el predominio de estos dos sectores, con la ganadería como actividad dominante en dos localidades (Pinos Sur y Pampa Redonda), y la agricultura de manera más importante en las otras nueve lo- 
calidades (como en San Andrés y Turumayo). La importancia relativa de la agricultura puede verificarse gracias al censo agrícola de 1995 de la Codetar que arroja que $53,6 \%{ }^{17}$ de las tierras declaradas por las Unidades Familiares Agropastoriles (UFA) ${ }^{18}$ en las localidades encuestadas estaban cultivadas, proporción que varía fuertemente de una comunidad a otra. Por lo tanto, es menor a $50 \%$ en ocho de las 14 comunidades (incluyendo Pampa Redonda con 26,1\%; Pinos Sur 39,1\%, y Turumayo, 46,9\%), entre 50\% y 70\% para cuatro de ellas (incluyendo Tolomosa Norte, con 55,0\%), y por encima de $70 \%$ para los dos restantes (incluyendo San Andrés, con 94,3\%). Podemos suponer que el resto de las tierras (las que no estas cultivadas) son parcialmente utilizadas para el desarrollo de la ganadería. ${ }^{19}$ Esto confirmaría la importancia de esta actividad en la localidad de Pampa Redonda, en contraste con la poca relevancia que tiene en San Andrés.

Según los resultados de Entol 2002, 76,6\% de 201 hogares censados (incluidas todas las comunidades) practican la agricultura y la ganadería; 12,9\% exclusivamente la agricultura, y $6 \%$ solamente la ganadería [cf. Fig. I-2]. Además, 84,4\% de 392 individuos de 15 años y más que trabajaron durante el curso de los siete días anteriores a la encuesta, lo hicieron en el sector agrícola y solamente 1,5\% lo hizo en la ganadería. Que se trate de la actividad de los hogares o de los individuos, los datos son bastante similares entre las comunidades ${ }^{20}$ [cf. Tab. I-10 y I-12 para los resultados desagregados por localidad]. Nuestra encuesta confirma un sistema de producción del valle principalmente basado en la agricultura, aunque es oportuno destacar que la ganadería ocupa un lugar representativo.

\footnotetext{
${ }^{17}$ Sea 2946 ha sobre 5 498. Estas informaciones se mencionan a título indicativo, dado la imposibilidad de verificarlas y la ausencia de metodología específica sobre su recolección. Sin embargo, parecen corresponder a la realidad y por lo tanto permitieron mejorar nuestra muestra y corroborar la representatividad de las comunidades seleccionadas.

${ }^{18}$ La Codetar designa así los hogares con una actividad relacionada con la agricultura o la crianza de animales.

${ }^{19} \mathrm{El}$ censo agrícola de la Codetar diferencia el uso de la tierra pastoral, lo que podría ser útil para calcular, de la misma manera que para la agricultura, la proporción de tierras reservadas a la ganadería. Sin embargo, el trabajo de la Codetar efectúa otras distinciones, particularmente entre los bosques y la erosión, igualmente frecuentados por el rebaño. Esto limita la validez de nuestros datos. Además, es difícil cuantificar el espacio reservado a la ganadería sin tener en cuenta las tierras comunales y el proceso de la trashumancia, una práctica aún muy extendida en la cuenca. ${ }^{20}$ La diferencia más significativa se refiere a la importancia de servicios (cerca de 15\%) para la más poblada de las comunidades del valle, San Andrés.
} 
Fig. I-2: Entol 2002 - Práctica de agricultura y ganadería por hogar y por individuos de 15 años y más

\section{El hogar declara practicar ...}

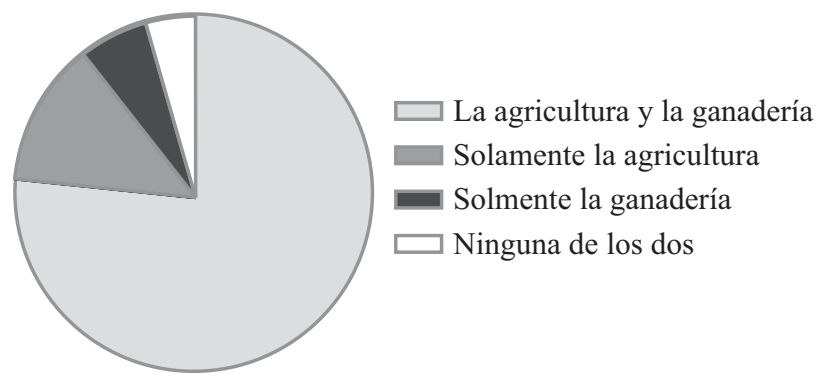

Subpoblación representada: 201 (total de hogares)

\section{Individuos de 15 años y más trabajando según el sector de actividad declarado}

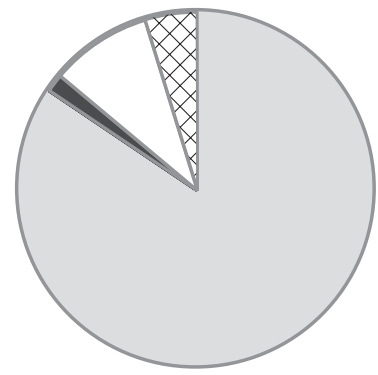

Sector de actividad

$\square$ Agricultura

- Ganadería

$\square$ Servicio

区X Otro

Subpoblación representada: 392 (total de individuos que declaró haber trabajado durante los últimos siete dias).

Fuente: Entol 2002.

\section{Preponderancia de las culturas tradicionales}

Según el censo agrícola de Codetar, la papa y el maíz constituyen la base de las culturas del valle (respectivamente 42,6\% y 43,2\% de la superficie total cultivada; cf. Tab. I-5 a detalle). Estos resultados varían fuertemente en las 14 comunidades, ya que el cultivo de la papa representa menos de $20 \%$ de la 
superficie utilizada en tres de ellas (incluyendo Pampa Redonda con 6,8\%). Para otras ocho comunidades este porcentaje oscila entre $20 \%$ y $50 \%$ (incluyendo Turumayo con 20,6\% y Pinos Sur con 33,6\%); y superior al 50\% para las tres restantes (incluyendo Tolomosa Norte, 51,0\%, y San Andrés, 60,8\%). También son importantes las diferencias en lo concerniente a la proporción de la siembra de maíz en el total de tierras cultivadas; para cuatro de las 14 localidades es inferior a 30\% (incluyendo Tolomosa Norte con 27,6\% y San Andrés con 26,6\%), para otras cinco comprende entre 30\% y $60 \%$ (incluyendo Pinos Sur, 56,4\%); y para las cinco restantes es superior a 60\% (entre ellas Turumayo, 68,9\% y Pampa Redonda, 91,9\%). Por último, según Codetar, la proporción de tierras destinadas a otros cultivos es sólo de 14,2\% sobre el conjunto de las 14 comunidades estudiadas en el valle; proporción inferior a $10 \%$ para cuatro localidades (entre ella Pampa Redonda, 1,4\% y Turumayo, 9,6\%); entre $10 \%$ y $20 \%$ para las otras siete (incluyendo Pinos Sur, 10,0\% y San Andrés, 12,6\%), y superior a 20\% para los tres restantes (entre ellas Tolomosa Norte con 21,4\%).

La encuesta Entol 2002 confirma las diferencias en cuanto al tipo de cultivo practicado en cada comunidad [cf. Fig. I-3]. De hecho, el 66,7\% de los 180 hogares encuestados declararon una actividad agrícola de cultivo de papa. La proporción es de 91,3\% si nos limitamos a Tolomosa Norte; de 78,5\% para San Andrés; 68,0\% para Pinos Sur; 57,7\% para Turumayo, y solamente $39 \%$ para Pampa Redonda. Otro cultivo preponderante es el de maíz, este representa 91,1\% del conjunto de hogares agrícolas encuestados; en cuanto a localidades, representa 100\% en Pampa Redonda, Turumayo y Pinos Sur, 82,6\% en Tolomosa Norte y 81,5\% en San Andrés. Por último la presencia de la horticultura (arveja, frijol, haba, cebolla, zanahoria) abarca solamente 15\% de hogares agrícolas, y encontramos la proporción más importante en San Andrés $(21,5 \%)$ y Tolomosa Norte $(34,8 \%)$, en estos dos casos las comunidades concentraron más de $80 \%$ de hogares que declararon haber adaptado una actividad hortícola.

Los datos de Codetar y Entol 2002 confirman el predominio de los cultivos de papa y maíz en las localidades del valle. Sobresalen dos tendencias: comunidades cuyas familias cultivan casi en la misma proporción papa y maíz así como un poco de hortalizas (San Andrés y Tolomosa Norte son ejemplos), y otras donde las familias practican sistemáticamente la siembra del maíz, algunas parcelas dedicadas a la papa y raramente siembran hortalizas (Pampa Redonda, Turumayo y Pinos Sur). 
Fig. I-3: Entol 2002 - Hogares y comunidades agrícolas según los cultivos que practican

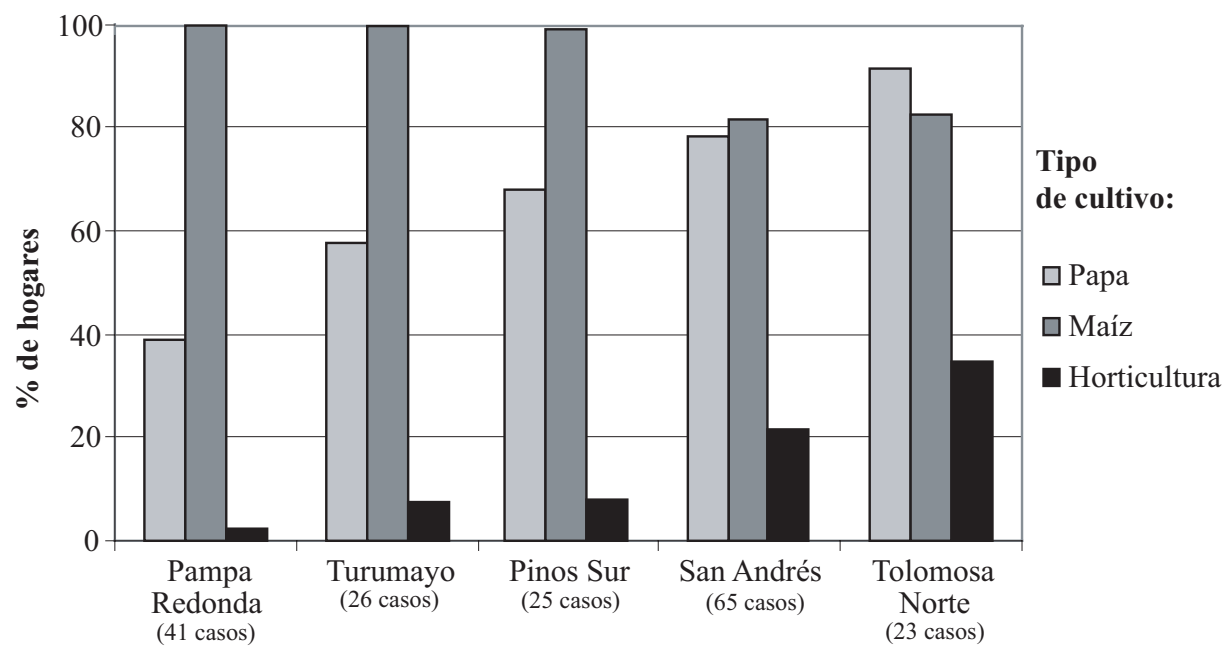

Nota: \% calculado sobre la base del total de hogares que declararon praticar la agricultura. Fuente: Entol 2002.

\section{El acceso a los recursos hídricos, causa de desequilibrios}

¿Podemos atribuir estas diferencias a las variaciones en el acceso a los recursos hídricos de las comunidades en el valle? La cuenca de Tolomosa se sitúa al pie de la montaña de Sama. Al igual que a la distancia desde la línea de cresta, las precipitaciones anuales disminuyen. Por lo tanto son relativamente importantes en Pinos Sur, San Andrés y Tolomosa Norte (respectivamente 1157,1030 y 1000 mm de lluvia anual) y las más bajas en Pampa Redonda (888 mm) y Turumayo (602 mm). La época de lluvias se presenta esencialmente de noviembre a marzo y contrasta con la sequía del periodo invernal de mayo a septiembre, cuando las precipitaciones son casi inexistentes. En este contexto, el riego de tierras de cultivo juega un papel importante. Según el censo agrícola de 1995 [cf. Tab. I-6 para los resultados completos] de 2949 ha cultivadas en las 14 comunidades encuestadas, cerca de $82 \%$ dispone de una fuente de riego. Sin embargo el desglose por localidad muestra una gran diversidad. Es así que encontramos tres comunidades con menos de $50 \%$ de tierras cultivadas irrigadas, especialmente en Pampa Redonda $(28,4 \%)$ y en 
Turumayo $(35,9 \%)$. Al contrario, cinco localidades tienen sistema de riego en $90 \%$ de sus tierras cultivadas, entre estas Pinos Sur (91\%), Tolomosa Norte $(95,7 \%)$ y San Andrés (100\%). Sin embargo, estos resultados deben estar matizados por la durabilidad del riego. Sobre las once comunidades estudiadas por Zonisig, solamente cinco (entre ellas San Andrés) poseen un riego anual; tres más entre siete y 11 meses del año; dos, la mitad del año (Pinos Sur y Turumayo), y solamente una con cuatro meses del año (Pampa Redonda).

Según Entol 2002, sobre los 176 hogares que declaran cultivos y tierras cultivadas, ${ }^{21} 44,9 \%$ disponen de riego sobre la totalidad de su terreno; $20,5 \%$ sólo sobre una parte y 33,5\% no cuenta con él. Como podemos observar en la Figura I-4, este resultado muestra fuertes variaciones según las localidades: en Pampa Redonda, solamente 2,4\% de hogares disponen de un sistema de

Fig. I-4: Entol 2002 - Hogares dedicados a la agricultura y que declararon tierras agrícolas según la presencia de riego y las comunidades

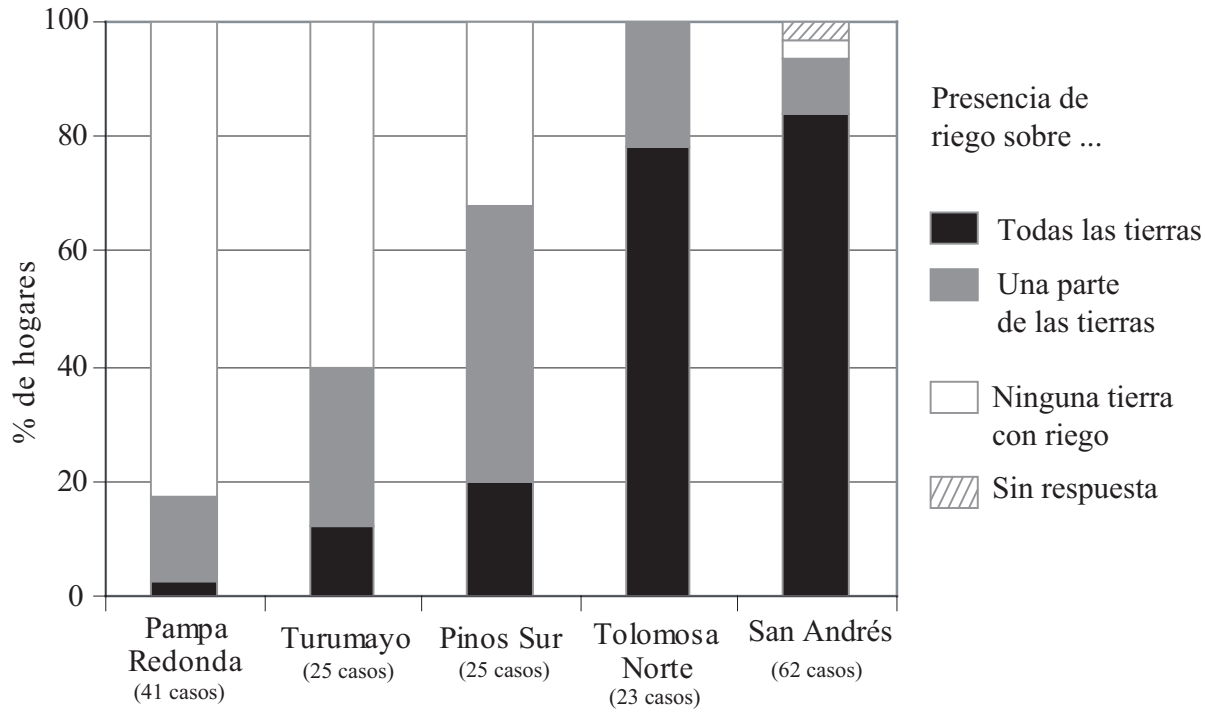

Nota: \% calculado sobre la base del total de hogares que delcararon cultivos y tierras cultivadas. Fuente: Entol 2002.

${ }^{21}$ Esta subpoblación varía de la anterior (180), cuatro hogares declararon cultivos pero no las tierras cultivadas (podemos suponer que cultivan una parte prestada de un terreno o que es un jardín cerca de la casa y piensan que no vale la pena declararlo. 
riego sobre la totalidad de sus tierras, y 14,6\% sobre una porción de tierra dedicada a la agricultura. Estas proporciones son superiores en Turumayo y Pinos Sur, $12,0 \%$ y 19,2\% respectivamente; mientras que $28,0 \%$ y $46,2 \%$ cuentan con sistema de riego parcial. Sin embargo, como hemos visto anteriormente, el riego sólo es posible seis meses al año, lo que limita su impacto. Por último, Tolomosa Norte, que presenta $78,3 \%$ de riego total y $21,7 \%$ de riego parcial y San Andrés con 83,9\% y 9,7\%, respectivamente, son comunidades que cuentan con riego a lo largo del año.

Lógicamente, no existe una relación entre la diversificación de la producción agrícola anteriormente señalada y este desequilibrio en el acceso a los recursos hídricos. De hecho, como podemos ver arriba en la Figura I-5, las comunidades con un riego permanente (San Andrés y Tolomosa Norte) coinciden con aquellas que declaran dedicarse a la horticultura, mientras que aquellas donde el riego no es anual, consideran solamente un ciclo agrícola (en periodo de lluvia), basado exclusivamente en los cultivos de papa y maíz.

\section{Ganadería, actividad secundaria o de sustitución}

Es interesante ver en qué medida las comunidades con una actividad agraria menos importante han desarrollado su ganadería. Para todo el valle, el censo agrícola de 1995 estima un promedio de 10 cabezas de ganado por Unidades Familiares Agropastoriles (UFA) [cf. Tab. I-7]. Sin embargo, esta cifra es superior en cuatro de las 14 comunidades (entre ellas Pampa Redonda con 14 cabezas por UFA y Tolomosa Norte con 12) y es inferior en seis (una de ellas Turumayo con nueve). Las restantes se encuentran en la media (particularmente Pinos Sur y San Andrés). En cuanto al resto de la actividad pastoral, en todo el conjunto de la Cuenca y por UFA, Codetar contó 10 cabezas ovinas, 14 aves de corral y cantidades menos significativas de cabras y cerdos. La importancia particular de la crianza de ganado bovino en Pampa Redonda se confirmó con la encuesta Entol 2002: el número promedio de cabezas de ganado por familia que declaró una actividad agrícola o ganadera ${ }^{22}$ es de nueve para todas las comunidades encuestadas, 15 si nos limitamos a Pampa Redonda y nueve o menos para las cuatro localidades restantes [cf. Tab. I-15 para ver resultados completos]. Del mismo modo, a nivel de la cuenca, podemos observar espacios ocupados para la crianza de ovejas (un promedio de

\footnotetext{
${ }^{22}$ Sea un subgrupo de 192 hogares a partir del cual hemos calculado nuestro promedio. Esta decisión permite comparar los datos con los de la Codetar.
} 
Fig. I-5: Valle de Tolomosa - Calendarios agrícolas de las comunidades según la presencia o ausencia del riego anual

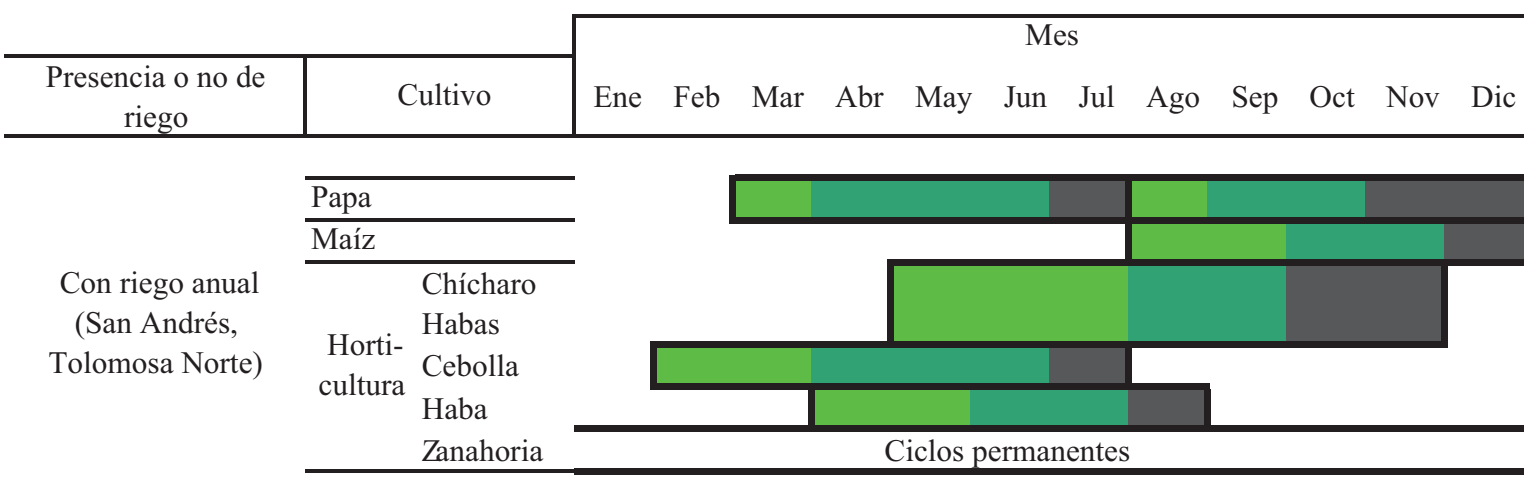

Sin riego anual

(Turumayo, Pinos Sur, Papa

Pampa Redonda)

Papa
Maíz

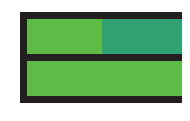

\section{Ciclo agrícola}

Fuente: Compilación de información de la Codetar (1995). 
cinco cabezas por hogar) y de producción avícola (10 aves por hogar), ${ }^{23}$ y la poca actividad en la crianza de cabra y cerdos (una cabeza y dos cabezas por familia en promedio, respectivamente).

Con en el objetivo de simplificar el análisis sobre la importancia de la crianza de animales en el valle de Tolomosa, trataremos por separado la presencia de ganado y reagruparemos el resto de los animales en una sola categoría a la que llamaremos "rebaño y aves". Esto último nos permitirá identificar las familias poseedoras de ovejas y/o de cabras y/o de cerdos y/o de aves de corral. Además, con el fin de distinguir los hogares propietarios de rebaño y aves con fines comerciales, los agrupamos en dos categorías: los que reportaron tener y los que contestaron no tener un rebaño de 30 cabezas o más de ovejas y/o cabras y/o cerdos y/o 30 aves de corral.

La Figura I-6 ilustra la magnitud de las diferencias entre las comunidades. En lo referente a la ganadería, sólo Pampa Redonda tiene una parte significativa de hogares con manadas de tamaño significativo: de 11 a 20 cabezas en $28,3 \%$ del conjunto de hogares encuestados y más de 20 cabezas en 19,6\% [cf. Tab. I-16]. En contraste, un porcentaje importante de hogares no se dedica a la ganadería en San Andrés (33,3\%) y Tolomosa Norte (44,4\%). En lo concerniente al ganado pequeño y animales de corral, se nota la misma preponderancia de Pampa Redonda, única comunidad que cuenta con una participación importante de los hogares $(26,1 \%)$ con al menos 30 cabezas o más de ovejas y/o cabras y/o porcino y/o aves de corral [cf. Tab. I-17]. Para las otras comunidades, resaltaremos la fuerte presencia de rebaños y aves de tamaño inferior: 69,2\% de hogares en Turumayo, 64,0\% en San Andrés, $51,9 \%$ en Pinos Sur y 63,0\% en Tolomosa Norte.

La crianza de animales en la cuenca de Tolomosa (en Tolomosa Norte, San Andrés, Turumayo y Pinos Sur) parece corresponder a una actividad complementaria de la agricultura por varias razones: fondo de ahorro, producción de fertilizantes, uso predominante de los animales de tiro en el modo de explotación agrícola del valle. Solamente una parte significativa de los hogares en Pampa Redonda se dedica a la crianza de animales, proporción que permite desarrollar una pequeña actividad comercial (como la producción y venta de queso).

\footnotetext{
${ }^{23}$ Cabe señalar, sin embargo, que no hemos investigado, durante Entol 2002, a los propietarios de las granjas industriales de producción avícola de Turumayo.
} 
Fig. I-6: Entol 2002 - Hogares según el número de cabezas de ganado vacuno, de rebaño (ovejas, cabras, cerdos) y aves declarados, por comunidad (continúa)

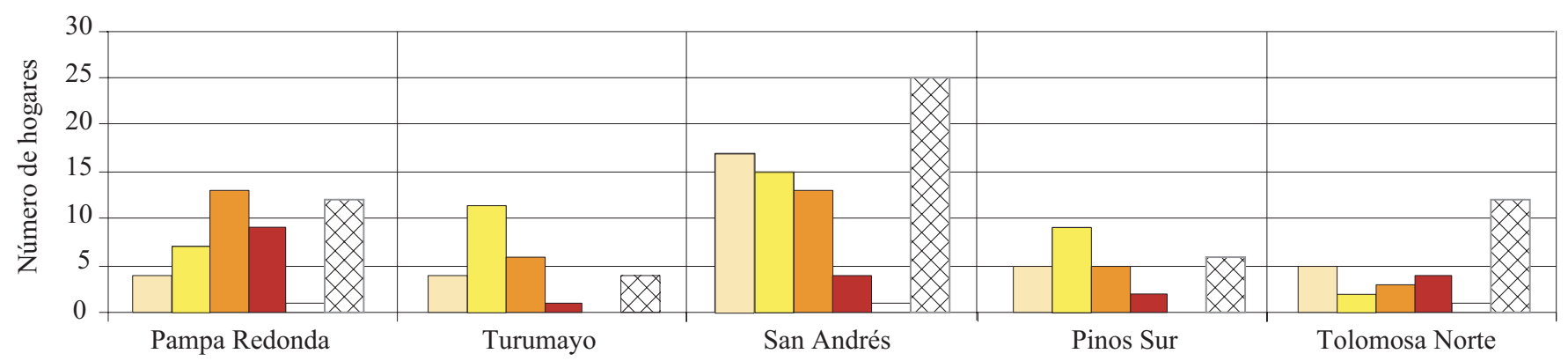

\section{Cantidad de ganado vacuno:}

$\square$ De 1 a 5

De 6 a 10
De 11 a 20

Más de 20
Sin respuesta

$\otimes$ Sin ganado
Presencia de rebaño (ovejas, cabras, cerdos) y aves:

Sí, con al menos 30 cabezas o más de la misma especie

Sí, pero sin que un especie alcance el umbral de 30 cabezas 
Fig. I-6: Entol 2002 - Hogares según el número de cabezas de ganado vacuno, de rebaño (ovejas, cabras, cerdos) y aves declarados, por comunidad

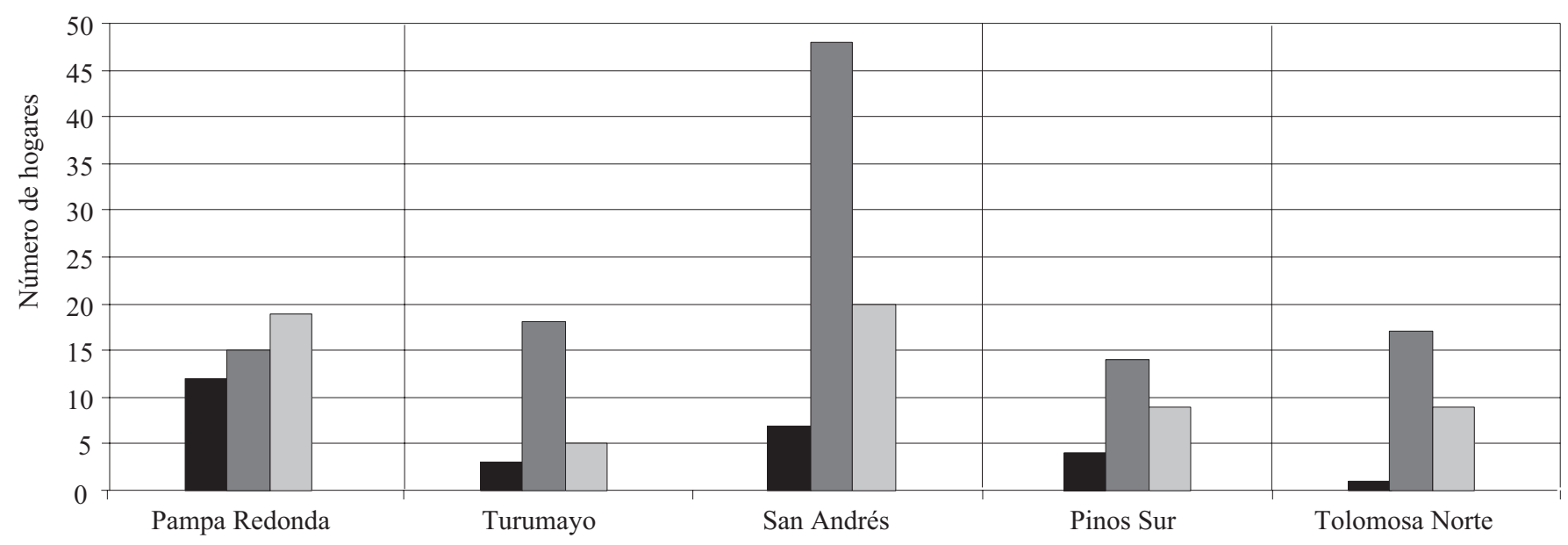

Cantidad representa para cada gráfico: 201 (total de hogares encuestados dentro de lo cuales hay al menos un miembro con residencia permanente en el valle de Tolomosa). Fuente: Entol 2002. 
El estudio del sistema productivo del valle constata la existencia de diferentes modelos, ilustrados por las comunidades seleccionadas en el marco de Entol 2002. San Andrés y Tolomosa Norte disponen de la actividad agrícola más desarrollada, se distinguen especialmente por la presencia de un sistema de riego anual y por la práctica de la horticultura. Por el contrario, Pampa Redonda sufre de importantes carencias en lo referente a los recursos hídricos, mismas que compensan con una actividad pastoral más fuerte. Por último, Turumayo y Pinos Sur observan una situación intermedia: están limitadas en su desarrollo agrícola sin que esto provoque una presencia importante de ganados.

\section{B. LAS DIFICULTADES DEL SECTOR AGRÍCOLA}

El presente análisis muestra importantes diferencias en los sistemas productivos de las localidades del valle. Estas desigualdades resultan particularmente de los desequilibrios entre las comunidades, especialmente con respecto a las desigualdades en los recursos hídricos y las repercusiones que esto pueda tener en la diversidad e intensidad de la actividad agrícola de las zonas estudiadas. Al tratar el tema de las oportunidades en el valle, ahora nos centraremos en el análisis de los límites del sistema productivo, así como en el desarrollo de las tierras agrícolas y su posible expansión. Terminaremos por abordar el problema de la subocupación de los habitantes del valle, lo que resulta fundamental para el estudio de los movimientos de población a seguir.

\section{Oportunidades comerciales limitadas}

El principal mercado de productos agrícolas de la cuenca de Tolomosa es la ciudad de Tarija (Zonisig, 2001), más precisamente el mercado campesino ${ }^{24}$ para los cultivos de hortaliza, papa o maíz, y el matadero municipal de ganado bovino y porcino. ${ }^{25}$ Dependiendo de las localidades encuestadas, el estudio Entol 2002 revela desigualdades en el comportamiento comercial de los hogares. De hecho, como podemos observar en la Figura I-7, en 68,0\% de hogares interrogados en San Andrés, al menos un miembro declaró ir periódicamente

\footnotetext{
${ }^{24}$ Principal mercado de la ciudad de Tarija en el que los campesinos venden su producción, sin intermediarios.

${ }^{25}$ Además, los agricultores pueden verse obligados a ir a la capital departamental para vender sus productos en la calle.
} 
a Tarija para vender sus productos agrícolas; ${ }^{26}$ esta proporción es de 63,0\% en Tolomosa Norte. Sin embargo, sólo es de 30,8\% en Turumayo, 22,2\% en Pinos Sur y 17,4\% en Pampa Redonda [cf. Tab. I-18 para la cifra]. Probablemente podemos atribuir estas variaciones, en parte, al hecho de que San Andrés y Tolomosa están particularmente bien comunicadas con la capital del departamento [cf. introducción de esta sección], también por el desarrollo de la estructura de su sistema agrario. ${ }^{27}$

La producción de tubérculos y maíz está generalmente destinada a la venta. ${ }^{28}$ En lo concerniente al maíz, sólo las comunidades que cuentan con riego anual, como en los casos de San Andrés y Tolomosa Norte, destinan una parte del cultivo a fines comerciales debido a que las dos cosechas anuales permiten excederse de las necesidades propias del hogar. Para las otras comunidades (Turumayo, Pinos Sur y Pampa Redonda), el maíz (como siembra preponderante) es principalmente utilizado para el autoconsumo (producción de masa y crianza de animales) (Hinojosa, Pérez et al., 2000). A esta diferencia se puede agregar el hecho de que San Andrés Norte y Tolomosa son las únicas localidades en las que existe una horticultura significativa, lo cual contribuye a explicar el desequilibrio comercial que se ha señalado. ¿Es posible desarrollar la comercialización de productos agrícolas? Tal vez por la construcción de instalaciones de almacenamiento (incluyendo silos), cuya escasez en el valle obliga un flujo inmediato de la producción en los mercados en Tarija.

Otros posibles avances son los referentes a las vías de comunicación del valle para conectar a las comunidades aisladas con la capital del departamento. ${ }^{29}$ Por el contrario, será difícil luchar contra la competitividad del sistema familiar del valle en comparación con los cultivos industriales argentinos. Según Hinojosa, en enero de 1999, la papa y la cebolla producidas en San

\footnotetext{
${ }^{26}$ Estos resultados se muestra en el módulo E "Movilidad cotidiana en Tarija" y particularmente en la pregunta tres, que cuestiona sobre si las idas y venidas a Tarija tienen por objetivo la venta de mercancía y si es así, qué tipo de mercancía es.

${ }^{27}$ Sobre la comercialización de los productos, conviene señalar que hay comerciantes que se desplazan hasta las comunidades para comprar directamente al productor, especialmente en el caso de compra de ganado.

${ }^{28}$ Según el diagnóstico del Cantón de Lazareto realizado en 1998 por la Unidad técnica de planificación de la Provincia Cercado (Uteplan), 80\% de la producción de papa de 1992 se comercializaba, $88 \%$ en cuanto a los guisantes y $97 \%$ para las cebollas.

${ }^{29}$ Notar que las vías de comunicación han mejorado desde la encuesta de 2001 con la consolidación de la pista en San Andrés y la construcción de un puente para cruzar el río Sola y acceder de manera permanente a las comunidades situadas río arriba como es el caso de Pinos Sur.
} 
Fig. I-7: Entol 2002 - Proporción de hogares con al menos un miembro que declaró viajar regularmente a la ciudad de Tarija para vender productos agrícolas, según la comunidad

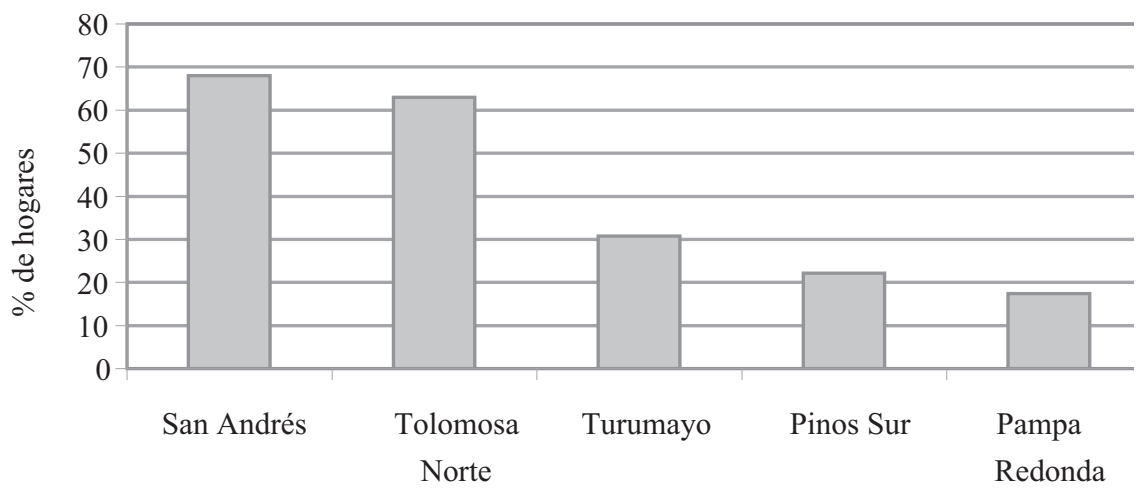

Nota: \% cálculos en relación al conjunto de hogares encuestados (75 en San Andrés, 27 en Tolomosa Norte, 26 en Turumayo, 27 en Pinos Sur, 46 en Pampa Redonda).

Fuente: Entol 2002 .

Andrés y vendidas en el mercado campesino, tuvieron un alza de $25 \%$ con relación a aquellos productos provenientes del país vecino. Podemos suponer que esta diferencia aumentó aún más después de la devaluación del peso argentino en diciembre del año 2000.

El potencial comercial del ganado en el valle también es limitado. La implantación de la práctica avícola industrial en Turumayo y la Guerra de Huayco reducen las oportunidades de venta de pollos de los campesinos de la cuenca; la trichinella ${ }^{30}$ reduce la posible comercialización de cerdos, el consumo de carne ovina es poco presente en las tradiciones alimenticias de los bolivianos. Además la lana está en competencia con las nuevas fibras sintéticas más baratas, el uso de las cabras se limita a la producción de leche, con pocas oportunidades, y la carne de bovino compite con razas más codiciadas y apreciadas de origen argentino, de Santa Cruz y del Chaco tarijeño. Estos hechos, sumados a la aridez de la cuenca, que impone una trashumancia anual hacia los valles subandinos, contribuyen a explicar el escaso desarrollo de la ganadería en el valle, que se limita a ser un fondo de ahorro.

${ }^{30}$ Gusano parásito que vive en estado de larva en los músculos así como en los intestinos de algunos animales y del mismo hombre. 


\section{Fragmentación del minifundio}

¿Qué pasa con la estructura de las tierras agrícolas en el valle de Tolomosa, tan determinante en el mundo rural? De acuerdo con el censo Codetar 1995, había 2946 ha cultivadas por 1343 UFA en la cuenca, un promedio de 2,19 ha/hogar reportando una actividad agrícola. Esta cifra varía de una comunidad a otra: más de 3 ha en San Andrés $(3,50)$ y Tolomosa Norte $(3,07)$; entre 2 y 3 ha en siete localidades e inferior a 2 ha en las cinco restantes, incluyendo Pinos Sur $(1,67)$, Turumayo $(1,39)$ y Pampa Redonda $(1,18)$ [cf. Tab. I-4]. Según Entol 2002, el promedio de superficie cultivada en 168 hogares encuestados (aquellos que declararon cultivos precisando sus superficies) es de 1,4 ha; para ser más precisos es de 1,7 en Tolomosa Norte; de 1,5 en San Andrés; de 1,3 en Pinos Sur y Turumayo y de 1,1 en Pampa Redonda [cf. Tab. I-19 para el método de cálculo]. Si este orden descendente es similar en las dos encuestas (el tamaño de las propiedades es más importante en San Andrés y Tolomosa Norte, medio en Pinos Sur y Turumayo, y más bajo en Pampa Redonda), hay que señalar, sin embargo, una reducción significativa de las diferencias y la tendencia a la disminución del tamaño de las propiedades. ${ }^{31}$

Una explicación para la disminución de la superficie cultivada puede residir en el modo de adquisición de la tierra. Como señalamos en la introducción, el régimen de tenencia de tierras en la cuenca de Tolomosa se vio sacudido por la reforma agraria iniciada en 1953. En 1995 (censo agrícola Codetar), en un grupo de 12 comunidades del valle de Tolomosa, ${ }^{32} 42,3 \%$ de tierras poseídas por las UFA habían sido adquiridas en el marco de la reforma agraria; ${ }^{33} 34,9 \%$ provenían de una herencia; $13,2 \%$ habían sido compradas, y

\footnotetext{
${ }^{31}$ Sin embargo, hay que señalar una posible subestimación del tamaño de las superficies cultivadas según Entol 2002. Una de las variables del cuestionario se refería a "otros cultivos" (diferentes a los de papa, maíz, horticultura y frutas). Sólo 31 hogares respondieron positivamente (de los cuales 17 corresponden a San Andrés y 6 a Tolomosa Norte), sin censar cuántas hectáreas ocupan sus cultivos. Es posible que este error en la colecta de datos limite la importancia de tierras cultivadas por hogar, notoriamente en las comunidades donde los propietarios agrícolas eran más importantes en 1995 (San Andrés y Tolomosa Norte).

${ }^{32}$ Errores estadísticos significativos fueron detectados en los datos proporcionados por la Codetar sobre la adquisición de tierra en Pinos Sur y Guerra Huayco, por lo cual no tomaremos en cuenta esas dos comunidades en nuestro análisis, el cual se centrará en 12 localidades.

${ }^{33}$ En lo referente a la reforma agraria, las tierras unidas a las haciendas han sido redistribuidas entre los campesinos que viven en el valle.
} 
Fig. I-8: Entol 2002 - Modo de adquisición de tierras agrícolas de los hogares en todas las localidades encuestadas en 1995 y 2002

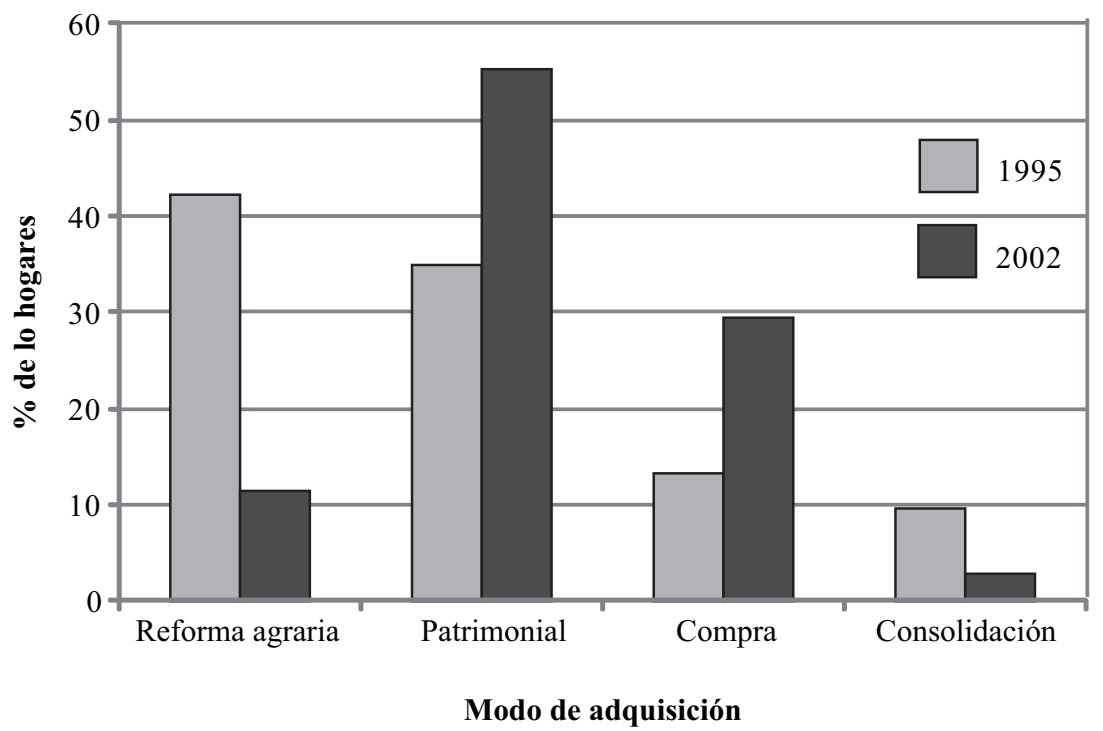

Nota: \% calculado en relación al conjunto de las familas proprietarias de tierras agrícolas y que declaran cultivos. Fuente de datos: censo Codetar 1995 y Entol 2002.

9,5\% se encontraban en proceso de consolidación. ${ }^{34}$ El desglose de estos datos por comunidad muestra el caso particular de Pampa Redonda [cf. Tab. I-8 para los resultados detallados]. En esa localidad, la proporción de las tierras obtenidas en el curso de la reforma agraria es sólo de 4\%, mientras que hay un porcentaje muy alto de adquisición por consolidación (49,8\%). Esta constatación confirma el estatuto específico de la localidad de Pampa Redonda, que no formaba parte de una hacienda, lo que explica el proceso de consolidación correspondiente a la principal forma de adquisición de tierras. ${ }^{35} \mathrm{El}$ estudio de la situación de la tierra al momento de la encuesta Entol 2002, siete años más tarde, indica que casi todos los hogares con cultivos $(89,3 \%)$ poseen sus

\footnotetext{
${ }^{34}$ Este es un proceso para legalizar la propiedad de la tierra que no se adjunta a las haciendas del valle.

${ }^{35}$ En Pampa Redonda, por lo general, ha sido para regularizar la situación de la tenencia de las tierras pertenecientes a las familias que cultivan.
} 
propias tierras [cf. Tab. I-20]. Además, el principal modo de adquisición es la herencia $(55,3 \%)$, seguido por la compra $(29,3 \%)$, mientras que la obtención por medio de la reforma agraria concierne a tan sólo una minoría $(11,3 \%)$ de la subpoblación estudiada [cf. Tab. I-21]. Por lo tanto (como se aprecia en la Figura I-8) al parecer hubo una redistribución, a través de la herencia y de la venta, de las tierras recibidas en los años sesenta después de la reforma agraria o la consolidación; lo que probablemente contribuyó a la fragmentación de las parcelas de cultivo por familia y castigó a las generaciones más jóvenes que integran el sector agrícola. Según Entol 2002, el estudio de la cantidad promedio de tierras cultivadas declarada por hogar según la edad del jefe de familia confirma esta tendencia: ${ }^{36}$ es de 1,23 ha si el jefe tiene entre 20 y 44 años; 1,41 ha para aquellos entre 45 y 59, y 1,63 ha para los mayores de 60. Esto sugiere que la redistribución del patrimonio por herencia no sólo conciencia los mayores, lo que contribuye a una fragmentación en minifundio. ${ }^{37}$

\section{Perspectivas limitadas}

¿Podría haber una reversión de esta tendencia que lleva a las microparcelas, especialmente a través de la expansión de las áreas cultivadas? Las tierras comunales, que podrían permitir a los pobres aumentar su capacidad de producción agrícola, a menudo son aisladas, se ubican en las laderas alrededor de la cuenca, y generalmente son reservadas para el ganado. Además, el espacio disponible en el valle que no se cultiva hoy en día, es objeto de una intensa erosión ${ }^{38}$ acentuada por el pastoreo salvaje.

Si la expansión de las áreas cultivadas parece difícil, ¿qué posibilidades existen de mejorar los métodos de producción? El minifundio ya ha llevado a la sobreexplotación de la tierra, dejando poco espacio para la práctica del barbecho y motivando una utilización excesiva de fertilizantes químicos. El desarrollo de la mecanización, que podría propiciar una mayor productividad de la tierra, se enfrenta a dos obstáculos: presencia de piedras en el fondo del

\footnotetext{
${ }^{36}$ Nos limitamos aquí a los hogares que declaran prácticas agrícolas y tierras propias.

${ }^{37}$ En contraste con los latifundios (grandes propiedades operadas en forma extensiva) los minifundios son explotaciones demasiado pequeñas y pobladas (Brunet, Ferras et al., 1993, p. 296).

${ }^{38}$ Conviene señalar que es difícil determinar el impacto de la erosión y su evolución en la cuenca de Tolomosa. Merecerían estudios específicos como el de Preston, Macklin et al., (1997) así como el de David Preston (2001).
} 
valle y falta de financiamiento. ${ }^{39}$ ¿Es posible ampliar el sistema de riego para todo el conjunto de comunidades? La ausencia de agua permanente arriba de las comunidades limita esta perspectiva, y en todo caso se requeriría de una inversión considerable, no justificada para estas pequeñas comunidades. Además, los recursos hídricos del valle alimentan la reserva de San Jacinto, ubicada en el extremo septentrional de la cuenca, misma que produce parte de la electricidad de la ciudad de Tarija y riego subterráneo (en la parte baja del valle Camacho y Guadalquivir). De hecho, cualquier gran proyecto destinado a mejorar el abastecimiento de agua en el valle de Tolomosa estará estrechamente controlado y limitado. ${ }^{40}$

\section{Subempleo en el sector agrícola de la cuenca}

Las perspectivas de desarrollo de la agricultura o ganadería no son favorables, pero ¿actualmente qué podemos decir de los trabajadores de esta actividad? Según Entol 2002, la gran mayoría de personas (337 de 392) mayores de 15 años trabajaron durante los últimos siete días en una actividad relacionada con la agricultura o la ganadería. El estudio de las categorías de empleo en esta subpoblación constata el predominio de trabajadores independientes $(46,0 \%)$, y de trabajadores familiares no remunerados (45,1\%). Existe una participación extremadamente baja ocupada por los patrones, empleados, jornaleros y aparceros (totalizan $8,9 \%$ ), lo que caracteriza la estructura familiar de la economía campesina: la tierra se cultiva sobre todo en tierras del hogar [cf. Tab. I-23]. La relación entre el número de personas por hogar que declara una actividad relacionada con la agricultura o la ganadería y la superficie total cultivada por la familia, permite calcular un índice de la superficie cultivada por trabajador agrícola. En cinco comunidades, el informe es inferior a 0,5 ha por trabajador; $25,5 \%$ de los 149 hogares informan de la tierra cultivada y los activos en los sectores antes mencionados. Entre 0,5 y 0,99 ha por trabajador con $36,2 \%$; entre 1 y 1,99 ha con $32,2 \%$, y más de 2 ha para el resto con $6 \%$. Por lo tanto, podemos concluir que existe una subocupación de la población activa, especialmente si ésta practica la siembra de maíz y papa, que no

\footnotetext{
${ }^{39}$ El estudio de Zonisig (2001) informa que sólo 55\% de los agricultores de la cuenca poseen los títulos de propiedad de sus tierras, lo que limita la posibilidad de la hipoteca.

${ }^{40}$ Esta posición estratégica de la cuenca explica los numerosos proyectos que tienen como objetivo frenar la erosión que causa la lixiviación del suelo y la obstrucción de la reserva de San Jacinto por el aporte de sedimentos.
} 
requieren una importante labor. ${ }^{41}$ Aunque el desglose de este resultado por comunidad no muestra grandes diferencias [cf. Tab. I-23], igualmente se debe informar la presencia o ausencia de riego con el fin de medir su impacto en la ocupación de los trabajadores agrícolas según las comunidades. De hecho, esta subocupación se magnifica en las localidades que no cuentan con riego anual y que por lo tanto no tienen actividad agrícola de abril a noviembre (Pinos Sur, Turumayo y Pampa Redonda). ${ }^{42}$ Al contrario, las localidades que cuentan con un sistema de riego durante todo el año (San Andrés y Tolomosa Norte) tienen un calendario agrícola repartido a lo largo de los 12 meses, lo que limita la subocupación [cf. Fig. I-5].

Por último, cabe preguntarse si la práctica de la crianza de animales - particularmente en Pampa Redonda- constituye una posible actividad de sustitución durante la temporada invernal. Al parecer la respuesta es no. La temporada de sequía (de mayo a diciembre) corresponde a los meses de trashumancia, principalmente debido a la escasez de pasto. Los rebaños se desplazan hacia los valles subandinos del departamento de Tarija (especialmente alrededor de la reserva natural de Tariquía) y por una remuneración son confiados a los autóctonos para su cuidado (Hinojosa, Pérez et al., 2000, y Zonisig, 2001).

\section{$* * *$}

La actividad agrícola, principal fuente de empleo en la cuenca de Tolomosa, se enfrenta a diversos problemas (minifundio, erosión, limitadas oportunidades comerciales) de intensidad variable según las localidades. Situadas en el centro del valle, San Andrés y Tolomosa Norte podrán — gracias al riego anual- diversificar su producción (particularmente en el desarrollo de un cultivo de hortalizas que complementen las siembras tradicionales de papa y maíz) y lograr dos cosechas al año (lo que ocuparía mano de obra agrícola durante los 12 meses). El resto de comunidades encuestadas (Turumayo, Pinos Sur y Pampa Redonda) no gozan de este sistema de riego anual y se benefician de una sola cosecha en el periodo estival, parcialmente destinada a fines co-

\footnotetext{
${ }^{41}$ De hecho, en Tolomosa, la necesidad de mano de obra en cultivos de papa y maíz se limita generalmente a los periodos de siembra y cosecha, dos meses al año (a excepción de dos cosechas anuales de papa en San Andrés y Tolomosa Norte).

${ }^{42}$ El ciclo agrícola de estas comunidades empieza con el arado de la tierra, justo después de las primeras lluvias.
} 
merciales. Observamos aquí algunas de las especificidades propias de cada una de estas localidades. Turumayo, situado en las afueras de Tarija, sufre particularmente de erosión y de un acceso limitado a los recursos hídricos. Con los mismos problemas, Pampa Redonda está más aislada, separada en el extremo sureste del valle, y sus habitantes han desarrollado una actividad en torno a la crianza de animales, pero se ocupa poca mano de obra durante el invierno. Finalmente en Pinos Sur, la lluvia es más importante y la presencia de una corriente de agua ha permitido el desarrollo de un sistema de riego que se utiliza durante el verano. Por otro lado, esta comunidad es la más aislada del valle, al extremo del eje occidental, y de difícil acceso en temporada de lluvias.

¿Estos límites del sector agrícola de la cuenca, y la subocupación que genera, pueden relacionarse con la importancia de los flujos migratorios de los Valles Andinos (Martin, 2010)? ¿La migración puede considerarse como una actividad que sustituye las dificultades encontradas en la economía tradicional? Justamente son estos desplazamientos los que a estudiaremos a continuación.

\section{IMPORTANCIA Y DIVERSIDAD DE LOS DESPLAZAMIENTOS DESDE EL VALLE}

Diferentes estudios tienden a enfatizar la existencia de los movimientos migratorios entre los valles centrales y Argentina; tendencia confirmada por el número relativamente alto de personas nacidas en el extranjero que viven en los valles centrales según el censo INE 2001 (Martin, 2010). Además, la observación de la estructura por edad de la población rural de esta región revela una clara ruptura a partir del grupo de 15-19 años, lo que implica una migración de los jóvenes [cf. Fig. I-9-a]. Son estos movimientos de población los que proponemos evidenciar a partir del ejemplo del valle de Tolomosa, utilizando principalmente los resultados de la encuesta Entol 2002, la única fuente fiable de información sobre migración en la cuenca. Se tomarán en cuenta los diferentes tipos de movimientos de población: los efectuados de manera estacional (A); los de más larga duración, que involucran un regreso al valle (B), y, finalmente, aquellos que están en curso (C), estudiados a partir del análisis de la descendencia de los hogares encuestados, y que actualmente reside fuera del valle.

En esta sección —más bien descriptiva— resaltaremos los motivos de estos desplazamientos. El tema de los lugares de destino será abordado brevemente y después será sujeto a un estudio más específico. $\mathrm{Al}$ final, nuestro análisis 
tiene como objeto la comprensión de la migración de todo el valle, por lo que propondremos un análisis global de las cinco localidades encuestadas señalando, cuando sea necesario, las diferencias entre estas unidades.

\section{A. Motimientos estacionales DE INVIERNO}

PARA REDUCIR EL SUBEMPLEO

Durante enero y febrero de 1998, en pleno verano, los puestos de salud de las localidades de San Andrés y Tolomosa Grande censaron la población de 16 comunidades de la cuenca, totalizando 11289 habitantes. ${ }^{43}$ En septiembre de ese año, la unidad técnica de planificación del municipio de Tarija efectuó un conteo de habitantes de estas mismas comunidades resultando 9 245 personas. ${ }^{44}$ Aunque la fiabilidad de estos datos no se verificó, ${ }^{45}$ muestran que existe una diferencia entre la población en el verano y la invernal en el valle. Además, la comparación entre las pirámides de edad del censo del INE y nuestras encuestas [cf. Fig. I-9-a $\mathrm{a}^{46}$ y I-9-b] observan características similares, especialmente en relación con el déficit de los jóvenes a partir de la edad de 15 años, pero con una justificación: la tendencia es menos pronunciada en el caso Entol 2002. Esta diferencia se puede atribuir, por una parte, al método de recolección de datos: el censo incluye sólo a las personas presentes ese día, mientras que las encuestas se apoyan sobre la noción de pertenencia o no al hogar, sin que la presencia de las personas concernientes sea obligatoria. Por otra parte, influye también el periodo de recolección de datos: el INE trabajó a finales de septiembre y Entol a finales de febrero.

¿Podemos vincular las diferencias de la población (de acuerdo con el volumen y estructura) observada previamente en la migración temporal de los jóvenes, explicada por una subocupación en el periodo invernal? ¿Las comunidades sin riego anual son las más afectadas por este fenómeno? Y de

\footnotetext{
${ }^{43}$ Este resultado, obtenido con el servicio departamental situado en los anexos del Hospital San Juan de Dios en Tarija, corresponde a la agregación de los efectivos de las 16 comunidades según el INE.

${ }^{44}$ Datos obtenidos con el Uteplan (Unidad técnica de planificación de la Provincia Cercado) cuya sede se encuentra en un anexo a la alcaldía del municipio de Tarija.

${ }^{45}$ La observación de ciertos errores estadísticos nos anima a cuestionar.

${ }^{46}$ Hay que considerar que la observación de la forma de la pirámide (una base amplia pero que se reduce para los niños más pequeños, una ruptura importante en las pistas del grupo de 1519 años y un extremo superior al final) es el mismo en función de si se considera el conjunto de las comunidades del valle, o simplemente las encuestadas.
} 
Fig. I-9: Valle de Tolomosa y Entol 2002 - Estructura por edad de la población de la cuenca

a) Todo el valle según

el censo del INE en 2001

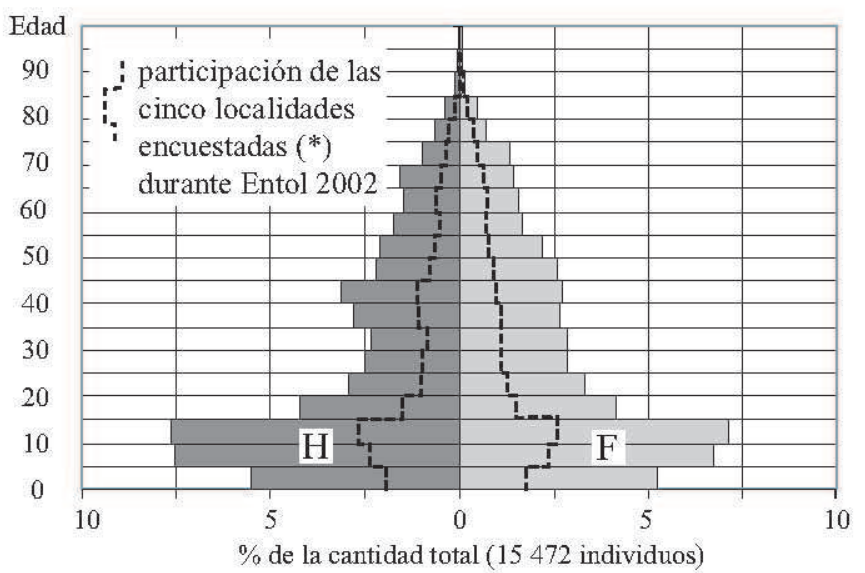

b) Las cinco localidades encuestadas (*) según Entol 2002

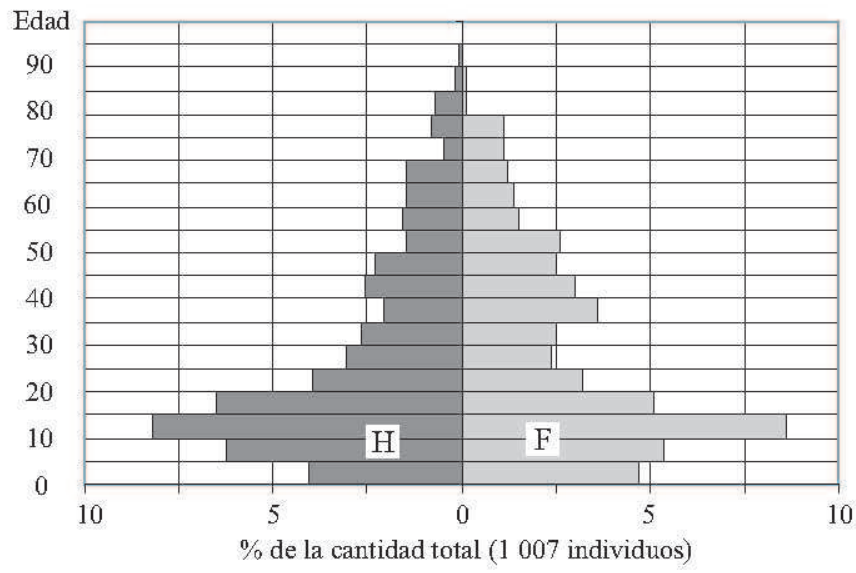

(*): Tolomosa Norte, Pampa Redonda, Pinos Sur, Turumayo y San Andrés Fuente de datos: censo 2001 (INE 2002 b) y Entol 2002. 
manera general, el precario sector agrícola observado anteriormente ¿puede estar relacionado con la existencia de la migración temporal?

Durante la encuesta Entol 2002, se registraron 511 eventos migratorios. ${ }^{47}$ Para casi la mitad de estas migraciones (exactamente 254 o 49,7\%), se observa que coinciden el año de llegada y el año de partida registrados: la duración de estas migraciones se encuentra entre los 6 meses y 1 año, y consiste en una ausencia durante el periodo de sequía (de abril a noviembre). Esta característica de Entol nos motiva a tratar estos 254 eventos por separado y los llamaremos "la migración estacional". Inicialmente, vamos a restringir nuestro análisis a las migraciones estacionales efectuadas por nativos del valle de Tolomosa ${ }^{48}$ entre 1945 y 2000, 158 eventos de migración fueron declarados por 123 personas. Más tarde volveremos sobre las 59 migraciones estacionales registradas en 2001. ${ }^{49}$

\section{Migraciones estacionales largas hacia Argentina}

Medir la evolución de las migraciones estacionales que provienen del valle de Tolomosa, tomando como base los datos recogidos durante la encuesta Entol 2002, no es algo fácil. De hecho, nos enfrentamos a dos fenómenos: 1) la falta de representación de los eventos de migración antigua, acabamos de señalar que la encuesta registra sólo los tres últimos movimientos migratorios, y 2) los límites de la observación retrospectiva (las migraciones estacionales detectadas son reportadas por los que siguen vivos o que no han

\footnotetext{
${ }^{47}$ Que corresponden a una instalación por un periodo de al menos seis meses en un lugar que no sea la localidad encuestada o la de nacimiento.

${ }^{48}$ No se dispone del año de instalación de los no nativos en la comunidad (en el valle de Tolomosa, la debilidad de esta subpoblación nos impide aplicar el módulo de "instalación" presente en las otras encuestas), por ello nos limitaremos a las personas nativas de la cuenca, con el fin de entender los desplazamientos desde el valle.

${ }^{49}$ Aprovechamos aquí para señalar algunas limitaciones en la recopilación de datos referente a las migraciones. Así 83 personas han declarado tres eventos migratorios (65 de ellas informaron al menos una migración estacional y 41 al menos una migración de una duración superior), en teoría, los tres más recientes. Esto tiene dos consecuencias: por un lado, no disponemos de información para estos casos con respecto a ocasionales migraciones suplementarias; por el otro, las migraciones realizadas durante los cuatro o cinco años anteriores a la encuesta están lógicamente sobrerrepresentadas. Otro punto, como veremos, la migración de los tolomosinos es a menudo objeto de trabajos ilegales en Argentina. Por lo tanto podemos suponer la retención de información de los encuestados la mayoría sospechosos, y por lo tanto una subestimación del número de migraciones estacionales.
} 
salido del valle). Sin embargo, como se muestra en la Figura I-10-a, ${ }^{50}$ nuestros datos permiten identificar dos tendencias. Para empezar, las primeras migraciones estacionales desde la cuenca de Tolomosa no son recientes: la primera registrada se remonta a 1945, y desde los años sesenta el número de partidas observadas es relativamente estable (hay que señalar, sin embargo, una disminución en los años ochenta y un crecimiento diez años más tarde, a la introducción de la paridad peso/USD en Argentina). En segundo lugar, hay un fuerte aumento en los eventos migratorios a partir de 1999, lo que se puede atribuir parcialmente al censo limitado a las tres últimas migraciones así como a la crisis climática de El Niño, que trastornó el sistema agrario durante el verano 1997-1998.

La Figura I-10-b nos muestra la estructura por edad y sexo de estas migraciones. En su mayoría son hombres (de los 158 eventos identificados, $72,8 \%$ fueron realizados por individuos del sexo masculino); incluso, si desde principios de los años noventa, hay un aumento en la migración estacional femenina (en las migraciones que tuvieron lugar antes de 1991, sólo 18,7\% fueron realizadas por mujeres, mientras que esta proporción es de 34,9\% para las migraciones que se llevaron a cabo entre 1991 y 2000) [cf. Tab. I-24]. Además, implica una población de adultos jóvenes (para 15,8\% de las migraciones estacionales, los sujetos tienen entre 15 y 19 años durante los años de la migración mostrados; la proporción es de 24,7\% para 20-24 años; $19,0 \%$ para 25-29 años, y 13,3\% para el grupo 30-34 años) $)^{51}$ [cf. Tab. I-25].

La búsqueda de una actividad laboral explica 89,9\% de los eventos migratorios (140 de 158 tienen como objetivo ir a trabajar y sólo dos estudiar y trabajar, cf. Fig. I-10-c), esta cifra sube a 97,4\% para los hombres, y sólo es de $69,8 \%$ en el caso de las mujeres, ya que una parte ${ }^{52}$ acompaña a sus familiares para cuidar el hogar [cf. Tab. I-26]. Una abrumadora mayoría de las migra-

\footnotetext{
${ }^{50}$ Durante nuestras representaciones gráficas de los eventos según los años y para limitar la importancia de las fechas que terminan en cinco o cero, estaremos regularmente obligados a igualar nuestros datos. En este caso, los datos fueron igualados por una media móvil de 3, es decir: total $(\mathrm{a})=(\operatorname{total}(\mathrm{a}-1)+\operatorname{total}(\mathrm{a})+\operatorname{total}(\mathrm{a}+1)) / 3$, donde total $(\mathrm{a})=$ número de personas instaladas durante el año (a).

${ }^{51}$ También en este caso, el hecho de no tomar en cuenta más que las últimas tres migraciones puede sesgar los resultados obtenidos por la omisión de las primeras migraciones realizadas por los encuestados, y por lo tanto subestimar los eventos producidos por la migración de los jóvenes.

${ }^{52}$ Conviene señalar otra explicación a esta subrepresentatividad de las migraciones profesionales en las mujeres: aquellas que se desplazan también por razones de formación ( $9,3 \%$ de las migraciones estacionales femeninas).
} 
Fig. I-10: Entol 2002 - Las migraciones estacionales entre 1945 y 2000 (continúa)

a) Año de realización de las actividades migratorias

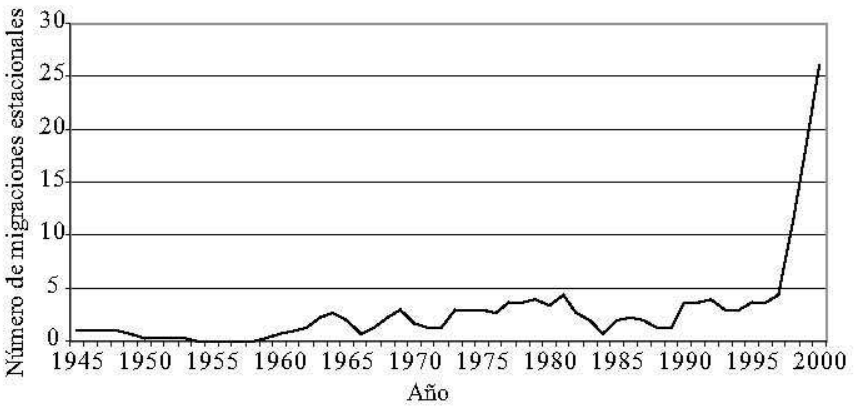

Eventos representados: 158 migraciones estacionales Metodología: alisado del afio de migración por 3

b) Edad en el inicio de la migración y género

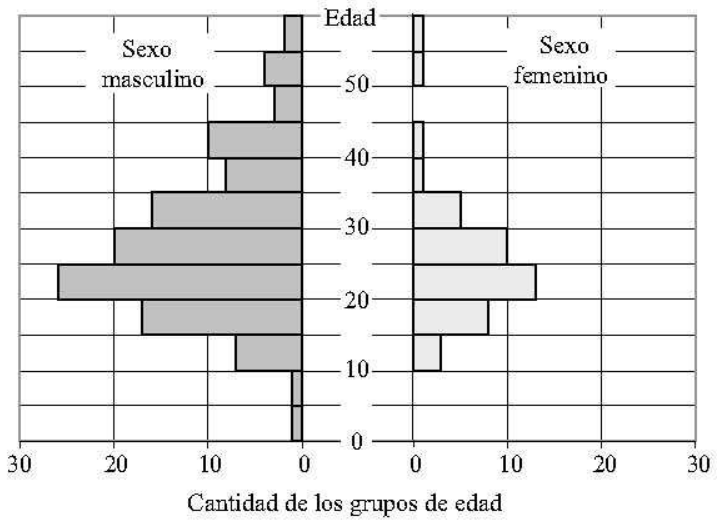

Eventos representados: 158 migraciones estacionales 
Fig. I-10: Entol 2002 - Las migraciones estacionales entre 1945 y 2000 (continúa)

c) Motivación principal de la migración estacional

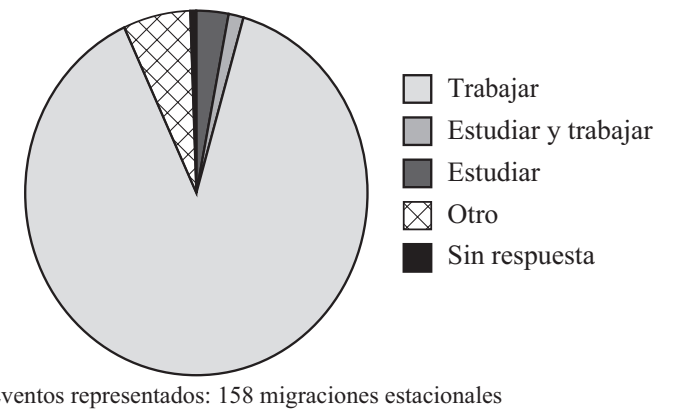

d) Sector de actividad de las migraciones estacionales profesionales

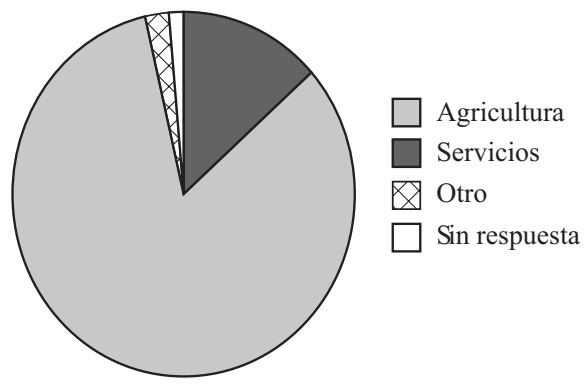

Eventos representados:

142 migraciónes estacionales parcialmente por razones profesionales

e) Categoría de empleo de las migraciónes estacionles profesionales

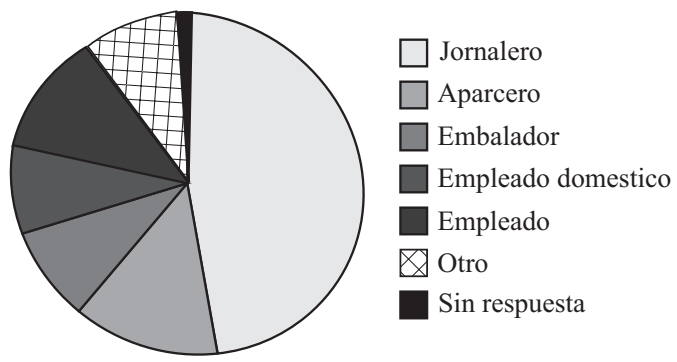

Eventos representados:

142 migraciónes estacionales parcialmente por razones profesionales 
Fig. I-10: Entol 2002 - Las migraciones estacionales entre 1945 y 2000

\section{f) Destino de la migración estacional}
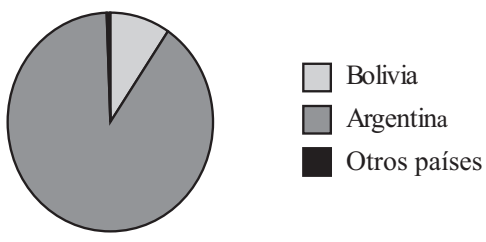

Eventos representados:

158 migraciones estacionales parcialmente por razones profesionales

g) Cantidad de migraciónes por hogares

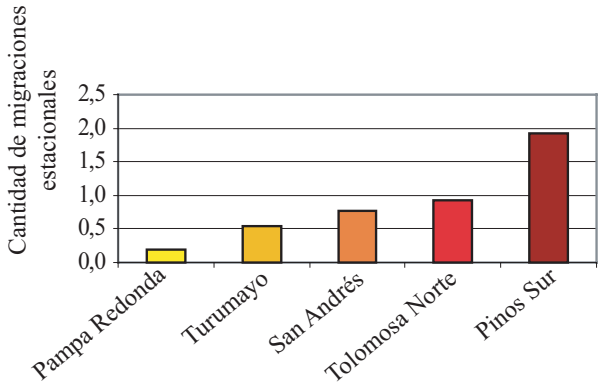

Cantidad de hogares encuestados: 201

h) Cantidad de migraciónes estacionales por individuo de 15 años y más nativo del valle

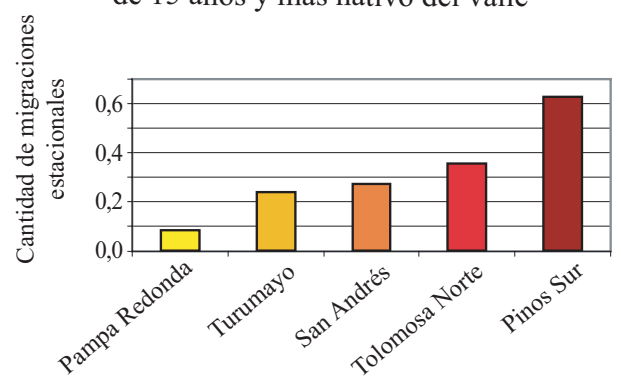

Cantidad total de individuos de 15 años y más y nativos del valle: 530

Fuente: Entol 2002. 
ciones laborales masculinas $(92,0 \%)$ está relacionada con un empleo en la agricultura, esta proporción es menor en el caso de las mujeres $(50,0 \%)$ pues ellas tienen actividades más diversas - 43,3\% de las migraciones estacionales están relacionadas con los servicios laborales, un importante porcentaje $(33,3)$ en el servicio doméstico- [cf. Tab. I-27 y I-28 para los resultados detallados y en la Figura. I-10-d y-e I-10 para una representación general de las migraciones laborales]. El trabajo agrícola se efectúa como jornaleros para más de la mitad (55,1\% de las migraciones estacionales están relacionadas con el ejercicio de una actividad laboral en la agricultura, en ambos sexos), las otras categorías laborales significativas son de arrendatarios ${ }^{53}(16,1 \%)$, y embaladores $^{54}(10.2 \%)$. Remarcaremos la pequeña proporción de los patrones ${ }^{55}$ $(3,4 \%)$, los trabajadores independientes $(1,7 \%)$ o trabajadores familiares no remunerados (3,4\%) [cf. Tab. I-27 para los resultados detallados].

Como se puede observar en el Gráfico I-10-f, la gran mayoría (89,9\%) de las migraciones estacionales se dirige hacia Argentina, principalmente hacia las provincias de Jujuy (30,4\% del total), Buenos Aires $(19,0 \%)$ y Salta $(17,7 \%) .{ }^{56}$ Es interesante repartir el resto de las migraciones hacia el país vecino según el año de desplazamiento [cf. Tab. I-30 para los resultados completos]. Así, para las migraciones registradas hasta 1990 (75 en total), una proporción no significativa de migrantes se dirigió hacia las provincias de Santa Fe $(14,7 \%)$ y Corrientes $(6,7 \%)$, mientras que la ciudad de Tarija no representa una proporción significativa de la migración estacional (1 de cada 75).

En los desplazamientos que se realizaron entre 1991 y 2000, se percibe una disminución de las migraciones hacia las provincias argentinas mencio-

\footnotetext{
${ }^{53}$ Según Hinojosa (2000) los arrendatarios no guardan más de 20\% a 30\% de su producción agrícola, y son muy dependientes de esta para rembolsar el dinero invertido.

${ }^{54}$ Trabajo calificado que consiste en seleccionar y acomodar los productos agrícolas antes de su comercialización.

${ }^{55}$ En el caso de Entol 2002, entendemos por patrón un individuo que emplea al menos tres personas. Con menos de tres empleados, los calificamos como trabajador independiente.

${ }^{56}$ Para estos destinos argentinos, no diferenciamos las localidades urbanas de las rurales, ya que esta información no fue bien colectada durante la encuesta. Esto se puede atribuir a una falta de conocimiento del país vecino por parte del encuestador y de los encuestados (si estos últimos fueron, sus desplazamientos se limitaron al trayecto para ir a trabajar), que confunden además los nombres de provincias, de capitales de provincias y de pequeñas localidades. También, la naturaleza de los trabajos efectuados durante las migraciones, en relación con la agricultura, provocaban dificultades para distinguir entre el mundo urbano y rural, debido al tipo periurbano de algunas zonas, las famosas cinturas verdes argentinas.
} 
nadas con anterioridad (Santa Fe contabiliza solamente 4,8\%, de las 83 migraciones estacionales de este periodo, y las de Corrientes, $12 \%$ y un aumento de los viajes a Tarija ( 8 de 83 casos, 9,6\%). Esta evolución sugiere una aproximación de las áreas de migración, probablemente a causa del fortalecimiento de los controles fronterizos por el gobierno argentino decididos en $1998 .{ }^{57}$ Por último, observamos ahora la poca importancia de la migración estacional en Bolivia (apenas seis casos, si no consideramos la ciudad de Tarija, lo que representa 3,8\% del total de nuestras 158 observaciones).

Si bien es cierto que no hay muestra de diferencias significativas al estudiar la estructura de las migraciones estacionales, es pertinente resaltar algunas. La cantidad de migraciones estacionales ${ }^{58}$ por hogar es de 0,8 para la totalidad de las comunidades (158 eventos migratorios por 201 hogares); de 1,9 para Pinos Sur; 0,9 para Turumayo y Tolomosa Norte; 0,8 para San Andrés, y 0,2 para Pampa Redonda. Además, la cantidad de migraciones estacionales declaradas por individuos nativos del valle con edades de 15 años o más es de 0,3 para el conjunto de las comunidades encuestadas (158 eventos para una subpoblación de 530 individuos); 0,6 en Pinos Sur; 0,4 en Tolomosa Norte; 0,3 en San Andrés; 0,2 en Turumayo, y 0,1 en Pampa Redonda [cf. Fig. I-10-g et h]. Las migraciones estacionales realizadas hasta el año 2000 son entonces más importantes en Pino Sur. Un análisis más preciso de estos desplazamientos provisorios en 2001, nos conduce a integrar a esta reflexión el estudio de las movilidades de corto plazo.

\section{Desplazamientos estacionales: una visión anual}

Una de las particularidades del cuestionario Entol 2001, en comparación con nuestras encuestas realizadas en el departamento de Tarija, fue introducir en el módulo 3 "miembro de familia" una variable respecto al tiempo de residencia en la comunidad, de la cual una de las modalidades fue: "de manera estacional, temporal". Esta modalidad permitió diferenciar a los miembros del hogar que efectuaron migraciones estacionales, según la percepción del informador (en general el jefe de hogar o su pareja). Los resultados de esta variable son reveladores: sobre el conjunto de 558 personas con edad entre 15 y 64 años (los más susceptibles a desplazarse), 13,6\% (73 casos) son resi-

\footnotetext{
${ }^{57}$ Este refuerzo se ha traducido en la proliferación de los controles en la frontera, también en todas las carreteras que unen la frontera boliviano-argentina en el centro del país vecino.

${ }^{58}$ Efectuados por los nativos del valle, ahora de 15 años y más entre 1945 y 2000.
} 
dentes temporales. Esta proporción es más importante en Pinos Sur $(28,0 \%$, 21 casos sobre 75), ligeramente superior al promedio para Pampa Redonda $(15,7 \%, 19$ casos sobre 121) e inferior al promedio para las otras tres comunidades (Tolomosa Norte 11,0\%, 8 casos sobre 64; Turumayo, 10,3\%, 7 casos sobre 68, y San Andrés, 9,5\%, 21 casos sobre 221)

¿Cómo se traduce esto en el estudio de los desplazamientos del año anterior a la encuesta? Para mostrarlo, revisaremos las 59 migraciones estacionales registradas durante el año 2001, independientemente del lugar de nacimiento del encuestado..$^{59}$ Sin embargo, un análisis exhaustivo de los movimientos temporales o estacionales no se puede reducir al estudio de las migraciones menores o iguales a seis meses, criterio de distinción de los 59 eventos en cuestión. Es por ello que usaremos algunos datos del módulo "movilidad" de Entol 2002 (realizada en febrero de ese año) que registra los desplazamientos que duran entre una noche y seis meses, durante los doce meses anteriores a la encuesta. Una de las variables de este módulo se refiere a la duración declarada del viaje: ${ }^{60}$ un día/menos de una semana/menos de un mes/más de un mes [cf. www.frontarbol.com para la observación del modulo correspondiente]. Sobre las 272 movilidades registradas durante la encuesta Entol 2002, 52 duraron más de un mes. Consideraremos que contribuyen a los desplazamientos temporales señalados más arriba (con alta probabilidad que fueron realizados en 2001) y los llamaremos "movilidades estacionales". La suma de las migraciones y movilidades estacionales totalizan 111 "desplazamientos estacionales" realizados en 2001, por 107 personas (cuatro personas declararon una migración estacional en 2001 y una movilidad de más de un mes). Estos 111 eventos nos permitirán medir los movimientos estacionales durante el año anterior a la encuesta [cf. Tab. I-32 para más detalles].

Tomando en cuenta las migraciones y las movilidades estacionales se observa un panorama preciso de los desplazamientos temporales durante un año (2001), desde las comunidades identificadas. De las 633 personas, de 15 años o más, encuestadas durante Entol 2002, un 16,9\% (o 107 casos) reportó un cambio estacional en el año 2001; que, en relación con cada comunidad, tiene algunos matices.

Así, en el caso de Pinos Sur, es cerca de un tercio de la población que se ve afectado $(29,4 \%, 25$ de 85$)$, mientras que esta proporción es mucho menor

\footnotetext{
${ }^{59}$ Los desplazamientos registrados ocurrieron justo antes de la encuesta, por lo cual deducimos que se realizaron desde la cuenca de Tolomosa.

${ }^{60}$ En caso de desplazamientos múltiples en un mismo lugar, esta variable se aplica a una duración más larga.
} 
para otras comunidades: Pampa Redonda, 18,1\% (25 de 138); San Andrés, 14,5\% (36 de 248); Tolomosa Norte, 13,8\% (12 de 75), y 12,0\%, Turumayo (9 de 75) [cf. Fig. I-11-A y Tab. I-33]. A nivel de los hogares encuestados, el fenómeno crece: más de un tercio de los hogares identificados durante Entol 2002 (33,8\%, 68 de 201) declara al menos una persona que ha realizado un desplazamiento estacional en 2001; en Pinos Sur son casi la mitad (48,1\%, 13 de 27) [cf. Fig. I-11-b y Tab. I-34].

Una proporción significativa de los hogares encuestados está compuesta de individuos que estuvieron ausentes por un periodo superior a un mes durante el año 2001, la proporción es más alta en dos de las tres comunidades que no tienen sistema de riego anual (Pampa Redonda y Pinos Sur). Estos desplazamientos inducen la existencia de una población flotante que reside durante el verano en el valle; esto puede ayudar a explicar las diferencias observadas entre la estructura de la población del INE y nuestras investigaciones. De hecho, es muy posible que algunas personas que reportaron un movimiento estacional en el año 2001 no estuvieran presentes durante el censo de septiembre de ese año. ${ }^{61}$

Es interesante comparar nuestros datos con los del equipo de Hinojosa (Hinojosa, Pérez et al., 2000), según los cuales 61 de las 80 familias de Pinos Sur entrevistadas en enero de 1999 (76,2\%) tenían al menos un miembro que había "emigrado" durante el año anterior a Argentina. Otros datos de este equipo: 44,2\% de la "población total de la comunidad" había "emigrado" el año anterior. ¿Estas proporciones, superiores a las de la encuesta Entol 2002, permiten concluir una disminución de la migración entre los años 1998 y 2001 ? $^{62}$ Es concebible, en particular tras el fortalecimiento de los controles aduaneros antes mencionados, pero es muy difícil de comprobar la comparación de estos datos. Tal vez no hemos identificado todos los movimientos estacionales de 2001, o quizás Hinojosa no emplea los mismos criterios de recolección de datos que nosotros. ${ }^{63}$

\footnotetext{
${ }^{61}$ Particularmente respecto a la ruptura del rango de edad 15-19 años y de la base uniforme entre los 20-24 y los 50-54 años.

${ }^{62}$ Con más razón si consideramos que el análisis de los datos de Entol 2002 no se limitó solamente a los desplazamientos hacia Argentina.

${ }^{63}$ Estos criterios no están especificados en el caso de ese estudio cualitativo, por lo cual limita la pertinencia de realizar un análisis comparativo. Simplemente señalaremos que el trabajo de este equipo confirma la extensión del fenómeno observado en la encuesta Entol 2002.
} 
Fig. I-11: Entol 2002 - Importancia de los desplazamientos estacionales en 2001 según las comunidades, los hogares encuestados y los individuos de 15 años o más

Número de desplazamientos estacionales realizados en 2001 declarados
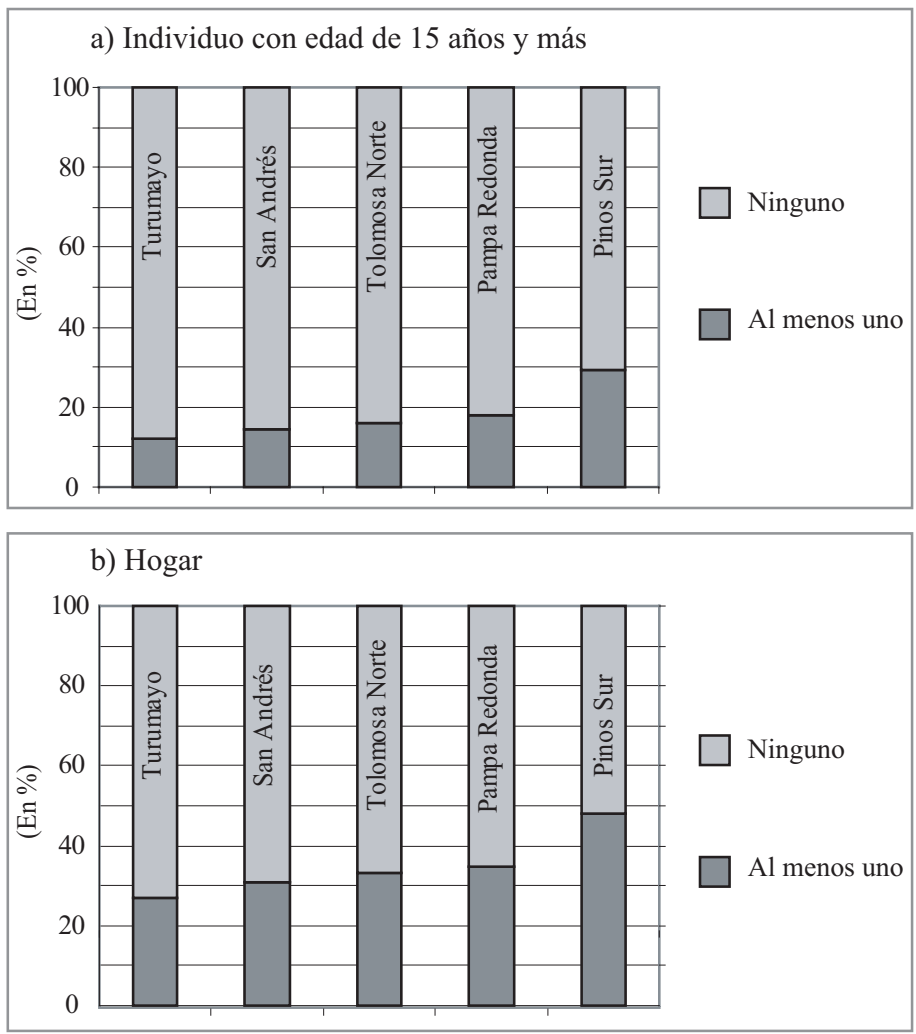

Fuente: Entol 2002.

Al igual que las migraciones estacionales del periodo $1945-2000,{ }^{64}$ la principal motivación del desplazamiento estacional es ejercer una actividad labo-

${ }^{64}$ Cabe señalar algunos matices, principalmente debido a la presencia de los movimientos estacionales de corta duración. Así, estos últimos se realizan en una proporción menos importante por motivos profesionales, y la proporción de mujeres y ancianos es más significativa [cf. Martin, 2010 para mas detalle]. 
ral $(71,2 \%$ de los eventos registrados). Del mismo modo, la agricultura es la actividad principal (75,9\% de los eventos migratorios estacionales laborales), completada por los servicios [cf. Tab. I-35, I-36 y I-37 para obtener información más específica]. ¿Podemos ver una conexión entre la subocupación de los habitantes del valle, ya discutida en esta sección, y los viajes laborales en 2001? La observación de la relación entre el número de hectáreas por trabajador agrícola y los movimientos por motivos de trabajo arroja datos sobre el tema. La correlación visible en la Figura I-12 es concluyente: 29,3\% de los hogares, con una superficie cultivada por trabajador agrícola inferior a una hectárea, declara al menos un movimiento estacional laboral durante el año 2001; esta proporción cae a 21,1\% si el área es mayor o igual a una hectárea. Del mismo modo, es 36,8\% si nos limitamos a los hogares que declaran tener trabajadores agrícolas sin tierras cultivadas y sólo 9,1\% en los casos en que no padecen de subempleo en la agricultura (hogares que declaran tierras de cultivo sin trabajadores agrícolas, o los que no declaran ni una cosa ni la otra) [cf. Tab. I-38].

Así, las migraciones y los desplazamientos estacionales son importantes en el valle de Tolomosa. ${ }^{65}$ Son movimientos de población antiguos, particularmente frecuentes en las comunidades aisladas sin riego anual. Su principal motivo, el ejercicio de una profesión, nos lleva a llamarlas actividades complementarias de la economía de la cuenca, especialmente para los hogares con una cantidad limitada de tierra y un alto potencial de mano de obra familiar. La segunda razón de estos movimientos temporales de personas, de tipo familiar (13,5\% de los movimientos estacionales en 2001), sugiere una dispersión espacial de los habitantes de Tolomosa, especialmente en el caso de Pampa Redonda (de la cual 44\% de los movimientos estacionales tiene como primer motivo una visita familiar, cf. Tab. I-35).

\section{B. MigraCiONES ANTERIORES, OTRO INDICADOR \\ DE DIVERSIFICACIÓN DE LA ACTIVIDAD}

Como movilidades o migraciones estacionales, entendemos eventos realizados por personas que residen parte del año en la cuenca y que participan activamente en los trabajos agrícolas del verano. Ahora tenemos que cuestionar

\footnotetext{
${ }^{65} \mathrm{Si}$ nos alejamos un poco, parece que la importancia de los desplazamientos estacionales en la cuenca de Tolomosa habría justificado un módulo aparte introducido, por ejemplo, con una pregunta filtro del tipo: "Durante el año 2011, ¿usted se desplazó fuera de la comunidad por un periodo superior a un mes?"
} 
Fig. I-12: Entol 2002 - Proporción de hogares que declaran al menos un desplazamiento estacional laboral en 2011, según la relación entre la superficie de tierras propias y cultivadas y el número de trabajadores agrícolas del hogar

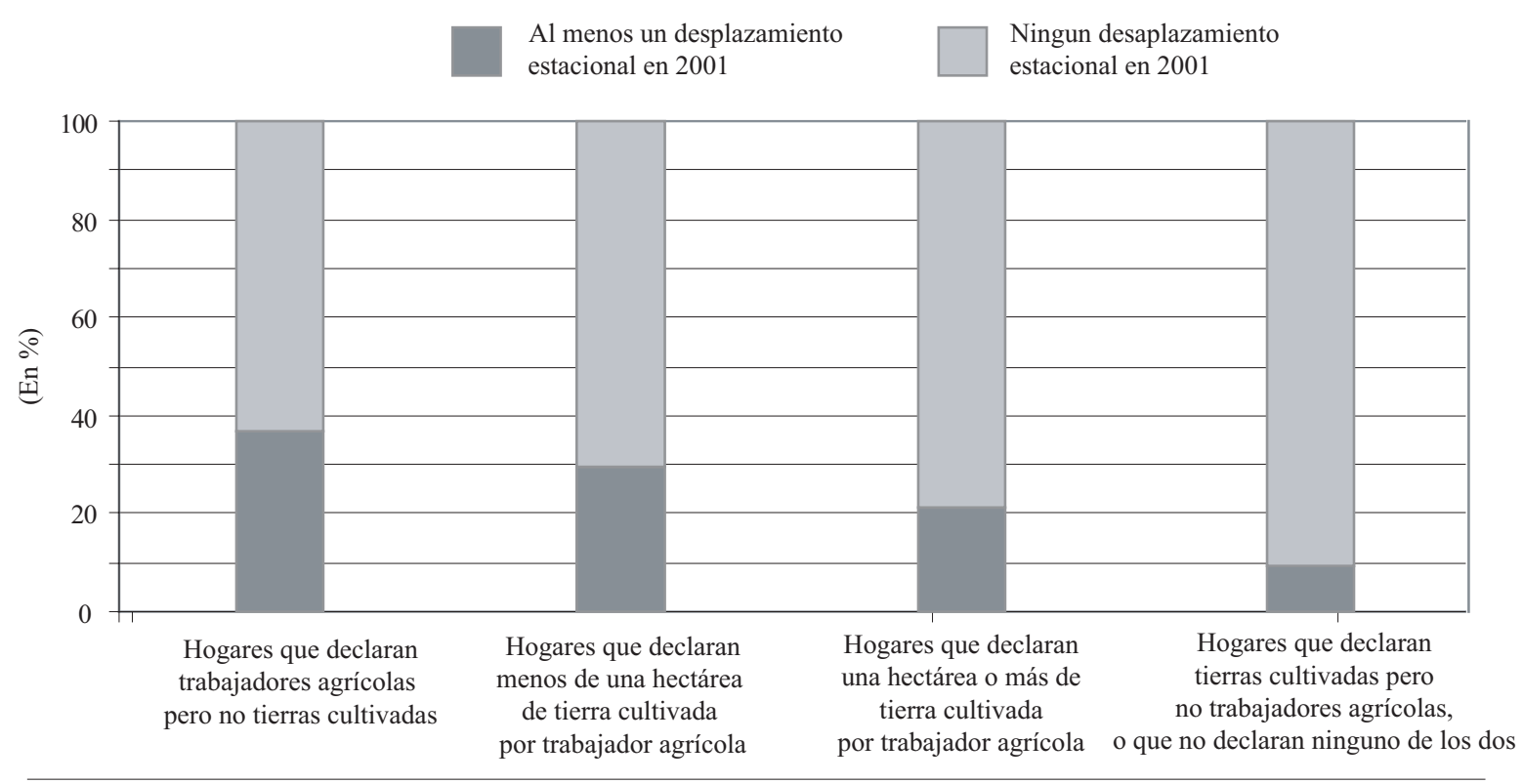

Fuente: Entol 2002 
la existencia y la importancia de otros tipos de migración que dan origen a salidas de mayor duración. Para ello analizaremos los movimientos de población de los cuales resultan cambios de residencia prolongados pero seguidos de reasentamiento en el valle. Vamos a tratar de comprender la estructura de estas emigraciones y percibir lógicas de regreso en el valle.

De los 511 eventos migratorios censados durante la encuesta Entol 2002, 254 fueron tratados como migraciones estacionales. De los otros 257 eventos, 47 fueron registrados con fechas incompletas, por eso no podemos afirmar que no son migraciones estacionales (eso justifica que no los tratamos). Concentraremos nuestro análisis entonces en los 210 eventos migratorios restantes, que no tienen el mismo año de salida ni de llegada (lo que induce que integran al menos un periodo estival y no correspondan a los criterios necesarios a las migraciones estacionales). Con el objetivo de estudiar los desplazamientos realizados en el valle, seleccionamos solamente las 146 migraciones realizadas por personas nativas de la cuenca fuera del valle de Tolomosa. Nuestra cantidad final de observaciones quedó en 16 migraciones [cf. Tab. I-39 para una recapitulación de las subpoblaciones de eventos migratorios] realizadas por 105 individuos repartidos en 77 hogares. Nombraremos estos desplazamientos "migraciones anteriores".

\section{Similitudes con las migraciones estacionales}

La importancia de las migraciones anteriores es significativa en Tolomosa. De hecho, en más de un tercio de los hogares encuestados (77 de 201, ó $38,3 \%$ ), al menos uno de los miembros nativos del valle que tiene 15 años o más declaró como mínimo una migración fuera de la cuenca ${ }^{66}$ [cf. Tab. I-40]. Estas migraciones son realizadas en su mayoría por hombres $(67 \%$ de las 146 observaciones, cf. Tab. I-42) de una población joven al momento de la salida (para 14,4\% de estos eventos la edad de partida es inferior a 15 años; para 83,56\% está entre 15 y 30 años, cf. Tab. I-43), y por razones laborales

\footnotetext{
${ }^{66}$ Dos razones nos motivan a no detallar los resultados por comunidad encuestada por el análisis de las migraciones anteriores: 1) si los datos recolectados revelan disparidades según las localidades encuestadas [cf. Tab. I-40 y I-41 la fiabilidad de los resultados está fuertemente comprometida debido a que no fueron censados tres eventos migratorios, lo que podría dar a pensar que las migraciones anteriores son más importantes en San Andrés que en los Pinos Sur mientras que, en esta última comunidad, la importancia de las migraciones estacionales limitó el censo de otros tipos de eventos migratorios, y 2) como lo veremos enseguida, las migraciones anteriores, en cuestión de redistribución de la población del valle, se mostraron menos estructurantes que las migraciones estacionales (analizadas más arriba) o que las migraciones actuales (como lo veremos después).
} 
(87\% de estos 146 desplazamientos, cf. Tab. I-44). Los empleos ejecutados durante estas migraciones son principalmente agrícolas (78,9\% de las 127 migraciones anteriores laborales, cf. Tab. I-45), como jornaleros (40\% de las 100 migraciones ligadas a un empleo agrícola), aparcero (29,0 \%) y trabajador familiar no remunerado (10,0\%) [cf. Tab. I-46 para los resultados completos]. Se nota la existencia de una minoría de migraciones ligadas a la práctica de un empleo en el sector de los servicios (17,3\% de las 127 migraciones laborales); la proporción es más relevante si nos limitamos a las mujeres (44,4\% de las migraciones anteriores laborales femeninas, cf. Tab. I-45) que trabajan como empleadas domésticas (30,6 \% de la misma subpoblación, cf. Tab. I-47). También en este caso, las migraciones anteriores tienen como destino principal Argentina (80,8\% de los 146 eventos), principalmente las provincias de Jujuy $(23,3 \%)$, Salta $(19,9 \%)$, Buenos Aires $(12,3 \%)$ y Santa Fe (14,4\%). Se nota una vez más la baja participación del Tarija $(5,5 \%)$ y de las otras regiones de Bolivia (13,0\%) [cf. Tab. I-48].

Los puntos comunes entre migraciones anteriores y migraciones estacionales son numerosos. Eso se refleja en sus duraciones, ¿indicador principal de diferenciación? Más de $80 \%$ de las migraciones anteriores son de una duración inferior o igual a cinco años (menos de dos años para 41,1\% de las 146 observaciones, y comprendidas entre dos y cinco años para 41,8\%, cf. Tab. I-49). El total de los años pasados fuera por un individuo que declara al menos una migración anterior, es un indicador revelador. En casi un tercio de los casos es inferior a dos años (33 de 105 casos o 31,4\%); en 44 casos $(41,9 \%)$ va de dos a cinco años.

\section{Improbables migraciones de regreso}

¿Existe un movimiento de regreso por parte de los habitantes de Tolomosa hacia el valle después de haber pasado varios años ejerciendo una actividad laboral fuera? Según nuestros datos ${ }^{67}$ las migraciones anteriores son cortas en general y conciernen categorías de empleo por las cuales la inserción de migrantes es difícil (así, notaremos la baja proporción de patrones o trabajadores independientes). A partir de lo anterior podríamos asimilar las migraciones menores de dos años a categorías estacionales prolongadas contra su voluntad (especialmente después de un fracaso que impida el financiamiento

${ }^{67}$ Limitados debido a que se toman en cuenta solamente tres experiencias migratorias. 
del regreso al primer año); y las comprendidas entre dos y cinco años a experiencias migratorias cortas, quizá a causa de mala inserción laboral. ${ }^{68}$

Por otra parte, ¿que se puede decir del regreso de tolomosinos a su cuenca natal para jubilarse? El estudio de edad de los individuos al momento de su ultima migración anterior no responde a esta pregunta [cf. Tab. I-50 para los resultados completos]. Este es de 30 años o menos con 65,7\% de las 105 personas que declaran al menos un evento migratorio anterior, de 40 años o menos con $81,0 \%$ de ellos, y de 50 años o menos $89,5 \%$. En febrero de 2002 no se constataban aún movimientos mayores de regreso de migrantes en edad de jubilarse.

La importancia y las motivaciones hacen de las migraciones anteriores un indicador suplementario de las estrategias de diversificación de la actividad de los habitantes de Tolomosa. Sin embargo, según nuestros datos, estos desplazamientos son de corto plazo, y no generan una inserción laboral de largo plazo en los lugares de destino, lo que nos hace suponer que son movimientos migratorios que no afectan de manera duradera el poblamiento del valle de Tolomosa. Por lo tanto, ¿cómo analizar el "éxodo" de la gente rural de los valles centrales, tema muy discutido en Tarija? Aproximarse a las migraciones que no generan regreso al lugar de origen nos documentará sobre este elemento.

\section{Dispersión DE LA DESCENDENCLA, TESTIMONiO \\ DE LAS MIGRACIONES ACTUALES}

El estudio de los lugares de vida de la descendencia de los hogares encuestados, especialmente de los hijos ${ }^{69}$ que viven fuera del valle, nos permite entender las migraciones actuales de las personas originarias de la cuenca. El interés de este análisis es doble: por un lado para establecer edad y proporción de los hijos que salieron del hogar familiar, y analizar cuál es la proporción que se queda en la cuenca o que decide emigrar, y por el otro, evaluar en aquellos individuos que se fueron del valle, la inserción en su lugar de destino y las eventuales consecuencias financieras sobre los hogares de origen.

\footnotetext{
${ }^{68}$ Es importante restituir el periodo de colecta de datos en el contexto, ya que febrero de 2002 es todavía temprano para medir los efectos de la crisis argentina de diciembre de 2001 y los regresos que puede generar.

${ }^{69}$ Lo empleamos aquí sin especificación de género.
} 
El estudio de la descendencia se hará a partir de la fusión de los datos que tratan sobre los hijos del jefe de familia del módulo "miembro del hogar", ${ }^{70}$ con aquellos que versan sobre el total de los individuos censados en el módulo "otros hijos del hogar". ${ }^{71}$ Esto permite una visión global de la descendencia del jefe de hogar (biológico o aceptado, la relación de parentesco en los dos casos está ligada a la percepción del encuestado, así que los hijos de una primera unión de la compañera del jefe de hogar pueden contabilizarse dentro de la descendencia, como cualquier hijo adoptivo).

Nuestro trabajo se orientara hacia la descendencia de 949 individuos (518 viviendo en el hogar de origen, ${ }^{72} 81$ fuera del hogar pero en el valle de Tolomosa y 350 fuera de la cuenca). ${ }^{73}$ Los 350 hijos viviendo fuera del valle corresponden a lo que llamaremos "migraciones actuales".

\section{Emigración masiva}

El estudio del comportamiento de la descendencia del jefe de hogar y su pareja, cuenta con abundantes datos respecto al tema de la emigración desde el valle de Tolomosa. En una primera instancia analizaremos el comportamiento residencial de la totalidad de los hijos del hogar, diferenciando a los individuos que viven todavía en él de manera permanente o temporal, de aquellos que lo abandonaron pero que se quedaron en el valle o que emigraron y viven fuera de la cuenca. Es sobre esta última categoría que trabajaremos después, midiendo, entre otras cosas, las emigraciones de acuerdo con las localidades encuestadas.

Casi la totalidad de los descendientes viven en el hogar familiar hasta la edad de 14 años [cf. Fig. I-13-a]; 80,2\% de los 15-19 años (105 de 131 casos); $44,5 \%$ para el intervalo 20-24 años (53 de 119); 33,9\% de los 25-29 años (37

\footnotetext{
${ }^{70}$ Más precisamente se trata de los hijos del jefe de hogar, censados en el módulo 3 de la ficha hogar de Entol 2002 [cf. www.frontarbol.com para el cuestionario completo].

${ }^{71}$ Este módulo lo introduce una pregunta filtro al jefe de hogar: "¿Tiene otros hijos que ya salieron de este hogar?"

${ }^{72}$ Distinguiremos los que viven allá de manera permanente (431) de los no permanentes (87).

${ }^{73}$ Se declararon 452 hijos en el módulo "otros hijos del hogar". Dividiremos esta subpoblación en dos partes: los hijos viviendo en la localidad encuestada o en el valle de Tolomosa (81) y los que se encuentran viviendo fuera del valle (371). Sin embargo, con el objetivo de estudiar la dispersión de la población desde la cuenca, nuestro análisis no tomará en cuenta los hijos que no viven en el valle al momento de la encuesta y que no nacieron en el mismo valle, eso en el caso de que los jefes de familia y/o sus parejas no nacieron en el valle o si permanecieron más de 10 años fuera de él ( 21 hijos de los 371 viviendo fuera del valle de Tolomosa). No se dispone del año de instalación de los no nativos en la comunidad, la eliminación de estos 21 individuos nos permite limitar la cantidad de hijos que no viven en el valle y que nunca vivieron ahí.
} 
Fig. I-13: Entol 2002 - Distribución de la descendencia de acuerdo con la temporalidad y lugares de residencia (continúa)

a) Lugar y temporalidad de residencia de la descendencia según la edad y sexo

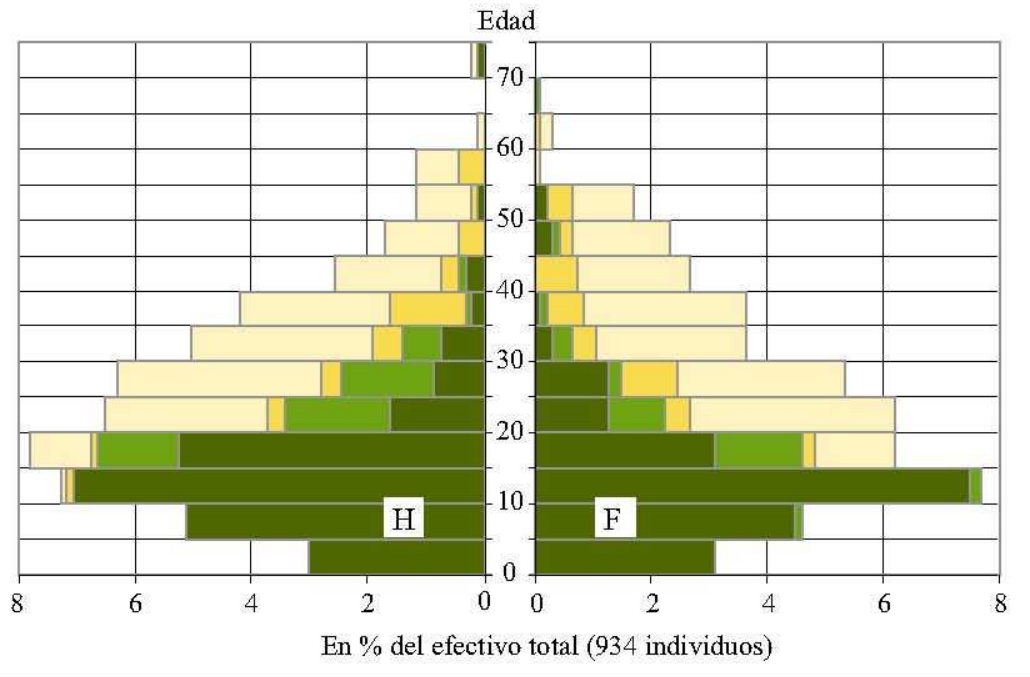

\section{Lugar de residencia:}

En el hogar

De manera permanente

De manera no permanente
Fuera del hogar

En el valle de Tolomosa

Fuera del valle de Tolomosa

Nota: para 15 individuos viviendo fuera del hogar, la edad no está registrada.

de 109 ); $23,5 \%$ de los $30-34$ años (19 casos de 81 ); y sólo $8,7 \%$ para la población mayor de 35 años (18 sobre 206). Notaremos que, si todavía viven en el hogar familiar, es de forma temporal para una cuarta parte de los individuos de $15-19$ años ( $25,7 \%$ o 27 de los 105 casos) y para casi la mitad de los $20-$ 34 años (47,7\% o 52 de 109). Quizá se puedan atribuir estas emigraciones al matrimonio, lo que supondría que cuna vez casados los hijos crean un nuevo hogar? Probablemente pero sólo de manera parcial, porque más de la mitad de ellos ( $52,9 \%$ o 228 hijos de los 431 que no viven en su hogar de origen) 
Fig. I-13: Entol 2002 - Distribución de la descendencia de acuerdo con la temporalidad y lugares de residencia

b) Repartición en \% del total de la descendencia de cada communidad según el lugar y la temporalidad de la residencia

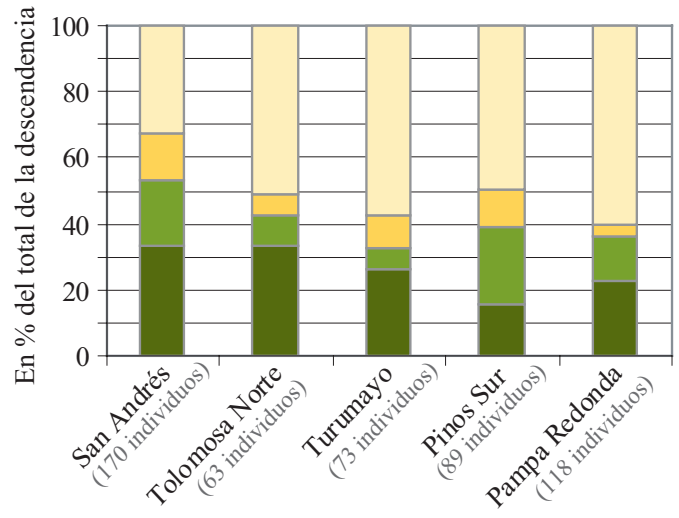

c) $\%$ de hogares declarando al menos un hijo según el lugar y la temporalidad de la residencia

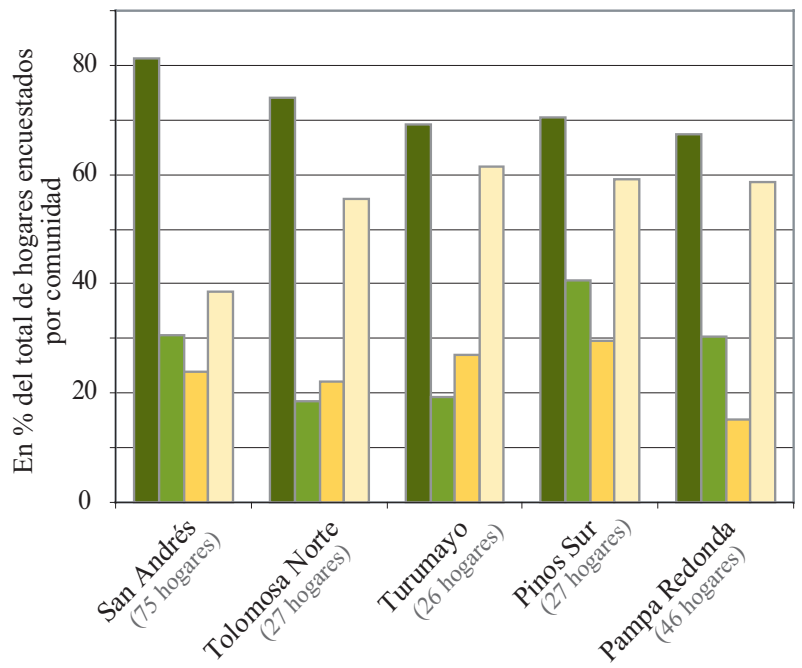

Fuente: Entol 2002. 
son solteros al momento de su emigración. ¿Cuáles son los lugares de residencia de los que se fueron del domicilio familiar? La mayoría lo hace fuera del valle de Tolomosa ( $81,2 \%$ o 350 de los 431 descendientes).

Podemos, desde ahora, notar importantes diferencias entre las comunidades encuestadas. Así, la Figura I-13-b muestra que en San Andrés y Tolomosa Norte los individuos del rango 15-39 años son relativamente más susceptibles a permanecer en el hogar familiar (52,9\% o 90 casos de 170 , y $42,9 \%$ o 27 de 63) y son los más nombrados como residentes permanentes (63,3\% o 57 de los 90 casos por San Andrés, y 77,8\% o 21 de los 27 casos por Tolomosa Norte). En Pinos Sur, la población entre 15 y 39 años es la menos propensa a quedarse en el hogar familiar (39,3\% o 35 casos de 89 ) y son estos los individuos menos considerados residentes permanentes (40,0\%, 14 de 35 casos), lo que puede, en parte, explicarse por la importancia de los desplazamientos estacionales en esta comunidad [cf. supra]. Finalmente, es en Pampa Redonda y Turumayo, que la proporción de los jóvenes adultos de 15-39 años que vive en el hogar familiar es menos significativa (36,4\% o 43 casos de 118 , y $32,9 \%$ o 24 de 73 , respectivamente).

Un dato interesante es que notamos varias realidades respecto a los lugares de residencia de los hijos salidos del hogar. En el caso de Pampa Redonda, $92,4 \%$ de ellos (109 de 118) se establecen fuera del valle de Tolomosa, mientras que esta proporción es de 70,0\% en el caso de San Andrés (84 de 120). En las otras tres comunidades la situación es intermedia: en Turumayo $79,1 \%$ de los hijos que dejaron el hogar no viven en el valle de Tolomosa (53 de 67); en Pinos Sur el dato es de 80,0\% (52 de 65) y en Tolomosa Norte de $85,2 \%$ (52 de 61).

¿Cuál es la importancia de estos viajes fuera del hogar? Más de la mitad de los hogares censados $(51,2 \%)$ declaran al menos un hijo viviendo fuera del valle de Tolomosa. Esta proporción es de 61,5\% para Turumayo, 59,3\% para Pinos Sur, 58,7\% para Pampa Redonda, 55,6\% para Tolomosa Norte y solamente 38,7\% para San Andrés [cf. Fig. I-13-c y Tab. I-53].

De esta manera, el análisis de los hijos que dejan los hogares encuestados muestra algunos matices. Recordemos que en las comunidades de Pampa Redonda, Turumayo y Pinos Sur los hijos dejan el hogar a una edad más temprana y son más quienes se instalan fuera del valle. Como lo podemos notar en la Figura I-14, en Pampa Redonda la magnitud del fenómeno es particularmente impactante: cerca de $60 \%$ de los hogares (más precisamente $58,7 \%$ ) declara al menos un hijo que reside fuera del valle, y más de un tercio $(34,8 \%)$ declara cuatro o más [cf. Tab. I-54]. En las otras dos comunidades 
Fig. I-14: Entol 2002 - Los hogares encuestados según la cantidad de hijos del hogar que residen fuera del valle

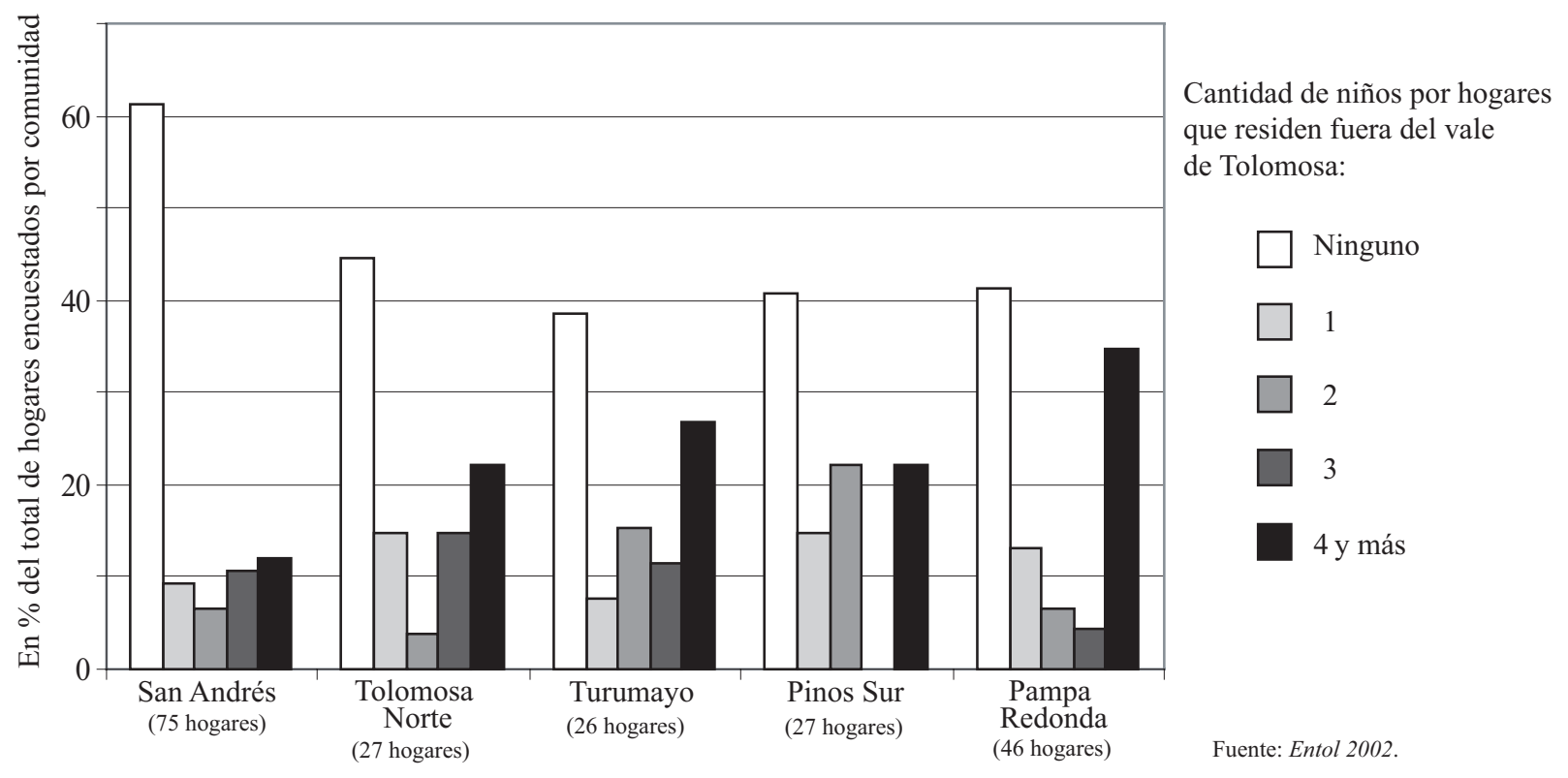


encuestadas (San Andrés y Tolomosa Norte) la importancia de estos viajes es menos marcada, sin embargo responde a un fenómeno de una dimensión significativa que conviene estudiar.

\section{Inserción laboral favorable y repercusiones financieras}

Una parte importante de la descendencia de los jefes de hogar encuestados en el valle de Tolomosa abandona la cuenca al cumplir la mayoría de edad, lo que puede deberse, parcialmente, a la nupcialidad. Para entender las motivaciones de sus viajes y la inserción de los hijos en sus lugares de destino, estudiaremos sus actividades (particularmente laborales) en su nuevo lugar de residencia y las remesas a los hogares de origen.

La descendencia que dejó el valle de Tolomosa está compuesta, sobre todo, por jóvenes adultos (70,0\% o 245 de los 350 individuos que forman esta subpoblación tienen entre 15 y 30 años) repartidos igualmente entre hombres y mujeres (174 individuos del sexo masculino para un 49,7\%) [cf. Fig. I-15-a].

Se notará la importante tasa de actividad de esta subpoblación; 85,4\% (299 de 350) trabaja, porcentaje superior al de los hijos que dejan el hogar pero que viven en el valle y que también trabaja (59 de 81 o 72,8\%). Esta diferencia puede deberse a que la descendencia fuera de la cuenca es más joven y compuesta por una proporción más importante de solteros. ${ }^{74}$ ¿Eso explicaría una tasa de ocupación femenina más importante con las mujeres que se fueron de la cuenca? 74,5\% (130 de 176 casos) que compone esta subpoblación trabaja, contra 52,4\% (22 de 42) que vive en el valle. Parecería que no. Si nos limitamos a las mujeres de entre 20 y 39 años que vive en pareja (perfil corriente de las amas de hogar), 76,5\% (62 de 81) de las que viven fuera de la cuenca trabajan, mientras esta proporción cae 30,0\% (6 de 20) para aquellas que residen en el valle. Concluiremos entonces que para la descendencia que reside en el exterior del valle la tasa de actividad superior proviene sin duda de una inserción laboral más fácil.

Respecto a esta inserción al mundo laboral, cerca de las tres cuartas partes de la descendencia que vive y trabaja fuera del valle lo hace en la agricultura $(73,6 \%$, cf. Tab. I-56 y cf. Fig. I-15-b], principalmente como jornaleros

\footnotetext{
${ }^{74}$ Los hijos instalados en el valle, solamente 60,5\% (49 de 81 ) tiene entre 15 y 39 años. Por otro lado, los hijos solteros salidos del valle representan 25,4\% (89 de 350) mientras que esta proporción es apenas de 4,9\% (4 de 81 ) para los que residen en el valle.
} 
Fig. I-15: Entol 2002-Descendencia que vive fuera de la cuenca según sus actividades laborales

\section{a) Ocupación principal según edad y sexo}

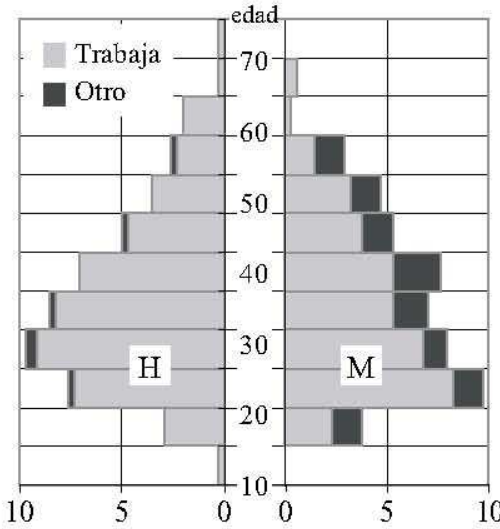

En \% de la cantidad total (340 individuos)

Para 10 casos, la edad no esta registrada

b) Sector de actividad de la descendencia que trabaja

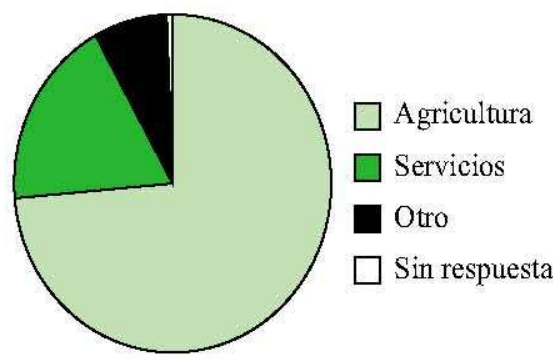

Subpoblación total representada: 299 individuos

c) Categorías de empleos de la descendencia
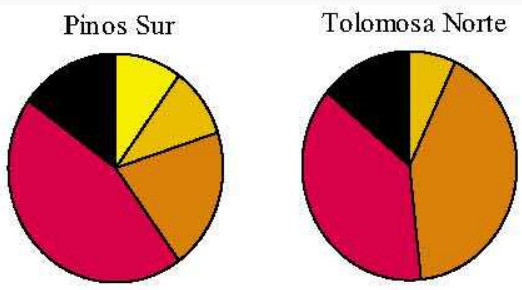
que trabaja en la agricultura, según las comunidades encuestadas

Jefe

Trabajador independiente

Aparcero

Jomalero

Otro
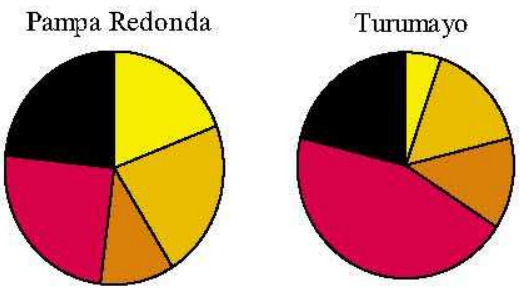

San Andrés

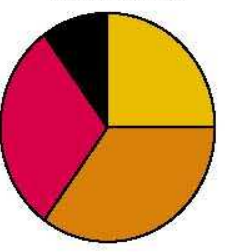

Fuente: Entol 2002.

$(34,5 \%)$ y apareceros $(21,4 \%)$; pero también como trabajadores independientes $(17,3 \%)$, patrones $(9,1 \%)$, embaladores $(8,6 \%)$, y trabajadores familiares no remunerados $(6,4 \%)$ [cf. Tab. I-57 para los resultados completos]. La diversidad de estas categorías de empleo es una señal de una mejor inserción 
laboral en la economía agrícola de la zona de acogida comparada con el caso de las migraciones estacionales o anteriores. ${ }^{75}$ Este resultado, según la comunidad de residencia actual del hogar encuestado, muestra fuertes disparidades [cf. Fig. I-15-c]. Para empezar, en el caso de Pampa Redonda, notaremos una proporción significativa de individuos que son trabajadores independientes $(21,9 \%$ de los hijos de los hogares encuestados en esta comunidad vive fuera del valle y trabaja en la agricultura), como patrones $(19,2 \%)$, mientras que los jornaleros son relativamente menos numerosos (24,7\%). En Pinos Sur y Turumayo ocurre lo contrario: los jornaleros son proporcionalmente más numerosos $\left(45,0 \%{ }^{76}\right.$ y $44,7 \%$, respectivamente) en comparación con los patrones y trabajadores independientes (las dos categorías totalizan 21,1\% para Turumayo y 20,0\% para Pinos Sur). Finalmente, las comunidades de San Andrés y Tolomosa Norte se distinguen por la ausencia de patrones, pero cuentan con una proporción superior de apareceros $(35,0 \%$ y $41,4 \%$, respectivamente) [cf. Tab. I-57]. Terminaremos señalando otro elemento interesante sobre la inserción laboral durante la emigración: una parte significativa de los hijos que emigraron, trabajan en el comercio (20 de 299 o 6,7\%) como independientes (19 de estos 20 casos), y en otros servicios (35 de los 299 o 11,7\%) particularmente como empleados domésticos en 15 casos. El porcentaje restante $(72,7 \%)$, que no trabaja en la agricultura, está compuesto mayoritariamente por mujeres (40 de 55 casos).

La inserción laboral parece relativamente favorable cuando el individuo abandona el valle. Entonces, podemos interrogarnos sobre las consecuencias financieras de estos movimientos migratorios sobre las comunidades de la cuenca. ${ }^{77}$ A escala de todas las localidades encuestadas durante Entol 2002 cerca del 30\% - 29,4\% para ser exactos — de los hogares reciben dinero de al

\footnotetext{
${ }^{75}$ Como recordatorio, la parte de los empleados en la migraciones estacionales se encuentra ligada a la práctica de un empleo agrícola 55,1\% mientras que las prácticas de patrones y apareceros no es tan notoria (respectivamente 3,4\% y 1,7\%) [cf. Tab. I-29]. En el caso de las migraciones anteriores, la parte de los jornaleros dentro las migraciones ligadas a un empleo agrícola es también importante $(40,0 \%)$, mientras que la de los patrones $(1,0 \%)$ y trabajadores independientes $(6,0 \%)$ son poco significativas [cf. Tab. I-46].

${ }^{76}$ La subpoblación de referencia es todavía de hijos que viven fuera del valle de Tolomosa y que trabajan en la agricultura.

${ }^{77}$ Una de las variables del módulo 4, "Otros hijos del hogar", se llama "remesas". Esta variable revela el envió de dinero — de manera regular o puntual— por hijo que no vive en el hogar (ver $<$ www.frontarbol.com> para el cuestionario). En este estudio nos limitaremos a una simplificación de estas modalidades de acuerdo con la presencia o ausencia de transferencias financieras.
} 
menos un hijo que vive fuera del valle [cf. Tab. I-58 por los datos]. En la Figura I-16-a podemos observar variaciones según las comunidades estudiadas: esta proporción es más importante en Pampa Redonda (30,4\%) y sobre todo en Pinos Sur (40,7\%) y Turumayo (42,3\%); en contraste es inferior en Tolomosa Norte $(25,9 \%)$ y notablemente bajo en San Andrés (21,3\%). El cálculo de un indicador correspondiente al total de hijos que vive fuera del valle y que están enviando dinero a su familia de origen, respecto a la totalidad de los hogares encuestados, resulta revelador de la magnitud de las remesas hacia la cuenca así como de los contrastes que existen según las comunidades. Al nivel de la totalidad de las localidades censadas, los hogares reciben en promedio dinero de un hijo; cifra que es de 1,2 para Pampa Redonda, Turumayo y Pinos Sur; de uno para Tolomosa Norte y solamente de 0,6 para San Andrés [cf. Fig. I-16-b para una representación visual de estos datos, y Tab. I-59 para ver los resultados detallados].

De este análisis sobre la actividad y las transferencias de dinero de los hijos que viven fuera del valle, resaltaremos dos tendencias principales: una, la inserción laboral es buena, sobre todo por la descendencia originaria de Pampa Redonda y para ambos sexos; segundo, esta situación se traduce en el envío de remesas importantes, particularmente en las tres comunidades que disponen de un sistema agrario muy limitado (Pinos Sur, Turumayo y Pampa Redonda), en menor proporción en Tolomosa Norte y relativamente poco en San Andrés.

\section{Predominio de Argentina}

Antes de terminar este estudio de la descendencia, nos interesaremos de manera más precisa en los lugares de residencia de los hijos que se fueron del valle de Tolomosa, fundamentalmente para medir la importancia de Argentina y de la ciudad de Tarija, respectivamente, como lugares de destino.

El estudio de los lugares de vida de la descendencia que reside fuera del valle de Tolomosa nos indica, una vez más, la preponderancia de Argentina $(76,6 \%$ de los lugares de vida censados) y la baja importancia de Bolivia $(6,3 \%)$ fuera de la ciudad de Tarija (14,1\%) [cf. Tab. I-60 para los resultados completos]. Una observación longitudinal muestra un aumento constante de las migraciones hacia el país vecino [cf. Fig. I-17-a]. Así, para los hijos que se fueron por primera vez antes de 1982, Argentina representa 69,0\% de los lugares de residencia actual, mientras que esta proporción sube a $72,9 \%$ para el periodo de 1982-1991 y finalmente a 83,6\% para 1992-2002, al momento de la paridad del peso argentino con el dólar estadounidense. Este aumento 
a) \% de hogares que recibe dinero de uno de sus hijos/as que vive fuera del valle de Tolomosa, según las comunidades estudiadas

Recibe dinero de al menos un hijo/a

No recibe dinero

No tiene hijo/a viviendo fuera

del valle y ligado/a al hogar

b) Número de hijos/as en promedio que vive fuera del valle de

Tolomosa y envía dinero

al hogar de origen, por hogar encuestado, según las comunidades estudiadas

Fuente: Entol 2002

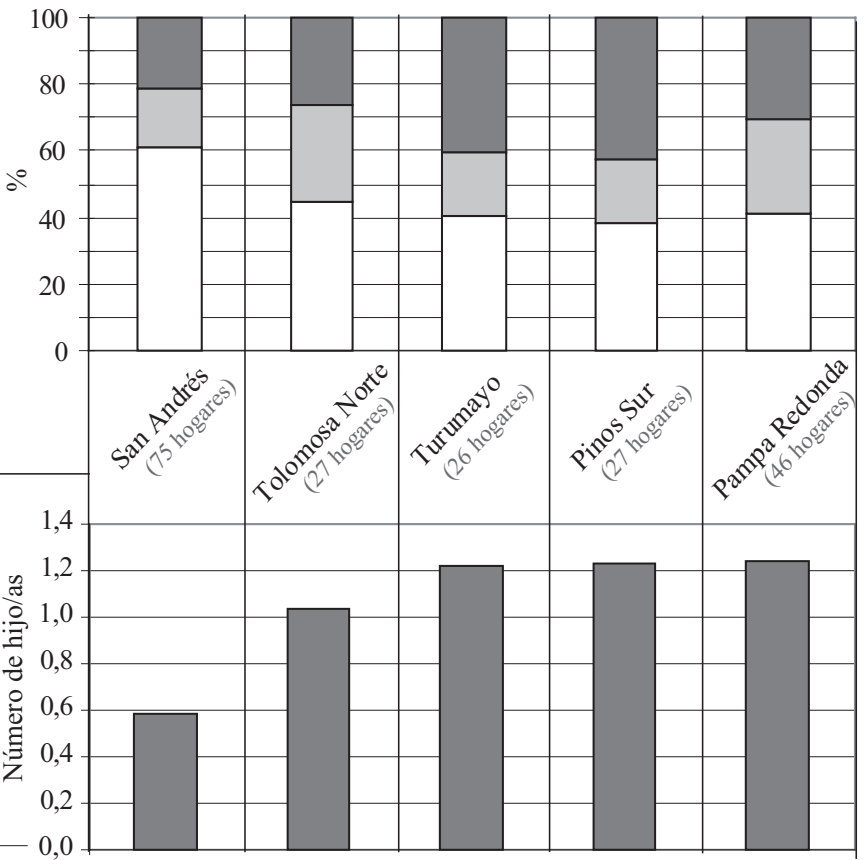


se observa al mismo tiempo del detrimento de la ciudad de Tarija que no representa más de 20,2\% de los lugares de residencia para el primer periodo, $14,6 \%$ para el segundo, y solamente $11,2 \%$ para el tercero. ${ }^{78}$ Sin embargo, se nota que el punto de destino Tarija varía de una comunidad a otra. De hecho, la capital departamental concentra una cuarta parte de los de hijos cuyo hogar está en San Andrés o Tolomosa Norte, mientras que esta proporción no es más de 11,9\% para los ligados con Pampa Redonda, 9,4\% para Turumayo y 1,9\% en el caso de Pinos Sur [cf. Fig. I-17-b y Tab. I-61].

Argentina concentra entonces, una vez más, los lugares de destino de los hijos que dejan el valle; principalmente se dirigen a las provincias de Jujuy (77 casos de 350 o 22\%), de Buenos Aires (55 casos o 16,3\%) de Corrientes $(11,1 \%$ o 39 casos), de Salta (38 casos o $10,9 \%$ ) y de Santa Fe (30 casos o $8,6 \%$ ). Notaremos algunos matices: la importancia del país vecino va aumentando con el tiempo, y la ciudad de Tarija es relativamente más atractiva para las localidades de Tolomosa Norte y San Andrés; eso corrobora de nuevo la hipótesis de una reactividad de las comunidades diferenciadas según la situación agrícola.

La emigración de jóvenes desde el valle de Tolomosa es de magnitud importante. Las migraciones estacionales no afectan considerablemente la estructura demográfica de la cuenca, mientras que las migraciones actuales son responsables de desequilibrios importantes. De hecho, como lo muestra la Figura I-18, la descendencia que vive fuera del valle completa la pirámide de edades de las personas encuestadas que muestra un déficit de 15 a 54 años y contribuye así a explicar las rupturas importantes notadas anteriormente. De la misma manera, podemos imaginar que tomar en cuenta a los hijos de esta descendencia que ya no viven en la cuenca completaría la base que es muy estrecha.

Estas migraciones - temporales o no- condicionan la redistribución del poblamiento desde el valle. Son motivadas por la búsqueda de oportunidades laborales en el país vecino, y son más comunes en localidades que padecen carencias de riego anual y de los efectos de los límites del sistema agrario del valle. Así, existen estrategias migratorias, particularmente hacia Argentina, que se traducen en la recepción de remesas.

\footnotetext{
${ }^{78}$ Esta correlación entre el año de la primera salida del hogar y el lugar de residencia al momento de la encuesta se usa con precaución. De hecho, no es posible saber si el destino, al momento de la ida, corresponde al lugar de vida al momento de la recolección de datos.
} 
Fig. I-17: Entol 2002 - La descendencia viviendo fuera del valle de Tolomosa según su lugar de vida actual, el año de la primera emigración y las comunidades encuestadas (continúa)

Lugar de vida de los descendientes que viven fuera de la cuenca de Tolomosa

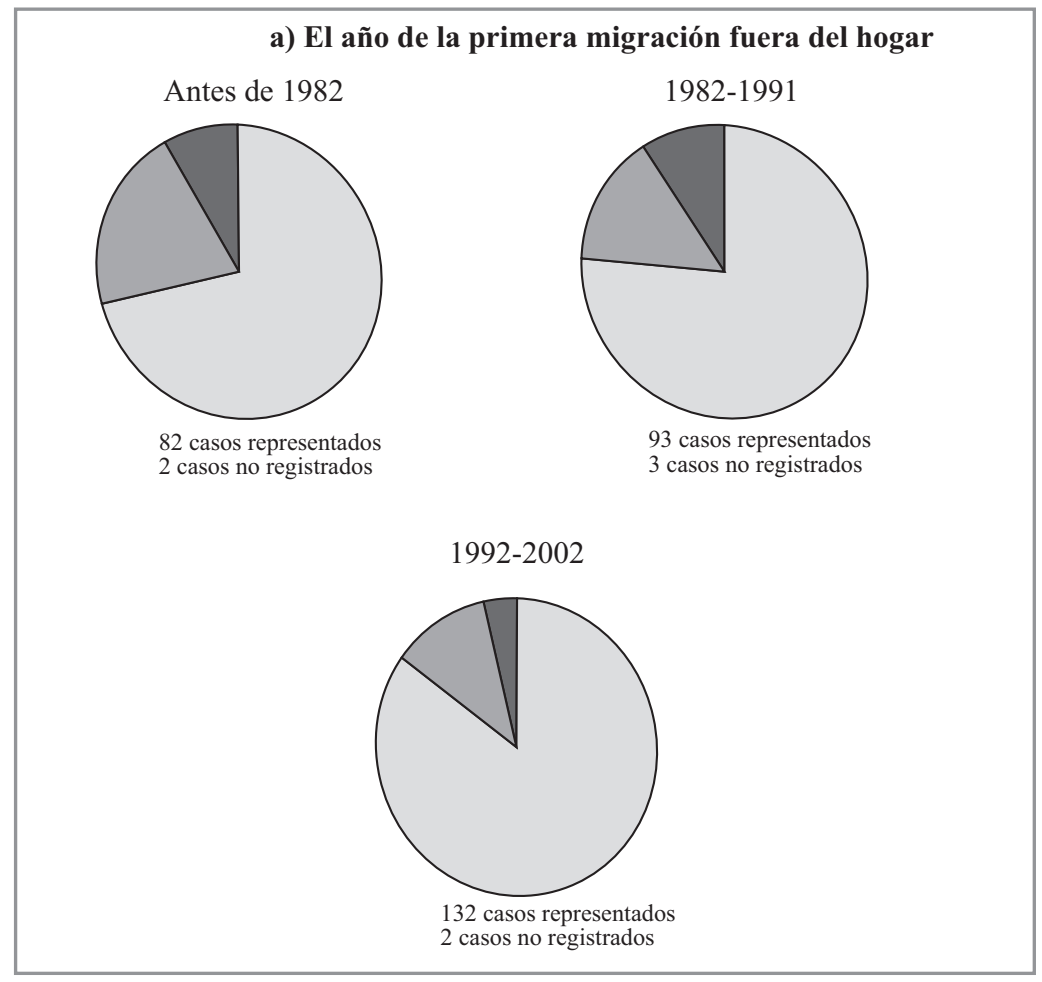
Lugar de vida actual: $\square$ En Argentina $\square$ En la ciudad de Tarija $\square$ Otro lugar en Bolivia

Nota: por 36 casos, el año de la primera migración no está registrado. 
Fig. I-17: Entol 2002 - La descendencia viviendo fuera del valle de Tolomosa según su lugar de vida actual, el año de la primera emigración y las comunidades encuestadas (finaliza)

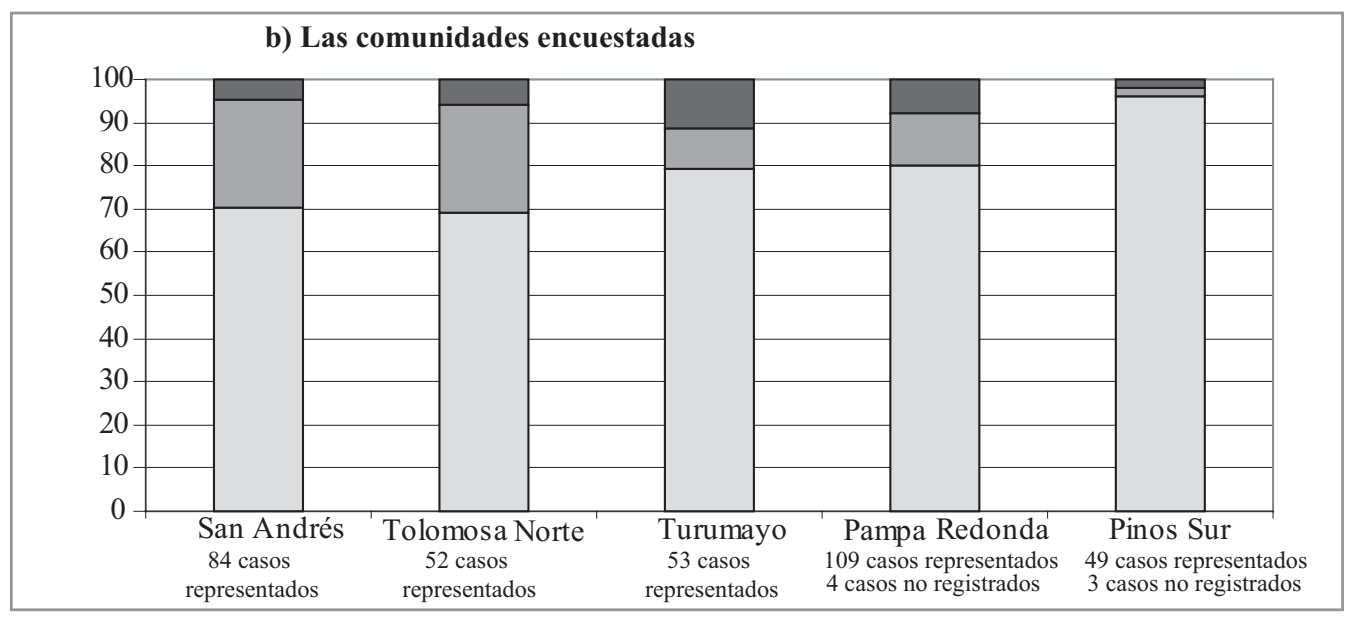

Fuente: Entol 2002. 
Fig. I-18: Entol 2002 - Pirámide de edad del valle de Tolomosa rectificada agregando la descendencia que emigró

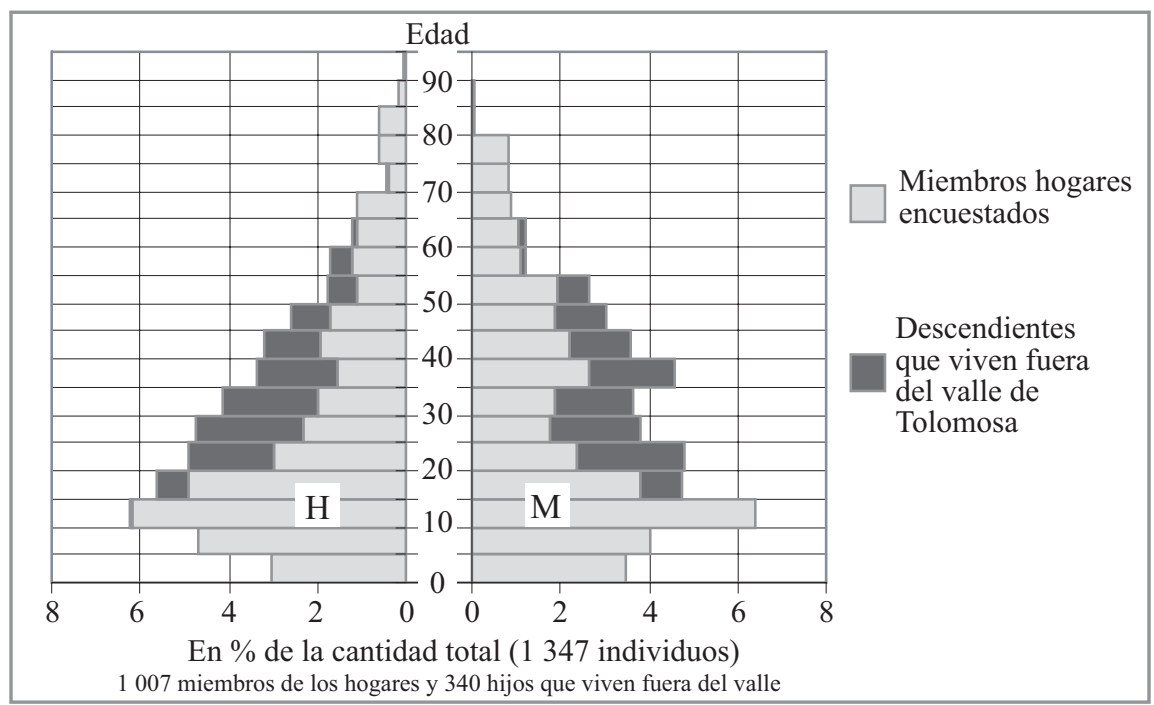

Fuente: Entol 2002.

Nota: Para 10 hijos que viven fuera de la cuenca, la edad no está registrada.

\section{EvOLUCiÓN DE UN MODELO BASADO eN los Desplazamientos hacia Argentina}

Migraciones estacionales, desplazamientos estacionales, dispersión de la descendencia (la cual corresponde a las actuales mitigaciones) y el estudio de la redistribución de la gente de Tolomosa al exterior de su valle de origen, confirman la idea de una población suficientemente móvil. Después de haber descrito los desplazamientos, intentaremos señalar la lógica principal de la inestabilidad del poblamiento de acuerdo con distintas situaciones contempladas en la cuenca (A), enseguida detectaremos las consecuencias y las evoluciones posibles de los patrones migratorios de los habitantes de Tolomosa (B).

\section{A. LA LÓGICA DE DESPLAZAMIENTOS MASIVOS}

La descripción de los movimientos migratorios desde el valle de Tolomosa muestra una cierta homogeneidad en la importancia del fenómeno y su desarrollo, sin embargo, podemos discernir variaciones de acuerdo con las 
localidades investigadas y los lugares de destino. Es a través de la observación de estas diferencias que se analizarán —en conjunto- las principales líneas estratégicas de migración de los habitantes de la cuenca.

\section{Estrategias relacionadas con las necesidades específicas de las comunidades}

Retomaremos los siguientes desplazamientos, todos efectuados desde el valle y hacia localidades situadas fuera de la cuenca: 146 migraciones anteriores, 158 migraciones estacionales realizadas antes de 2001, 111 desplazamientos estacionales realizados en 2001 y 350 migraciones actuales relacionadas con la descendencia; o sea un total de 765 desplazamientos identificados [cf. Tab. I-62 para las subpoblaciones detalladas por comunidad].

La mayoría de los eventos migratorios registrados desde el valle de Tolomosa tiene como objetivo el empleo ${ }^{79}$ [cf. Fig. I-19]. De hecho de 765 desplazamientos, $84,5 \%$ son del orden laboral y el alcance del fenómeno afecta al total de los hogares de la cuenca, ya que $83,1 \%$ de los hogares encuestados reportaron al menos un individuo que se ha desplazado fuera del valle y que ha trabajado (o trabaja) en su lugar de migración ${ }^{80}$ [cf. Tab. I-63 y I-65].

Como lo hemos visto, estas migraciones laborales conciernen a una población prioritariamente masculina y joven cuando se trata de acontecimientos que implican el regreso (migraciones estacionales y anteriores), y a una mayoría de la descendencia sin distinción de género. Además, en general, hemos remarcado una relación entre la importancia de estos desplazamientos con los límites del sector agrario de la cuenca, ya que conciernen, sin duda, a la mayoría de los hogares encuestados; pero la magnitud del fenómeno es más pronunciada para aquellos que disponen de poca tierra cultivable. En estas condiciones, ir a trabajar fuera del valle puede ser una estrategia de la que se observan muchas variantes, en función de las localidades estudiadas:

- En el caso de Pinos Sur son particularmente importantes las migraciones y desplazamientos estacionales. Permiten a una población joven reintegrarse a la comunidad durante la temporada estival, cuando las precipitaciones y el riego semianual vuelven posible la actividad agrícola.

\footnotetext{
${ }^{79}$ Sólo los desplazamientos estacionales en 2001 manifiestan, una parte importante, otras motivaciones: esencialmente la visita de la familia, como lo hemos remarcado anteriormente.

${ }^{80}$ Se incluyen las migraciones anteriores, las migraciones estacionales hasta el año 2000, los desplazamientos estacionales en 2001 y las migraciones actuales.
} 
- Para Turumayo y Pampa Redonda, es la dispersión de la descendencia la que es sorprendente. Fenómeno que se explica por la escasez especialmente grave de tierras cultivables y un sistema de riego prácticamente inexistente. En estas condiciones, la presencia de jóvenes activos en la comunidad, aunque sea temporal, es innecesaria. Hemos remarcado la buena inserción de los originarios de Pampa Redonda en los lugares de emigración. ${ }^{81}$ Sería interesante saber si está relacionada al estatus particular de esta comunidad cuyos habitantes no han estado bajo el yugo de un hacendado. ${ }^{82}$

- Por último, las comunidades de San Andrés y Tolomosa Norte se caracterizan por una menor importancia de migraciones y desplazamientos laborales sin duda relacionados a una situación agraria más favorable, debido a la presencia de riego anual. ${ }^{83}$

\section{Adaptación a los cambios del mercado laboral agrícola argentino}

Como lo señalamos al principio de este capítulo, no hemos mencionado los lugares de destino de acuerdo con su pertenencia al mundo rural o urbano. La importancia de Argentina en nuestro análisis está al origen de esta elección. De hecho, enlistar los lugares de desplazamiento en el país vecino no es fácil, los informantes rara vez son las personas que han efectuado la migración o el desplazamiento estacional y, por lo tanto, tenemos dudas en cuanto a los nombres de las localidades indicadas. Además, las denominaciones de la división administrativa argentina pueden prestarse a confusiones con respecto a Bolivia. El nivel superior argentino es la provincia, que corresponde al departamento boliviano, inversión que se encuentra en el siguiente nivel: los departamentos argentinos equivalen a las provincias bolivianas. Por último y más importante, el sector de actividad más citado — la agricultura — nos permite dudar del carácter urbano de la migración de la investigación, aun si fue en una localidad de más de 5000 habitantes. Tomamos como ejemplo el

\footnotetext{
${ }^{81}$ Este éxito de algunos migrantes originarios de Pampa Redonda es particularmente visible durante el periodo estival, a partir de su regreso al país para las fiestas de fin de año y para el carnaval, al volante de su vehículo 4 × 4 .

${ }^{82}$ Ver introducción de este capítulo para una explicación sobre el sistema de haciendas vigente en el valle de Tolomosa, hasta la reforma agraria de los años 50 en Bolivia. Según Hinojosa (2000), la comunidad de Pampa Redonda nunca estuvo unida a una hacienda, la elevada aridez de sus tierras, al igual que su escaso atractivo, pueden explicar este estatus excepcional.

${ }^{83}$ Cabe señalar que estas dos comunidades están desarrollando estrategias particulares, incluso a través de movilidades profesionales cortas que aseguran una presencia para cubrir los distintos ciclos agrícolas posibles, gracias al riego anual [cf. Martin, 2010 para los detalles de estas movilidades de corta duración].
} 
Fig. I-19: Entol 2002 - Actividades y eventos migratorios censados

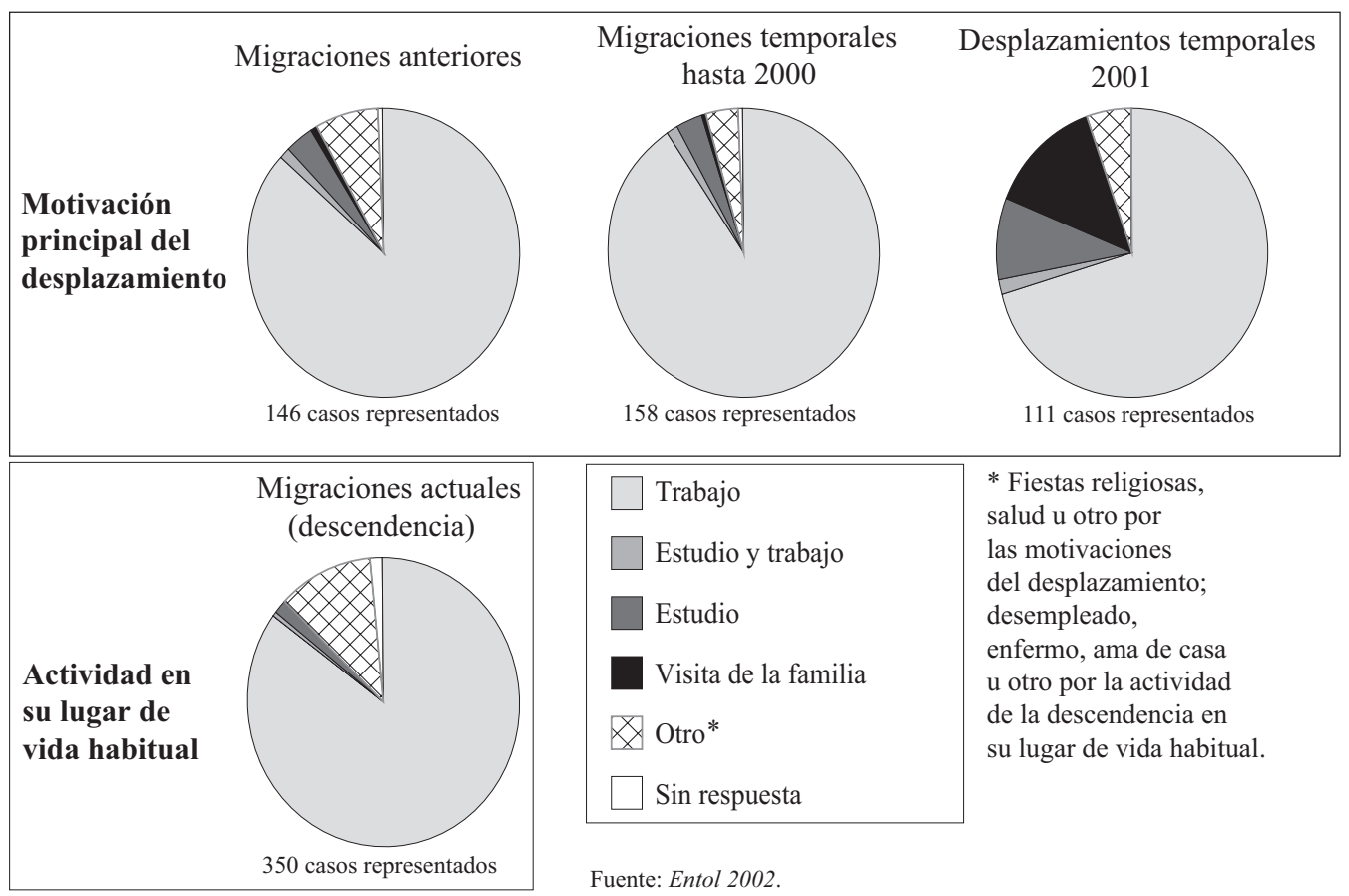


caso de Fraile Pintado (localidad de 11894 habitantes en 2001 según el censo del INDEC) ${ }^{84}$ destino de 94 desplazamientos laborales censados a partir de Entol 2002, de los cuales 88 fueron para trabajar en la agricultura y 43 como jornaleros (que suelen ser alojados en la explotación). ¿Cómo determinar la proporción de estos desplazamientos que han dado lugar a un cambio de residencia rural (Tolomosa) - urbano? Nos abstendremos de realizar este tipo de análisis, que podría ser objeto de un estudio independiente, con el objetivo de determinar en qué medida la gente de Tolomosa se dirige hacia los cinturones verdes de las grandes ciudades del país vecino.

La Figura I-20 muestra, claramente, la importancia de Argentina entre los lugares de destino de los desplazamientos laborales seleccionados en nuestro análisis. De hecho, el vecino país concentra 83,6\% de los 652 eventos migratorios relacionados al ejercicio o la búsqueda de empleo.

En Argentina, estos desplazamientos laborales se realizan principalmente hacia las provincias fronterizas de Jujuy $(25,9 \%$ del total de los eventos migratorios relacionados con el trabajo) y de Salta (17,0\%) [cf. Tab. I-66 para los datos y Mapa I-2 para la localización de las provincias]. Se trata de la cuenca tradicional de migraciones bolivianas hacia el país vecino. Datan de finales del siglo XIX, cuando se desarrolla ${ }^{85}$ el cultivo de la caña de azúcar, cuya explotación requiere una mano de obra abundante (Whiteford, 1981). Sin embargo, este sector ha experimentado una fuerte mecanización en los años setenta y paradójicamente es el cultivo menos mecanizado del tabaco, ${ }^{86}$ a lo largo del siglo XIX, que lo remplaza gradualmente. Más recientemente, los cultivos hortícolas - especialmente en los alrededores de las localidades frecuentemente citadas de Fraile Pintado ${ }^{87}$ y Colonia Santa Rosa — ${ }^{88}$ atraen la mano de obra boliviana (86 y 33 de los 652 desplazamientos laborales, respectivamente). Además de estos factores históricos, la importancia de las provincias fronterizas para los desplazamientos laborales también puede justificarse, simplemente, por la proximidad de la zona, factor que reduce los costos de transporte y los riesgos de los controles policiales. Esto puede explicar que 80,6\% (50 de 62) de los desplazamientos estacionales laborales efectuados en Argentina en 2001, por

\footnotetext{
${ }^{84}$ Instituto Nacional de Estadística de Argentina.

${ }^{85}$ Especialmente en los departamentos azucareros de Oran (Salta) y de San Pedro de Ledesma (Jujuy).

${ }^{86}$ Concierne a los departamentos de Cerrios, Chicoana, la Viña, Rosario de Lerma y General Güemes por la parte de Salta, y El Carmen en cuanto a Jujuy.

${ }^{87}$ Provincia de Jujuy, a $100 \mathrm{~km}$ de la ciudad de Tarija.

${ }^{88}$ Provincia de Salta, a $170 \mathrm{~km}$ de la ciudad de Tarija.
} 
Fig. I-20: Entol 2002 - Los desplazamientos laborales (anteriores, actuales, estacionales) desde el valle de Tolomosa según los lugares de destino (continúa)
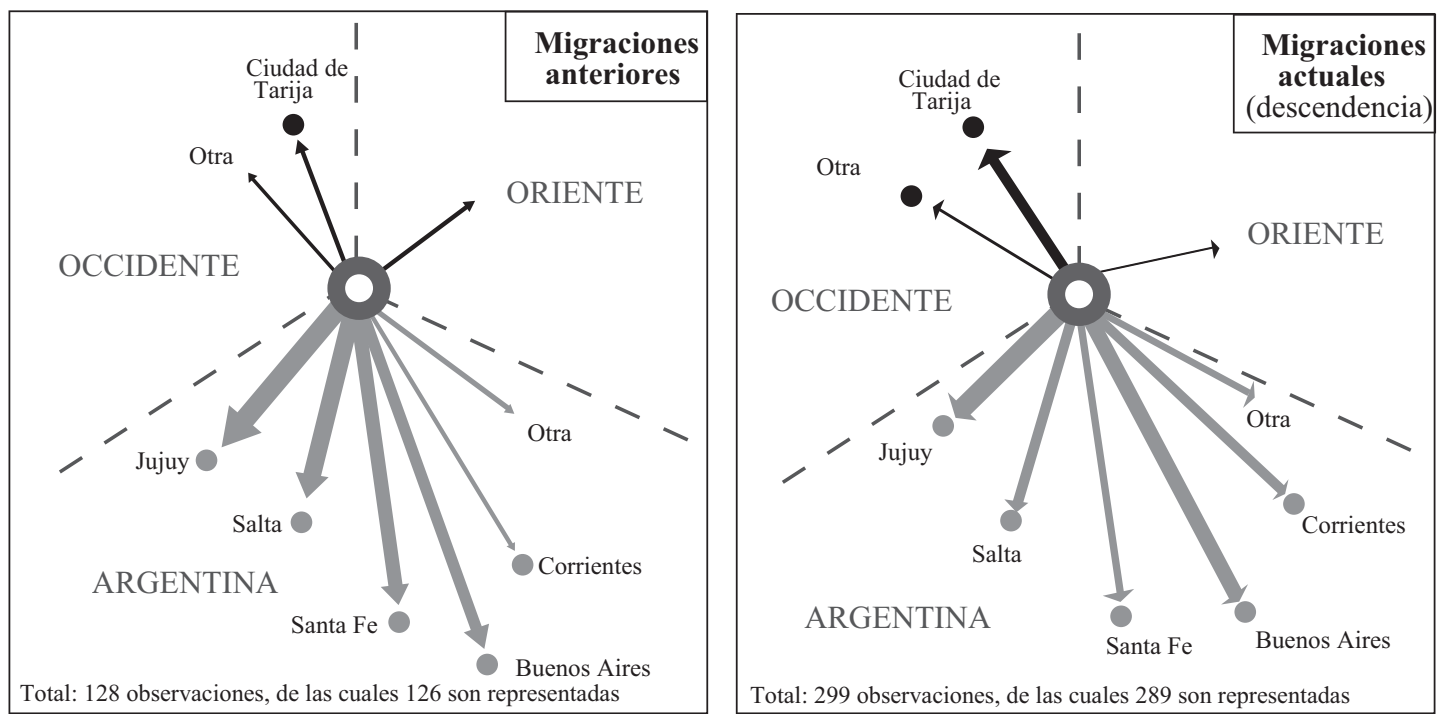
Fig. I-20: Entol 2002 - Los desplazamientos laborales (anteriores, actuales, estacionales) desde el valle de Tolomosa según los lugares de destino (finaliza)
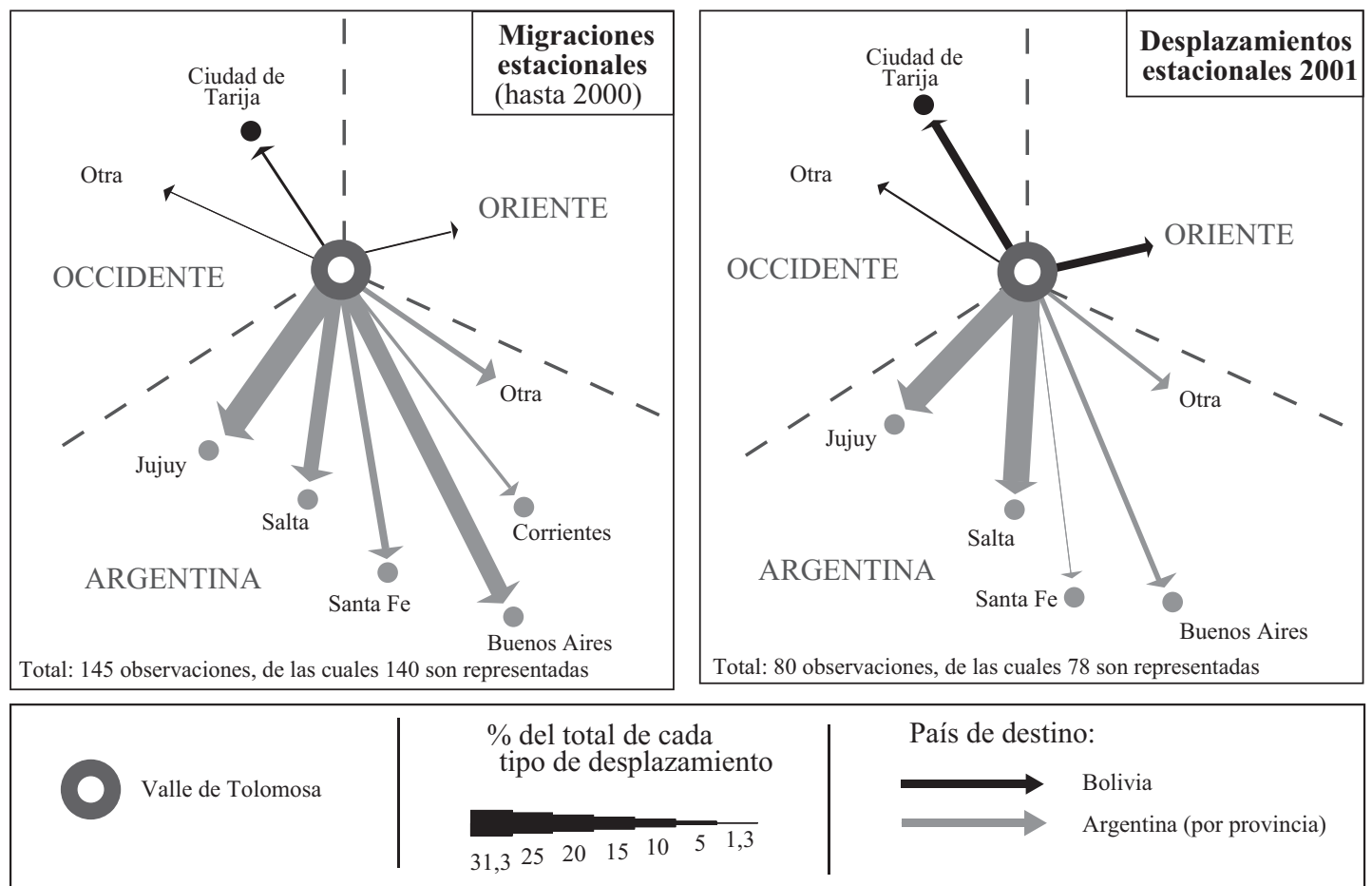

Fuente: Entol 2002. 
una población que dispone sólo parcialmente del derecho a trabajar en el país vecino, ${ }^{89}$ ha tenido como destino las provincias de Jujuy o Salta.

Sin embargo, los desplazamientos laborales hacia Argentina no se limitan a las provincias fronterizas. De los 652 casos censados, 38,9\% tiene como destino otras provincias distintas a Salta y Jujuy: $16,0 \%$ va hacia la provincia de Buenos Aires; 9,0\% hacia las de Santa Fe; 7,2\% rumbo a las de Corrientes; y $6,7 \%$ hacia otras provincias ${ }^{90}$ [cf. Tab. I-62 y Mapa I-2 para la localización de estas provincias]. Esta proporción de desplazamientos laborales en Argentina hacia provincias no fronterizas con Bolivia es más importante si se consideran desplazamientos de larga duración: migraciones actuales (56,5\% o 169 de los 299 descendientes que dejaron el valle y trabajan) y anteriores (40,6\% o 52 de 128 migraciones anteriores laborales). Por último, señalamos que estas migraciones hacia destinos más lejanos fueron, sin duda, parcialmente motivadas por salarios superiores que se ofrecían en el centro de Argentina ${ }^{91}$ o por mejores oportunidades de trabajo, lejos de provincias donde la mano de obra boliviana es altamente representada (Jujuy y Salta) y en cercanía a los mercados urbanos argentinos (incluyendo Buenos Aires).

Cualquiera que sea la provincia de destino, el sector de actividad principal continúa siendo la agricultura (86,7\%, 469 de los 541 desplazamientos relacionados al trabajo en Argentina), lo que implica una baja inserción de los migrantes en una economía urbana sobre todo terciaria y favorece la hipótesis de movimientos rurales-rurales o con destino a las periferias de las grandes ciudades, ${ }^{92}$ donde se ha desarrollado un sistema de producción agrícola intensiva, cerca de los principales mercados.

Hemos remarcado la reducida importancia de la ciudad de Tarija como un centro de atracción de desplazamientos laborales de más de un mes: sólo

\footnotetext{
${ }^{89}$ De los 62 desplazamientos estacionales realizados por razones profesionales en el país vecino en 2001, 27 o 43,5\%, son hechos por personas que no tienen el documento para radicar en Argentina, documento que también permite a los migrantes trabajar legalmente. Esto sugiere que han cruzado la frontera como turistas o evitando los controles.

${ }^{90}$ Once casos se localizan en Argentina sin que la provincia sea precisada.

${ }^{91}$ Según Hinojosa (2000), al inicio del año 1999, los salarios jornaleros eran de ocho a 10 pesos argentinos en las provincias fronterizas, y de 15 a 25 más al sur, en aquellas de Santa Fe o de Corrientes. ${ }^{92}$ Algunas ciudades importantes de Argentina se citan en el estudio de desplazamientos profesionales: Santa Fe (39 casos), Corrientes (35), La Plata (30), Mar de Plata (27), Salta Capital (15), San Salvador de Jujuy (11), Córdoba (10), Tucumán (9) y Buenos Aires (7). Sin embargo, como se indica en la parte metodológica, tenemos dudas sobre la fiabilidad de las localidades declaradas, especialmente de las provincias no fronterizas.
} 
Mapa I-2: Argentina - Principales provincias de destino

de las migraciones y desplazamientos laborales según Entol 2002

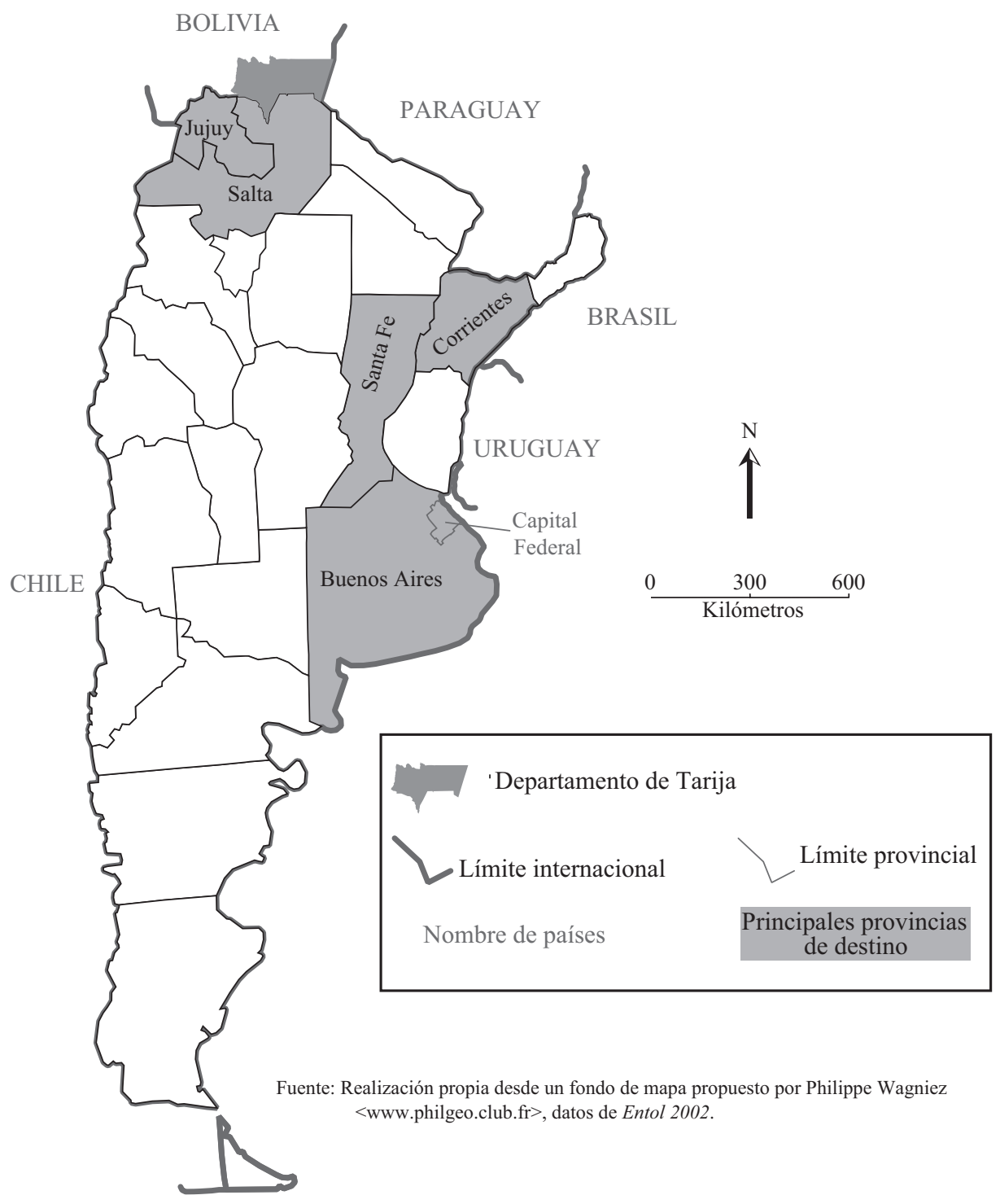


8,4\% se dirigen a la capital departamental [cf. Tab. I-66]; finalmente, movimientos laborales insignificantes tienen como destino el resto del Occidente boliviano $(2,9 \%)$ o el conjunto del Oriente $(3,8 \%)$ que constituye, sin embargo, un centro de atracción histórico (por la caña de azúcar en Bermejo y las ciudades fronterizas) y contemporáneo (sobre todo en Santa Cruz).

\section{B. IMPACTO DEL MODELO MIGRATORIO Y EL FUTURO DEL VALLE}

Hemos sido capaces de discernir con claridad la existencia de importantes estrategias migratorias hacia Argentina en los habitantes del valle de Tolomosa. Ahora conviene cuestionarse sobre el impacto que estos movimientos de población pueden tener en la cuenca, y sobre cuáles son las posibles evoluciones de un modelo de organización del espacio que se basa fundamentalmente en un sistema agrario limitado y en la movilidad de la población.

Regulación de la presión antrópica, principal efecto de la migración

¿Cuál es el impacto de la migración en el valle de Tolomosa? Ya sea estacional o de mayor duración, la migración inyecta dinero en la economía del valle y así contribuye a superar la complicada monetización de la cosecha de la cuenca. ¿Cómo se traduce este apoyo financiero y qué otros efectos se pueden detectar? De acuerdo con nuestro trabajo de campo, los cambios resultantes de estos desplazamientos son menores pero aún así es posible señalar varias evoluciones que, por lo menos en parte, podrían resultar de las estrategias migratorias.

En primer lugar, respecto a la construcción de diversas infraestructuras, hemos detectado una concentración de vivienda - tradicionalmente dispersa- alrededor de los núcleos centrales de las comunidades y a lo largo de las principales vías de comunicación. Este proceso ocasiona la construcción de nuevas viviendas (el adobe ${ }^{93}$ es reemplazado por ladrillos), lo que requiere una inversión financiera comúnmente posible gracias a la contribución de la actividad migratoria. Además, remarcamos la construcción de instalaciones recreativas - a menudo campos y clubes deportivos — también financiados por los emigrantes. Pero los cambios de mayor impacto como la electrificación de las comunidades, su conexión a la red de agua potable, el saneamiento

\footnotetext{
${ }^{93}$ Ladrillos hechos de una mezcla de barro y de hierba que se endurecen al secarse.
} 
de viviendas tradicionales con capas de cal sobre el adobe para evitar que la vinchuca (insecto portador de una enfermedad) se instale allí, reflejan más bien los proyectos financiados por organizaciones no gubernamentales, y son los fondos públicos los que permiten la mejora de las vías de comunicación. Por último, la construcción constante de hospitales y/o de escuelas es resultado del financiamiento internacional. Por lo anterior podemos decir que el impacto de la migración sobre las infraestructuras básicas del valle parece menor.

Por otra parte, ¿cuál es la influencia de las estrategias migratorias sobre el desarrollo agrícola de la cuenca? Idas y regresos entre el valle y Argentina (migración y desplazamientos estacionales, al igual que la migración de larga duración que se acompaña de estancias regulares en la comunidad de origen $)^{94}$ han sido, durante mucho tiempo, acompañadas de transferencia de conocimiento y con ello de mejoras al sistema agrario (especialmente en lo que respecta a fertilizantes y semillas). Destacan igualmente los cambios más recientes, que permiten ahorros acumulados en el país vecino: la compra de tractores ${ }^{95}$ y su renta. Sin embargo, la mecanización de la agricultura se adapta poco a los suelos pedregosos del valle y estos cambios no pueden resolver los principales límites del sistema agrario de la cuenca (minifundio, erosión, falta de riego y de oportunidades comerciales). Lo anterior nos lleva a concluir una influencia mínima de la migración sobre las posibles mejoras a la economía agrícola de Tolomosa.

Por último, es sobre la regulación de la presión antrópica en la cuenca que el efecto de la migración es más importante. En primer lugar, podemos suponer que las migraciones estacionales tienden a superar el subempleo estructural del ciclo agrícola de invierno en Tolomosa, y así contribuir al mantenimiento de la residencia principal de una parte de la población en la comunidad de origen. Entonces, parece que el éxodo masivo de los habitantes del valle (es decir, la migración de larga duración censada y las salidas de familias enteras $)^{96}$ reduce la presión ejercida por la densidad de población

\footnotetext{
${ }^{94}$ Según Entol 2002, de los 350 hijos que abandonaron el valle de Tolomosa, 66,0\% (231 casos) regresó al menos una vez a sus comunidades de origen durante los últimos 12 meses; 16,9\% (59) para un estancia mínima de entre una semana y menos de un mes; 25,1\% (88 casos) de uno a tres meses, y $6 \%$ (21 casos) por más de tres meses.

${ }^{95}$ Según Hinojosa (2000), en 1999 fueron 16 en todo el valle.

${ }^{96}$ Ya que nuestra investigación tuvo lugar después de las fiestas del Carnaval, sólo se obtuvo una muestra demasiado pequeña como para ser tratada. Además, estas familias son casos espe-
} 
sobre el medio y los recursos de la cuenca. Por último, según Hinojosa (Hinojosa, Pérez et al., 2000), la migración también se traduciría en un descenso de la fecundidad (sobre todo relacionada con los cambios en el comportamiento de las migrantes estacionales). ${ }^{97}$ En estas condiciones, al dejar el valle, la gente de Tolomosa hace perdurar un sistema tradicional de organización del espacio que de otra manera sería cuestionable, pero que no ofrece nuevas perspectivas.

\section{Perspectivas: continuación de la migración y desarrollo urbano de Tarija}

¿Cuáles son las perspectivas de un modelo de este tipo, basado en una serie de estrategias migratorias que si bien inyectan dinero en el valle, sólo contribuyen a mantener una población envejecida viviendo de una pequeña agricultura sobrepasada? Hay dos factores que deben tomarse en cuenta al considerar el futuro del valle de Tolomosa: un posible regreso de los inmigrantes o una disminución de la emigración — sobre todo después de la reciente crisis argentina- y los cambios inherentes a la proximidad de la ciudad de Tarija.

Sin un estudio detallado, no resulta sencillo medir el impacto de la devaluación argentina de diciembre de 2001 sobre los movimientos de la población desde la cuenca. Sin embargo, vamos a proponer varias hipótesis. En primer lugar, la migración hacia Argentina no es nueva, ya existía antes de la instauración de la paridad peso/dólar estadounidense que la ha hecho tan lucrativa. Así, como lo señala Samantha Punch (2001), el movimiento migratorio no se redujo durante el periodo 1988-1989, cuando el cambio en

ciales que requieren un tratamiento distinto, con al menos un módulo específico. Esto podría ser una investigación complementaria a realizarse en el valle central de Tolomosa durante los períodos de retorno (finales de diciembre, principios de enero), o sobre los lugares de emigración en Argentina. Sería interesante ver cómo los lugares de vida y los comportamientos de estos emigrantes difieren de las de los descendientes, de los cuales una parte de la familia (los padres) se mantuvo en la comunidad. Cabe señalar, sin embargo, la importancia del fenómeno visible gracias a los datos del último censo. Según el INE, en septiembre de 2001, sólo 75,8\% de las viviendas del valle (1 817 de 2 396) fueron censadas. Esta proporción es menor para Pampa Redonda (66,8\%, 129 de 193) Tolomosa Norte (71,2\%, 52 de 73) y Pinos Sur $(71,7 \%$, 99 de 138) y más importante para Turumayo (84,3\%, 113 de 134) y San Andrés (83,5\%, 274 de 328).

${ }^{97}$ Este cambio se debe principalmente a la asimilación de los hábitos de contracepción entre las mujeres dispuestas a trabajar y, en general, a la difusión de la mentalidad relativamente moderna del mundo argentino. 
esta época colocaba los salarios argentinos a un nivel inferior en comparación con los bolivianos. Según la coyuntura más actual, y asumiendo la permanencia de salarios diarios de 15 pesos bolivianos en San Andrés, en 1999; y de 8 a 10 pesos argentinos (60 pesos bolivianos) del otro lado de la frontera (Hinojosa, Pérez et al., 2000), siempre es más lucrativo trabajar en Jujuy que en Tolomosa, a pesar de una devaluación que dividió por 2,5 el valor de la moneda argentina. Finalmente, un último supuesto sobre los pocos regresos para los emigrantes que hayan invertido en Argentina (patrones, trabajadores independientes), es que el contexto actual del país de acogida no es el adecuado para la reventa.

Y entonces, podemos volver a cuestionarnos por qué reintegrar el valle de Tolomosa o detener la migración estacional. Como hemos visto, el sector agrario de la cuenca encuentra varios tipos de límites a causa de la escasez de tierras agrícolas y de oportunidades comerciales, este último punto debido principalmente a la competencia de los productos argentinos, que son todavía más competitivos después de la devaluación. ${ }^{98}$ En este contexto, parece lógico seguir cruzando la frontera para probar suerte en un mercado laboral relativamente más favorable, o establecerse en Argentina incluso para invertir. Según Hinojosa (Hinojosa, Pérez et al., 2000), es lo que hacen los emigrantes cuando sus esfuerzos laborales resultan exitosos. Entonces, invierten en la adquisición de tierras, de invernaderos, en el establecimiento de sistemas de riego desarrollados (como el gota-a-gota), y en la diversificación de las semillas. ${ }^{99}$

Por último, si la migración en Argentina tiene como motivación principal el ejercicio de una actividad laboral, especialmente para hacer frente a las dificultades locales; Punch (2001) señala que también éstas se deben a la búsqueda de servicios públicos de mejor calidad (particularmente en los renglones educación y salud), al deseo de satisfacer la curiosidad, sobre todo al ceder a la llamada de una cierta modernidad y de compartir una gran ex-

\footnotetext{
${ }^{98}$ Es interesante señalar aquí que la población de Tolomosa migra hacia Argentina para participar en la producción de alimentos que después encontramos en los mercados de Tarija, lo que refuerza las dificultades del sistema agrario local que a su vez magnifica la cantidad de movimientos migratorios hacia Argentina.

${ }^{99}$ Se podría suponer que esta confianza en el mercado argentino podría verse afectada por la aguda crisis económica que azotó al país en 2001. Sin embargo, tras haber realizado varias entrevistas en el valle de Tolomosa (en noviembre de 2003 y noviembre de 2004), parecería que no es el caso. Los emigrantes, de vuelta en el valle para las fiestas estivales, nos han afirmado que seguirán invirtiendo en la producción agrícola en Argentina, tratando de controlar toda la cadena comercial de los cultivos hortícolas.
} 
periencia entre amigos. Estas motivaciones serán ligeramente afectadas por la crisis actual.

Sin embargo, no debe limitarse a la situación del país vecino para pronunciarse sobre la evolución del comportamiento migratorio de los habitantes de la cuenca. De hecho, la diversificación de funciones en el valle permitiría una mejor inserción (o reinserción) de la gente de Tolomosa en otras áreas diferentes a la agricultura, lo que reduciría la frecuencia de los desplazamientos estacionales y que incluso podría provocar retornos.

Ahora bien, la cuenca, cerca de Tarija, está fuertemente influenciada por la evolución de la ciudad. La capital departamental, cuyo crecimiento demográfico es sostenido, se ha extendido hacia el Norte, pero ve su expansión bloqueada por una zona erosionada con suelos inestables. Lo mismo para su desarrollo a lo largo del eje este-oeste que conecta San Lorenzo con Concepción pasando por la ciudad. Por lo tanto, las perspectivas de crecimiento urbano hacia el valle de Tolomosa, en el Sur, son muy probables. Ya se detectan los primeros signos con la implantación en la parte baja de la cuenca, en torno a la reserva de San Jacinto, residencias secundarias lujosas cuyos propietarios viven en Tarija. La fácil accesibilidad de la zona (a $10 \mathrm{~km}$ por carreteras pavimentadas del centro de la ciudad) anuncia su muy probable transformación en residencias principales. Aunque se encuentran alrededor del lago artificial, las comunidades de Tolomosa Grande, Tolomosa Oeste y Tolomosa Centro, son las únicas localidades que experimentan un cambio demográfico positivo y significativo entre 1992 y $2001^{100}$ como resultado, probablemente, de la instalación in situ de los habitantes de la capital. Sin embargo, el desarrollo residencial de este sector del valle es fuertemente debilitado por la erosión, el relieve accidentado y la influencia de la retención de agua en las tierras planas. El segundo polo de desarrollo en el valle se sitúa, pues, a lo largo del eje, recientemente pavimentado, que une la capital departamental con San Andrés, una comunidad con un potencial de suelo edificable no disponible en la ciudad; y que además cuenta con un colegio, un pequeño hospital y una gran plaza central que, una vez equipada, no tendría nada que envidiar a las de otros pequeños pueblos bolivianos. San Andrés y la comunidad vecina de Tolomosa Norte forman una discreta aglomeración urbana (a 20 minutos del centro de la ciudad de Tarija), y las localidades de

${ }^{100}$ Según el INE la tasa media de crecimiento anual respectivamente 4,9\%, 2,3\% y 3,5\% [cf. Tab. I-67]. 
Turumayo y Guerra Huayco — cercanas a la capital departamental— los suburbios residenciales de la ciudad vecina. ${ }^{101}$

¿Cuál será el futuro de la gente de Tolomosa en este contexto? Algunos tratarán de beneficiarse de la diversificación de las actividades, invirtiendo en el comercio minorista ${ }^{102} \mathrm{o}$ en el transporte, lo que generará un retorno de migrantes y una sedentarización de las migraciones estacionales. Para otros, podría significar el aumento de la emigración a partir de la venta de parcelas agrícolas (para construir) si no logran una reconversión laboral. En todos los casos, la necesidad de modernidad intervendrá menos en los motivos de emigración. A destacar, sin embargo, que estas especulaciones sobre la evolución del valle no conciernen en lo inmediato a las comunidades en las que la dimensión de la emigración es la más alta (Pinos Sur y Pampa Redonda en el caso de nuestra muestra), para las cuales se espera que continúe el modelo actual.

$$
* * *
$$

Entonces, a través del estudio de la cuenca de Tolomosa somos capaces de entender mejor las dificultades que encuentran las localidades rurales en los valles centrales de Tarija, y en general en el campo del Occidente tarijeño. Confrontado con varias limitaciones de su sistema agrario (erosión, escasez de recursos hidráulicos, competencia de la producción argentina), que representa la actividad principal de la cuenca, el valle ve su poblamiento actual dependiente, en gran medida, de las estrategias migratorias. En efecto, mientras que la inmigración es insignificante, la diversidad y la importan-

\footnotetext{
${ }^{101}$ Este fenómeno sería alentado fervientemente por la buena reputación de San Andrés entre los tarijeños quienes conocen bien la comunidad gracias a la fiesta de la papa que, en enero, atrae turismo urbano considerable. Es normal durante el resto del año escuchar a los ciudadanos alabar la zona por su calma y sus espacios verdes, fruto del riego anual, en contraste con la sequía de las tierras alrededor de la ciudad de Tarija.

102 Algunas casas en el centro de la comunidad, de las cuales la construcción estaba detenida al momento de nuestra encuesta (febrero de 2002), ya están terminadas. Los comerciantes de la localidad nos informaron que se trataba de emigrantes en Argentina, que regresaron después de la devaluación del peso, y que prefieren dedicar su tiempo a completar su casa en San Andrés. Una de estas familias pensaba también beneficiarse de la localización céntrica de su vivienda para abrir un comercio al por menor. Otra persona había comprado una camioneta con la intención de alquilarla a los interesados. Uno más había adquirido un trufis (pequeño autobús de transporte público) para hacer viajes a la ciudad de Tarija. Este dinamismo de los migrantes que lograron ahorrar en sus experiencias migratorias, podría tener impacto en el desarrollo de la comunidad en caso de la diversificación de sus funcionalidades.
} 
cia de las formas de emigración son importantes. Estas son principalmente las migraciones estacionales - sobre todo en las localidades que sufren de una subocupación de la mano de obra agrícola durante el invierno- y de emigraciones más largas, algunas de las cuales son probablemente definitivas (modelo que encontramos en las comunidades localizadas en las zonas particularmente áridas, donde el desarrollo de la agricultura es limitado). Todas estas migraciones están claramente influenciadas por la demanda de mano de obra agrícola en el mercado argentino, específicamente en las provincias de la frontera cuando se trata de desplazamientos cortos, o en un espacio más grande hasta Buenos Aires para las migraciones largas. A través de las transferencias de dinero que implican, podemos considerar estas estrategias migratorias como una de las actividades principales de la cuenca para contribuir al mantenimiento de una parte de la población rural en su lugar de origen, sin que esto implique el favorecimiento del desarrollo.

Los empleos ocupados durante estos desplazamientos -independientemente de su duración - son principalmente agrícolas, lo que demuestra que no se trata de éxodo rural, sino de emigración en busca de mejores salarios. Al encontrarlos en Argentina, las estrategias de los habitantes de Tolomosa se inscriben en la lógica de la jerarquía de espacios económicos, entre regiones próximas que no se benefician de las mismas condiciones naturales, ni de las mismas condiciones de desarrollo (Domenach y Picouet, 1995). Esta relación es de hecho tan fuerte que vuelve poco significativos los desplazamientos hacia la ciudad de Tarija (en las afueras del valle y que fue un centro atractivo mayor de la región en los últimos años) ${ }^{103}$ o hacia otros países; a diferencia de Geneviève Cortes (2004) que hace hincapié en la existencia de corrientes recientes entre las comunidades rurales de Cochabamba y España, Israel o Estados Unidos. Además, la inserción laboral en Argentina parece buena, lo que seguramente permite a la corriente aguantar los periodos agitados que vive el país vecino, como fue el caso en 2002-2003, sin que tenga un efecto importante en el patrón migratorio de la cuenca. De lo contrario, conviene estar atentos a los impactos potenciales del crecimiento de la capital departamental, cuya expansión podría paulatinamente poner en duda las funcionalidades únicamente rurales de Tolomosa.

A través de este estudio, se pudieron observar la actividad y los movimientos de la población de un modelo anterior de organización del espacio,

${ }^{103}$ Ver d'Andréa \& Martin, 2007 sobre el crecimiento de la ciudad de Tarija. 
aquel de las zonas rurales tradicionales del Occidente. ¿Qué pasa con los sistemas emergentes del Oriente? El ejemplo de Caigua nos permitirá ilustrar otro aspecto, el de las dinámicas recientes de colonización agrícola, otra dinámica rural de Tarija. 


\section{Capítulo 2 \\ Oriente: colonización agrícola y emigración hacia las ciudades bolivianas}

En el Sur boliviano notamos una concentración excepcional de población rural en el Piedemonte ${ }^{1}$ del departamento de Tarija. Así, a lo largo de una franja de tierra que se extiende sobre 15 kilómetros de ancho por 115 de largo, situada entre la cadena de Aguaragüe y la llanura del Chaco, la densidad rural es la más alta del departamento con $12,5 \mathrm{hab} . / \mathrm{km}^{2}$ e incluye 18 de las 31 comunidades de 500 o más habitantes del Oriente tarijeño (Martin, 2010). Cabe señalar que esta situación demográfica es reciente, a principios del siglo xx el Piedemonte estaba esencialmente poblado por nómadas, principalmente guaraníes dedicados a la cría extensiva de ganado. A través del estudio de la comunidad de Caigua, ubicada en la parte septentrional del Piedemonte, nos proponemos aportar elementos para explicar esta dinámica del poblamiento oriental rural del departamento de Tarija. Como en el caso de Tolomosa, prestaremos especial atención a las actividades de la comunidad. ¿Qué pasa con la colonización agrícola del Oriente del departamento de Tarija (Martin, 2010)? ¿Cómo se formó el sistema agrario? ¿Qué tipos de cultivos se practican? ¿La cría, actividad tradicional en la región, se mantuvo? A través de estas preguntas, evaluaremos si — como en Tolomosa - el sistema productivo de Caigua tiene que enfrentar límites; de ser así, si los mismos factores están involucrados y si las mismas estrategias son implementadas. Para la diversificación de las fuentes de ingresos, la comprensión de la migración es, una vez más, fundamental. La proximidad de Argentina (a una hora en automóvil desde Caigua) podría promover la migración agrícola, mientras que la de Villamontes (a 10 minutos) puede resultar en una emigración hacia las ciudades, con cambio intersectorial de actividad.

\footnotetext{
${ }^{1}$ Se emplea aquí la mayúscula, ya que se refiere a la región del Piemonte de Tarija, como se presenta en Martin, 2010.
} 
Inicialmente, estudiaremos el crecimiento demográfico reciente de Caigua, analizando la contribución migratoria que ha ayudado al poblamiento de la localidad, y señalando los principales factores que han controlado estos desplazamientos de la población (I). Enseguida, nos cuestionaremos sobre la situación actual de la colonización agrícola, principal motor del crecimiento de Caigua, tratando de medir la viabilidad del sistema (II). Indagaremos en qué medida asistimos a una diversificación de las actividades en la comunidad y relacionaremos las eventuales limitaciones o cambios detectados en el estudio de la emigración desde Caigua (III). De esta forma nos preguntaremos sobre la hipotética inestabilidad del poblamiento de la comunidad: ¿por qué y en qué medida la función receptora de una inmigración reciente se complementa por una función redistributiva?

En esta sección, nos referiremos periódicamente a los datos de la encuesta Envil 2002, más precisamente a aquellos relativos a la localidad de Caigua ${ }^{2}$ (ver anexo para metodología completa). Nuestra encuesta, realizada el viernes 5 de julio de 2002, identificó 344 personas repartidas en 72 hogares (esto es 4,77 personas por hogar). Como se puede observar en la Tabla II-1, el número de subpoblaciones utilizado será en ocasiones bajo, lo que limita el cruce de datos y obliga a actuar con cierta prudencia en nuestro análisis.

Igualmente explotaremos los datos del INE, incluyendo aquellos del censo de septiembre de 2001 (realizado en un momento comparable al de la encuesta Envil 2002, en periodo de cultivos de invierno). La población de Caigua era entonces de 708 personas distribuidas en 155 hogares (un promedio cercano al de la investigación de 4,56 personas por hogar). ${ }^{3}$

\section{INMIGRACIÓN Y AGRICULTURA, MOTORES DEL DESARROLLO}

Sin que sea posible establecer una fecha precisa de la creación de la comunidad de Caigua, parecería que los primeros habitantes se establecieron ahí después de la guerra del Chaco (1936). ${ }^{4}$ Además, al no contar con infor-

\footnotetext{
${ }^{2}$ El proyecto Envil 2002 incluyó varias localidades: Villamontes, Caraparí y Caigua.

${ }^{3}$ Recordemos que se trata de un censo, de hecho sólo las personas presentes ese día son censados ya sean o no originarias de la localidad. Sólo una persona declaró que vivía en otro lugar, por lo cual los datos del INE conciernen casi solamente a habitantes de Caigua.

${ }^{4}$ De hecho se instaló el padre del corregidor de la comunidad al momento de la encuesta (representante del subprefecto), Pastor Garay. Después de participar en la guerra del Chaco, notó el potencial agrícola sin explotar del Piedemonte Norte y en especial de Caigua. De acuerdo con el corregidor, en la comunidad sólo había unas pocas familias.
} 
Mapa II -1: Departamento de Tarija/Piedemonte Norte - Localidades, red hidrográfica y vías de comunicación

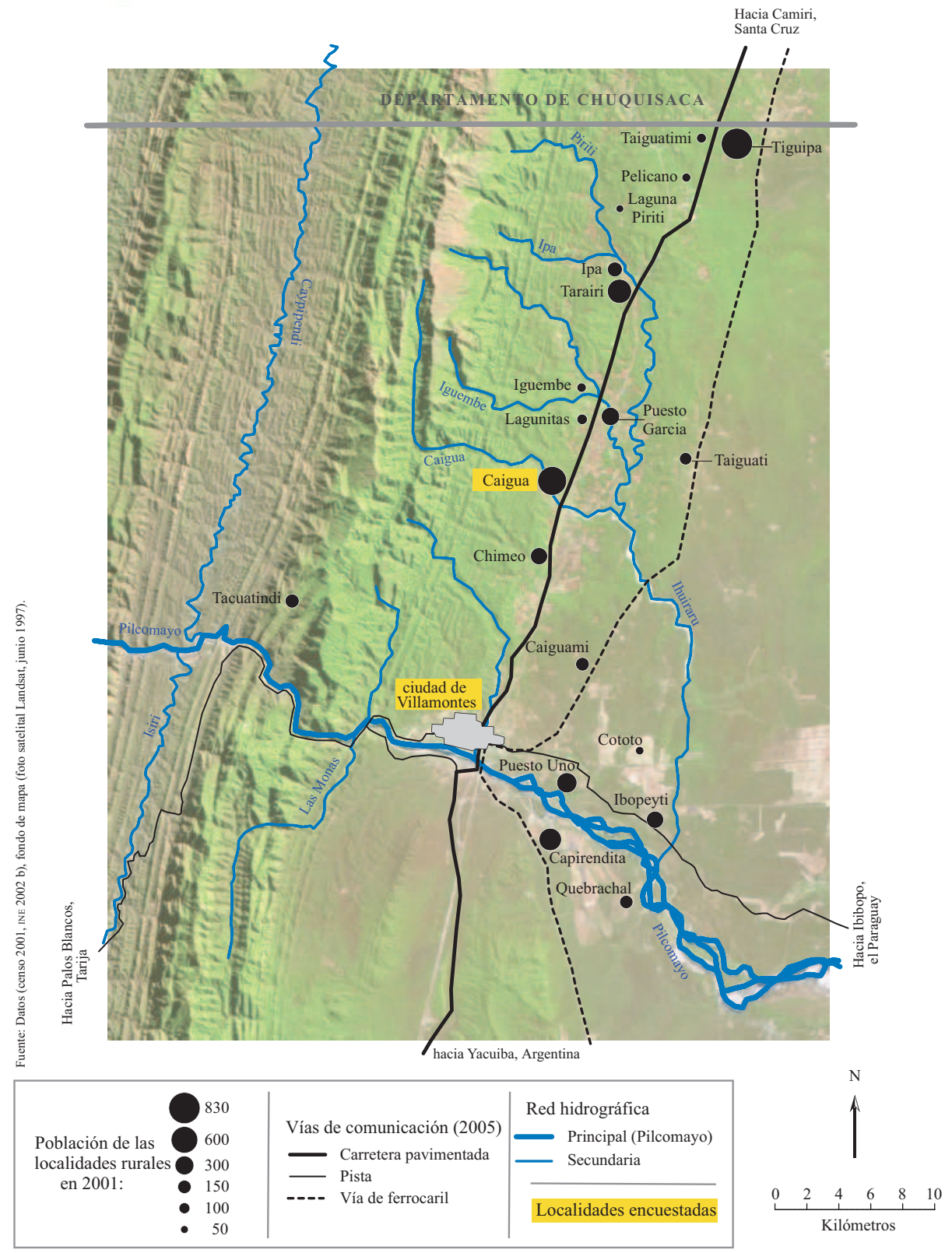


mación sobre la población de la localidad en el censo INE 1950, es a partir de 1976 que se puede cuantificar el crecimiento de Caigua. ${ }^{5}$ Para ese año, la comunidad contaba con 307 habitantes, número que asciende a 583 en 1992 y luego a 708 en 2001. Por lo tanto, remarcamos un alto incremento demográfico entre 1976 y 1992 (crecimiento medio anual del 4,1\%), ${ }^{6}$ mismo que disminuye entre 1992 y 2001 (tasa media de crecimiento anual de 2,2\%). Durante el periodo 1976-2001, el crecimiento de Caigua es sostenido (3,4\% de crecimiento medio anual), lo que representa el doble del crecimiento anual de la población rural de la provincia de Gran Chaco (tasa media de crecimiento anual del $1,7 \%$ respecto al mismo periodo) y 3,4 veces el de la población rural del departamento de Tarija (1\%) [cf. Tab. II-2]. Para interpretar este aumento utilizaremos los datos de Envil 2002 así como conocimientos de campo e información bibliográfica disponible sobre la región. Inicialmente, haremos todo lo posible para calificar la importancia de la inmigración hacia Caigua mediante la determinación de las grandes fases de poblamiento de la comunidad y al tratar de medir su área de atracción (A). Para explicar estos movimientos de población, enseguida detallaremos los motivos de esta inmigración e intentaremos relacionarlos con la historia reciente de Caigua y de su espacio regional (B).

\section{A. ATRACCIÓN CRECIENTE}

Caigua es, sin lugar a dudas, una aldea poblada por la migración reciente: $81,9 \%$ de los jefes de hogar nacieron fuera de la localidad, 47,8\% si nos limitamos a otros miembros del hogar [cf. Tab. II-3]. A continuación abordaremos de manera descriptiva la distribución de estos recientemente llegados a lo largo del tiempo y especificaremos los principales lugares de origen.

\footnotetext{
${ }^{5}$ Estos datos producidos por el INE, han requerido el uso de diversas fuentes de información. Para los de 1976 es el diagnóstico del municipio de Villamontes, documento preparado bajo la dirección de Zonisig (Zonisig-APDs, 2000), el que nos informó sobre el número de habitantes. En 1992, el INE publicó una lista muy detallada de municipios, uno de ellos correspondiente a Caigua. Finalmente, en 2001, utilizamos los datos del departamento Tarija por localidad (INE, 2002 b).

${ }^{6}$ Nótese, sin embargo, la debilidad de la variación neta de este crecimiento (276 personas).
} 


\section{Tres ciclos de inmigración ${ }^{7}$}

De la observación de la Figura II-1 resultan tres grandes periodos de instalación. Hasta 1980, las llegadas son pocas, aún más, se observa un ligero incremento a partir de 1970. Durante los años ochenta, experimentan un fuerte incremento que culmina entre 1981 y 1986, pero el final de la década se caracterizó por su franco declive. La recuperación es lenta a principio de los años noventa: crecimiento de instalados al inicio del periodo que se traduce en un pico excepcional en 1997-1998, seguido por un fuerte descenso desde el año $2000 .{ }^{8}$

Fig. II-1: Envil 2002/Caigua - Personas instaladas a la edad de 15 años o más según el año de llegada

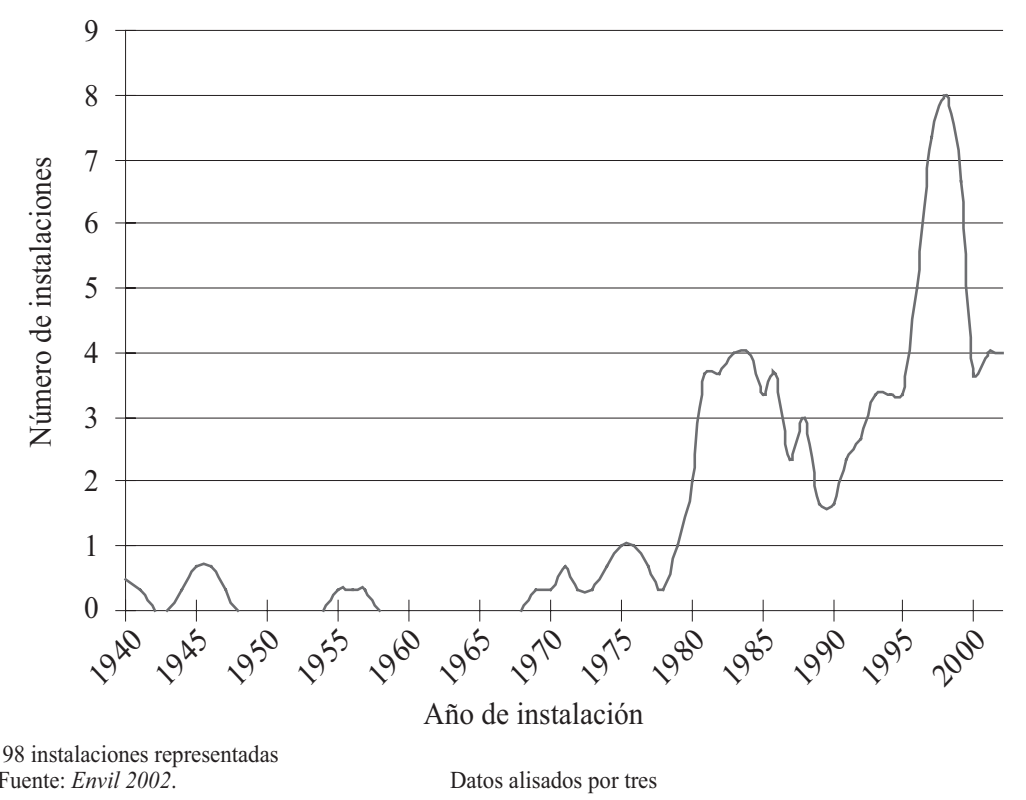

\footnotetext{
${ }^{7}$ A diferencia de Entol 2002, el cuestionario Envil 2002 contaba con un valioso módulo para el análisis de la inmigración de personas de 15 años y más de edad al momento de la encuesta (141 casos). Para evitar las distorsiones causadas por la falta de recaudación de información sobre las personas menores de 15 años en el momento de la recolección de datos, no tomaremos en cuenta más que los que llegaron a la edad de 15 años y más a la comunidad (98 casos).

${ }^{8}$ Hay que tener cuidado con la tendencia para el año 2002. Dado que nuestro estudio se llevó a cabo en julio, podemos suponer que tenemos sólo una parte de las instalaciones en Caigua de ese año.
} 
El ciclo de llegadas de acuerdo con Envil 2002 sigue, de manera general, aquel del crecimiento de la población de acuerdo con el INE. Cabe señalar que no hay muchas más instalaciones en el periodo 1976-1992 que en el lapso 1992-2001; ' sin embargo, se aprecian diferencias a partir del análisis del crecimiento demográfico de la comunidad según el INE. Este matiz puede sugerir que algunos individuos instalados en Caigua entre 1976 y 1992 han, desde entonces, abandonado la comunidad, fenómeno que puede estudiarse como parte de la investigación que es retrospectiva (que incluye sólo a los individuos que viven en la localidad al momento de la recolección de datos).

Esta breve presentación diacrónica de los flujos migratorios nos obliga a discernir tres fases de la instalación: antes de 1980 (10 instalaciones), durante los años ochenta (32) y entre 1990 y 2002 (56). El bajo número del primer periodo nos anima a mantener sólo dos grupos para este análisis: los individuos que se establecieron hasta 1989 (42 casos) y los que llegaron a partir de 1990 (56 casos). Pasaremos ahora a los lugares de origen de los inmigrantes, y verificaremos la existencia de una posible relación según los periodos.

\section{Ampliación del área de atracción}

Los lugares de origen permitirán definir el área de atracción de Caigua. De hecho, estos corresponden al último sitio de residencia antes de la llegada a la comunidad, por lo tanto es útil estudiar la correlación entre el espacio (el último lugar de residencia antes de inmigrar) y la fecha de instalación en la localidad. Para las 98 personas llegadas a la edad de 15 años y más a la comunidad, los lugares de origen se componen de la siguiente manera:

- Lugares de nacimiento, para aquellos que no declaran una migración antes de la instalación en la comunidad (62 casos) o que declaran una salida con duración entre el evento migratorio y la llegada a Caigua igual o superior a cinco años, o sea desconocido ${ }^{10}$ (8 casos);

- Lugares de la última migración antes de la instalación para aquellos que declaran una que se llevó a cabo poco tiempo antes de llegar a Caigua ${ }^{11}(28$ casos).

\footnotetext{
${ }^{9} \mathrm{Al}$ haber omitido el mes de instalación en nuestra pregunta, resulta difícil comparar con precisión las fechas de las llegadas de acuerdo con Envil 2002 con aquellas de los censos, que normalmente se llevan a cabo a mediados del año.

${ }^{10}$ Como recordatorio, fuera de la comunidad de Caigua y de los lugares de migración declarados, suponemos que la persona regresó a vivir a su lugar de nacimiento.

${ }^{11}$ Menos de cinco años en este caso. Notamos que, la gran mayoría, es de menos de un año (17 casos) o menos de dos años (21 casos).
} 
Mapa II-2: Bolivia - No nativos de Caigua instalados a la edad de 15 años y más según sus lugares de origen

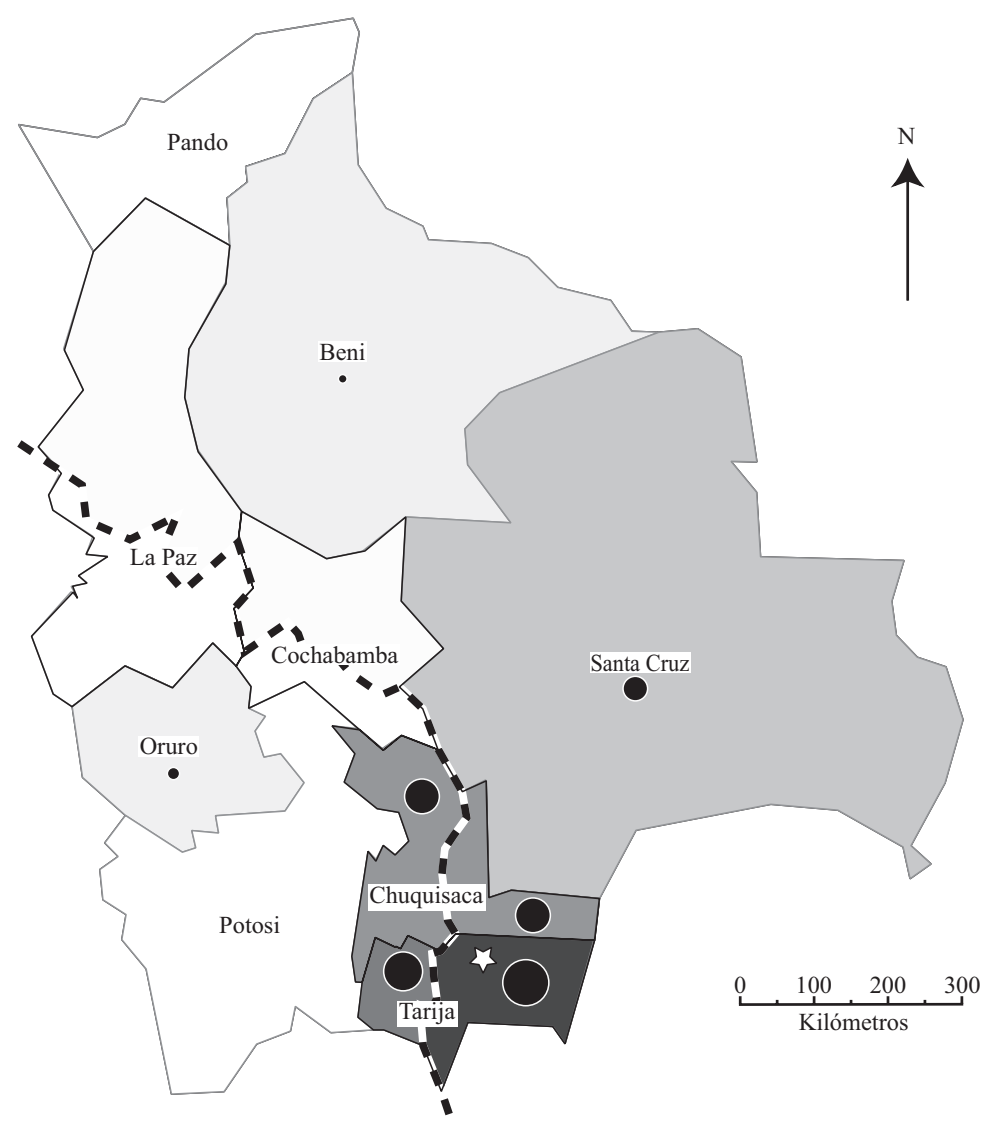

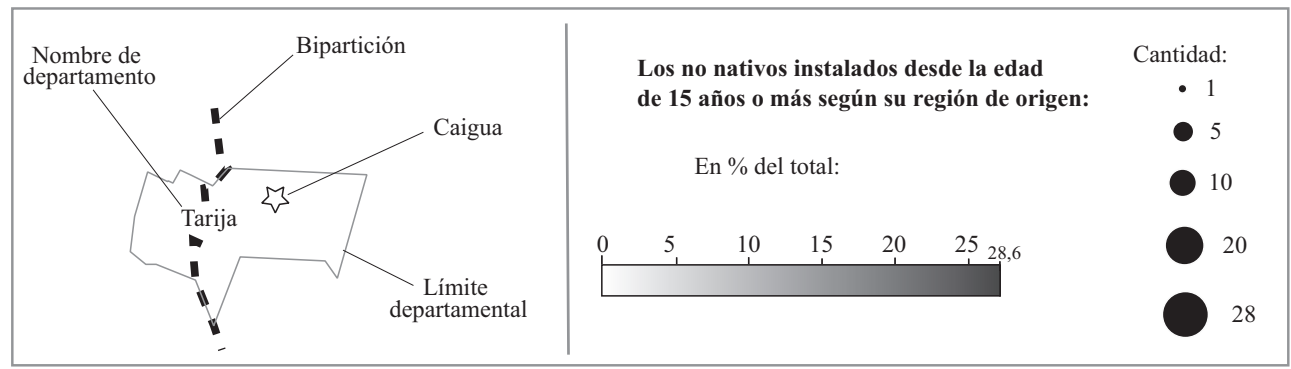

Fuente: Bipartición de Bolivia: d'Andréa 2004; bipartición del Tarija mismo; datos de Envil 2002. 
Mapa II-3: Sureste boliviano - No nativos de Caigua instalados

a la edad de 15 años y más según sus lugares de origen

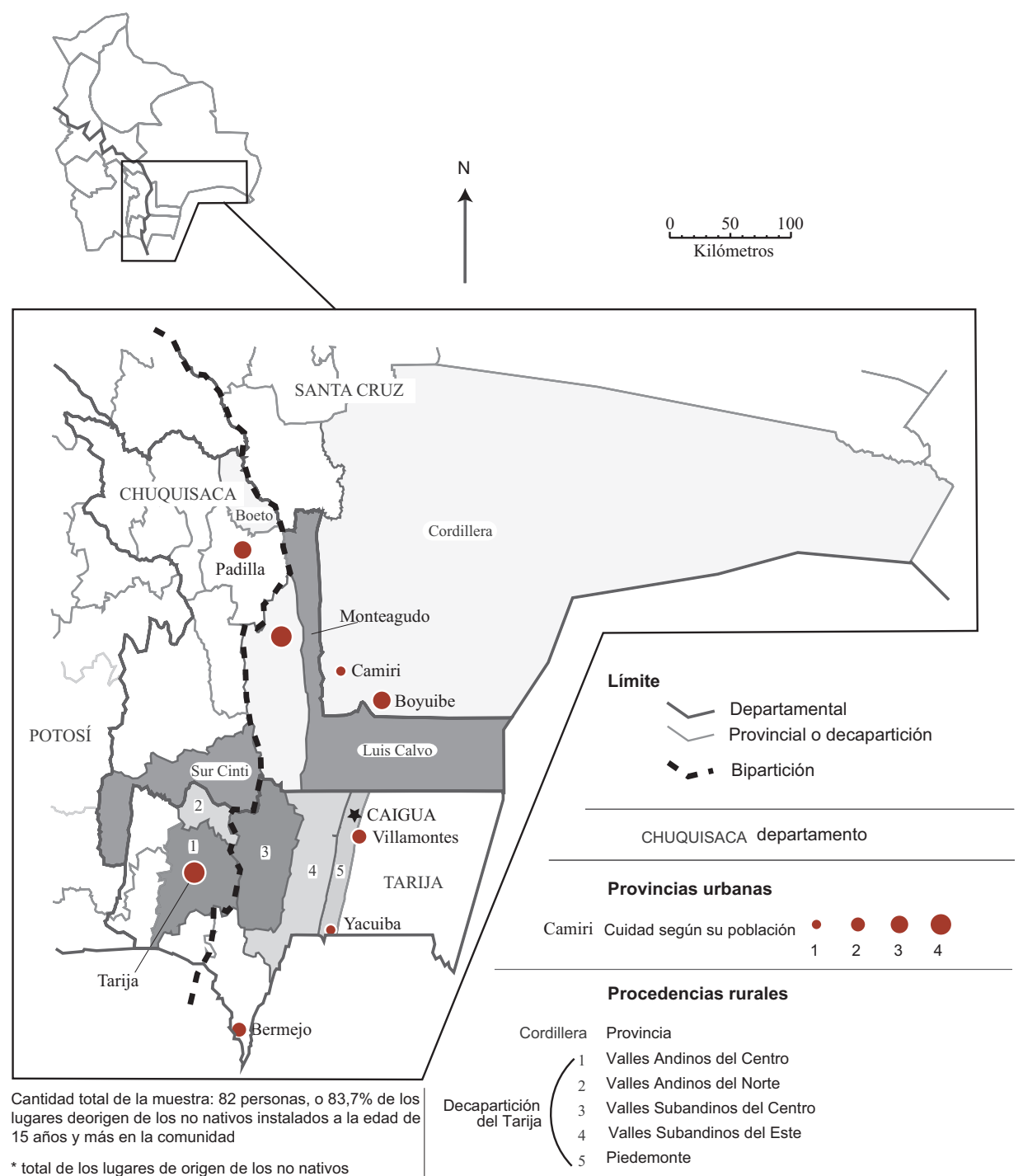

* total de los lugares de origen de los no nativos instalados en la comunidad de Caigua

a la edad de 15 años y más (98 individuos)

En \% del total de los lugares de origen*

Umbral urbano/rural establecido a 5000 hab.

Fuente:

bipartición de la Bolivia: d'Andréa 2004;

bipartición y decapartición de Tarija propia;

datos de Envil 2002. 
Fig. II 2: Envil 2002/Caigua - No nativos instalados a la edad de 15 años y más según sus lugares de origen
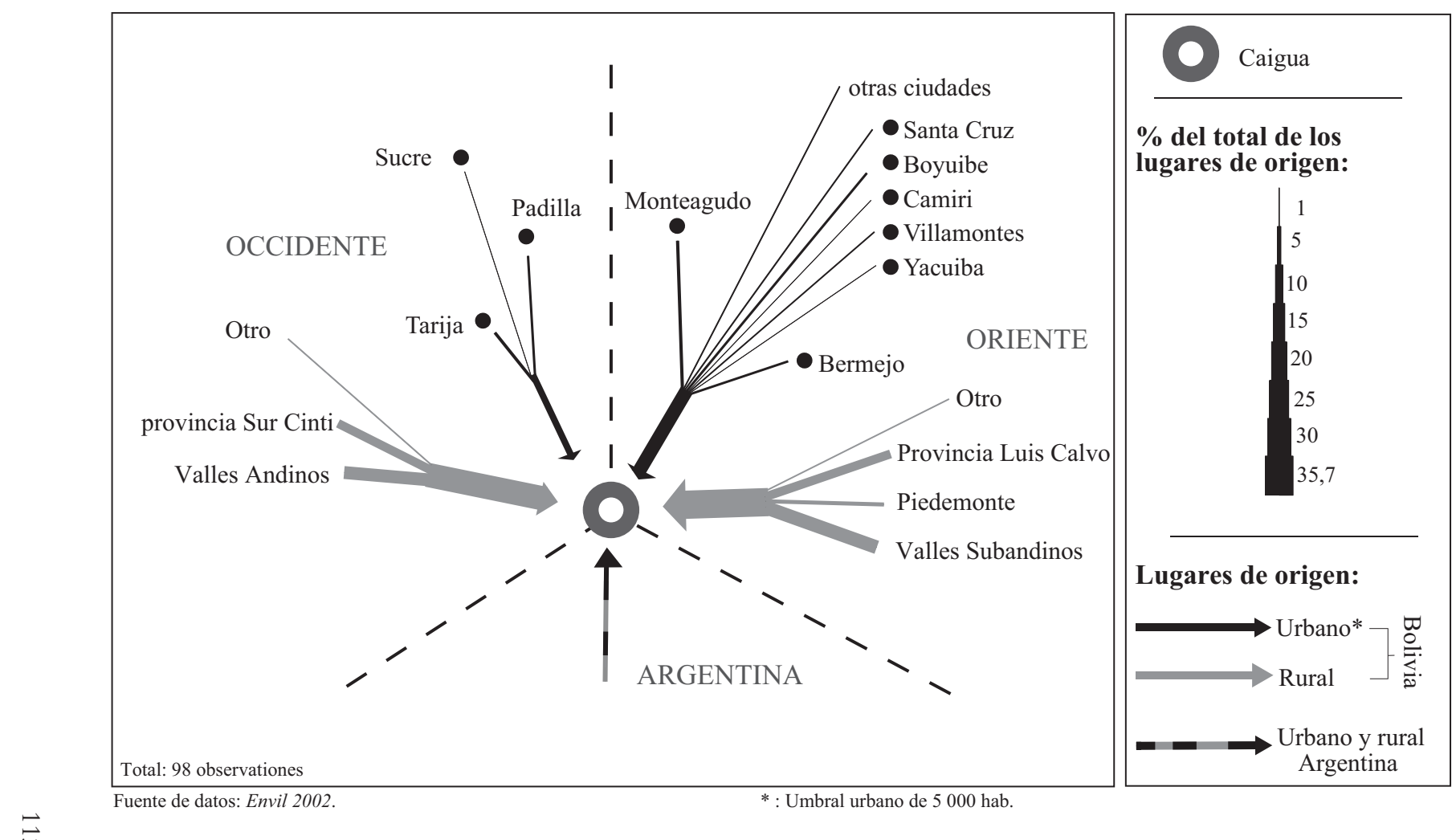
Los lugares de origen de los inmigrantes de Caigua son variados [cf. Fig. II-2]. En efecto, si aquellos que vienen del Oriente boliviano son mayoría (55,1\% de todo el conjunto de observaciones, cf. Tab. II-4), el Occidente del país concentra aún más de un tercio de las procedencias (38,8\%) y Argentina la minoría restante $(6,1 \%)$. Otro hallazgo, la gran mayoría de los no nativos proviene del espacio rural boliviano (66,3\% del conjunto de todos los lugares de origen, cf. Tab. II-5) pero también de localidades urbanas (25,5\%, principalmente de pequeñas ciudades orientales: $17,3 \%$ ). Pero más que la diversidad de procedencias según la bipartición y el medio urbano o rural, es la importancia de las migraciones de proximidad que se debe retener [cf. Mapa II-2]. De hecho, del conjunto de 98 inmigrantes estudiados, $86,7 \%$ proviene del departamento de Tarija, de Chuquisaca o del sur de la provincia Cordille$\mathrm{ra}^{12}$ (ubicada en la parte meridional de Santa Cruz, a menos de 100 kilómetros de la localidad estudiada), zona cercana a Caigua [cf. Tab. II-4].

¿Cómo calificar con mayor precisión la migración de proximidad? El Mapa II-3 permite visualizar dos tendencias principales. Primero, las migraciones desde localidades rurales del Oriente provienen principalmente de los Valles Subandinos del Centro (departamento de Tarija) y de la vecina provincia de Luis Calvo (departamento de Chuquisaca). En menor medida, los Valles Subandinos orientales y el Piedemonte contribuyen también al poblamiento de la comunidad. Finalmente, los individuos vienen de Monteagudo, Camiri, Boyuibe, Villamontes, Yacuiba y Bermejo, ciudades pequeñas del Oriente boliviano. Por otro lado, las procedencias occidentales son importantes desde los Valles Andinos del departamento de Tarija (en especial los del centro) y de la provincia de Sur Cinti. Los migrantes provenientes de las ciudades de Padilla y Tarija (Occidente boliviano) constituyen un movimiento menor del poblamiento de Caigua.

¿Los lugares de origen han evolucionado según las principales fases de instalación señaladas anteriormente? Exactamente la mitad $(50 \%)$ de las personas que se instalaron antes de 1990 provenían de las zonas rurales del Oriente boliviano, mientras que esta proporción era sólo de $25 \%$ para quienes llegaron después de 1990 [cf. Fig. II-3 y Tab. II-5]. Por el contrario, la inmigración desde las localidades rurales del Occidente sólo representa $23,8 \%$ del total de las instalaciones antes de 1990, llegando a 35,7\% durante el siguiente periodo. Este aumento también concierne a los llegados de las

\footnotetext{
${ }^{12}$ Más precisamente $5,1 \%$ de lo cual $1 \%$ de la ciudad de Camiri, 3,1\% de la de Boyuibe y $1 \%$ de una localidad rural de Cordillera.
} 
Fig. II-3: Envil 2002/Caigua - No nativos llegados a la edad de 15 años o más según el año de instalación y la región de origen

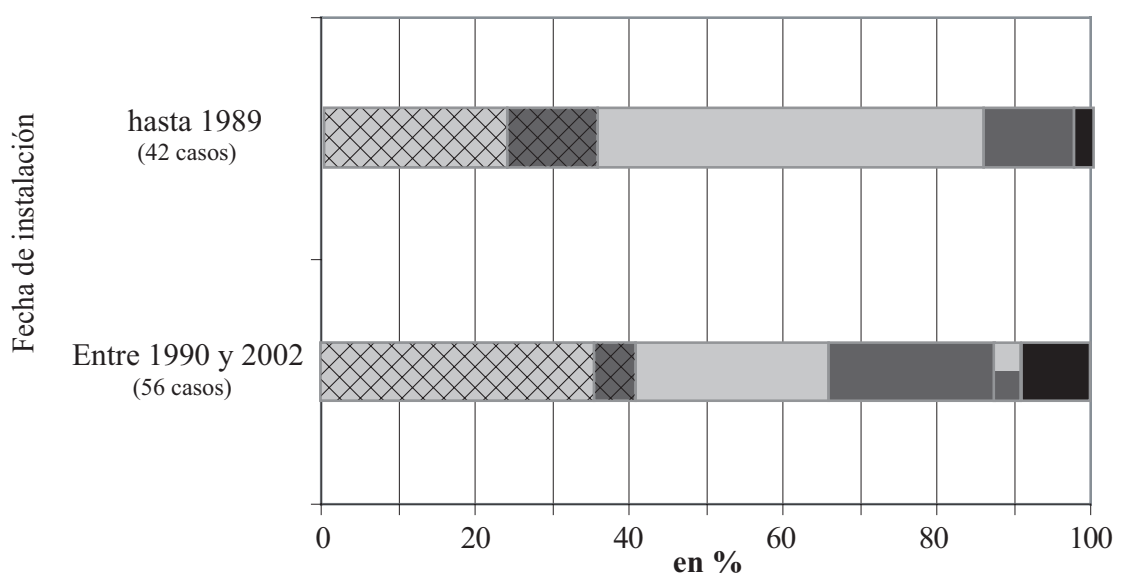

Región de origen :

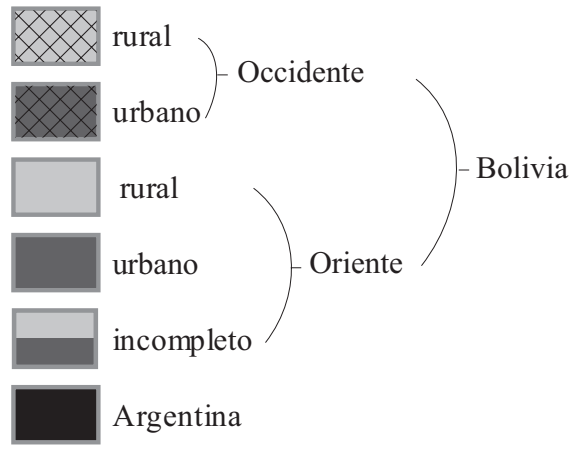

Fuente : Envil 2002

ciudades orientales (11,9\% en el primer periodo, $21,4 \%$ en el segundo) y de Argentina (2,4\% y $8,9 \%)$.

Así, hemos descrito con exactitud los principales flujos migratorios que han contribuido al poblamiento de Caigua. Por un lado, notamos una evolución reciente e irregular de la inmigración: las primeras instalaciones señaladas se remontan a la mitad del siglo xx, pero no fue sino hasta los años 
ochenta que identificamos un aumento significativo en el número de llegadas seguido por una baja al comienzo de la década siguiente y de una fuerte recuperación durante los años noventa, y de una nueva disminución a partir del año 2000. Por otro lado, la evolución de los lugares de origen es indicativa de una ampliación del área de atracción de Caigua. Tradicionalmente (antes de 1990), la comunidad ha atraído a más personas de las zonas rurales orientales próximas, aunque las llegadas de las zonas rurales occidentales ya existían. Posteriormente, durante los años noventa, estas procedencias se han diversificado, dando un lugar relevante a los individuos provenientes de las localidades rurales de los Valles Andinos del departamento de Tarija o del sur de Chuquisaca, al igual que de las pequeñas ciudades del Oriente boliviano y de Argentina. Nos centraremos ahora en aportar elementos de explicación de estos importantes movimientos migratorios que han contribuido al poblamiento de Caigua.

\section{B. FACTORES DE UNA DINÁMICA DE VALORACIÓN INÉDITA}

La inmigración es fundamental para el crecimiento demográfico de la comunidad de Caigua, lo que es signo de un dinamismo rural reciente del Piedemonte tarijeño y que contrasta con el antiguo poblamiento de los Valles Andinos. ¿Por qué la comunidad de Caigua constituye un pequeño centro de atracción regional? Vamos a tratar de aportar elementos que respondan a este cuestionamiento para posteriormente regresar sobre las diferentes oleadas de llegadas, evocando ciertos factores que puedan ayudar a comprender la evolución de estos ciclos migratorios.

\section{Inmigración de una población joven y activa ${ }^{13}$}

La inmigración ha atraído una población joven a la comunidad [cf. Fig. II-4 -a]. De hecho, 45,5\% de los no nativos son menores de 15 años al momento de su instalación, ${ }^{14} 32,3 \%$ de 15 a 29 años y 12,7\% de 30 a 44 años [cf. Tab.

\footnotetext{
${ }^{13}$ Para calificar a la población inmigrante, utilizaremos el módulo "instalación” de la ficha individual [cf. www.frontarbol.com para el cuestionario completo] que identifica la ocupación profesional de la encuesta en su lugar de origen, su estado civil a su llegada a Caigua y la motivación de su instalación. Si esta última se relaciona con el trabajo, entonces hemos registrado el sector de actividad y la categoría del empleo ocupado.

${ }^{14}$ Se observa en la Figura II-4-a un déficit de niñas menores de 10 años. No hacemos comentarios sobre el bajo número (esta subpoblación concierne 24 casos, cf. Tab. II-6) y la ausencia
} 
II-6]. Estos datos implican una inmigración compuesta de familias cuyos padres son jóvenes y están acompañados de niños. Sin embargo, la situación es más compleja, ya que los no nativos instalados a la edad de 15 años y más en Caigua (98 casos) son hombres en su gran mayoría (55,1\%, 54 casos), una tendencia exacerbada si nos limitamos a los que llegaron antes de 1990 (57,1\%, 24 de los 42 no nativos instalados a la edad de 15 años o más antes de este año eran hombres). ¿Significa esto que la inmigración familiar se complementa con la llegada de hombres solteros? Sí, en la medida en que de los 54 hombres no nativos instalados a la edad de 15 años y más en Caigua, 55,6\% (30 casos) no vivía en pareja al momento de su llegada, proporción que es sólo de 36,4\% para las mujeres.

La inmigración hacia Caigua es por parte de una población de hombres jóvenes y solteros (tendencia significativa antes de 1990) o por familias que se instalan con sus hijos. Para el resto de nuestro análisis, sólo retendremos los no nativos mayores de 15 años y más durante su instalación (98 casos), quienes son los más susceptibles de efectuar una migración laboral hacia la comuniad. Se trata de una población con un alto nivel de actividad en su lugar de origen: ${ }^{15}$ 64,3\% declaró haber trabajado en ella, proporción que es de 75,9\% para los hombres y 50\% para las mujeres [cf. Tab. II-7 y Fig. II-4-b]. Los empleos ocupados en sus últimos lugares de residencia son en su mayoría agrícola $(66,7 \%)$ aunque la proporción de personas que trabajaron en los servicios es significativa (19,0\%) [cf. Tab. II-8]. Se trata de mujeres y personas de origen citadino quienes conforman esta minoría de individuos que trabajan en el sector terciario, $40,9 \%$ de las mujeres que se estableció a la edad de 15 años y que trabajaba en su lugar de origen declara haber ocupado un empleo relacionado con los servicios, proporción que es de $47,1 \%$ si nos limitamos a los provenientes (ambos sexos) de las ciudades [cf. Tab. II-8 y II-9, y Fig. II-4-c y II-4-d]. Finalmente, recordemos que la mayoría (54,1\%) de estos inmigrantes de 15 años o más al momento de su instalación han venido para trabajar; $83,3 \%$ son hombres y $18,2 \%$, mujeres $(75 \%$ de ellas declara haber viajado para acompañar a sus padres o maridos) [cf. Tab. II-10, Fig. II-4-e].

de la edad de instalación (para los menores de 15 años al momento de la encuesta), vuelve difícil analizar a esta escala.

${ }^{15}$ Cuando el lugar de origen corresponde al lugar de nacimiento, se utilizan las preguntas 1 y 2 del módulo A de la ficha individual: “¿Trabajaba usted en su lugar de origen?” y “¿Qué trabajo hacía?" Cuando el lugar de origen corresponde a la última migración, es el motivo de este evento lo que es retenido (ver www.frontarbol.com para los cuestionarios completos). 
Fig. II-4: Envil 2002/Caigua - Sexo y edad de la instalación del conjunto de los no nativos; ocupación laboral y motivo de instalación de los migrantes llegados a la edad de 15 años y más (continúa)

a) Conjunto de no nativos de Caigua según sexo y edad de instalación en la comunidad

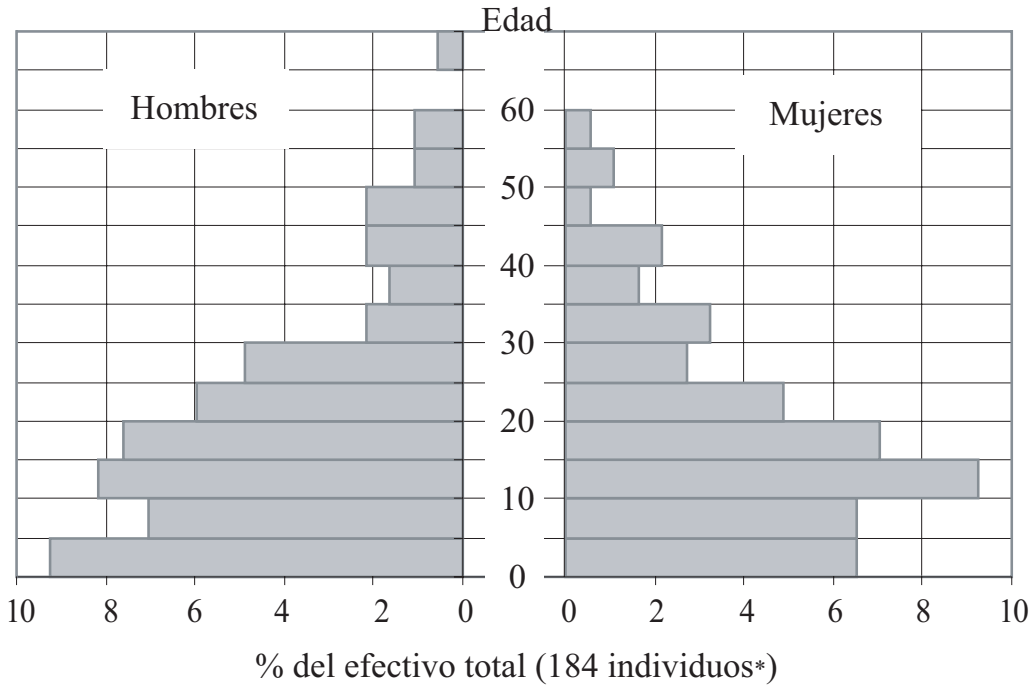

* 97,4 \% de 189 no nativos (la edad o el año de instalación no fue informada para 5 casos)

Nota: para los no nativos de menos de 15 años al momento de la encuesta, es su edad en julio 2002 que se seleccionó como edad de instalación.

La inmigración hacia Caigua está principalmente estructurada en torno a la llegada de los adultos jóvenes, ya muy activos en su lugar de origen y que viajan a Caigua por razones laborales (los hombres) o por acompañar a sus familias (las mujeres). Pero ¿qué convierte a la comunidad en un centro de atracción para estos inmigrantes?

Poblamiento y contexto del desarrollo agrícola

De los 53 individuos que llegaron a la edad de 15 años y más a Caigua para trabajar, 79,2\% lo hace en la agricultura [cf. Tab. II-11]. Por lo tanto, es necesario explicar tal atractivo del sector primario en la comunidad. Para ello, 
Fig. II-4: Envil 2002/Caigua - Sexo y edad de la instalación del conjunto de los no nativos; ocupación laboral y motivo de instalación de los migrantes llegados a la edad de 15 años y más (continía)

Los no nativos instalados a la edad de 15 años y más en la comunidad

\section{b) ¿Trabajaron en su lugar de origen?}

Hombres (54 casos)
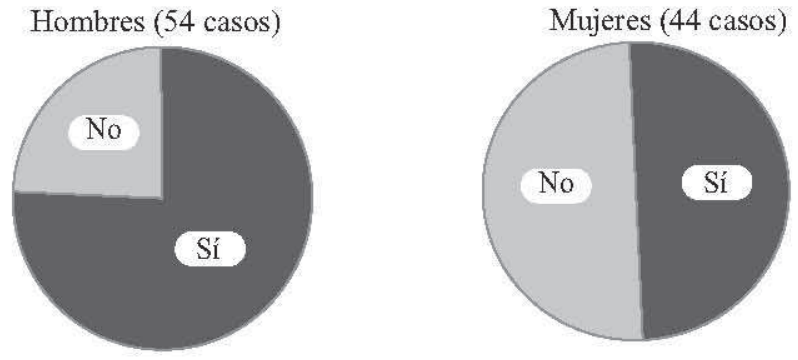

Los individuos declaran haber trabajado en su lugar de origen según el sector de actividad del empleo declarado

c) $\mathrm{Y}$ el sexo

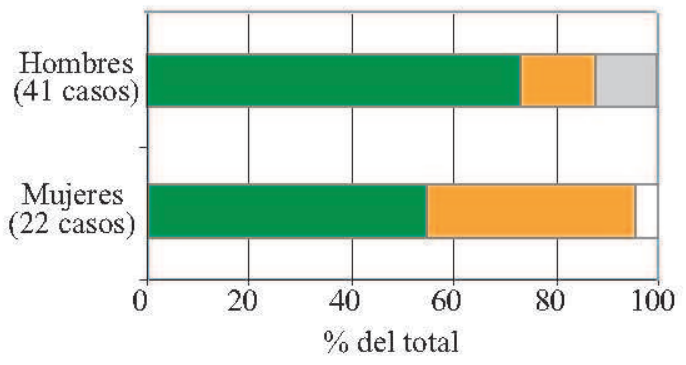

d) $\mathrm{O}$ la vivienda del lugar de origen*

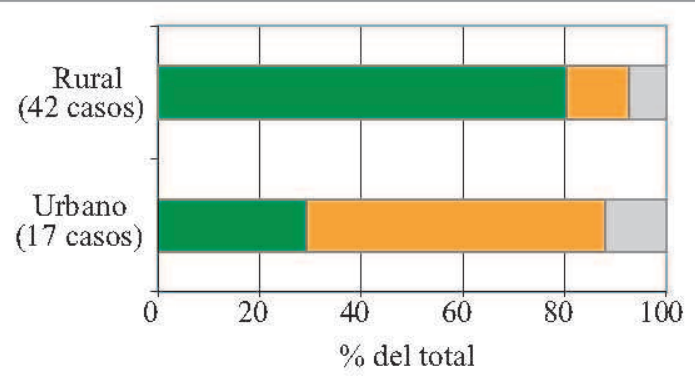

Servicios

Agricultura / Ganadería

Otros Sin respuesta

* Umbral urbano / rural de 5000 hab. en el censo del INE (Bolivia) o INDEC (Argentina) de 2001, para cuatro casos, la información obtenida no permite la distinción 
Fig. II-4: Envil 2002/Caigua - Sexo y edad de la instalación del conjunto de los no nativos; ocupación laboral y motivo de instalación de los migrantes llegados a la edad de 15 años y más

e) Motivo de instalación en Caigua
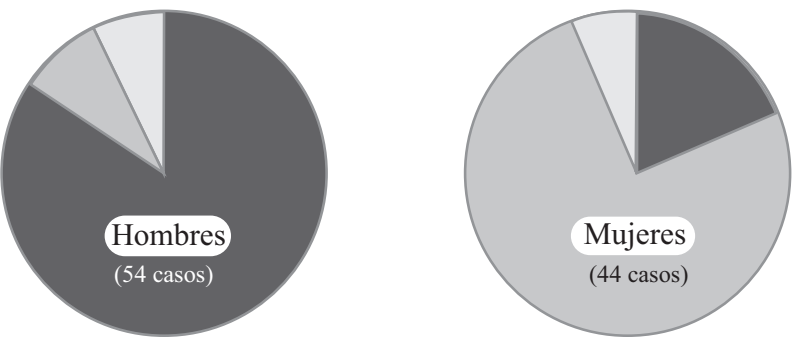

Trabajar

Acompañar a los padres o a la pareja

Otro

Fuente: Envil 2002.

no trataremos la situación actual de la agricultura —esta se abordará en la segunda sección de este capítulo- pero propondremos un enfoque histórico del desarrollo de Caigua (principalmente a través de la evolución de su función agrícola) tratando de establecer un vínculo con las fases principales del poblamiento previamente identificadas.

Hasta mediados del siglo pasado, la actividad agrícola del Piedemonte Norte se limitaba a la presencia de cultivos dispersos y sin riego (Zonisig-APDS, 2000). Esta situación se explica por las tradiciones de los autóctonos de la región - principalmente seminómadas dedicados en gran parte a la cría-, por las grandes distancias a cualquier mercado y por el mal estado de las vías de comunicación, obstáculos para el crecimiento de una agricultura comercial. Es difícil saber cuándo ese paisaje rural cambió en la comunidad, pero podemos suponer un impacto significativo de la reforma agraria de 1953 que favoreció la implantación de colonos mediante la distribución de derechos para cultivar. De acuerdo con el diagnóstico de Zonisig (Zonisig-APDs, 2000), es a partir de la introducción de este sistema que la inmigración hacia el Piedemonte Norte se desarrolla, proveniente de los Valles Subandinos del departamento de Tarija y de Chuquisaca. Son estos mismos movimientos migratorios hacia Caigua 
que identificamos a partir de los años setenta [cf. supra], a partir del establecimiento de los inmigrantes desde las localidades rurales de Bolivia oriental (Valles Subandinos del Centro del departamento de Tarija y la provincia de Luis Calvo de Chuquisaca, ubicada en la extensión septentrional del Oriente tarijeño, cf. Mapa II-3). Estas regiones, tradicionalmente dedicadas a la agricultura diversificada (maíz, maní, cítricos) extensiva o intensiva de riego (INE, 1999), sufren una falta de acceso a los mercados (Zonisig-APDS, 2000), lo que habría restringido su desarrollo agrícola y constituye la razón principal de la emigración. En su camino a Caigua, las personas originarias de estas tierras han llevado a cabo transferencias de tecnología, particularmente en lo que respecta al control de las técnicas de riego, y por lo tanto han favorecido el desarrollo agrícola del Piedemonte y contribuido al reforzamiento de su atractivo.

Pero es en realidad durante los años 80 que la inmigración se ha acelerado. El paisaje agrario de Caigua está marcado por la apertura de la refinería de semillas oleaginosas de Villamontes en $1974^{16}$ y los proyectos públicos de asistencia al desarrollo agrícola que la acompañan (creación de un sistema de riego, desarrollo de tierras para la agricultura y otros instrumentos financieros y técnicos) (Zonisig-APDS, 2000). Sin embargo, como hemos visto, la explotación de la refinería demostró, en poco tiempo, ser un fracaso. Nunca superó $15 \%$ de su capacidad de producción (CEDLA, 1988) y los proyectos de ayuda fueron interrumpidos. Por lo tanto, podemos asumir que la crisis de la refinería es en parte responsable de la disminución observada en las llegadas a partir de 1987, una vez que el atractivo de la región había desaparecido. Este decremento podría explicarse por el agotamiento de las tierras para su distribución a finales de los años ochenta, como lo han señalado las autoridades de la comunidad (volveremos a este punto en la siguiente sección).

Sin embargo, el número de instalaciones en Caigua vuelve a aumentar considerablemente a partir de 1990. El desarrollo agrícola en la comunidad pudo beneficiarse de la pavimentación de la carretera Yacuiba-Camiri, a lo largo del Piedemonte, terminada a mediados de la década. Así, la apertura de esta vía remplaza una pista en muy malas condiciones, casi intransitable en temporada de lluvias, y por lo tanto, abre el acceso a nuevos mercados: la comunidad se encuentra a 20 minutos de Villamontes (11 086 hab. según el censo del INE de 1992), a 90 minutos de Yacuiba (30 912 hab. en 1992, puerta

\footnotetext{
${ }^{16}$ Fundada en 1974 , se puede asumir su participación en las primeras instalaciones de los migrantes desde 1975 .
} 
de entrada a Argentina) y a tres horas de Camiri (27 971 hab. en 1992). Pero si la apertura de la carretera aventajó en un primer momento a la agricultura comercial de Caigua, se puede suponer que provocó competencia con otras zonas productoras en un segundo tiempo. Además, la demanda del mercado de Yacuiba —en aumento importante hasta 1998 debido al crecimiento demográfico de la ciudad $-{ }^{17}$ luego disminuyó significativamente (d’Andréa, 2004). Por último, el diagnóstico del municipio de Villamontes (Zonisig-APDS, 2000) señala también algunos efectos negativos de la Nueva Política Económica (NEP) ${ }^{18}$ creada en los años ochenta y cuyos efectos adversos (competencia de los cultivos industriales argentinos en particular) se han hecho sentir en los años noventa. Estos tres factores han contribuido al nuevo debilitamiento sobre el atractivo del sector agrícola de Caigua y por lo tanto a la baja de las instalaciones desde el año 2000.

La instalación de familias pioneras en Caigua se remonta a la primera mitad del siglo xx, pero es sólo recientemente (a partir de los años setenta) que el crecimiento de la comunidad experimentó una evolución significativa. Ejerciendo como primer recurso su atracción sobre las zonas rurales vecinas que enfrentan problemas de desarrollo agrícola, la localidad recibe individuos provenientes de lugares muy diversos, incluyendo los Valles Andinos del departamento de Tarija y el sur de Chuquisaca, valles que enfrentan límites de sus sistemas agrarios. Al parecer, el poblamiento de la comunidad se deriva directamente de la fase crítica afrontada por el sector rural boliviano, los migrantes que buscan beneficiarse de los recursos agrícolas de una región hasta el momento subutilizados y con mejores servicios. Sin embargo, el poder de atracción de Caigua no se limita a estas zonas rurales próximas, ya que también concierne a pequeñas localidades urbanas, e incluso Argentina, destacando la importancia de la atracción ejercida por la comunidad sobre una población joven y activa. Las prácticas agrícolas de la localidad se vieron afectadas luego de la transferencia de tecnología por los recién llegados (en su mayoría agricultores atraídos por el potencial de este sector en Caigua) ${ }^{19}$

\footnotetext{
${ }^{17}$ Ver Souchaud \& Martin, 2007 sobre el crecimiento de la ciudad de Yacuiba.

${ }^{18}$ La NEP, introducida por el gobierno de Paz Estensoro en 1985, limita considerablemente los subsidios gubernamentales y el proteccionismo. Por lo tanto, las importaciones están libres y sujetas a una tasa única de $10 \%$.

${ }^{19}$ Se puede suponer que la agricultura domina ampliamente las motivaciones de las instalaciones en la comunidad. La hipótesis del diagnóstico de Zonisig (Zonisig-APDS, 2000) que evoca
} 
incluyendo el desarrollo del riego. El crecimiento del sector primario también se ha beneficiado de la realización de un proyecto agroindustrial en la cercana ciudad de Villamontes y de la reciente mejora en las vías de comunicación. Sin embargo, se observó que existen límites a este progreso, especialmente en relación con la reciente falta de tierras para distribuir, el cierre de la refinería de semillas oleaginosas y la competencia de cultivos industriales que provienen de Argentina. Estas limitaciones explican la desaceleración de las nuevas instalaciones en la comunidad -fenómeno especialmente notable a partir del año 2000 - y señalan posibles dificultades del sector agrario en Caigua, situación que abordaremos a continuación.

\section{LÍMITES ACTUALES DE LA COLONIZACIÓN AGRÍCOLA}

Las condiciones naturales del Piedemonte Norte del departamento de Tarija (clima relativamente húmedo: precipitación anual de 1000 a $1200 \mathrm{~mm}$, suelo fértil y con riego por agua de la superficie posible durante todo el año) han generado una diversificación gradual de las actividades, la ganadería tradicional fue complementada por la agricultura (Zonisig-APDS, 2000). ¿Cómo se produjo esta mutación en el caso de la comunidad de Caigua? Para responder esta pregunta, primero nos centraremos (A) en describir la importancia y la diversidad del sector primario de hoy, especialmente en la inserción de los inmigrantes en el sistema productivo de Caigua. Enseguida, nos enfocaremos (B-1) más específicamente sobre la tenencia de la tierra en la comunidad para resaltar los principales cambios a nivel local en la redistribución de la tierra, lo cual está relacionado con las dinámicas del poblamiento. Terminaremos nuestro estudio con la medición de la dependencia de la población de Caigua sobre el sector primario, además abordaremos el tema de la diversificación de las actividades (B-2). En general, nos cuestionaremos con regularidad sobre las diferencias y similitudes con el modelo productivo de Tolomosa.

\section{A. UNA COMUNIDAD ESTRUCTURADA POR LA AGRICULTURA}

En Caigua, la mayoría de los hogares encuestados $(81,9 \%)$ declaró cultivos agrícolas ( $34,7 \%$ sólo cultivos y $47,2 \%$ cultivos y ganadería), mientras que

el papel de Caigua como zona de refugio para las poblaciones autóctonas provenientes de la llanura del Chaco no ha sido verificada en nuestro análisis. Además, el desarrollo de actividades relacionadas con los hidrocarburos en la comunidad no puede ser directamente correlacionado con el crecimiento demográfico [cf. Martin, 2010 para más detalles]. 
Fig. II-5: Envil 2002/Caigua - Hogares según las prácticas declaradas: agrícolas y/o ganaderas

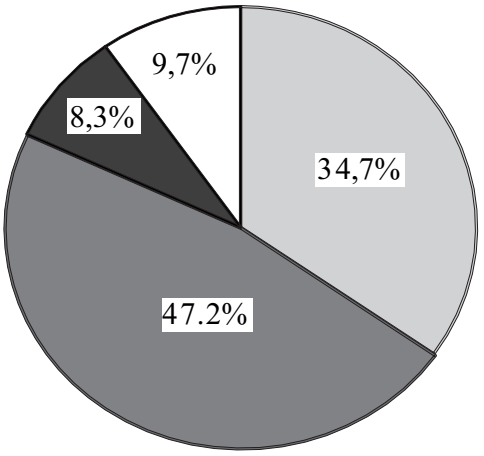

El hogar declara las siguientes prácticas:

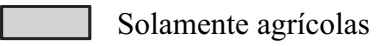

$\square$ Agrícolas y crianza de animales

Solamente crianza de animales

$\square$ Ninguna de las dos

Fuente: Envil 2002.

Total representado: 72 hogares

poco más de la mitad (55,5\%) posee animales de cría $(8,7 \%$ sólo de ganadería y $47,2 \%$ cultivos y animales) [cf. Fig. II-5 y Tab. II-15]. Otro hallazgo: de los 104 individuos de 15 años y más que trabajaron durante los siete días anteriores a la encuesta, $69,2 \%$ ocupaba un empleo relacionado con la agricultura, ${ }^{20}$ y apenas $1,9 \%$ con la ganadería [cf. Tab. II-13]. Sin embargo, la distribución de la superficie agropastoral entre la tierra destinada para la agricultura o la ganadería revela un desequilibrio en favor de la segunda categoría. De hecho, la superficie agrícola total es de 233 ha, mientras que el del ganado es de 325,5 ha [cf. Tab. II-16]. ${ }^{21}$ En primer lugar, analizaremos brevemente la situación paradójica de la ganadería en la comunidad, ya que ésta requiere de grandes extensiones de pastizales pero poco personal, no obstante parece ser practicada de manera extensiva. En segundo lugar, describiremos brevemente la práctica de la agricultura en Caigua, que sin duda es la actividad principal de la comunidad. Enseguida, propondremos, como tercer punto, una visión diacrónica de la evolución del sistema agrario en la comunidad tratando de entender el impacto de los inmigrantes en su desarrollo.

\footnotetext{
${ }^{20} \mathrm{Al}$ cultivo de los campos, huertos, jardines.

${ }^{21}$ Para las tierras agrícolas, se trata del total de la tierra destinada para este uso por los hogares que declararon cultivos. Para las tierras de ganado, se trata del total de la tierra destinada para este uso por los hogares que declararon animales de cría.
} 


\section{Ganadería, actividad extensa y marginal}

Las familias con animales de cría declaran principalmente bovinos $(65,0 \%$, cf. Tab. II-17) y rebaños ${ }^{22}$ (82,5\%, cf. Tab. II-18). Además, casi la mitad tiene al menos un caballo o un burro $(47,5 \%, 19$ de los 40 hogares con cabezas de ganado), sin que el tamaño del ganado sea superior a las 10 cabezas, lo que sugiere que se trata de animales de tiro o de transporte. Para determinar mejor la importancia de la ganadería en Caigua, nos concentraremos en las dos categorías principales.

De los hogares que practican el ganado, 34,5\% (15 casos sobre 40) no declara tierras relacionadas con esta actividad. Todos poseen un rebaño y aves (sobre todo en pequeñas cantidades: $80 \%$ no reporta conjuntos mayores a las 30 cabezas, ver Tab. II-18) y sólo un tercio (33,3\%) tiene bovinos, por lo general en pequeñas cantidades (solamente 13,3\% declara una manada de más de 10 cabezas, ver Tab. II-17). Es de suponer que los lugares de pastizales corresponden a los espacios intersticiales (bordes de vías o de parcelas) y a los lados del Aguaragüe, reserva natural ${ }^{23}$ que deja numerosos espacios inexplotados. ${ }^{24}$ Dada su poca importancia, la ganadería debe constituir una actividad complementaria para estas familias que destinan la mayor parte del rebaño y aves al consumo doméstico, aunque seguramente corresponde también a una forma de ahorro para cubrir gastos puntuales e imprevistos (de salud por ejemplo).

En contraste, el 50\% (20 de 40) de los hogares que practican la ganadería asocia tierras a esta actividad. Sin embargo, por lo general se trata de pequeñas superficies, ya que de estos 20 casos, sólo 30\% reportó más de 10 ha de pastizales (siendo el máximo de $100 \mathrm{ha}$ ); $20 \%$ entre seis y 10 ha; y $50 \%$, 5 ha o menos [ver Tab. II-19]. El hecho de declarar tierras de pastoreo no influye en la importancia del pequeño rebaño: sólo $25 \%$ tenía un rebaño de 30 cabezas y aves, y 50\% declaró rebaños aún más pequeños. Por otro lado, la posesión de ganado bovino para estas familias es significativo: $60 \%$ tiene

\footnotetext{
${ }^{22}$ Como en el caso de Tolomosa y siempre en aras de la simplicidad, hemos creado una categoría de "rebaño y aves", que comprende ovejas, cabras, cerdos y aves de corral.

${ }^{23}$ El Parque Nacional y Área Natural de Manejo Integrado de la Serranía del Aguaragüe es oficialmente un área protegida. En la práctica, pocos controles se llevan a cabo, permitiendo que los habitantes de la comunidad se beneficien libremente de este espacio, siempre y cuando se implante alguna infraestructura permanente.

${ }^{24}$ Esta gran superficie puede explicar la presencia de dos hogares con 12 y 35 cabezas de bovinos, pero sin tierras de pastoreo.
} 
manadas de más de 10 cabezas y sólo 10\% de ellas declara no tener ninguna [ver Tab. II-17]. Si entramos en detalles, pastizales y ganadería aumentan de la mano: aquellos que declaran entre 0,5 y 5 ha tienen en promedio 7,8 cabezas por familia, media que es de 16,8 cuando declaran entre 6 y 10 ha y de 30 para más de 10 ha [ver Tab. II-19]. Al parecer mientras más un hogar emplea tierras para la actividad pastoral, más se concentra en el ganado bovino, sin duda con fines comerciales. En general (y de acuerdo con nuestras suposiciones anteriores), la ganadería bovina se practica ampliamente: se registra un total de 342 cabezas de este tipo de ganado distribuidas en 325,5 ha, relación muy baja de 1 cabeza/ha. ${ }^{25}$

Podemos concluir que si las tierras de pastoreo son importantes en Caigua, se debe principalmente a la presencia de los grandes terratenientes que explotan de forma extensiva su dominio. El impacto de la actividad en la comunidad es pequeño ya que sólo algunos hogares parecen ejercerla a una escala comercial, mientras que, en general, su papel es sólo complementario, especialmente en la actividad agrícola, ya que 85,0\% (34 de 40) de las familias con animales también practican la agricultura. En este sentido, el modelo de Caigua es similar al observado en Tolomosa.

\section{Agricultura diversificada de pequeñas explotaciones familiares}

La mayoría de los hogares entrevistados en Caigua (81,9\%) declararon prácticas agrícolas y 174 de las 233 ha reservadas para esta actividad estaban cultivadas al momento de la encuesta. ${ }^{26} \mathrm{El}$ lugar del maíz en la agricultura de la comunidad es importante [ver Fig. II-6]: 62,7\% de los hogares con actividad agrícola lo declararon [ver Tab. II-20], además ocupa casi la mitad de la superficie total cultivada (45,8\%, ver Tab. II-21). Enseguida vienen los cultivos hortícolas (especialmente los tomates, al igual que los pimientos): 61,0\% de

\footnotetext{
${ }^{25}$ Conviene tomar con precaución el estudio de cantidad de tierra dedicada al ganado. Durante la encuesta, se preguntaba la superficie total de tierra ganadera utilizada, que fuese de uso propio o comunal. Es difícil asegurar que el encuestado haya declarado la tierra comunal (o el parque Nacional vecino) como tierra utilizada, y si fuese el caso no sabemos si lo utiliza solo o con otros miembros de la comunidad.

${ }^{26}$ De hecho, censamos dos tipos de superficies agrícolas. Aquellas declaradas por el hogar de manera general, obtenidas por la pregunta 9 del módulo 5, y aquellas que corresponden al total de la superficie cultivada al momento de la encuesta, es decir la suma de las superficies consagradas a cada uno de los cultivos declarados a partir de la pregunta 6 del mismo módulo.
} 
Fig. II-6: Envil 2002/Caigua - Importancia y diversidad de los tipos de cultivo declarado

Proporción (en \%) de hogares

agrícolas declarando este cultivo
Cantidad (en hectáreas)

cultivadas para todos los hogares

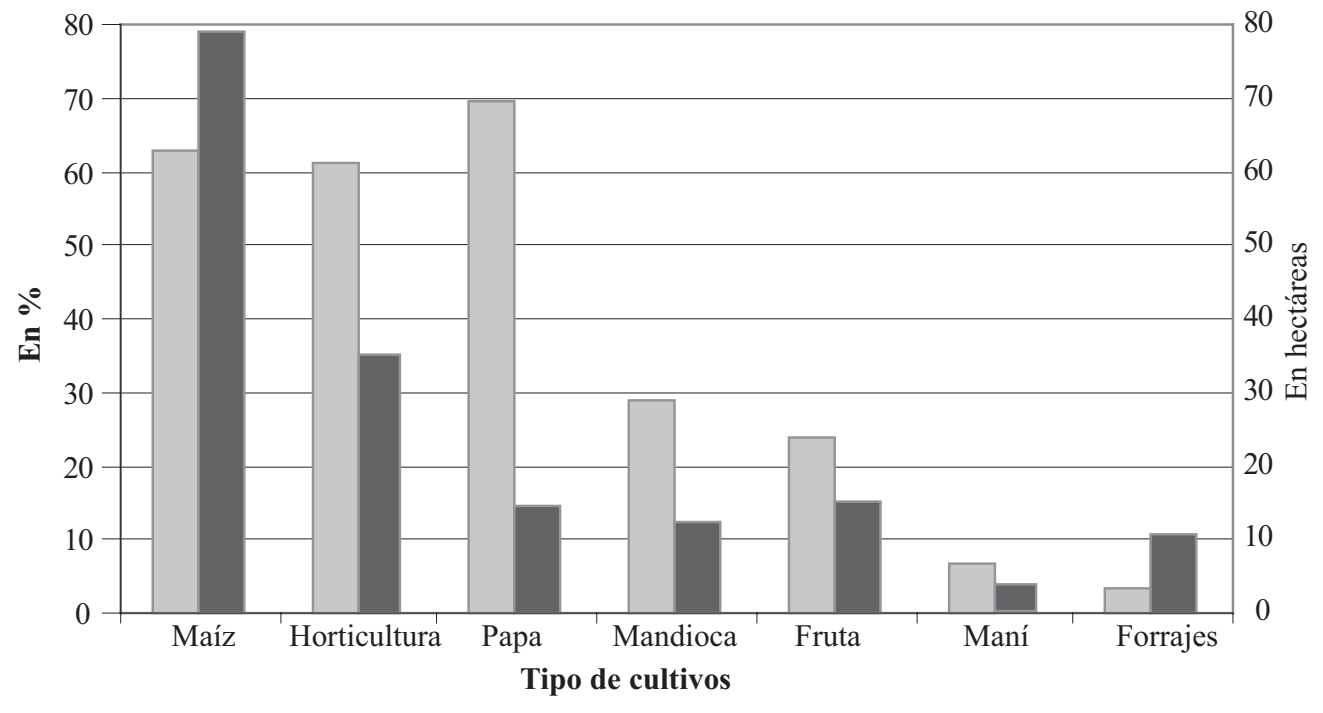

Fuente: Envil 2002. 
las familias agrícolas tienen este tipo de cultivo y se le destina el 34,5\% de la superficie cultivada. Dos cultivos de víveres ocupan cada uno 15 ha, la yuca y la papa (15,5 ha para el primero, 13,8 para el segundo); cabe señalar que el cultivo de la papa está generalizado (69,5\% de los hogares agrícolas tienen alguno), mientras que el de la yuca es minoritario $(28,8 \%)$. Enseguida, destacaremos el lugar de la fruticultura (especialmente cítricos: naranjas, mandarinas, toronjas, limones $)^{27}$ que ocupa quince hectáreas $(15,8)$ y cerca de un cuarto de los hogares con una actividad agrícola $(23,7 \%)$. Finalmente, concluiremos señalando la presencia de 11 ha de cultivos forrajeros y 3,8 ha de maní, declarados por minorías (3,4\% de los hogares agrícolas para el primero, 6,8\% para los segundos). Nótese la ausencia de cultivos de soja, algodón, trigo y arroz. ${ }^{28}$

Por tanto, estamos en presencia de una amplia variedad de prácticas agrícolas, sin embargo es difícil discernir las destinadas al autoconsumo de aquellas destinadas al comercio. Por un lado, observamos varios casos ambiguos. De acuerdo con el diagnóstico municipal (Zonisig-APDS, 2000), la producción de maíz tiene esencialmente como objetivo el autoconsumo y la alimentación del rebaño (cerdos en particular) y aves, aunque sugiere la existencia de una parte destinada a la industria avícola de la región de Tarija. Sin embargo, si los rendimientos de maíz en el Piedemonte Norte son superiores a los del departamento (2,6 t/ha frente a 1,6, ver Tab. II-22) ${ }^{29}$ la rentabilidad de este cultivo es baja (67 USD/ha), por lo que su comercialización es poco interesante. Además, los cultivos de papa y de yuca corresponden a los hábitos alimenticios de diversas poblaciones que componen la comunidad (las papas para los originarios del Occidente boliviano, la yuca para los que vienen del Oriente) que de esta forma consumen una parte de las cosechas, vendiendo sólo el excedente. También en este caso, conviene relativizar el interés comercial de estos cultivos: el rendimiento de la papa en el Piedemonte Norte es prácticamente el mismo al del departamento $(11,5 \mathrm{t} / \mathrm{ha}$ contra 11,2$)$ y la rentabilidad de la yuca es muy baja (29 USD/ha). Por otro lado, distingui-

\footnotetext{
${ }^{27} \mathrm{El}$ cuestionario no distingue entre los cultivos frutales, son nuestras observaciones de campo y algunas fuentes bibliográficas (principalmente el diagnóstico de Zonisig - Zonisig-APDs, 2000) los que nos permiten afirmar que se trata de una mayoría de cultivos de cítricos.

${ }^{28}$ Cada uno de estos cultivos es el tema de una pregunta separada en el cuestionario, esta información es fiable.

${ }^{29}$ Los datos de la Tab. II-22 se obtuvieron a partir de varios documentos encontrados en el Piedemonte Norte. Su precisión no pudo ser verificada, por lo que es conveniente manejarlos a título estrictamente indicativo.
} 
mos cultivos estrictamente comerciales a sabiendas que de $80 \%$ a $90 \%$ de la producción hortícola o frutícola se destina a los mercados (Zonisig-APDS, 2000): la rentabilidad de los cítricos se mide a largo plazo ya que no es alta (626 USD/ha) a partir del quinto año; en cuanto a los cultivos hortícolas, el tomate es altamente rentable (705 USD/ha) y su rendimiento excepcional (12,9 t/ha en el Piedemonte Norte, frente al 6,3 del departamento), lo que se explica por las lluvias invernales y el riego proveniente de las vertientes del Aguaragüe, permitiendo múltiples cosechas anuales.

En conclusión, se distinguirán dos grandes categorías: los cultivos tradicionales, generalmente víveres, ocasionalmente comerciales (maíz, papa, yuca, maní, forraje); y los cultivos específicamente comerciales (frutas y hortalizas), evidentemente innovadores si consideramos su reciente desarrollo en el Piedemonte. De los 59 hogares que declararon una actividad agrícola, $25,4 \%$ tiene solamente cultivos tradicionales, $54,2 \%$ cultivos tradicionales y comerciales y $20,3 \%$ únicamente cultivos comerciales [ver Tab. II-23].

Este policultivo parece implicar pequeñas explotaciones pero altamente irrigadas, gestionadas como parte de una economía familiar. A estas explotaciones las calificamos de pequeñas porque $59,3 \%$ de los hogares agrícolas reportan menos de 3 ha cultivadas; 23,7\% entre 3 y 4,99 hectáreas y sólo 16,9\% 5 hectáreas o más [ver Tab. II-24]. Remarcamos que los hogares que practican exclusivamente los plantíos comerciales son los que cultivan menos tierra (91,7\% declara menos de $3 \mathrm{ha}$ ), lo que limita la incidencia local de esta actividad. Por lo general, y de acuerdo con nuestras observaciones de campo, las pequeñas superficies destinadas a la agricultura y con presencia de animales de tiro son indicio de un bajo nivel de mecanización de la agricultura. El tamaño pequeño de las explotaciones se compensa con una buen riego: $55,9 \%$ de los hogares reporta la totalidad de sus tierras irrigadas y $18,6 \%$ sólo una parte [ver Tab. II-25]. Destaca que esta bonificación de tierras únicamente concierne a la minoría de los hogares que practican sólo los cultivos tradicionales, ya que $62,5 \%$ de ellos no se benefician de ninguna forma de riego. Esto explica, sin duda, que estas mismas familias declaran cultivos más rústicos que no requieren el aporte hídrico constante. Por último, las explotaciones agrícolas son de tipo familiar ya que $80,6 \%$ de las 72 personas que han trabajado durante los siete días anteriores a la encuesta parece haberlo hecho dentro del hogar [ver Tab. II-13]: 58,3\% (42 de estos 72 casos) como trabajadores independientes, $16,7 \%$ (12 casos) como trabajadores familiares no remunerados y $5,6 \%$ (4 casos) como patrones. 
Ejercida en el marco de pequeñas explotaciones familiares, la agricultura de Caigua constituye la actividad principal de la comunidad. Se hizo hincapié en la existencia de una gran diversidad en los tipos de cultivos practicados revelando dos grandes conjuntos compuestos, por un lado, de cultivos tradicionales y, por el otro, por cultivos más innovadores destinados al uso comercial. Por lo tanto, ¿debemos ver expuesta la complejidad de un territorio en mutación? Y si es así, ¿podemos vincular esta mutación con la llegada de inmigrantes o con otros factores que implican el conjunto del Piedemonte?

\section{Formación de un paisaje agrícola compuesto}

Tal yuxtaposición, sin una real especialización de actividades agrícolas, plantea interrogantes acerca de sus orígenes. ¿Estará relacionada con la diversidad cultural de los inmigrantes que pueblan la comunidad o al surgimiento de culturas de sustitución sin que las prácticas del pasado desaparezcan? Un enfoque diacrónico se impone para evaluar las transformaciones recientes del territorio y relacionarlas con la importancia de la inmigración hacia Caigua, esencial para comprender el desarrollo de su agricultura, ya que 83,1\% (49 de 59) de los jefes de hogar que declaran prácticas agrícolas, no son nacidos en la localidad.

La falta de un estudio longitudinal sobre el paisaje agrario del Piedemonte de Tarija dificulta esta investigación que deberá basarse principalmente en los datos Envil 2002. Por lo tanto, es a través del estudio del tipo de cultivo practicado por las familias a partir de la fecha de instalación del jefe de familia en la comunidad o de su lugar de origen ${ }^{30}$ que se analizarán las principales tendencias del desarrollo agrario de Caigua. ${ }^{31}$

Cuando se hace referencia a las familias u hogares agrícolas a lo largo del siguiente análisis, se tratará implícitamente a aquellos dedicados a los cultivos, 59 casos en total.

\footnotetext{
${ }^{30}$ Como lugar de procedencia, hemos elegido el lugar de origen (de nacimiento) que parece más apropiado para abordar las prácticas agrícolas; de hecho, la influencia cultural del lugar de nacimiento priva, para nosotros, sobre aquel de eventuales experiencias migratorias.

${ }^{31}$ Reiteramos que nuestros datos hablan de la agricultura al momento de realizar la encuesta; por lo que este es un análisis retrospectivo que no detecta los cultivos practicados por las personas que hayan fallecido o partido, ni los cultivos abandonados. Se puede hacer referencia a las Tablas II-26 y II-27 o la Figura II-7 para los resultados completos, teniendo en cuenta que no hemos considerado los cultivos de maní y de forraje, muy poco presentes para que su inclusión tuviese sentido.
} 
¿Cuál fue el tipo de cultivo que se implementó después de mediados del siglo xx, cuando la actividad principal en el Piedemonte Norte (y por lo tanto en Caigua) era la ganadería extensiva? La observación retrospectiva no detecta la presencia de oleaginosas, sino más bien de cultivos tradicionales. De hecho [ver Fig. II-7], el maíz y la yuca son ampliamente plantados por las hogares agrícolas cuyo jefe nació en el mismo lugar (90\% declaran el maíz y 40,0\% la yuca), o no es nacido pero se instaló en Caigua antes de 1980 (respectivamente $90 \%$ y 40\%) o entre 1980 y 1989 (70,6\% y 29,4\%); mientras que estas dos plantas son minoría entre las familias agrícolas cuyo jefe se instaló entre 1990 y 2002 (21,1\% y 5,3\%). Por el contrario, el cultivo de la papa parece más reciente en Caigua ya que sólo concierne a 10\% de las familias agrícolas cuyo jefe no nacido se haya instalado antes de 1980, proporción de 47,5\% para aquellos instalados entre 1980 y 1989, y de 31,6\% para los que llegaron entre 1990 y 2002. Así, podemos distinguir una implantación diferida de los cultivos tradicionales que no requieren aporte tecnológico importante, y que corresponden a los hábitos alimenticios de los inmigrantes. Por un lado, el maíz y la yuca (originarios de la cuenca amazónica, en el Oriente boliviano) están muy presentes en los hogares de jefes nacidos en Caigua o instalados antes de 1990, en una época en que la inmigración hacia la comunidad se realizaba más desde Bolivia oriental. Por otra parte, observaremos que 72\% de las familias agrícolas cuyo jefe nació en el Oriente boliviano practican el cultivo del maíz, y 36\% de la yuca. Por otro lado, la papa es importada por las familias de inmigrantes que llegaron a partir de 1980, principalmente por aquellos hogares cuyos jefes nacieron en el Occidente boliviano, región de origen de este cultivo (45,8\% de entre ellos cultivan la papa).

Parece que la práctica de cultivos comerciales innovadores se ha desarrollado en un segundo tiempo y ha evolucionado [ver Fig. II-7]. La fruticultura está presente en $20 \%$ de los hogares agrícolas cuyo jefe ha nacido en la comunidad; en 30\% de los casos de jefes no nativos e instalados antes de 1980; $35,3 \%$ de aquellos instalados entre 1980 y 1989; y sólo 10,5\% de los últimos llegados, entre 1990 y 2002. Mientras tanto, el análisis diacrónico del desarrollo de los cultivos hortícolas muestra un crecimiento constante. De hecho, se trata de $40 \%$ de las familias agrícolas cuyo jefe nació en Caigua, proporción que supera $50 \%$ para aquellos instalados antes de 1980, es de 58,8\% para aquellos que llegaron entre 1980 y 1989 y finalmente llega a 78,9\% para aquellos instalados entre 1990 y 2002. La naturaleza e importancia de los cultivos comerciales han, entonces, evolucionado: la fruticultura, que nunca ha ocupado un lugar preponderante, disminuye significativamente a medida que 
Fig. II-7: Envil 2002/Caigua - Familias que declaran una actividad agrícola por tipo de cultivo practicado y el lugar de nacimiento o la fecha de instalación del jefe de hogar (para los no originarios) (continúa)
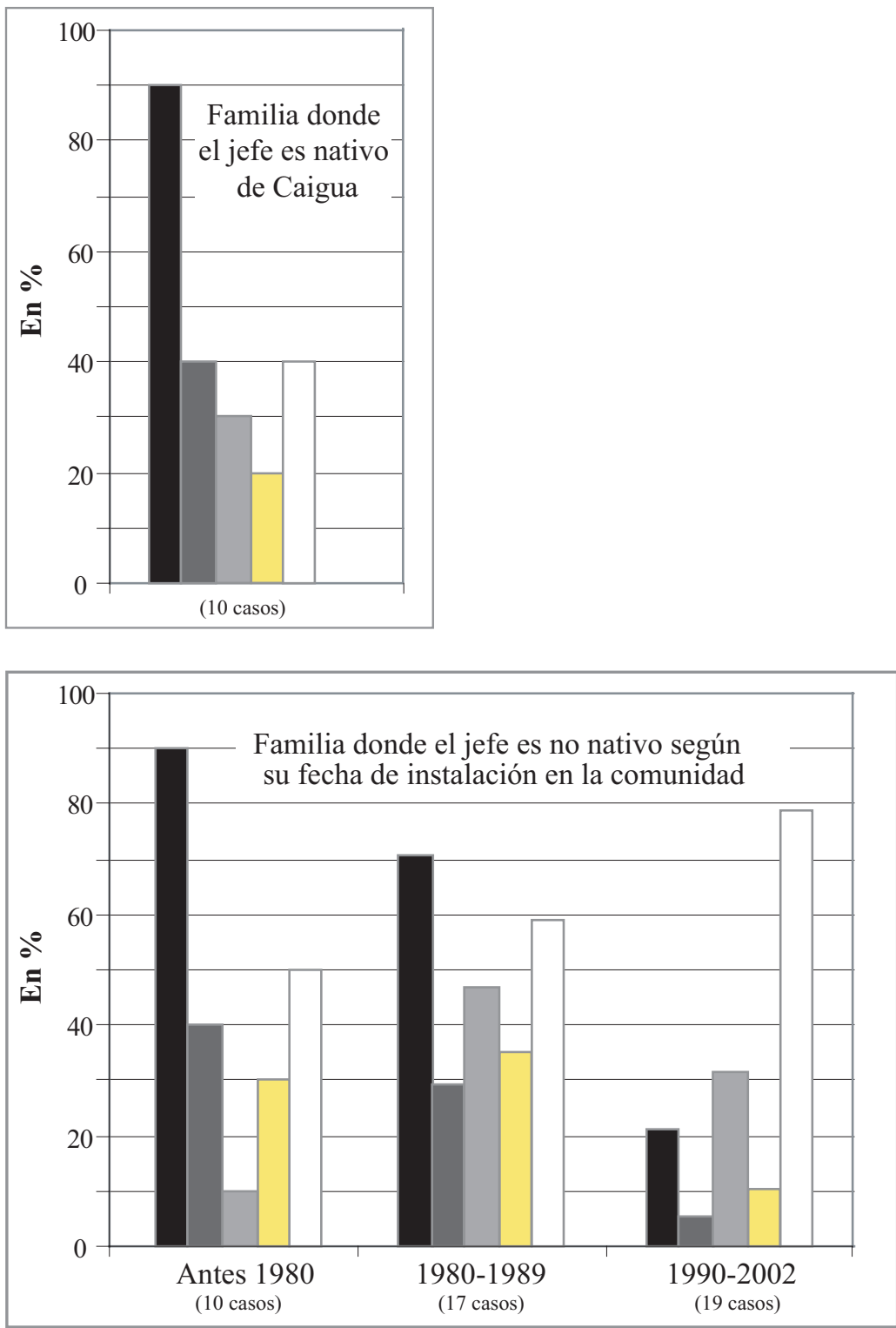
Fig. II-7: Envil 2002/Caigua - Familias que declaran una actividad agrícola por tipo de cultivo practicado y el lugar de nacimiento o la fecha de instalación del jefe de hogar (para los no originarios) (finaliza)

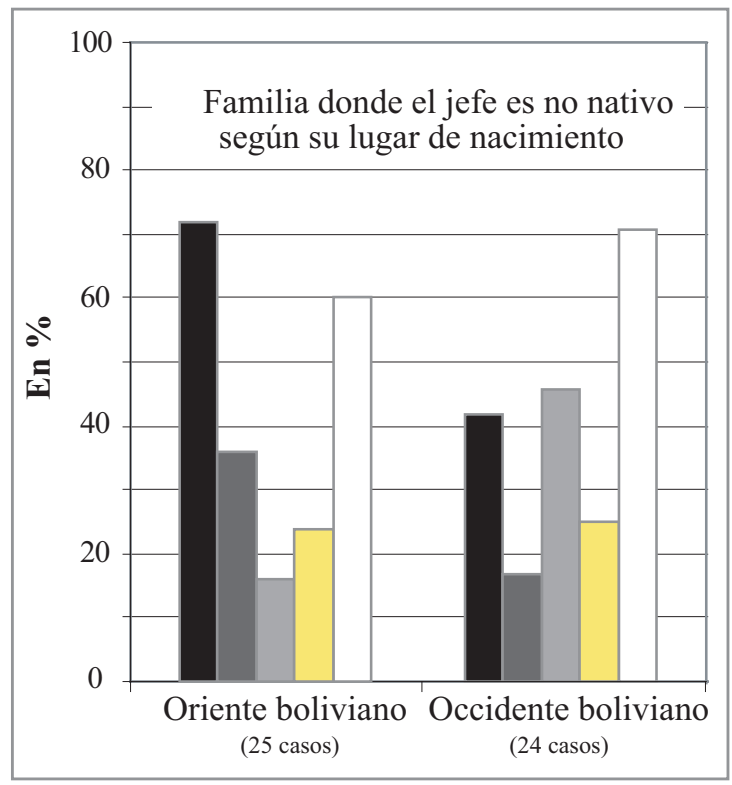

\section{Tipo de cultivo:}
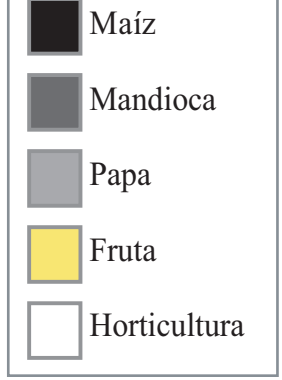

Fuente: Envil 2002.

vemos un aumento (guardando las proporciones) considerable de los cultivos hortícolas. Este incremento se explica parcialmente por un flujo rápido de los productos frágiles autorizados debido a la apertura de la carretera YacuibaCamiri, pavimentada a mediados de los años 90. Además, el diagnóstico de Villamontes (Zonisig-APDS, 2000) relaciona el cierre de la refinería de Villamontes a principios de los años noventa con el desarrollo de las prácticas agrícolas comerciales que luego sustituirían a la de las oleaginosas. Por último, a menudo se asume que los migrantes son más emprendedores, lo que podría ser confirmado por la importancia de las prácticas hortícolas en función del lugar de nacimiento del jefe de hogar: sólo 40\% de los hogares agrícolas cuyo jefe es originario de Caigua consagra una parte de sus tierras para la horticultura, contra 60\% de los nacidos en otras localidades del Oriente boliviano, y $70,8 \%$ de los nacidos en el Occidente del país. 
A través de lo anterior, se define claramente la actividad de la población de Caigua, organizada principalmente alrededor de las pequeñas explotaciones agrícolas familiares que practican de forma complementaria la ganadería. El reciente desarrollo del policultivo (incluidos los cultivos comerciales) podría indicar una relativa emancipación de la pequeña agricultura. Pero a la inversa, otras señales acreditan que el sector encuentra algunos obstáculos, como el equilibrio de las microparcelas y la presencia casi sistemática de cultivos de víveres -implantadas por los inmigrantes para el consumo doméstico (mandioca, papa) - y que indica, por lo general, una frágil economía alimenticia. Es sobre la precariedad del sistema productivo de Caigua que ahora nos enfocaremos, tratando de restituir los límites de la colonización agrícola evocados por el diagnóstico municipal (Zonisig-APDS, 2000) y también de proporcionar los elementos que expliquen la baja notable en las instalaciones a partir del año 2000.

\section{B. CRISIS EN LA TENENCIA DE LA TIERRA AGRÍCOLA \\ Y ATRACCIÓN POR LA PLURIACTIVIDAD}

Comenzaremos por el estudio de la tenencia de la tierra agrícola en la comunidad de Caigua, ya que el modo de asignación de tierras ha influenciado directamente la cuestión del poblamiento de la comunidad. A continuación, nos preguntaremos sobre la existencia de estrategias complementarias destinadas a reducir la dependencia de cara a un sector agrícola omnipresente, pero frágil.

\section{El acceso a la tierra, freno al crecimiento de Caigua}

Como lo señalamos anteriormente, la gestión de la mayor parte de la tierra en el Piedemonte tarijeño durante el siglo xIx caía en las misiones religiosas presentes en la región desde los años 1850 (Mendoza, 2003). En el caso del Piedemonte septentrional, es la misión franciscana de Tarairi, fundada en 1854 a $10 \mathrm{~km}$ al norte de Caigua [ver Mapa II-1], la que cubre esta función. Los religiosos de entonces buscaban la implantación de colonos distribuyéndoles tierras, recibiendo a cambio una parte de sus cosechas. Este sistema se ve alterado por la reforma agraria de 1953 que funda la Comunidad Grande de Tarairí (según los límites territoriales de la misión), que comprende varias subdivisiones, una de las cuales es Caigua. Según la información recogida 
en campo, ${ }^{32}$ el total de la tierra se convierte en comunitaria, destinada a ser distribuida entre las familias de los inmigrantes que deseaban establecerse en la región. Entonces, se les atribuía de manera provisional 10 ha que debían cultivar durante cinco años, lapso que permitía a los colonos ser reconocidos como miembros, a parte entera, de la comunidad. ${ }^{33}$ Según el diagnóstico (Zonisig-APDS, 2000), la disminución neta de las tierras a redistribuir ha provocado el desarrollo de su comercialización: ya que, aunque los miembros no son propietarios de tierras, y por lo tanto no pueden venderlas, tienen el poder de transferir o legar sus derechos de miembros de la comunidad, así como derecho a eventuales bonificaciones otorgadas a su explotación (plantaciones de cítricos, desarrollo de un sistema de riego). Es en este sentido que trataremos "compra" y "herencia" continuando con nuestro objetivo.

Los asuntos relativos al estatuto de la tenencia de la tierra agrícola no se limitan a las tierras cultivadas al momento de la encuesta, sino que se refieren al total de la superficie declarada por los hogares ( $233 \mathrm{ha}$ ), siendo este total lo que emplearemos en el estudio que sigue. Además, y como anteriormente lo hicimos, entendemos como "familias agrícolas" aquellas que hayan declarado cultivos, 59 casos en total..$^{34}$

A partir de nuestro análisis de la tierra cultivada al momento de la encuesta, ya habíamos señalado el pequeño tamaño de las explotaciones en Caigua, lo que se confirma por el estudio de la superficie utilizada por los agricultores, ya que 39\% de las familias agrícolas reporta menos de 3 ha, $30,5 \%$ entre tres y cuatro y sólo 18,6\% entre cinco y nueve. El régimen de propiedad domina $(71,2 \%$ de las familias agrícolas son propietarias de sus tierras) y la compra sigue siendo el principal modo de adquisición (40,5\% de los casos) seguido por la herencia $(23,8 \%)$. El desglose de esta información de acuerdo con el lugar de nacimiento y con la fecha de llegada del jefe de hogar (para los no originarios) permite revelar varios puntos:

\footnotetext{
${ }^{32}$ Particularmente del Pastor Garay, corregidor (representante del subprefecto) de la comunidad en 2002, cuyo padre se estableció antes de la reforma agraria.

${ }^{33}$ Esto es válido para las tierras agrícolas. Para aquellas destinadas a la ganadería, las explotaciones son mucho más importantes, el principio (exagerado) de 5 ha por cabeza bovina fue utilizado para calcular la superficie a redistribuir (Mendoza, 2003). De esta forma podemos explicar la presencia de un hogar que declara 100 hectáreas de tierra para la ganadería en nuestra encuesta.

${ }^{34}$ Para una mejor comprensión del análisis que sigue, referirse de manera regular a la Figura II-8 y a las Tablas II-28, II-29 y II-30.
} 
Fig. II-8: Envil 2002/Caigua - Tenencia de la tierra agrícola de las familias agrícolas (continúa)

Las familias agrícolas según el lugar de nacimiento y la fecha de instalación de los jefes de hogar

a) Y la cantidad de hectáreas utilizadas

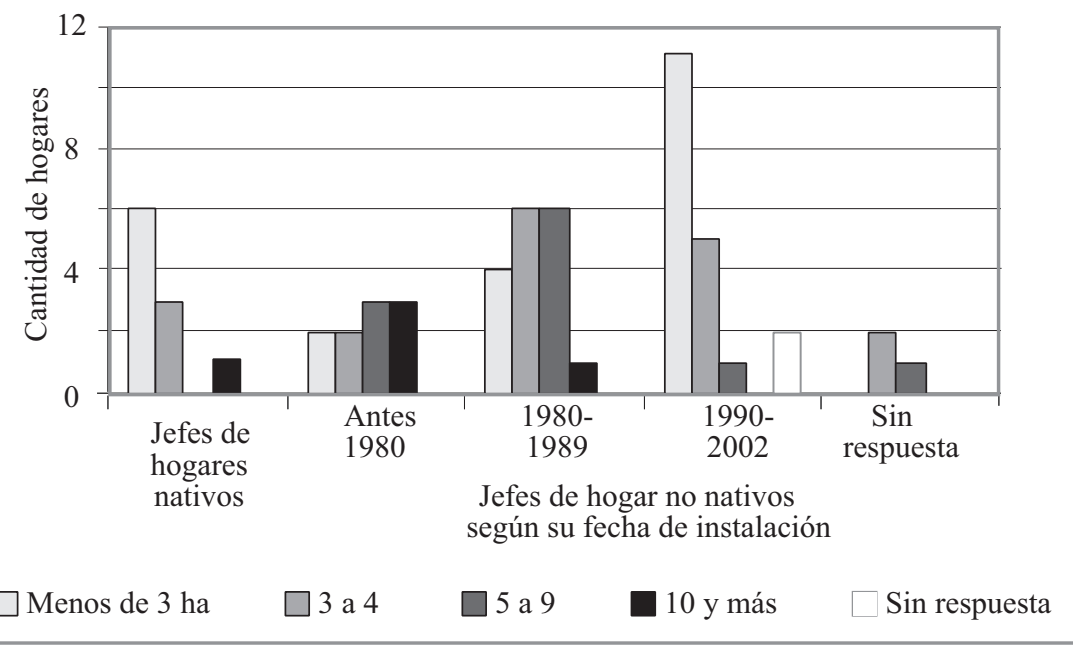

b) Y estatuto de la tenencia de las tierras utilizadas

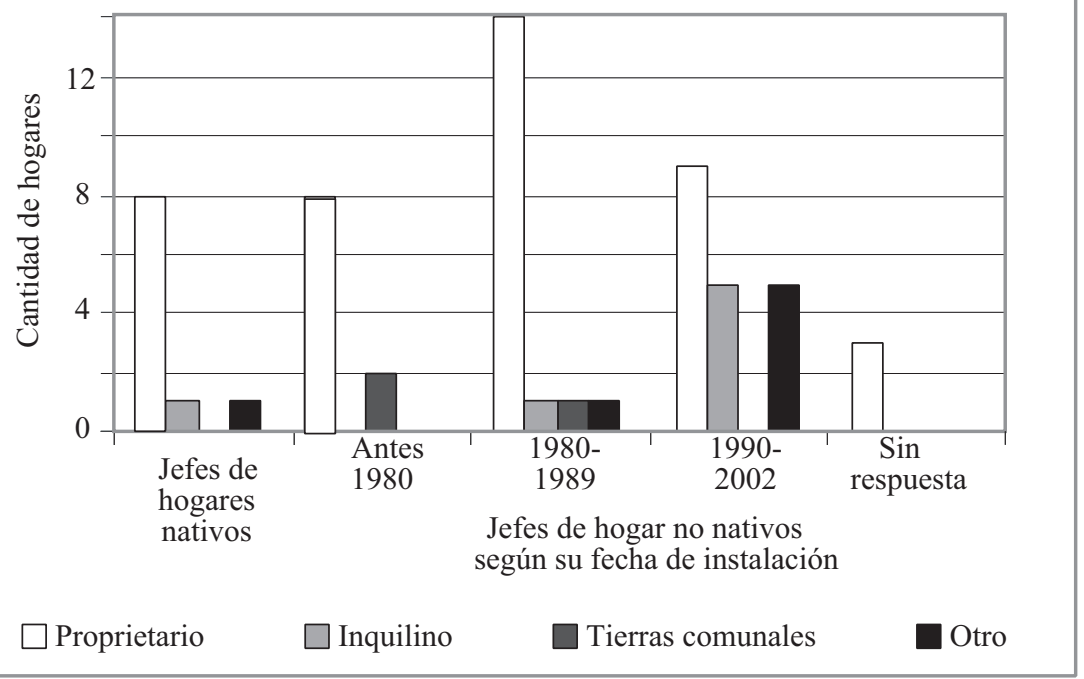


Fig. II-8: Envil 2002/Caigua - Tenencia de la tierra agrícola de las familias agrícolas (finaliza)

\section{c) Y modo de adquisición de las tierras utilizadas (por los propietarios)}

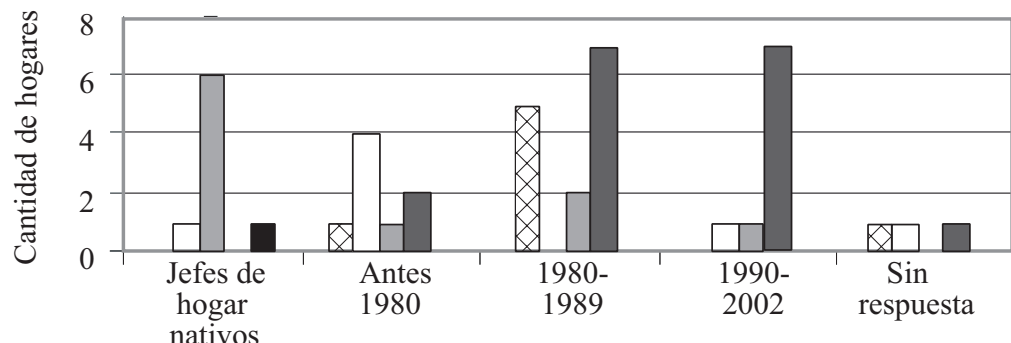

según su fecha de instalación

区 Dotación (Reforma agraria)

$\square$ Consolidación (Después de procesos administrativos)

$\square$ Herencia

$\square$ Compra

Otro

- Las familias agrícolas, cuyo jefe se instaló entre 1990 y 2002, se encuentran entre los propietarios minoritarios $(47,4 \%)$, mientras que la proporción se eleva a 80,0\% o más para aquellos cuyo jefe llegó antes o es originario de la comunidad. Dos hipótesis pueden explicar esta diferencia: en primer lugar, una fase de acumulación es necesaria antes de convertirse en propietario; segundo, el acceso a la propiedad ha sido más difícil a partir de 1990. ¿Este último punto podría deberse a la escasez de tierra a redistribuir en la comunidad o a una saturación de la tenencia de la tierra agrícola?

- Los modos de adquisición de la tierra varían según las épocas. La mitad $(50 \%)$ de tierras en propiedad de los jefes que llegaron antes de 1980 fueron adquiridas a través de la consolidación. ${ }^{35}$ Para los que se instala-

\footnotetext{
${ }^{35} \mathrm{La}$ "consolidación" se refiere a la regularización del derecho a cultivar las tierras ocupadas antes de la implementación de la reforma agraria. A diferencia de Tolomosa, no se trata de un derecho de propiedad, inexistente en el contexto de la Comunidad Grande de Tarairi.
} 
ron durante los años ochenta, $50 \%$ de la tierra fue comprada y $35,7 \%$ se obtuvo a través de la distribución establecida por la reforma agraria. Finalmente, si llegaron a partir de 1990, notaremos una abrumadora mayoría de las tierras adquiridas $(77,8 \%)$. Por lo tanto, retenemos una evolución diacrónica que inicia por un periodo de regularización seguido por otro de distribución, estos dos modos de adquisición desaparecen gradualmente para dar paso a la compra, que se convierte en la única forma de acceder a la propiedad de las tierras agrícolas para los inmigrantes llegados durante los años noventa.

- Para las ocho familias agrícolas propietarias cuyos jefes son originarios de la comunidad, la herencia representa $75 \%$ de los modos de adquisición. La edad promedio de esos ocho jefes de familia es de 35 años [ver Tab. II-31], y sus parientes por lo general no son nacidos en Caigua (sólo dos tienen padre y madre nacidos en la comunidad), por lo que podemos suponer que se trata de familias instaladas por su cuenta en los años noventa, y que hubieran heredado de sus familias inmigrantes en Caigua antes de 1980 (lo que es aceptable vista la media de edad de esos jefes de familia: 63,5 años, ver Tab. II-31).

- La relación entre el tamaño de la explotación y el periodo de instalación de los jefes de hogar también es significativa. Hay una gran mayoría $(60 \%)$ de las familias agrícolas que llegaron antes de 1980 y que gestiona explotaciones de 5 ha o más. Esta proporción disminuye de manera significativa en los hogares cuyo jefe llegó entre 1980 y 1989 (41,2\%) y desciende drásticamente para aquellos instalados a partir de 1990 (5,3\%). Al mismo tiempo, observamos un aumento de la parte de las pequeñas explotaciones (4 ha o menos) que concierne a $40 \%$ de los hogares agrícolas cuyo jefe se instaló antes de 1980, 58,8\% para los que llegaron entre 1980 y 1989, y 84,2\%, a partir de 1990. Para los hogares agrícolas cuyo jefe es originario y que probablemente se instaló por su cuenta en los años noventa [ver supra], el tamaño de las explotaciones es similar al de los inmigrantes que llegaron a Caigua durante el mismo periodo, ya que $90 \%$ tiene explotaciones de 4 ha o menos. Por lo tanto, a sabiendas de que las parcelas asignadas por la reforma agraria fueron de 10 ha por familia, se puede concluir que desde entonces han sido divididas para su reventa y por la herencia.

Esta evolución pone de manifiesto la existencia de un límite interno para el desarrollo de la comunidad: la distribución o la legalización de los derechos 
para cultivar parcelas agrícolas, lo que sin duda corresponde al principal motor de crecimiento de Caigua, que ha dado paso a los modos de adquisición más convencionales: compra y herencia. En estas condiciones, los últimos llegados tienen dificultades para acceder a la condición de propietario y se ven afectados por la fragmentación de la tierra, justo como los jóvenes originarios que tienen explotaciones de tamaño inferior a aquellas de sus padres. En general, el potencial de crecimiento de Caigua a través de la redistribución de la tierra agrícola está en peligro además de afrontar un proceso de formación de minifundios. La combinación de estos dos factores podría ser la causa de una de las conclusiones del diagnóstico del municipio de Villamontes: la expansión de la frontera agrícola en el Piedemonte Norte está a punto de llegar a su límite máximo (Zonisig-APDS, 2000, p. 45) lo que ayuda a explicar la disminución de instalaciones registradas a partir del año 2000.

\section{Rumbo a una diversificación de las actividades}

La agricultura de Caigua sigue siendo la actividad principal de la comunidad, pero nos damos cuenta de la existencia de límites en su desarrollo actual. En estas circunstancias, es apropiado preguntarse sobre las estrategias utilizadas por sus habitantes.

La dependencia de los hogares frente a la actividad agrícola de Caigua no es uniforme [ver Fig. II-9-a]. Así, casi la mitad (47,8\%, ver Tab. II-32) de los hogares cuyo jefe se instaló entre 1990 y 2002 declara menos de una hectárea de tierra cultivada por trabajador agrícola, ${ }^{36} \mathrm{o}$ trabajadores agrícolas pero no tierra cultivada, mientras que esta proporción es significativamente menor para el resto de la población $(26,3 \%$ si el jefe se instaló entre 1980 y $1989 ; 14,3 \%$ si su llegada fue antes de 1980 y $23,1 \%$ si es originario). En contraste, sólo el 4,3\% de los hogares cuyo jefe se instaló entre 1990 y 2002 declara cultivos pero no trabajadores agrícolas; $21,1 \%$ para aquellos cuyo jefe llegó entre 1980 y 1989; de 21,4\% antes de 1980 y 30,8\% si es originario. La dependencia frente al sector agrícola parece, por lo tanto, mucho mayor para los hogares cuyo jefe se instaló recientemente en Caigua; por el contrario, los otros han sido claramente capaces de diversificar sus estrategias econó-

\footnotetext{
${ }^{36}$ Como en el caso de Tolomosa, se calculó la relación entre el número de personas del hogar que hayan declarado una actividad relacionada con la agricultura (no se tiene en cuenta a la minoría de los ganaderos) y la superficie total cultivada por la familia (resultado de la variable 6 del módulo 5 de la ficha de familia, ver < www.frontarbol.com> para el cuestionario completo).
} 
Fig. II-9: Envil 2002/Caigua - Dependencia de los hogares encuestados frente a la agricultura según el lugar de nacimiento y la fecha de instalación (para los no originarios) del jefe de hogar (continúa)

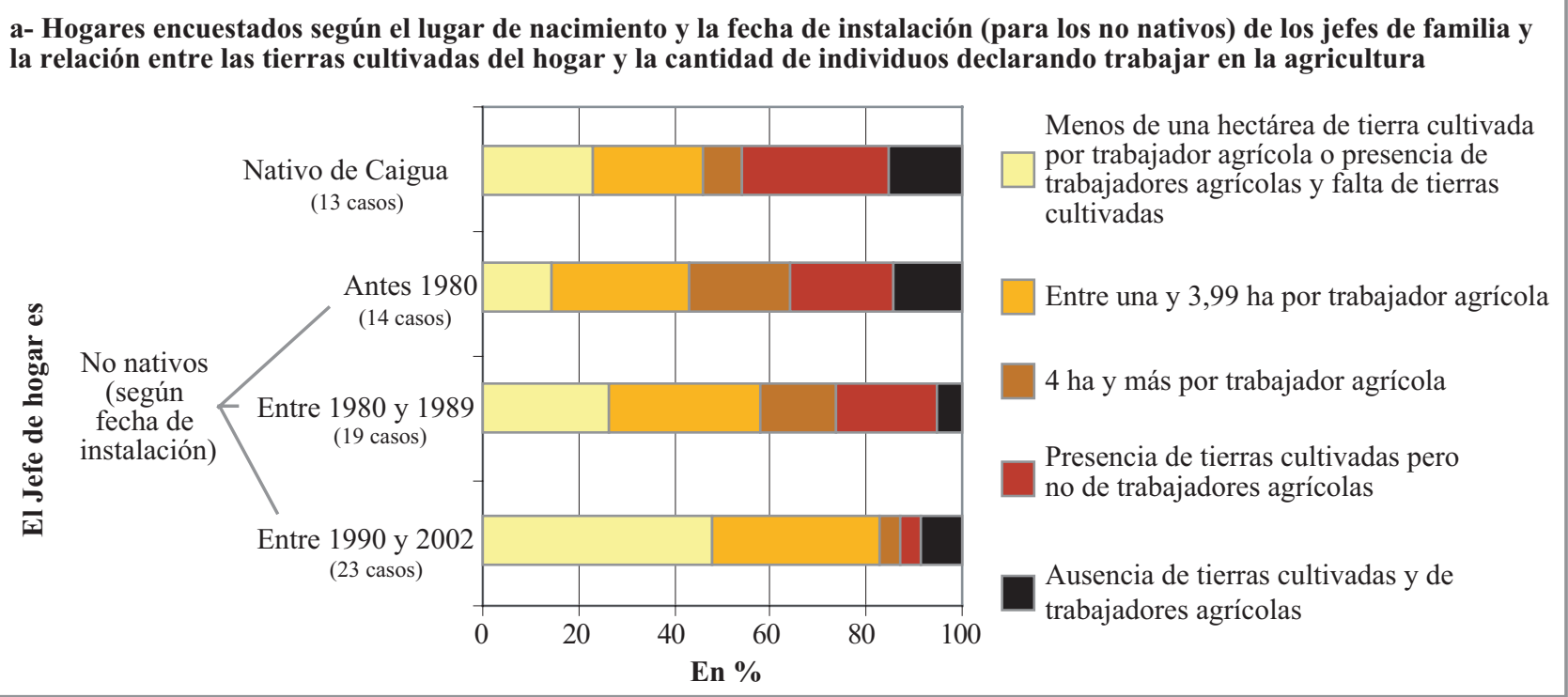


Fig. II-9: Envil 2002/Caigua - Dependencia de los hogares encuestados frente a la agricultura según el lugar de nacimiento y la fecha de instalación (para los no originarios) del jefe de hogar (finaliza)

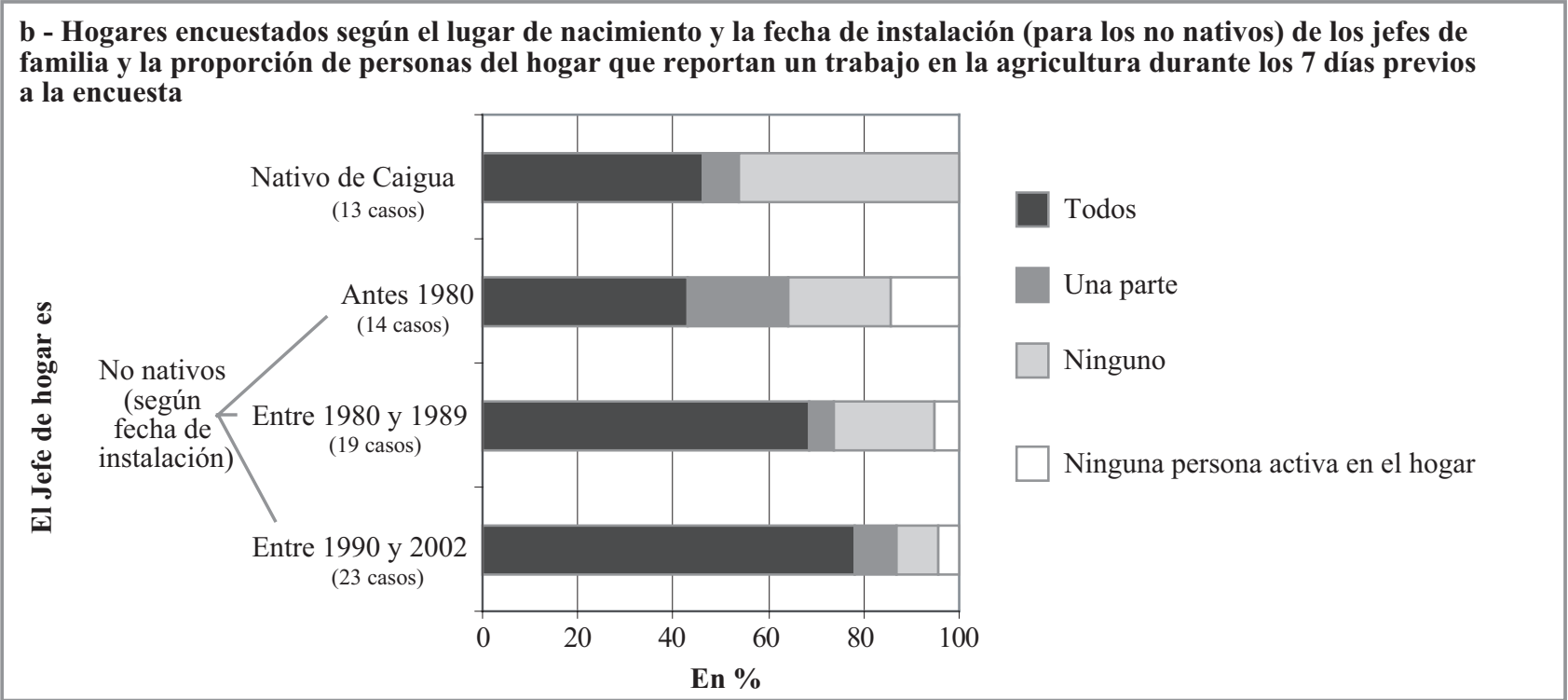

Fuente: Envil 2002. 
micas. Esta hipótesis se confirma por el estudio de la proporción de gente trabajando en el sector agrícola según las familias [ver Fig. II-9-b]: en casi el 80\% de las familias cuyo jefe se estableció entre 1990 y 2002 (78,3\%, ver Tab. II-33) los miembros que trabajan declaran una actividad agrícola durante los 7 días anteriores a la encuesta, mientras que esta proporción es menor para los hogares cuyo jefe se instaló entre 1980 y 1989 (68,4\%) e incluso mucho menor para quienes llegaron antes de 1980 (42,9\%) o que son originarios de la comunidad $(46,2 \%)$. La diversidad de las ocupaciones laborales en este último caso se ve ampliamente reflejada por el hecho de que el $46,2 \%$ de estos hogares declaran integrantes activos sin que ninguno de ellos se relacione con el sector agrícola [ver Tab. II-33].

La actividad de los miembros de la comunidad sigue estando, en gran parte, dirigida hacia la agricultura, pero notamos una creciente relación entre la edad de implantación en Caigua y la pluriactividad de los hogares. Una vez más, las familias instaladas entre 1990 y 2002, que sufren de un acceso difícil a las tierras agrícolas, son paradójicamente las que dependen más de ello.

¿De qué manera se traduce esta pluriactividad de los hogares? Al menos una persona trabaja en un sector diferente al de la agricultura en casi un tercio de las familias encuestadas (31,9\%, ver Tab. II-33). El bajo número de esta subpoblación (23 casos) nos impide desagregar este resultado según el lugar de nacimiento o la fecha de instalación de los jefes de hogar; calificaremos entonces las actividades secundarias privilegiando un enfoque individual [ver Tab. II-13]. Del grupo de personas de 15 años y más que trabajaron durante los últimos siete días al momento de la encuesta, $69,2 \%$ lo hizo en la agricultura y $1,9 \%$ en la ganadería, $6,7 \%$ en la construcción (albañiles), ${ }^{37} 4,8 \%$ en el comercio (de proximidad), $2,9 \%$ en el transporte (taxis) y $12,5 \%$ en otras ramas del sector servicios (educación, cuidado de niños, ama de casa). El sector terciario concentra la mayoría de las actividades no agrícolas declaradas por los habitantes de Caigua.

La repartición de los hogares que declaran otra(s) fuente(s) de ingreso ${ }^{38}$ corrobora la diversificación de las actividades. De hecho, 38,5\% de los hoga-

\footnotetext{
${ }^{37}$ Aquí se especifican los principales empleos censados dentro de las actividades detalladas, variable específica que permite obtener el trabajo en su totalidad durante la encuesta Envil 2002.

${ }^{38}$ Una de las originalidades del cuestionario Envil 2002 es un módulo que se refiere a las otras actividades del hogar [ir a www.frontarbol.com para ver el cuestionario completo]. El objetivo era capturar los ingresos adicionales recibidos por los hogares encuestados a través
} 
res con jefes nativos de Caigua declara por lo menos otra fuente de ingreso (dueño de una tienda almacén o empresa, alquiler o trabajo secundario), proporción que es de 31,6\% si el jefe llegó entre 1980 y 1989, y sólo de 13\% si llegó entre 1990 y 2002 [cf. Tab. II-34].39

\section{$* * *$}

Es interesante observar la evolución de Caigua. La ganadería, actividad tradicionalmente llevada a cabo en la región, hoy en día ocupa un papel secundario, ya que la comunidad se ha redirigido principalmente hacia las prácticas agrícolas. Esta mutación, estrechamente vinculada al poblamiento de la localidad, ha generado un modelo basado en el policultivo que se caracteriza por la introducción de cultivos alimentarios (maíz, yuca, papa, en función al origen de los inmigrantes) y la superposición de los cultivos comerciales (fruticultura y horticultura, posibles gracias al desarrollo del riego y al mejoramiento de las vías de comunicación). Se puede suponer que estos cultivos comerciales han sustituido a aquellos que han alimentado la refinería de Villamontes, cuya actividad ha cesado a principios de los años noventa y que recién ha reabierto parcialmente en 2008.

$\mathrm{Al}$ inicio de este capítulo habíamos notado ya ciertas limitaciones que enfrenta el sector agrícola de Caigua, particularmente en lo que respecta a la competencia de los cultivos industriales argentinos, cuyas importaciones se ven favorecidas por la política liberal de Bolivia. El análisis de la tenencia de la tierra agrícola de la comunidad reveló la existencia de una evolución negativa adicional. De hecho, la atracción de Caigua resultaba directamente de la existencia de tierras vírgenes al origen de la asignación de 10 hectáreas cultivables a cada familia que deseara establecerse en la región; pero las dimensiones de las super-

de negocios diversos, el alquiler, el trabajo secundario, el retiro o de otra manera. Como parte de este análisis, se mantendrán sólo los tres primeros casos, las pensiones están estrechamente vinculadas a la edad de los miembros del hogar y no corresponden a una actividad en sí misma y los otros ingresos se limitan a las transferencias de dinero realizadas por personas que ya no viven en la comunidad, punto que será discutido más adelante en este capítulo. La debilidad de la subpoblación que declara una de estas tres actividades secundarias (17 familias de 72) nos anima a tratar estas variables en su conjunto a través de un índice de otra fuente de ingreso binario (presencia o ausencia) que corresponde a las variables 1, 4 y 7 del módulo 6.

${ }^{39}$ Notaremos que ningún hogar en el cual el jefe no es nativo de Caigua y que se instala antes de 1980 no declara otras fuentes de ingresos, hecho sin duda imputable a la avanzada edad de los jefes de hogar (63,5 años en promedio, mínimo 42 y máximo 86) y por lo tanto tienen una menor actividad. 
ficies utilizadas ha disminuido considerablemente desde entonces. Así las explotaciones actuales son de tipo minifundio, resultado de modos de adquisición de la tierra clásicos (compra, herencia) que contribuyeron a una división de las parcelas distribuidas durante la reforma agraria. Estos dos obstáculos principales (baja competitividad, subdivisión de la tierra) recuerdan nuestro diagnóstico de la agricultura de Tolomosa. ¿Qué impacto han tenido en la comunidad? En primer lugar, retendremos la diversificación de actividades, especialmente por los hogares previamente implantados, los menos dependientes frente a la agricultura local. En segundo lugar, la crisis también podría justificar la disminución observada de las instalaciones a partir del año 2000. Finalmente, podemos cuestionar en qué medida estos cambios han impactado en la emigración de los habitantes de la comunidad, pregunta que ahora nos disponemos a abordar.

\section{SuRgimiento DE UNA EMIGRACIÓN HACIA LAS CIUDADES}

A partir de nuestro estudio sobre la inmigración hacia Caigua, ya se ha mencionado la probable existencia de una emigración a partir de la comunidad, ahora intentaremos determinar la forma actual que toma la redistribución de la población. De hecho (como se informa en la sección II), la población de Caigua se compone claramente por inmigrantes que vinieron a trabajar en la agricultura y algunos de ellos, hoy en día, se enfrentan a los límites del sistema agrario de la comunidad. Los últimos llegados tienen dificultades para integrarse, además su descendencia no cuenta con las condiciones favorables que anteriormente encontraron sus padres. Frente a este nuevo contexto, ¿qué estrategias han desarrollado los habitantes de la localidad? Una parte de las familias ha diversificado sus actividades dedicándose a los servicios de proximidad. Sin embargo, esta tendencia se ve limitada por la naturaleza de Caigua, que sólo es una comunidad pequeña y rural. Por lo tanto, podemos preguntarnos sobre la existencia de otras estrategias, tales como la emigración. Nuestro análisis del valle de Tolomosa destacó la importancia de este tipo de comportamiento: las personas originarias del valle que parte hacia Argentina para las actividades laborales relacionadas con la agricultura. ¿Observamos la misma tendencia en Caigua?

Empezaremos por estudiar por separado las migraciones anteriores (con salida y posterior regreso a la comunidad) y las migraciones actuales (en curso) mediante la medición de su importancia y describiendo la naturaleza de estos desplazamientos (A). En una segunda fase, nos centraremos en los lu- 
gares afectados por estas emigraciones, con el fin de identificar los polos de atracción que rigen la eventual redistribución de la población de Caigua (B).

\section{UNA SEDENTARIZACIÓN EN LAS INTENCIONES ${ }^{40}$}

A pesar de las dificultades propias del sector primario de Caigua, los jefes de hogar encuestados no expresan la intención de abandonar la comunidad, la mayoría piensa permanecer (88,9\%, ver Tab. II-35), aunque esta proporción es ligeramente inferior para aquellos que se instalaron entre 1990 y 2002 (73,9\%). Además, $83,3 \%$ de estos mismos jefes de familia no prevén tampoco la partida de su descendencia, proporción que es menor en los originarios o los instalados después de 1990 (respectivamente 76,9\% y 78,3\%), fuertemente afectados por la fragmentación de las tierras [ver Tab. II-35]. Para comprender mejor esta renuencia a desplazarse, podemos señalar algunos elementos contextuales de julio de 2002, cuando se llevó a cabo la encuesta. $\mathrm{Al}$ norte de Caigua, la inactividad predomina en la región de Camiri desde los últimos diez años. Hacia el sur, después de haber vivido un periodo de fuerte crecimiento, la ciudad de Yacuiba ha sido gravemente afectada por la crisis argentina, y las localidades rurales de la parte meridional del Piedemonte son escenario de violentos conflictos entre propietarios y aquellos sin tierra. ${ }^{41}$ Además, las dificultades encontradas en el país vecino, especialmente a partir de diciembre de 2001, han reducido considerablemente su poder de atracción. Por último, en vísperas de las elecciones más importantes al momento de la encuesta (sufragios presidenciales en agosto de 2002), los bolivianos se encuentran desilusionados por ver siempre las mismas candidaturas. En estas condiciones el optimismo necesario para la emigración no está presente y las perspectivas de integración en la región se reducen. Debemos preguntarnos ahora cómo estas intenciones de no emigrar se materializan en la práctica.

\footnotetext{
${ }^{40}$ Antes de analizar en detalle los movimientos de población desde Caigua, observaremos las intenciones de emigrar por parte de los habitantes de la comunidad. Esto es posible gracias a un módulo de la ficha hogar de Envil 2002, en particular a las variables 3: "¿Piensa usted partir?” y “¿piensa que por sus hijos es mejor... quedarse?, ¿'salir?”. Estas preguntas están dirigidas a los jefes de hogar.

${ }^{41}$ Señalaremos aquí la muy publicitada "masacre de Pananti" en noviembre de 2001. Situada cerca de Caiza "J" en el Piedemonte Sur, esta comunidad ha sido el escenario de un violento conflicto entre propietarios de tierras y los sin tierra, con saldo de siete muertos y 22 heridos del lado de estos últimos.
} 


\section{A. ¿PARTIDAS SUSCITADAS POR LA CRISIS?}

¿En qué medida Caigua, comunidad de inmigración reciente, redistribuye su población? Abordaremos el tema de la emigración mediante el estudio, en primer lugar, de los desplazamientos, seguido de un retorno a la localidad para luego centrarse en aquellos en curso, a partir del análisis de la descendencia, lo que proporcionará información sobre la capacidad de la comunidad para retener a las generaciones más jóvenes.

\section{Migraciones anteriores: desplazamientos laborales de corta duración}

El módulo "migración” de la encuesta Envil 2002 identificó 109 eventos realizados por los habitantes de Caigua: 49 hechos por los no nativos antes de su instalación en la comunidad (algunos de ellos están incluidos en los lugares de proveniencia, procesados en la primera sección de este mismo capítulo), 32 por no nativos después de su primera instalación y 28 por originarios de la localidad. Estas últimas dos categorías —un total de 60 eventos migratorios que conciernen a 55 personas - serán estudiados ahora como una ilustración de los desplazamientos desde Caigua que hayan implicado un retorno hacia la comunidad. A estos eventos los llamaremos "migraciones anteriores".

En primer lugar, nos preguntaremos sobre la existencia de estrategias migratorias estacionales, las cuales eran importantes para Tolomosa. De acuerdo con la información obtenida en campo, no observamos este tipo de movimientos en Caigua, y los datos de Envil 2002 parecen confirmar esta tendencia. De hecho, sólo nueve individuos declaran migraciones laborales anteriores (desde la comunidad para trabajar o buscar trabajo) cuyos años de partida y de regreso coinciden, ${ }^{42}$ y ninguno de ellos ha realizado más de un desplazamiento de este tipo. La debilidad de la subpoblación involucrada en lo que podría ser la migración estacional laboral y no repetición de los eventos migratorios nos anima a concluir la ausencia de tales estrategias. Atribuiremos parcialmente esta diferencia con Tolomosa a las condiciones climáticas del Piedemonte: a pesar de las pocas lluvias de invierno, la combinación de la humedad en esta temporada con el riego anual proveniente del Aguaragüe permite ocupar la mano de obra agrícola durante todo el año. Otro factor a

\footnotetext{
${ }^{42}$ Como recordatorio, se trataba de uno de los criterios de las migraciones anteriores: si el año de partida y de regreso eran el mismo, significaba que el desplazamiento forzosamente había tenido lugar durante el periodo de invierno.
} 
considerar: la migración estacional hacia Tolomosa se debe principalmente a desplazamientos para trabajar en la agricultura de Argentina, movimientos favorecidos por la antigüedad y la importancia de los vínculos entre los habitantes del valle y del país vecino. En el caso de Caigua, ¿remarcamos este tipo de relaciones? ¿Establecemos a la comunidad dentro del trabajo en el sector primario? Nuestro análisis de la redistribución de la población de Caigua nos permitirá aclarar estos puntos.

La importancia de la migración anterior es significativa en Caigua ya que más de un cuarto de la subpoblación de 15 años y más declara al menos un evento $(27,4 \%$, ver Tab. II-36) y en casi la mitad de los hogares $(48,6 \%)$ al menos una persona ha realizado uno o más [ver Tab. II-37]. Volviendo ahora a estos movimientos migratorios, precisamos que el bajo número de personas estudiadas excluye cualquier análisis detallado.

Como se muestra en la Figura II-10, las migraciones anteriores son realizadas por una población joven (al principio del desplazamiento las personas están por debajo de la edad de 15 años en 23,3\% de los casos, entre 15 y 24 años $48,3 \%$, ver Tab. II-38), compuesta - casi a partes iguales- por hombres y mujeres (respectivamente 32 y 28 de 60 migraciones anteriores). Regularmente se trata de desplazamientos cortos, ya que de los 60 eventos migratorios 25\% (15 casos) duró menos de un año; 21,7\% (13 casos) entre uno y dos años; la misma proporción entre dos y tres años; $23,3 \%$ (14 casos) entre tres y cinco años y sólo 8,3\% (cinco casos) más de seis años. Para una gran mayoría (61,7\%) un motivo laboral está detrás de la migración: $55 \%$ de los eventos tienen por objetivo el ejercicio de un trabajo, $1,7 \%$ una combinación de estudio y trabajo, y $5 \%$ la búsqueda de empleo [ver Tab. II-39]. Segundo motivo invocado es la búsqueda de un currículo educativo $(21,7 \%$ del cual $20.0 \%$ para estudiar, $1,7 \%$ para estudiar y trabajar). Finalmente, apenas $6,7 \%$ de las migraciones anteriores están relacionadas con el acompañamiento de la familia, y $11,7 \%$ se explica por otros motivos. Las migraciones anteriores son en gran medida los desplazamientos laborales, independientemente del género (las motivaciones de las mujeres son sustancialmente idénticas a las de los hombres, ver Tab. II-39), por una población joven, desplazándose individualmente ${ }^{43}$ para trabajar y estudiar. Se analizan brevemente estas migraciones anteriores cuando se deban a razones laborales o estudiantiles.

\footnotetext{
${ }^{43}$ No disponemos del estado civil de los migrantes al momento del inicio de su migración, pero su edad y su motivación nos permite suponer que se trata de desplazamientos de solteros.
} 
Fig. II-10: Caigua/Envil 2002 - Migraciones anteriores según la edad de la persona declarada, el inicio del evento, el género y la razón principal del desplazamiento

Edad

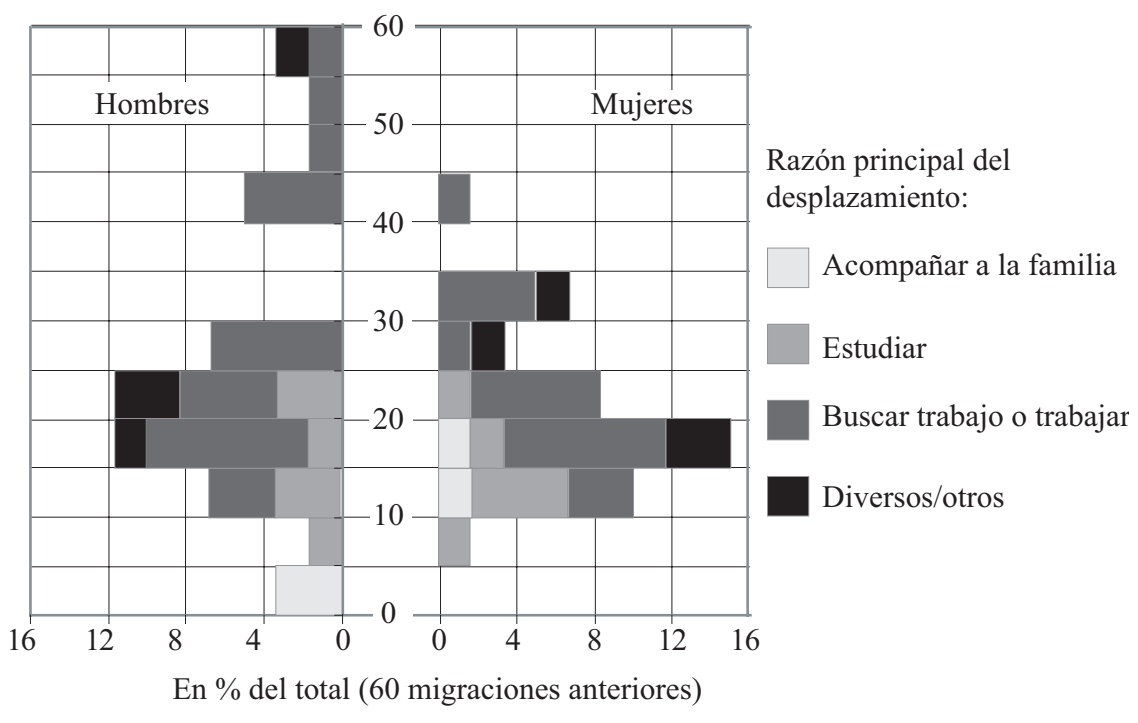

Fuente: Envil 2002.

Las migraciones anteriores laborales (para ejercer un empleo o buscar alguno) son esencialmente realizadas hacia las localidades urbanas $(81,1 \%$ del total de 37 casos, ver Tab. II-42). La naturaleza de los empleos ejercidos depende en gran medida del sexo de quien emigra [ver Fig. II-11 y Tab. II40]. Por un lado, de las 18 migraciones laborales masculinas, $38,9 \%$ concierne a la agricultura o la ganadería, $11,1 \%$ a la construcción, $11,1 \%$ al comercio y $33,3 \%$ a otros servicios. Por otro lado, de las 16 migraciones anteriores laborales llevadas a cabo por mujeres, sólo un caso se relaciona con el sector primario, el resto se engloba en el sector terciario: $50 \%$ al servicio doméstico, $12,5 \%$ al empleo comercial y $31,3 \%$ a otros servicios. La diversidad de categorías de empleo declarada por el total de estos migrantes es amplia: incluso si la condición de empleado mensual domina ( $41,2 \%$ de estos desplazamientos) notamos $23,5 \%$ de trabajadores domésticos y $11,8 \%$ de jornaleros [ver Tab. II-41], dos categorías sugieren una cierta precariedad, lo que en parte puede 
Fig. II-11: Envil 2002/Caigua - Migraciones anteriores que hayan implicado el ejercicio de un empleo según el sexo y el sector de la actividad declarados
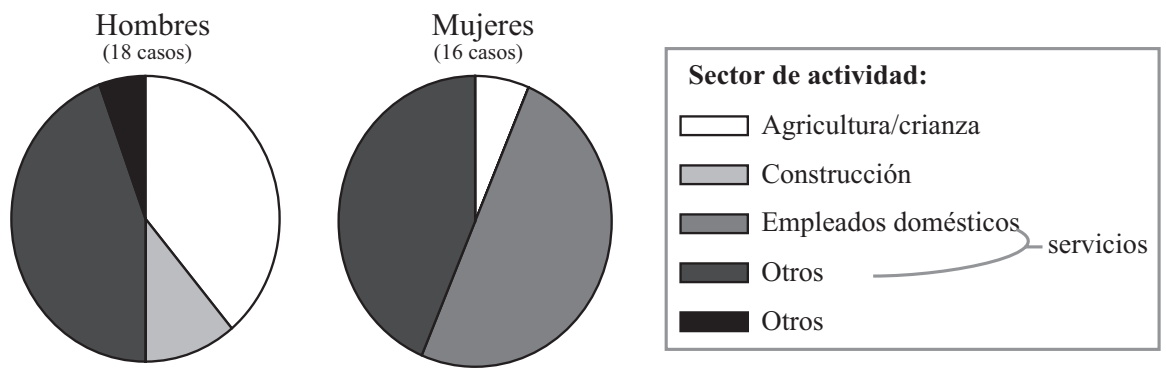

Fuente: Envil 2002.

explicar el fracaso de estos desplazamientos y la reinstalación en Caigua. ¿Es posible asimilar estas migraciones anteriores laborales a las intenciones de diversificación de la actividad tras la crisis descrita anteriormente? Como se puede observar en la figura II-12, ${ }^{44}$ la importancia de estas migraciones va en aumento con el tiempo, lo que acreditaría esta hipótesis: $:^{45}$ 13,5\% (5 casos) de 37 migraciones anteriores laborales comenzaron antes de 1980, 21,6\% (8 casos) entre 1980 y 1989, y la gran mayoría, 64,9\% (24 casos) entre 1990 y 2001, en el apogeo de la crisis en el sector inmobiliario.

El segundo grupo de migraciones anteriores (a causa de la búsqueda de trayectoria educativa) se realiza principalmente también hacia los destinos urbanos (84,6\% del total de los 13 eventos estudiados, ver Tab. II-43). ¿A qué nivel de estudio corresponden las migraciones? De 13 desplazamientos, ocho conciernen a secundaria y cinco a un nivel de educación superior. Dado que Caigua no ofrece ninguna formación más allá de la primaria, este movimiento migratorio se puede explicar simplemente por el deseo de una minoría de continuar sus estudios.

Las migraciones anteriores desde Caigua son principalmente desplazamientos de jóvenes que buscan oportunidades laborales que son difíciles de encon-

\footnotetext{
${ }^{44}$ Para facilitar la legibilidad, hemos representado sólo las partidas desde 1970, omitiendo voluntariamente un evento migratorio que comenzó en 1956.

${ }^{45}$ Sin embargo, se debe suponer que este aumento depende igualmente del crecimiento demográfico de la comunidad.
} 
Fig. II-12: Envil 2002/Caigua - Migraciones laborales anteriores (para trabajar, estudiar y trabajar o buscar un trabajo) iniciadas después de $1970^{46}$ según la fecha de inicio del evento migratorio

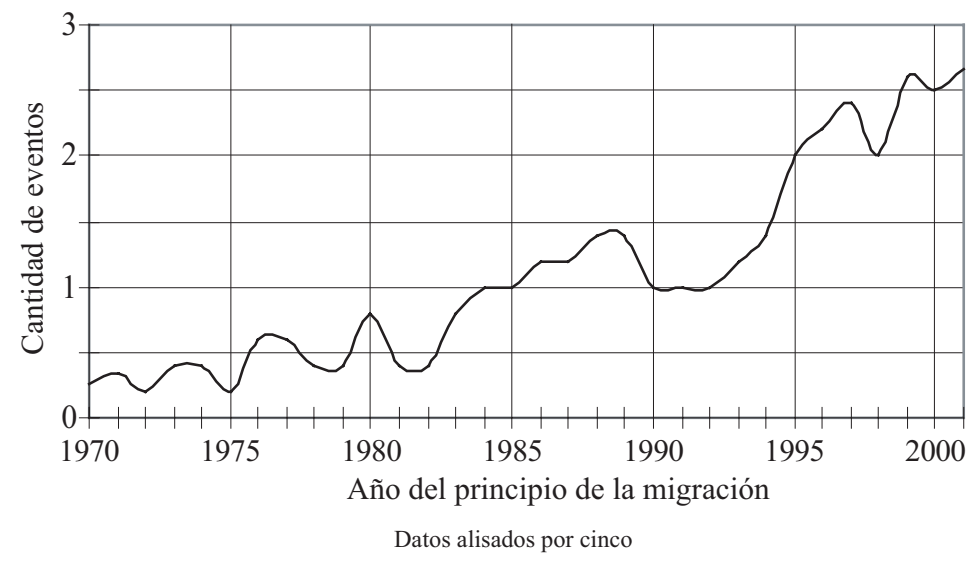

Fuente: Envil 2002.

trar en la comunidad. Su importancia es cada vez mayor, lo que anima a interpretarlos como la búsqueda de actividades de sustitución frente a la reciente crisis de la tenencia de la tierra agrícola local. Además, hemos señalado la existencia de un pequeño movimiento de personas que desean continuar sus estudios. El total de estos desplazamientos se realizan, por lo general, hacia las ciudades.

\section{La descendencia: retención o instalación fuera de la comunidad}

Al igual que en el procesamiento de la encuesta Entol 2002, el estudio de la descendencia pasa a través de la fusión de datos sobre los hijos del jefe de familia que siguen viviendo en el hogar (módulo "miembro de la familia") o que lo hayan dejado (módulo "otros hijos del hogar"). Esto permite tener una visión general de la descendencia real o asimilada (es la encuesta la que determina la relación de parentesco, así que los hijos del primer matrimonio de la esposa del jefe de familia, pueden ser considerados en este estudio). La subpoblación resultante de esta fusión es de 278 individuos de los cuales 266 viven en la comunidad o han residido en un momento u otro en Caigua. ${ }^{47}$

\footnotetext{
${ }^{46}$ No obstante, principalmente en la agricultura, la ganadería representa sólo un caso de siete. ${ }^{47}$ En la continuidad de nuestros análisis anteriores, queremos centrarnos en el comportamiento de los hijos que viven o han vivido en Caigua. Para lograrlo, excluiremos de nuestro
} 
De los 266 hijos que componen la descendencia de Caigua, 69,2\% sigue viviendo en el hogar, $11,3 \%$ vive fuera de la casa pero en la comunidad y $19,5 \%$ en otra localidad [ver Tab. II-44]. Un estudio por lugar de residencia según la edad de los habitantes muestra que casi todos los hijos menores de 15 años viven en el hogar de sus padres, ${ }^{48}$ permanece en el hogar $78,4 \%$ del grupo de 15-19 años, el porcentaje disminuye a 57,6\% para los hijos de 20 a 24 años, proporción que cae a 16,7\% para los de 25-29 años y es mínima a partir de los 30 años [ver Fig. II-13 y Tab. II-44]. Otro elemento de análisis: la proporción de hijos que deja la casa de la familia y permanecen en la comunidad, esta es cercana a 50\% para el rango de edad de $25-29$ años $(45,8 \%)$ y es de 47,6\% para el grupo de 30-39 años pero nunca es mayoría; en cambio, el porcentaje de quienes abandonan la comunidad está en constante crecimiento y representa más de la mitad para el grupo de 30-39 años $(52,4 \%$ y más de dos terceras partes (80\%) para los de 40 años y más.

Si los hijos que viven en el hogar familiar hasta los 24 años son mayoría, casi siempre lo dejan después, y sólo un poco menos de la mitad de estos jóvenes adultos permanece en Caigua, la mayoría opta por la emigración. Se trata entonces de un importante movimiento migratorio desde la comunidad ya que cerca de un tercio $(29,2 \%$, esto es 21 de 72$)$ de los hogares encuestados declara por lo menos un hijo que haya emigrado. Es esta subpoblación, compuesta por 52 descendientes que salieron de Caigua, la que nos permitirá analizar la migración actual desde la localidad.

¿Cuál es la ocupación de la descendencia que ha dejado la comunidad? [Ver Fig. II-14-a]. La mayoría de los hombres trabaja (72\%), una minoría estudia (12\%); en el caso de las mujeres casi la mitad (44,4\%) declara un empleo, misma proporción es ama de casa y el porcentaje restante $(11,1 \%)$

análisis a las personas que posiblemente nunca vivieron en la comunidad. Nos limitaremos a las subpoblaciones siguientes:

- Aquellos que viven actualmente en Caigua, 214 casos.

- Aquellos que no residen actualmente ahí pero que son originarios de la comunidad, o cuyo padre lo es, o cuya edad estimada de instalación en la localidad es inferior a 15 años (la edad de instalación se deduce de la edad del hijo al momento de la encuesta y del año de la primera instalación del jefe del hogar al cual pertenece), 52 casos en total (una vez más el tamaño de la subpoblación nos limita en la aplicación de filtros adicionales sobre la inclusión del cónyuge, por ejemplo, o de las experiencias migratorias de los padres).

${ }^{48}$ No comentaremos aquí la escasa representación de las niñas de cero a cuatro años ni aquella de los hijos de cinco a nueve años, anomalía estadística probablemente debida a su bajo número. 
Fig. II-13: Envil 2002/Caigua - Pirámide de edad de la descendencia según el lugar de residencia

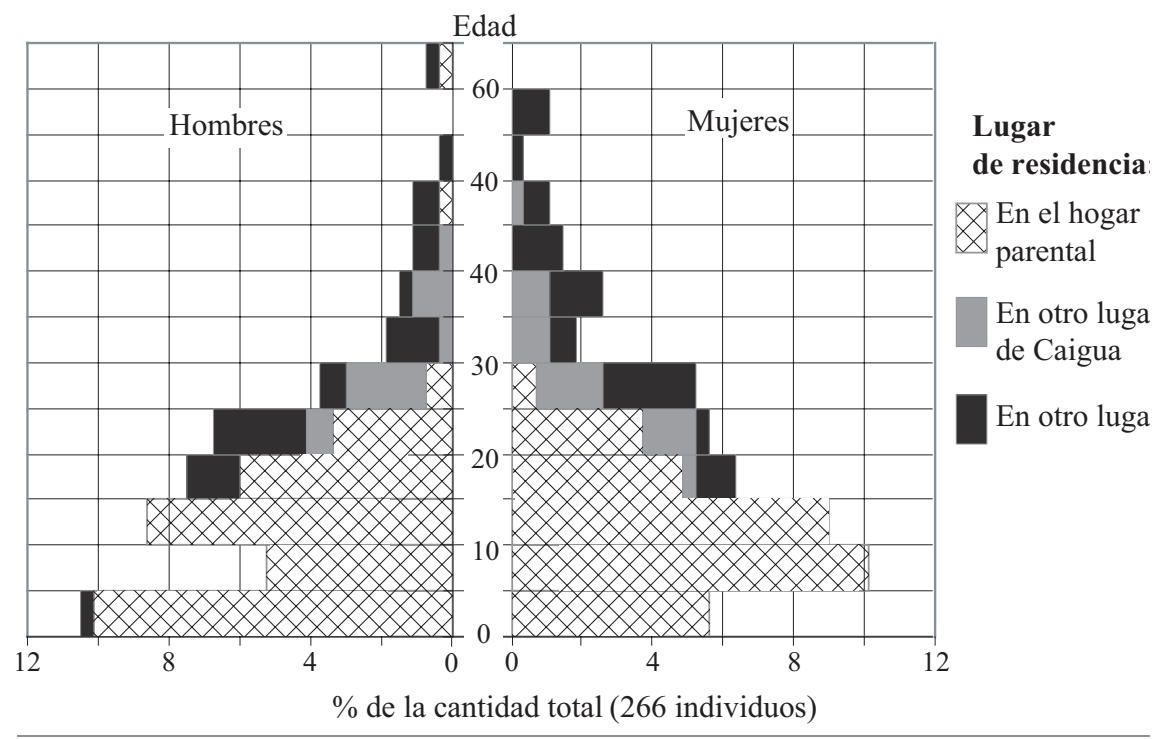

Fuente: Envil 2002.

continúa sus estudios [ver Tab. II-45]. Desde otra perspectiva, es ilustrativo comparar la proporción de la descendencia femenina activa emigrada con aquella de las hijas que se mantienen en Caigua pero que ya no viven más en el domicilio parental: de los 17 casos que conforman esta subpoblación, sólo 11,8\% (2 casos) declara un empleo en lugar de 44,4\% anterior. Es claro que la inserción laboral de las mujeres es mejor cuando salen de la comunidad, ${ }^{49}$ aun si una parte significativa de ellas se declara ama de casa $(44,4 \%)$, lo que puede ser interpretado como una sedentarización de esta población emigrada. Esta sedentarización podría ser confirmada por el hecho de que más de la mitad de hijos que partieron de Caigua vive en pareja (59,6\%, 31 de 52 casos).

Los hijos que han dejado la comunidad y tienen empleo viven principalmente en las localidades urbanas (80\% de 30 observaciones, ver Tab. II-48). $50 \%$ de esta descendencia masculina trabaja en los servicios [ver Fig. II-14-b]

\footnotetext{
${ }^{49}$ Sin embargo, se debe relativizar esta conclusión. De hecho, la mayor parte de la descendencia femenina que se queda en Caigua, se declara ama de casa (15 de 17 casos o el 88,2\%), pero podemos suponer que participan cuando es necesario en los trabajos agrícolas del hogar.
} 
Fig. II-14: Envil 2002/Caigua-Descendientes que dejaron la comunidad según el sexo, la ocupación principal y el sector de actividad

a) Ocupación principal de la descendencia

b) Sector de actividad (para los que trabajan) que salió de la comunidad de Caigua

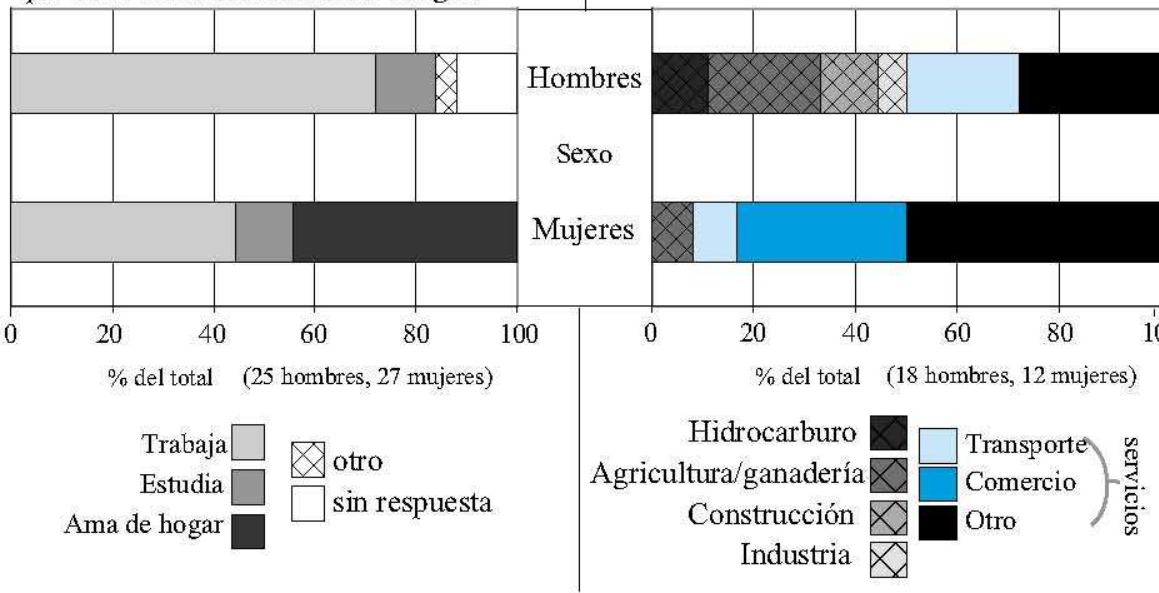

Fuente: Envil 2002.

especialmente en el transporte $(22,2 \%)$; casi una cuarta parte $(22,2 \%)$ lo hace en la agricultura y la ganadería; el resto labora en los hidrocarburos $(11,1 \%)$, en la construcción $(11,1 \%)$ y en la industria $(5,6 \%)$ [Ver Tab. II-46]. En el caso de las mujeres, el sector terciario ocupa la mayor parte $(91,6 \%)$ de las profesiones declaradas; de esa mayoría un tercio $(33,3 \%)$ desarrolla actividades comerciales, casi una décima parte $(8,3 \%)$ trabaja en el transporte y la mitad restante $(50,0 \%)$ se dedica a otros servicios (secretarias, enfermeras y costureras). Todos estos empleos sugieren una buena integración en su lugar de vida ya que $50 \%$ es trabajador por cuenta propia y $43,3 \%$ asalariado [ver Tab. II-47].

Por otra parte, dos tercios $(66,7 \%)^{50}$ de la migración de estudiantes se dirige a alguna ciudad, como era de esperarse, y el otro tercio $(33,3 \%)$ a una localidad rural [ver Tab. II-48]. La edad de estas personas (entre 16 y 20 años) nos lleva a referirnos al movimiento de las migraciones anteriores motivadas

${ }^{50}$ Esto representa el total de los seis casos implicados. Por lo tanto la debilidad de esta subpoblación debe ser manejada con precaución. 
por el deseo de cursar un programa de estudios que no está disponible en Caigua.

Estos comportamientos específicos de la descendencia podrían ser indicativos de un cambio por parte de los habitantes de la comunidad del mundo rural hacia el urbano. En efecto, a partir de que ellos ya no viven con sus padres, la mayoría de los hijos dejan Caigua, sobre todo para moverse rumbo a la ciudad. Son muchos los que trabajan - sobre todo en el sector terciario-y una minoría continúa estudiando. ¿Podemos atribuir estas salidas a la crisis del sector agrario local? No hay duda de que es una manera de limitar la presión antrópica sobre la tenencia de la tierra de la comunidad, pero la baja proporción de hijos que envían dinero a su familia de origen reduce ciertamente el impacto financiero sobre Caigua: sólo 13,5\% (7 casos de 52) lo hace con regularidad, la misma proporción lo hace ocasionalmente.

\section{¿Retornos condicionados por la situación económica de los hogares?}

Hemos identificado dos tipos de migración desde Caigua: 1) las anteriores, representativas de las idas y venidas de los jóvenes entre la comunidad y la ciudad, y 2) las que están en curso, o definitivas, que confirman un movimiento del Piedemonte rural del departamento de Tarija hacia las localidades urbanas. Es difícil afirmar la existencia de una relación entre las dificultades del sector agrario de la comunidad con estas estrategias migratorias. ${ }^{51}$ Nos limitaremos a recordar el aumento de las migraciones anteriores cuando aparecieron los límites en cuanto a la disponibilidad de la tierra en Caigua (años 90) y la existencia de una proporción mayoritaria de hijos que salen de la comunidad después de abandonar el hogar familiar. Estos dos puntos nos permiten suponer que la emigración contribuye a reducir la presión antrópica sobre una localidad donde las nuevas generaciones y los inmigrantes recientes tienen dificultades para integrarse. Sin embargo, la correlación entre

\footnotetext{
${ }^{51}$ La comparación de los desplazamientos desde Caigua y la situación de los hogares en relación con las dificultades de la comunidad sería sesgada. De hecho, las más afectadas son las familias cuyo jefe es joven o se ha instalado recientemente. Por lo tanto, el enfoque comparativo habría requerido la aplicación de filtros (por ejemplo, los hogares cuyo jefe es de 30 años o menos, o los desplazamientos efectuados a partir de 1995), lo cual fue imposible por el bajo número de nuestra muestra.
} 
el tipo de emigración detectada y el nivel de equipamiento ${ }^{52}$ del hogar parece reveladora [ver Fig. II-15]: las familias mejor equipadas son también las que más declaran al menos una migración anterior (60,0\%, ver Tab. II-49), mientras que en cuanto más bajo es el equipamiento del hogar, menos numerosas son las salidas (50\% y 25\%). En contraste, es con los menos afortunados que encontramos la mayoría de hogares que declararan al menos un hijo que haya salido de la comunidad ( $50 \%$, ver Tab. II-50), y las proporciones se invierten con el aumento de la riqueza de los hogares (30\% y 25\%). Podría suponerse, con estas cifras, que los hogares más ricos son los más afectados por las migraciones puntuales y además que tienen la capacidad de reintegrar a sus miembros. Por el contrario, los hijos de las familias más pobres están optando por migraciones probablemente permanentes, estrategia que puede estar relacionada con la dificultad de inserción local.

Ya sea que se trate de migraciones anteriores y provisionales o de migraciones actuales en parte definitivas, son generalmente efectuadas hacia las ciudades. Es el momento adecuado para estudiar a detalle los destinos de estos emigrantes.

\section{B. REDISTRIBUCIÓN HACIA LAS CIUDADES \\ DEL SURESTE BOLIVIANO}

¿Cuáles son los polos de atracción que controlan la redistribución de la población en Caigua? Hemos señalado la importancia de la migración laboral respecto al sector terciario, contrastante con la de los Valles Andinos, pero no hemos estudiado la atracción ejercida por Argentina sobre Caigua. Es así que surgen diversas preguntas: ¿este atractivo del país vecino, es tan fuerte como sucede en el caso de Tolomosa? ¿La proximidad de la ciudad de Tarija, en alto crecimiento desde 1950 (d'Andréa \& Martin, 2007), tiene un impacto sobre

\footnotetext{
${ }^{52}$ Para contar con una herramienta de diferenciación de los hogares encuestados de acuerdo con su situación económica, hemos desarrollado un índice aplicable a todas las encuestas bolivianas del programa Frontarbol, utilizando variables sobre el equipamiento de los hogares. Se trata entonces de un índice simple que ha demostrado ser discriminador, suficiente en el marco de este estudio. Para el total de nuestras encuestas, las variables disponibles son la posesión de un refrigerador, un teléfono, un televisor, una bicicleta, una motocicleta y un automóvil. Sólo un trabajo minucioso hubiera permitido una ponderación de estos diferentes equipos, así que optamos por un cálculo del índice correspondiente a la suma de las variables booleanas (cifradas según la presencia - 1 punto — o la ausencia — 0 puntos — del equipamiento en el hogar). Ver Martin, 2010 para obtener más detalles sobre este punto.
} 
Fig. II-15: Envil 2002/Caigua - Hogares encuestados por el nivel de equipamiento y la presencia o ausencia de al menos una migración anterior o actual (hijos que dejaron la comunidad)

El hogar declara que al menos ...

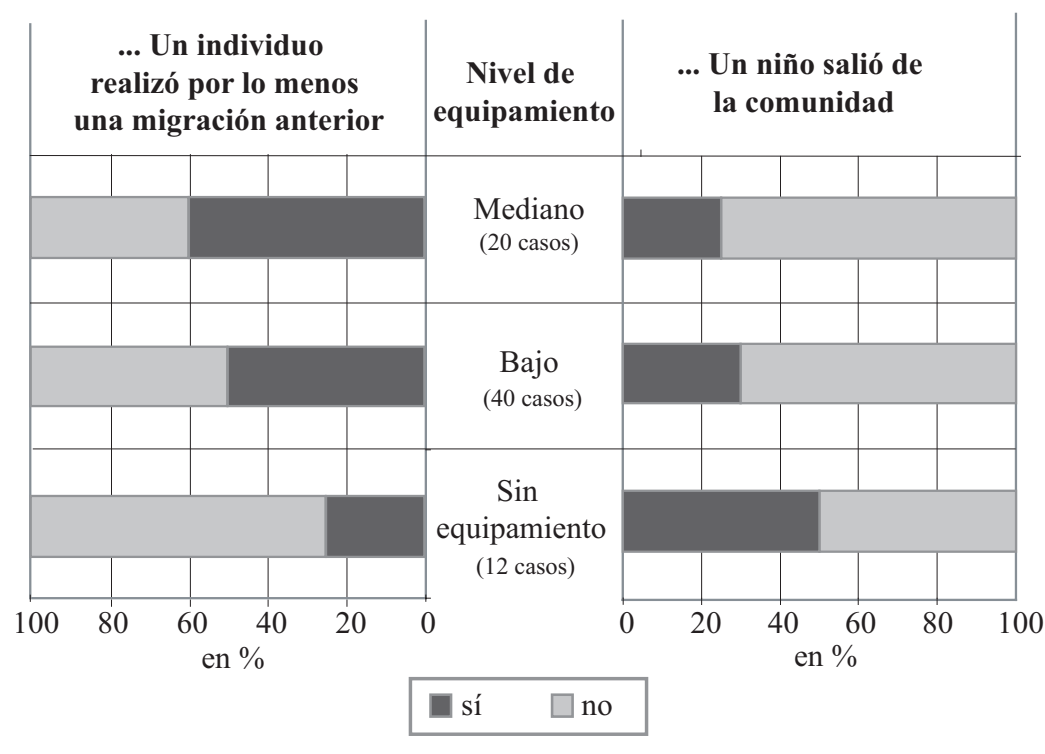

Fuente: Envil 2002 
la comunidad?, o ¿son las ciudades del Oriente las que concentran la mayoría de los destinos? De ser así, ¿cuáles son esas ciudades? Las posibilidades son numerosas: Villamontes está muy cerca, el desarrollo de Yacuiba ha sido fenomenal durante los años noventa y la dominación de Santa Cruz es, hoy en día, considerable. Inicialmente, realizaremos una observación diacrónica sobre la evolución de estos polos de atracción, para luego enfocarnos en sus especificidades, a través del estudio de los lugares de destino de la migración laboral y de formación.

\section{Descripción de los lugares de destino}

Enseguida trabajaremos simultáneamente sobre las 60 migraciones anteriores y las 52 migraciones actuales (descendencia que vive fuera de Caigua). Así, tenemos un total de 112 eventos migratorios realizados y partiendo de la comunidad.

La importancia de la migración de proximidad desde Caigua es crucial ya que más de la mitad de los eventos migratorios (anteriores o actuales) se dirige hacia localidades cercanas a la comunidad [ver Tab. II-51]. Primero hacia las ciudades de Villamontes (30,4\% de 112 eventos registrados) y de Yacuiba $(8 \%)$, respectivamente situadas a 20 y $115 \mathrm{~km}$ por la carretera que lleva a Argentina. Segundo hacia localidades rurales cercanas de los departamentos de Tarija, de Chuquisaca o de la parte meridional de Santa Cruz (15,2\%). También observamos cierta diversidad en los lugares de migración: el Oriente boliviano concentra dos tercios $(67 \%)$ pero el Occidente representa una parte importante $(19,6 \%)$ y los otros países, un complemento igualmente significativo $(11,6 \%)$.

El enfoque diacrónico de la evolución de los lugares de migración muestra ligeras variaciones [ver Fig. II-16]. Si los destinos orientales están en la mira de la mayoría de las migraciones anteriores (75\%, ver Tab. II-51), esta proporción baja cuando se trata de migraciones actuales (57,7\%). Esta tendencia no puede atribuirse a una disminución en el atractivo de Villamontes, que se mantiene, por mucho, como el lugar de destino por excelencia $30 \%$ de migraciones anteriores, 30,8\% de las actuales) ni a una recesión en Santa Cruz, menos importante pero estable (respectivamente $11,7 \%$ y 9,6\%) pero sí a una fuerte caída en los desplazamientos hacia Yacuiba $(10 \%$ y $5,8 \%$ y las zonas rurales del Oriente (20\% y 9,6\%). Argentina también manifiesta una caída en la atracción, aunque refleja un lugar importante en las migraciones anteriores $(13,3 \%)$ hay una disminución en las migraciones actuales $(7,7 \%)$. 
Fig. II-16: Envil 2002/Caigua - Comparación entre los lugares de destino de las migraciones anteriores y actuales
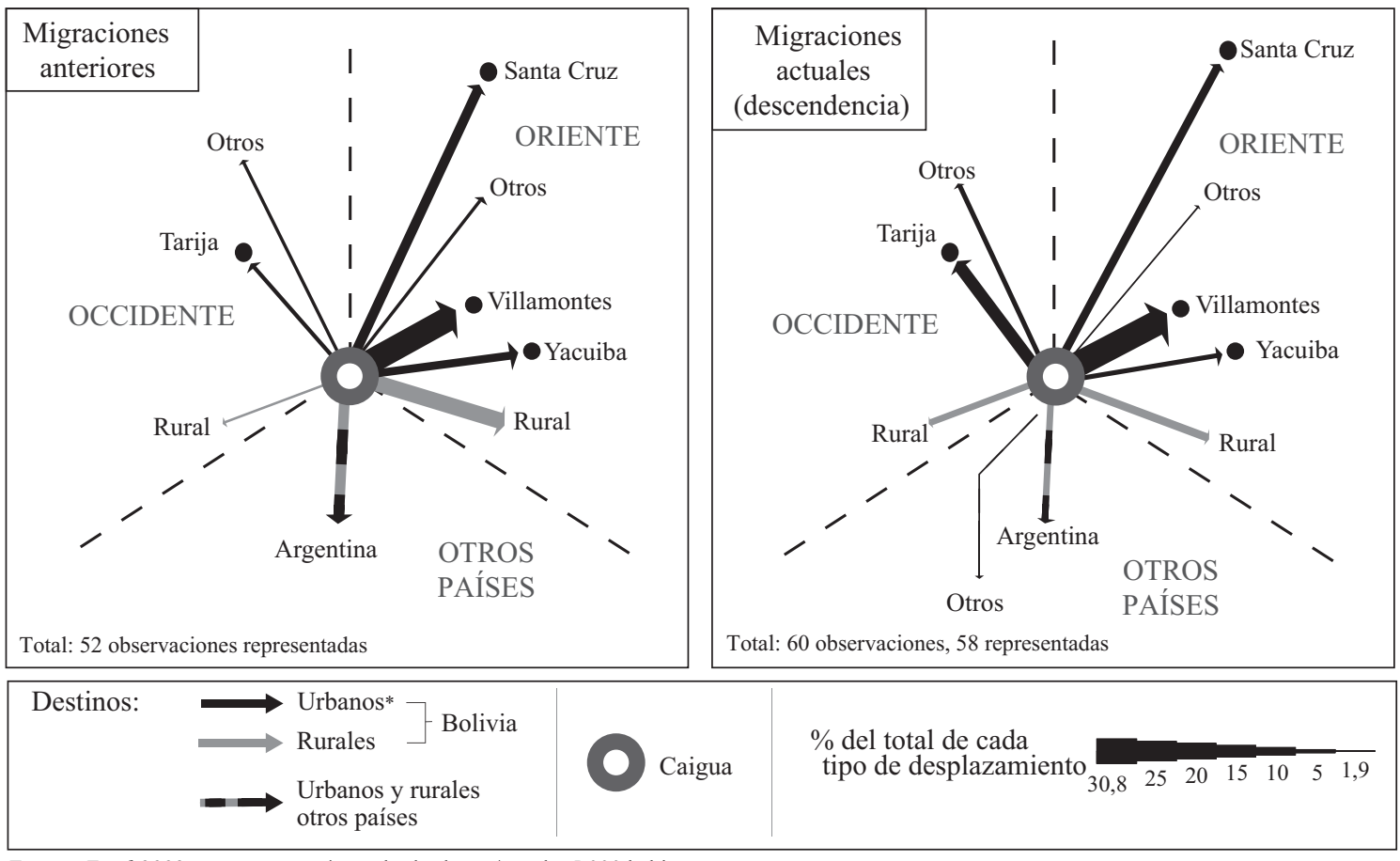

Fuente: Envil 2002. $\quad$ * : umbral urbano / rural a 5000 habitantes 
Estas mutaciones benefician al Occidente boliviano, ya que sólo concentra una minoría de los eventos migratorios anteriores $(11,7 \%)$ pero más de un cuarto de los que están en curso $(28,8 \%)$, evolución debida principalmente a un aumento en el atractivo de la ciudad de Tarija (respectivamente 5\% y $15,4 \%)$, y en menor medida de la de Sucre $(1,7 \%$ y $5,8 \%)$ y de las zonas rurales occidentales $(3,7 \%$ y $7,7 \%)$.

Vamos ahora a detallar estas evoluciones a través del estudio de las funcionalidades de los diferentes polos de atracción para la población de Caigua. Como ya lo hemos visto, es la motivación laboral la que determina principalmente las salidas. Con $31,3 \%$ de la migración laboral ${ }^{53}$ que se produce en Villamontes [ver Tab. II-52], esta ciudad vecina es sin duda el primer lugar de destino, seguida por Santa Cruz (16,4\%), Yacuiba y Tarija (9\% cada una). Además, observamos la presencia de un movimiento minoritario hacia las localidades rurales de Bolivia (13,4\% en el Oriente, $3 \%$ en el Occidente) y un último hacia otros países (11,9\% Argentina, 1,5\% otros). La observación diacrónica permite destacar algunas tendencias [ver Fig. II-17]. La comparación del esquema de la izquierda (migraciones anteriores) con el de la derecha (emigración actual) muestra que Villamontes gana en influencia: 24,3\% de los desplazamientos laborales anteriores la eligieron como destino por $40 \%$ de los desplazamientos actuales; mismo caso en Tarija (a la alza) pero con cifras de $2,7 \%$ y $16,7 \%$. En contraste, los otros lugares han perdido su importancia: Santa Cruz va de $18,9 \%$ a $13,3 \%$ y Yacuiba cae bruscamente de $13,5 \%$ a 3,3\%, los desplazamientos hacia las localidades rurales bolivianas también disminuyen: de $18,9 \%$ a $13,3 \%$, y es la misma tendencia para aquellos con destino a otros países: de $16,2 \%$ a $10 \%$.

La observación de los lugares de destino de la migración de formación permite analizar una distribución diferente ${ }^{54}$ [ver Fig. II-17]. Las ciudades de Villamontes y de Tarija comparten el primer lugar con 21,1\%, cada una, del total de la migración de formación ${ }^{55}$ [ver Tab. II-53], seguidas por Sucre

\footnotetext{
${ }^{53}$ Es decir, migraciones anteriores cuyo motivo es "trabajar", "estudiar y trabajar" o "buscar trabajo" o migraciones actuales (descendencia que haya dejado Caigua) realizadas por las personas que trabajaban al momento de la encuesta.

${ }^{54}$ El bajo número de las migraciones de formación no permite un análisis diacrónico pertinente del fenómeno.

${ }^{55}$ Es decir, las migraciones anteriores motivadas por los "estudios" o por "estudiar y trabajar", y aquellas en curso (descendientes que hayan dejado Caigua) cuya principal ocupación es estudiar.
} 
Fig. II-17: Envil 2002/Caigua - Lugares de destino de las migraciones laborales y de formación desde la comunidad (continúa)

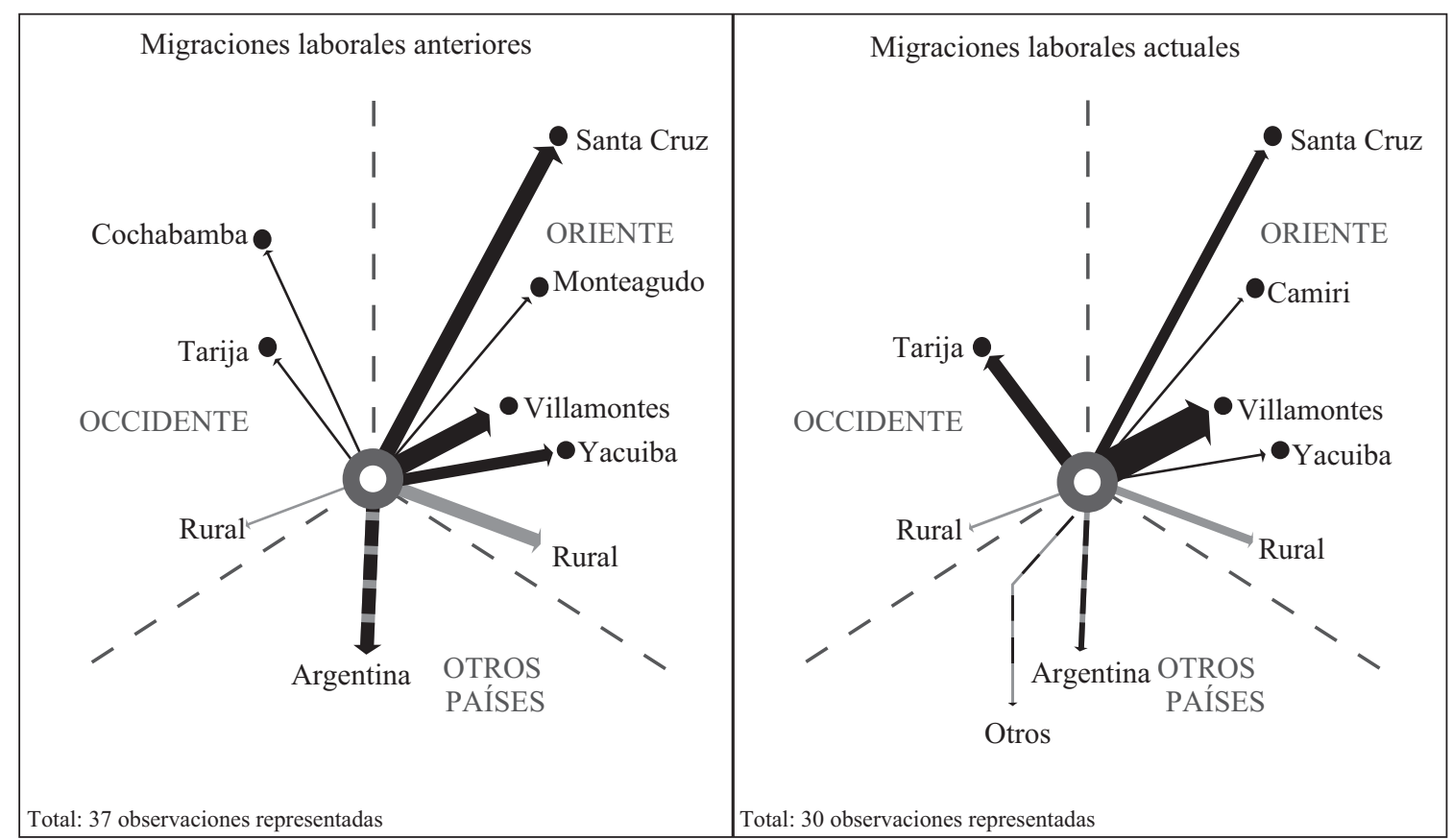


Fig. II-17: Envil 2002/Caigua - Lugares de destino de las migraciones laborales y de formación desde la comunidad (finaliza)
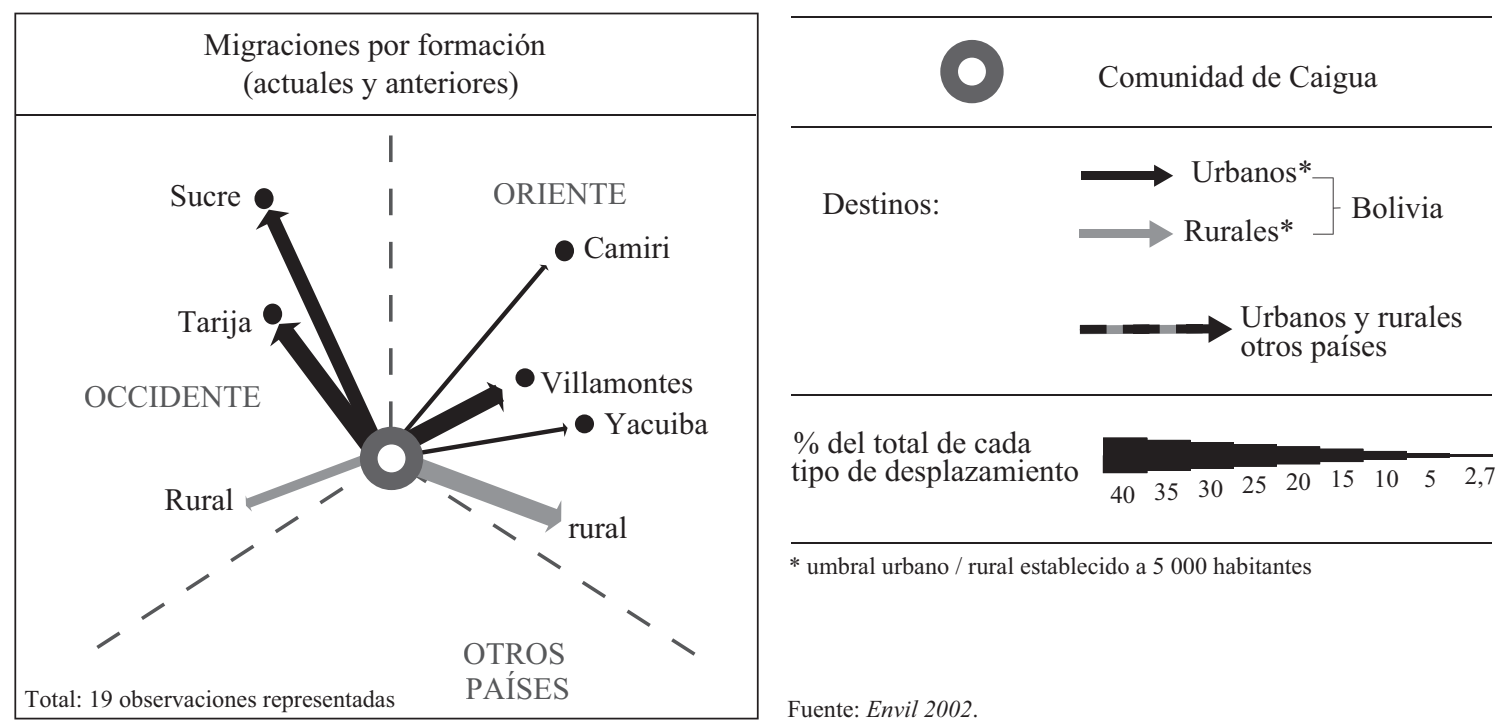

* umbral urbano / rural establecido a 5000 habitantes 
$(15,8 \%)$, después por otras ciudades orientales $(10,5 \%$ en total $)$ y, finalmente, por las localidades rurales del Occidente del departamento de Tarija, del Oriente de Chuquisaca o de Santa Cruz (10,5\% cada uno). Remarcaremos la ausencia de la capital cruceña en estos destinos.

Es a partir de este análisis descriptivo de la evolución y de las funcionalidades de los lugares de destino de la población de Caigua que ahora propondremos una visión general de los polos de atracción que estructuran la redistribución de los habitantes de la comunidad.

\section{Atracción de las ciudades del Oriente y movimientos emergentes hacia el Occidente}

Cuando emigran de su comunidad, los habitantes de Caigua tienden a dirigirse a las ciudades del Oriente boliviano. En primer lugar, Villamontes que constituye sin duda el principal destino. Situado en el eje Yacuiba-Santa Cruz, regularmente recorrido por transporte público, las localidades de Caigua y de Villamontes están separadas por sólo 20 minutos. Es probable que esta proximidad explique el rol desempeñado por Villamontes, un pequeño centro urbano de 16113 habitantes (censo INE, 2001), en los lugares de destino de los habitantes de la comunidad. En cuanto a la migración laboral, hemos remarcado la importancia cada vez mayor de los movimientos realizados hacia Villamontes, aumento que podemos atribuir a las recientes actividades gaseras y a los empleos directos e indirectos inducidos en esta ciudad. Finalmente, aunque el atractivo de Villamontes para la migración de formación es menor, sigue siendo significativo, lo que confirma la importancia de esta ciudad vecina para los habitantes de la comunidad.

La ciudad oriental de Santa Cruz, segundo polo de atracción, capta un movimiento migratorio proveniente de Caigua. Recordemos que la capital del Oriente boliviano es una de las ciudades más grandes del país (1,12 millones de habitantes según el censo de 2001), al centro de una particular dinámica regional (D’Andréa, 2007). Es, sin duda, esta vitalidad económica la que anima a los habitantes de Caigua a moverse hacia un centro urbano, aun si este se localiza lejos de la comunidad (alrededor de $420 \mathrm{~km}$, un día en autobús). ${ }^{56}$ Habremos notado, sin embargo, dos puntos que relativizan la magnitud de este movimiento: en primer lugar, el atractivo de Santa Cruz sólo se ejerce

\footnotetext{
${ }^{56}$ La pavimentación del tramo de Camiri-Abapo en 2004 redujo el tiempo del trayecto, haciéndolo practicable todo el año.
} 
sobre la migración laboral, y no sobre las de formación; por otro lado, la importancia de la ciudad como un lugar de destino revela un ligero descenso entre las migraciones anteriores y actuales. ${ }^{57}$

Siguiendo con las ciudades de Oriente, podemos considerar que Yacuiba es un polo de atracción obsoleto para los habitantes de Caigua. La comunidad, ubicada a sólo $115 \mathrm{~km}$ de la capital provincial, se encuentra bien comunicada por una carretera asfaltada que es utilizada con frecuencia por los transportes públicos. Precisamente esta buena comunicación es la razón por la que algunos habitantes de Caigua se hayan desplazado a partir del excepcional desarrollo de la función comercial de la ciudad, desarrollo que ha generado la creación de un gran número de empleos de baja calificación (construcción, comercio y diversos servicios como hotelería, restaurantes, transporte) asegurando la integración laboral de los provenientes de Caigua. La poca importancia de Yacuiba en la migración actual para trabajar también se explica por la crisis que ha afrontado la ciudad en los últimos años (Souchaud y Martin, 2007).

Además, vamos a discutir brevemente la existencia de un flujo migratorio minoritario hacia las localidades rurales del Oriente boliviano. La disminución de intensidad de este movimiento es, sin embargo, indicio de que se trata de una tendencia del pasado, que se refiere principalmente a los agricultores y ganaderos (de los ocho eventos en la lista, seis están relacionados a un empleo en el sector primario).

No se puede limitar el estudio de los lugares de destino de los emigrantes de Caigua hacia el Oriente boliviano. Como se ha señalado, los desplazamientos hacia el Occidente del país van en aumento. Esta tendencia se debe principalmente al poder de atracción de la ciudad de Tarija. La capital departamental se encuentra a sólo $275 \mathrm{~km}$ de la comunidad, pero la pista que la une al Piedemonte Norte es sinuosa, en mal estado durante la estación lluviosa y poco frecuentada por los medios de transporte públicos. Sin embargo, notamos la aparición de un flujo migratorio hacia este centro urbano por razones laborales y de formación.

Por último, es conveniente retomar brevemente la existencia de una migración hacia el extranjero; aunque se realice en proporciones ampliamente inferiores a las de Tolomosa, existe un flujo migratorio por razones laborales

${ }^{57}$ Dado el escaso número de efectivos, se deben manejar con cuidado estas tendencias tan bajas. 
entre Caigua y Argentina, cuya frontera está a sólo 90 minutos en autobús. A diferencia de lo que sucedes en nuestra unidad de análisis de los Valles Andinos (la cuenca de Tolomosa), estos desplazamientos se efectúan sólo de forma minoritaria hacia las provincias fronterizas, dirigiéndose principalmente hacia la región de Buenos Aires y las ciudades del centro del país. ${ }^{58}$ Parecería que se trata de un movimiento estructurado en torno al empleo agrícola (cuatro de ocho migraciones) y a diversos servicios. Sin embargo, como se mencionó anteriormente, el atractivo del país vecino concierne a las migraciones anteriores ya que actualmente han disminuido de manera importante, lo que sin duda se puede atribuir a la crisis económica argentina a finales de los años noventa y a la devaluación del peso en diciembre de 2001. Este descenso pone en relieve la fragilidad de este flujo migratorio.

\section{$* * *$}

Por lo tanto, se señaló la existencia de una importante emigración laboral desde Caigua, visualizando los empleos del sector terciario, lo que confirma la idea de una diversificación estratégica de las actividades. A pesar de que estas partidas disminuyen la presión antrópica sobre la tenencia de la tierra agrícola de la comunidad, la debilidad de las transferencias financieras efectuadas por la descendencia que vive fuera de Caigua hacia a los hogares de origen, no permite que sean consideradas una actividad lejana de la población de Caigua, al contrario de lo que hemos detectado en Tolomosa. Además, los lugares de destino, principalmente ciudades, implican la existencia de un flujo migratorio clásico de jóvenes rurales que desean cambiar su lugar de residencia para vivir una experiencia urbana. En cuanto a los lugares de destino, la atracción de Villamontes explica la importancia de las ciudades en el Oriente que se complementa con los polos secundarios de Santa Cruz y Yacuiba, este último en representación de un flujo pasado. Sin embargo, hemos notado una diversificación de los lugares de emigración, ya que los desplazamientos hacia la ciudad de Tarija podrían representar una nueva tendencia, y aquellos rumbos a ciertas zonas rurales bolivianas o de Argentina son importantes aunque minoritarios (sobre todo para la migración actual). Se trata pues, de una diferencia suplementaria con Tolomosa, la redistribución de los habitantes sólo se

\footnotetext{
${ }^{58}$ Del total de ocho migraciones profesionales desde Caigua hacia Argentina: tres tienen como destino la provincia de Salta; dos, Mar del Plata; dos, Buenos Aires; una, Córdoba, y una, Rosario.
} 
realiza en menor medida hacia el país vecino. En estas condiciones, podemos entender mejor la inexistencia de migraciones estacionales al contrario de lo que observamos en el Valle Andino.

El reciente crecimiento de la población rural del Piedemonte tarijeño lo convierte en una de las regiones más pobladas del departamento. Este hecho es particularmente debido al nuevo desarrollo de una agricultura intensiva que ha relegado la actividad pastoral extensiva a la llanura del Chaco. En el caso de la comunidad de Caigua, esta tendencia condujo primero hacia una inmigración de la gente de provincia, de las zonas rurales orientales (y en menor medida de pequeñas ciudades), cercanas a la comunidad, atractivo que posteriormente ganaron las regiones rurales occidentales, los Valles Andinos de Tarija y el suroeste de Chuquisaca, ambas fuertemente afectadas por la emigración de sus habitantes (Martin, 2012). Incluso, aunque sólo explica en parte el poblamiento de Caigua, se observa la existencia de un movimiento rural/rural en la transferencia de población Occidente/Oriente que remarcamos a la escala de Bolivia.

Sin embargo, cabe preguntarse acerca de las perspectivas de este crecimiento rural del Piedemonte ya que la distribución de tierras agrícolas fértiles, lo que constituía el principal atractivo de Caigua (una de las unidades de la comunidad indígena de Tarairi) ${ }^{59}$ parece haber encontrado sus límites durante los años noventa: no hay más parcelas para distribuir y la subdivisión de las tierras ha llevado a una drástica disminución del tamaño de las explotaciones agrícolas. En este contexto, los inmigrantes más recientes y las familias jóvenes tienen dificultades para mantener una actividad agrícola que pueda competir con los cultivos industriales argentinos. Como resultado, se ha producido una diversificación de actividades y la aparición de una emigración desde Caigua, que se traduce en desplazamientos puntuales por los hogares más ricos o sin duda por las familias que no pueden reintegrar a sus emigrantes. Se trata esencialmente de migraciones hacia los centros urbanos, para ejercer los empleos en los servicios, provocando no sólo un cambio en el medio de hábitat de residencia sino también en el sector de actividad desempeñado. Como tal, pueden

\footnotetext{
${ }^{59}$ Es interesante señalar a este respecto la ausencia de guaranís en Caigua, un grupo étnico que constituye la mayoría de los indígenas locales. En este sentido, la redistribución de la tierra en nuestra unidad de análisis no se realiza en beneficio de los autóctonos.
} 
ser integrados al éxodo rural. Son las ciudades del Oriente las que constituyen el destino principal, consecuencia de importantes migraciones de proximidad hacia Villamontes, localidad que concentra alrededor de un tercio de los destinos. No obstante, cabe matizar esta atracción de la ciudad vecina [ver Mapa II-4]: Argentina y Yacuiba constituyen los destinos antiguos y coyunturales, la capital de Tarija un destino emergente y Santa Cruz se mantiene bastante estable.

Esta redistribución de la población de Caigua hace hincapié en la importancia de la inestabilidad del poblamiento de la comunidad, y constituye una alternativa a la excesiva presión antrópica ejercida sobre la tenencia de la tierra agrícola. Pero la agricultura podría beneficiarse en los próximos años de cambios importantes, lo que abre otras perspectivas de desarrollo. Uno de los proyectos presentados por la provincia Gran Chaco para lograr regalías del gas se refiere a la construcción de una presa en el río Caigua, ubicado arriba de la comunidad. Dicho programa tendría un gran impacto en la localidad por la plusvalía y el mejor aprovechamiento de las tierras agrícolas a través de un riego permanente y generalizado. De acuerdo con el contexto macroeconómico, un aumento en la práctica de policultivos comerciales promovería la viabilidad de las explotaciones agrícolas y podría conducir a una mayor demanda de mano de obra y de inversiones financieras (incluyendo la mecanización).$^{60}$ Además, la reapertura de la refinería de aceite de Villamontes a partir de 2008 (Itika S.A.) tal vez se acompañó por una demanda de soja ${ }^{61}$ lo que merecería unos estudios complementarios. Pero, cabe señalar, Caigua dispone de tierra virgen al otro lado de la carretera que lleva a Santa Cruz y que atraviesa la comunidad, y el aumento del potencial de riego y la colonización de tierras hasta el momento incultivables podrían permitir el desarrollo de cultivos industriales. Por último, el continuo crecimiento de Villamontes y el mejoramiento de la red de transporte entre la ciudad y sus alrededores, también ofrecen nuevas perspectivas. Los habitantes de Caigua trabajan cada vez más en el sector terciario, aumentando la posibilidad de hacerlo en Villamontes viviendo en la comunidad, y así permanecer en los trabajos agrícolas si fuese necesario. Por el contrario, la población de Villamontes podría esta-

\footnotetext{
${ }^{60}$ Sin embargo, el tamaño de las parcelas y su ubicación sobre el relieve accidentado de laderas escarpadas del Aguaragüe imposibilitan una agricultura mecanizada.

${ }^{61}$ Según el periódico "El Diario" del 8 de julio de 2005, la planta podría llegar a requerir 50000 toneladas de soja por año. Sin embargo, la producción anual disponible en la "región" en ese momento era apenas de 15000 toneladas, las importaciones desde Argentina serían necesarias en un primer momento <www.eldiario.net>.
} 
Mapa II-4: Principales movimientos de población hacia y desde la comunidad de Caigua

\section{Los principales movimientos migratorios}
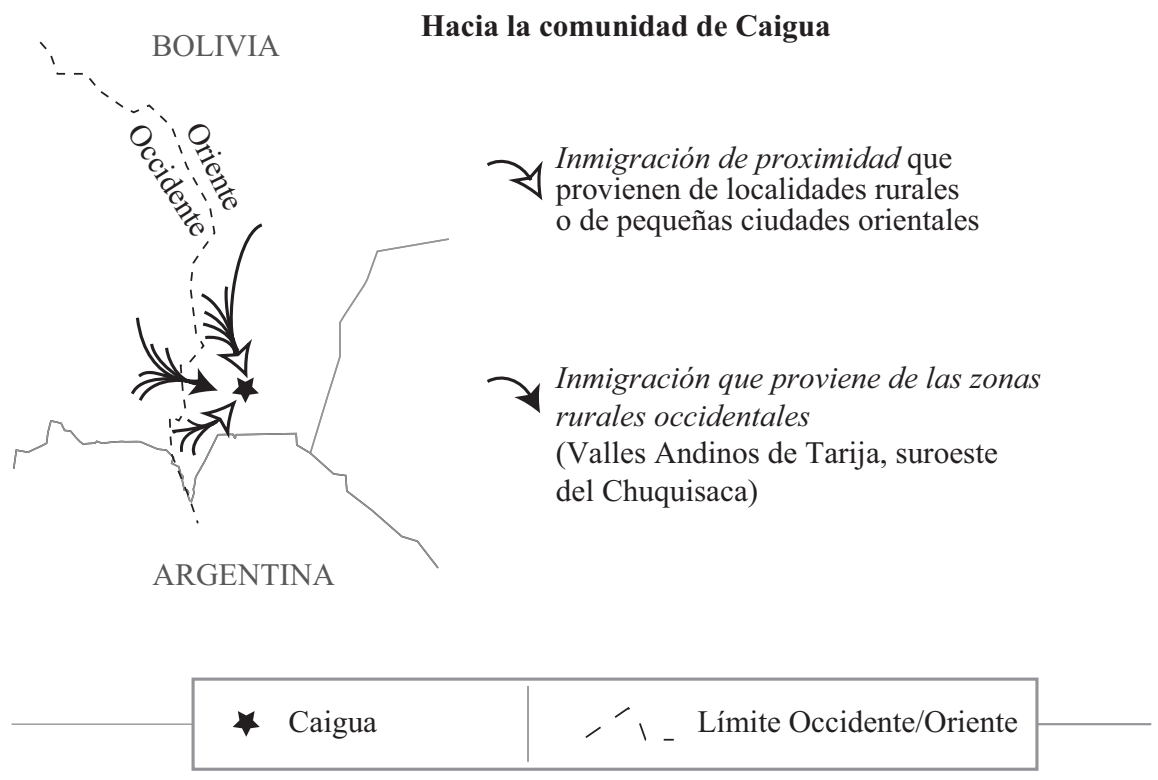

Desde la comunidad de Caigua

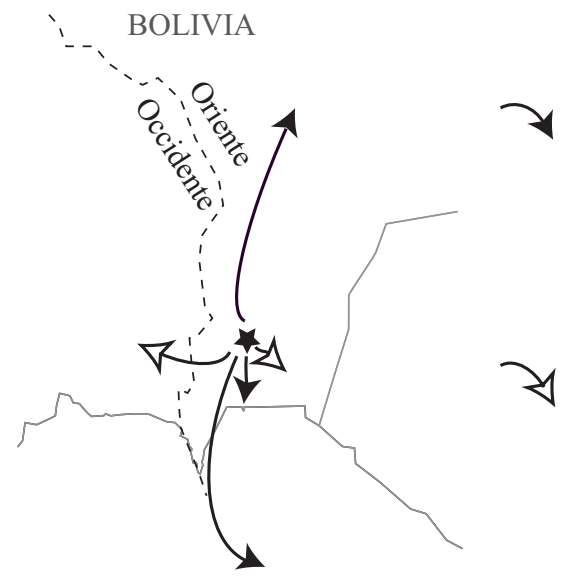

Migración laboral

hacia Argentina y Yacuiba (antiguos movimientos) y hacia la ciudad de Santa Cruz

Migración laboral y de capacitación hacia la ciudad de Villamontes (movimiento principal) y hacia la ciudad de Tarija (movimiento reciente)

\section{ARGENTINA}

Fuentes: Fondo de mapa <www.philgeo.club.fr>; datos Envil 2002. 
blecerse en la comunidad que goce de un entorno agradable. ${ }^{62}$ Estos cambios, y la recuperación potencial del desarrollo de Caigua que resulta, dependen del crecimiento de la ciudad vecina.

${ }^{62}$ Las condiciones materiales de vida están mejorando constantemente en Caigua: en 2003 la vivienda en adobe ha sido mejorada, se abrió una escuela maternal en 2004 y la construcción del sistema de agua potable y alcantarillado se hizo, por lo menos parcialmente, en 2005. 


\section{Conclusión: Las dinámicas rurales diferenciadas}

Hemos analizado las dinámicas rurales del Sur boliviano a partir de dos modelos distintos. En primer lugar, Tolomosa, valle de tradiciones agrícolas y de poblamiento antiguo, en el Occidente del departamento. Posteriormente, Caigua, comunidad recientemente repoblada, ejemplo de colonización oriental de intersticios del Piedemonte, resultado (después de varios siglos) de una voluntad política para volver sedentaria a la población en la región del Chaco. La observación comparativa de los resultados de nuestros análisis ofrece una nueva mirada sobre la evolución reciente de las dinámicas rurales en el Sur boliviano.

\section{REDES Y CULTURAS MIGRATORIAS: PRÁCTICAS DIFERENCIADAS DEL ESPACIO}

Resulta interesante constatar que los modelos con bases tan diferentes encuentran dificultades comparables. Los dos sistemas de producción, basados principalmente en la agricultura y el acceso a las tierras individuales iniciada por la reforma agraria, encuentran dificultades; consecuencia de la competencia de los cultivos industriales argentinos, de la fragmentación parcelaria (relacionada con el crecimiento natural sostenido de su población) y del limitado acceso a los recursos hídricos. Nuestros ejemplos se colocan, por lo tanto, como parte de una problemática más general que concierne al total de los pequeños agricultores bolivianos, de los cuales la producción se estanca o está a merced de las condiciones meteorológicas, de las políticas de liberalización económica y de los precios internacionales de los productos agrícolas (Franqueville, 2000, p. 19). Estas dificultades económicas y el poco atractivo del mundo rural boliviano para los jóvenes, han provocado una migración importante. Como prueba, el comportamiento de la descendencia: ya sea en 


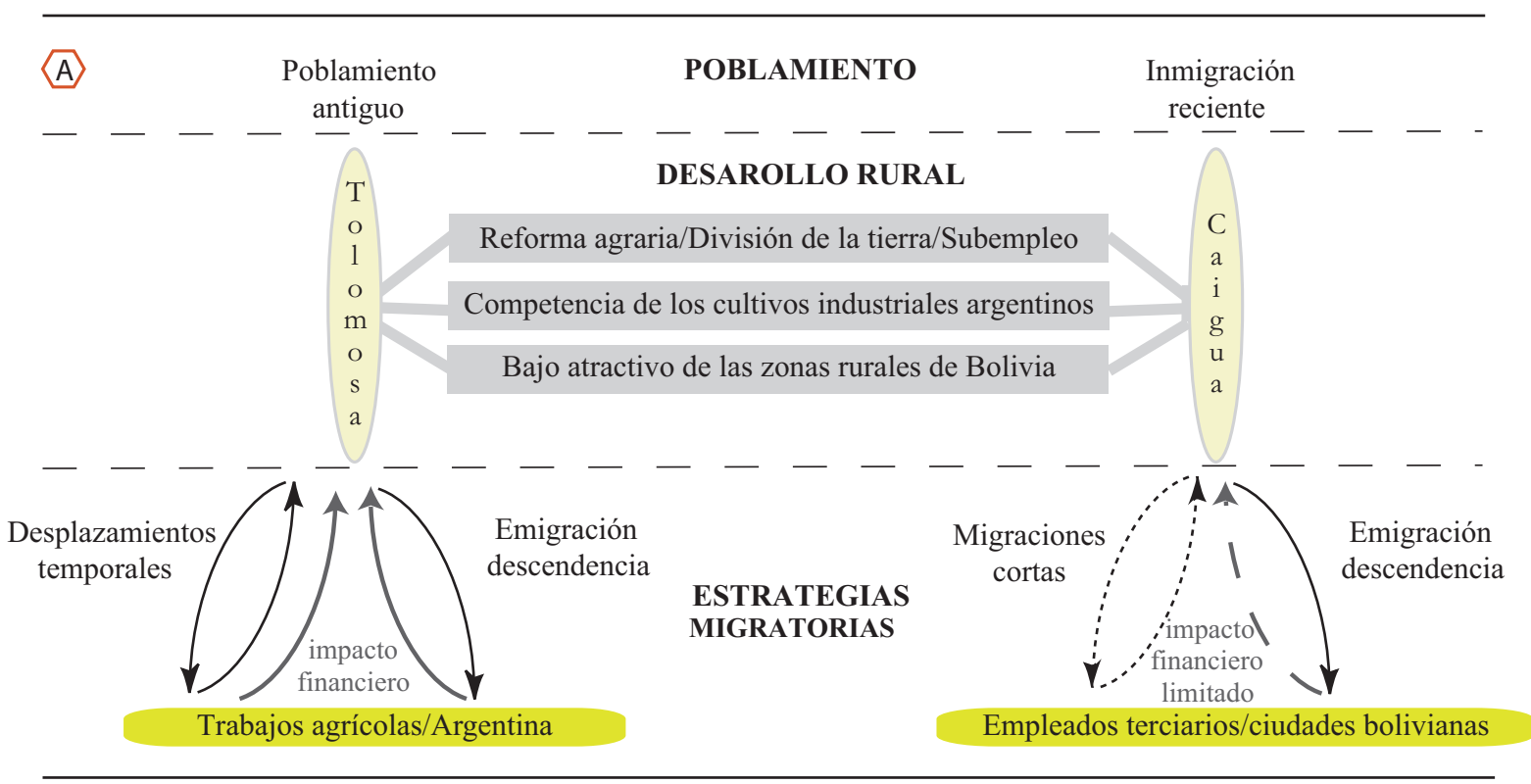


B El jefe de hogar*

Lugar de nacimiento

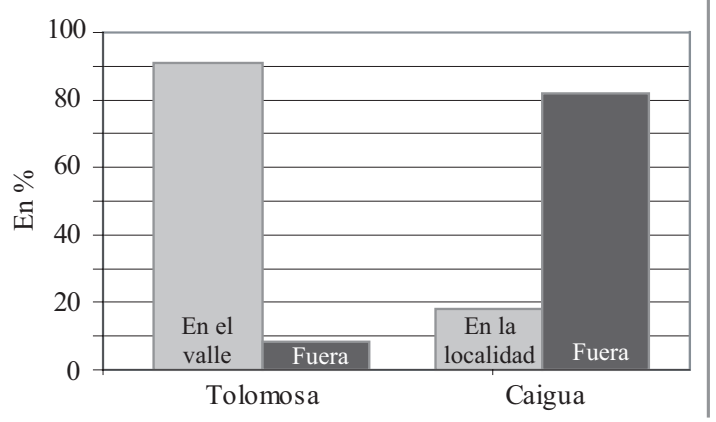

\section{Edad}

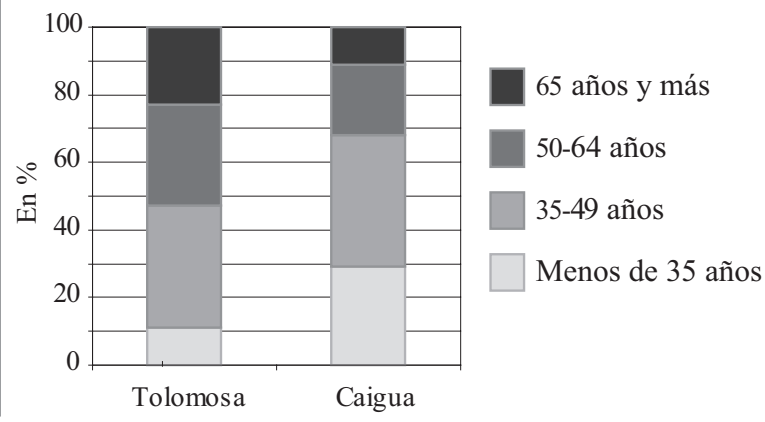

* 201 casos para el valle de Tolomosa, 72 en Caigua

(C) ¿Las estrategias migratorias tienen un impacto financiero sobre los hogares?

Valle de

Tolomosa (1)

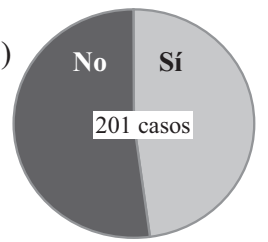

Comunidad de Caigua (2)

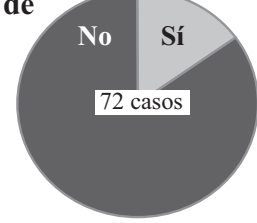

(1) el hogar recibe dinero de un hijo(a) que salió del valle y/o uno de sus miembros declara un viaje profesional en 2001 (2) el hogar recibe dinero de un hijo(a) que salió de la comunidad 
D Los hogares* declaran al menos un(a) hijo(a) que salió

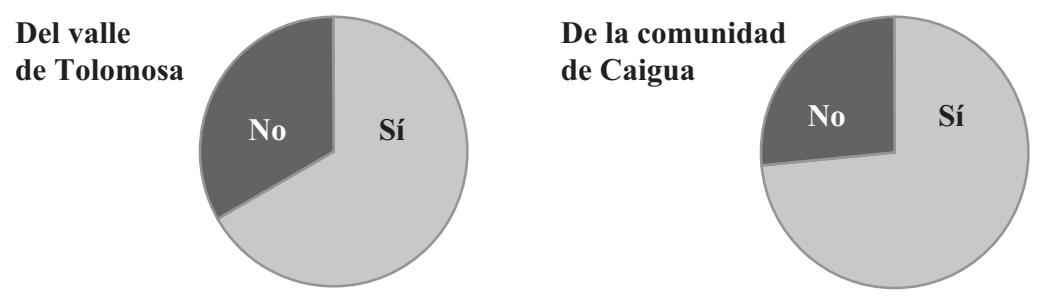

* declaran al menos un(a) hijo(a) de 18 años y más (que viven o no en el hogar), lo que representa 139 familias en Tolomosa y 33 en Caigua 

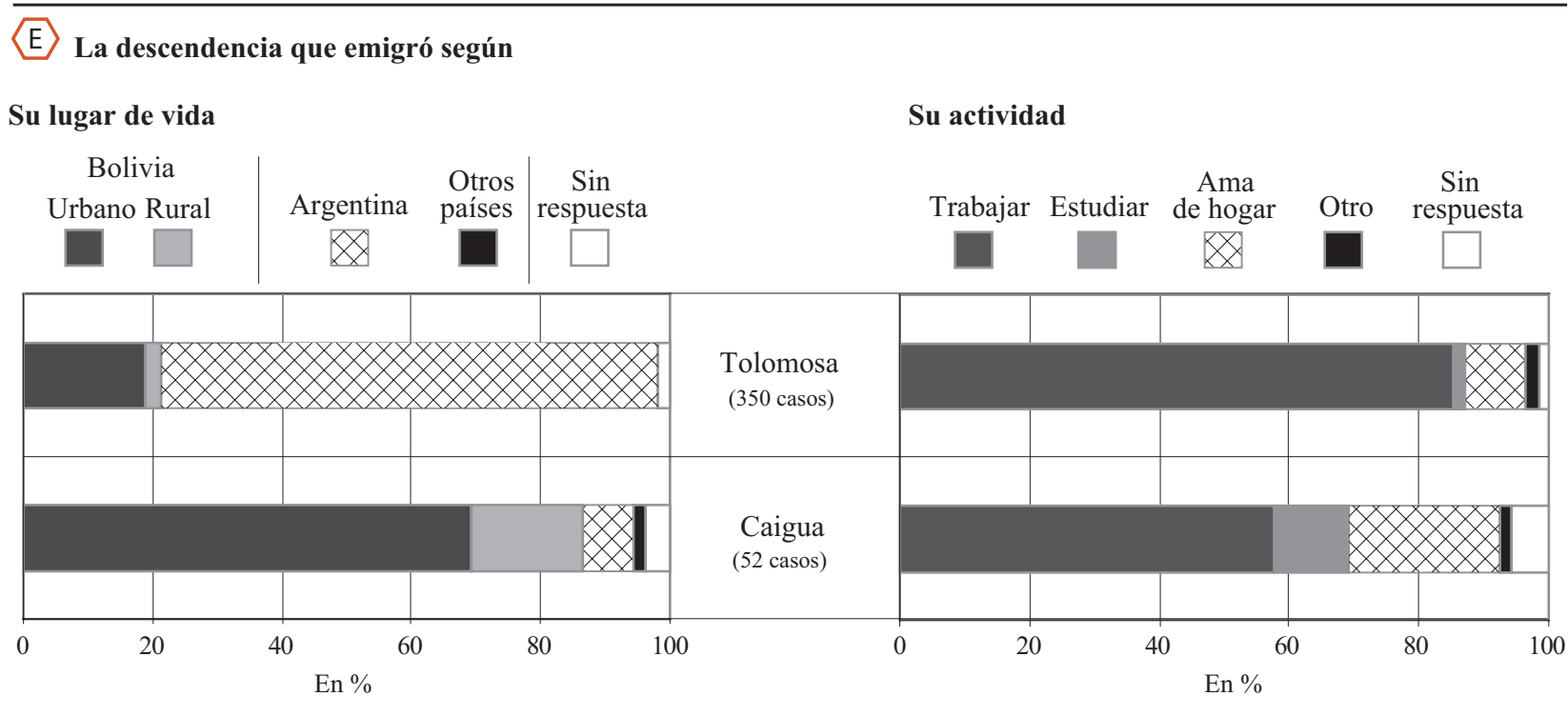

Los sectores de actividad

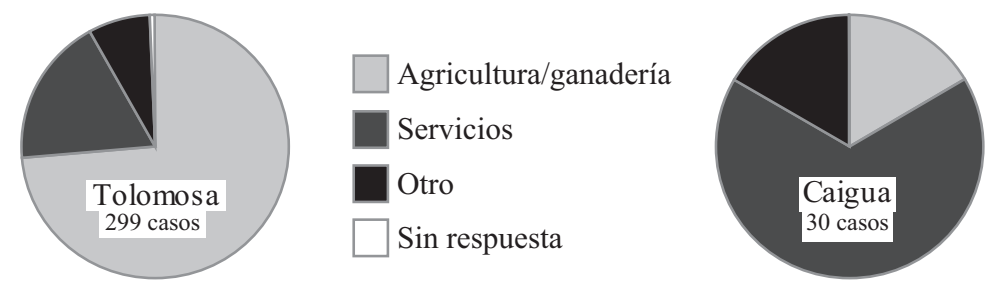

Fuente: Entol 2002, Envil 2002. 
Caigua o Tolomosa, cerca de tres cuartas partes de los hogares ${ }^{1}$ declaran al menos la partida de un hijo. En conjunto, esta dinámica migratoria común a ambos sitios muestra que la población se ajusta a la capacidad productiva de los sistemas agrícolas, un hallazgo que pone de manifiesto un mecanismo de ajuste demográfico favorecido por el atractivo de la modernidad. En detalle, las estrategias puestas en marcha responden, sin embargo, a lógicas diferentes, según las temporalidades, los lugares y las actividades.

En Tolomosa, dos tipos de desplazamientos parecen complementarios: estacionales para los hogares que necesitan mano de obra durante el invierno, y de larga duración para aquellos que no tienen actividades agrícolas viables. En ambos casos, la migración internacional es dominante y exclusivamente orientada hacia Argentina, especialmente para los empleos agrícolas relativamente mejor pagados que proponen las cuencas agroindustriales del norte del país o los cinturones horticultores periurbanos. Así pues, contrariamente al ejemplo de Geneviève Cortes (2004), la población tradicional rural de Tarija tiene una alternativa de proximidad a la colonización interna. Igualmente, a la diferencia de lo observado por David Preston (Preston, Macklin et al., 1997) en Camacho, no notamos migraciones estacionales hacia el Oriente durante la época seca, para la trashumancia del ganado. Por otro lado, Caigua difiere de este modelo, las estrategias de migración de sus habitantes pueden ser clasificadas como éxodo rural clásico: las salidas son sistemáticamente de larga duración (reducidas en caso de fracaso de la experiencia migratoria o de la posibilidad de reintegración), ${ }^{2}$ se realizan hacia las ciudades bolivianas (la más cercana es la más atractiva) e implican cambios intersectoriales de actividad (se pasa de la agricultura a los servicios).

Una mejor comprensión del modelo tradicional de Tolomosa, a través de su inscripción en una perspectiva histórica, enriquece la comparación con el modelo reciente de Caigua. Las prácticas migratorias actuales de las poblaciones rurales del Occidente hacia Argentina, ¿podrían asimilarse a una forma moderna de las tradiciones de movilidad de las poblaciones andinas — la de los comunarios ${ }^{3}$ que se practicaban a larga distancia, organizadas entre pisos

\footnotetext{
${ }^{1}$ Que declaran al menos un hijo de 18 años o más.

${ }^{2}$ Esta tendencia de retorno hacia zonas de colonización agrícola por fracaso fue notada por Sophie Blanchard en la periferia de Santa Cruz (Blanchard, 2006).

${ }^{3}$ Según Franqueville (2000), el comunario es el miembro de una ayllu, comunidad territorial andina (aymara o quechua) fundada a partir de lazos de parentesco y que forman el marco de las relaciones sociales y de las actividades económicas.
} 
ecológicos (Franqueville, 2000, p. 85)? Tal vez no con la misma intensidad (Amilhat Szary, 2007) pero se podría entender el comportamiento de la población de Tolomosa como una práctica original del espacio de los campesinos andinos, que se caracteriza por un fuerte vínculo entre emigración y comunidad de origen. Ya sea migración estacional o emigración de los descendientes, hemos hecho hincapié en la importancia de los retornos (financieros y físicos) que acompañan a estos diferentes movimientos de población, y en el mantenimiento de la actividad de partida, los trabajos agrícolas. Por lo tanto, la emigración podría ser percibida como una estrategia comunitaria marcada por los costos y beneficios de los desplazamientos. La observación de los mecanismos migratorios nos lleva a varias conclusiones. Primero, el tipo predominante de emigración (estacional o largo plazo) depende de las necesidades de las comunidades. Segundo, la alta tasa de ocupación laboral de los que dejan Tolomosa revela una orientación económica de los desplazamientos. Tercero, los salarios relativamente altos en Argentina compensan las difíciles condiciones de trabajo (especialmente para los inmigrantes ilegales). Cuarto, los destinos en el vecino país (provincias limítrofes de las migraciones cortas, a veces más lejanas si son largas) inducen la consideración del factor distancia-costo.

Estos diferentes elementos nos llevan a reconsiderar las estrategias de Tolomosa en una problemática más general, la de un proceso migratorio organizado y gestionado por la sociedad, que con esto encuentra un medio de resistencia a la degradación de sus condiciones de vida (Domenach y Picouet, 1995, p. 115). A la escala de Bolivia, sigue siendo Geneviève Cortes, a través de su estudio de la migración infradepartamental de las comunidades andinas de Cochabamba, quien ha determinado la actualidad de tal fenómeno: la expansión del espacio campesino corresponde a una voluntad, y muchas veces a una necesidad de encontrar alternativas económicas frente al deterioro de las condiciones de producción agropastoral en el espacio comunitario de origen (Cortes, 2004). Por lo tanto, ¿cómo explicar que no encontramos las mismas estrategias en Caigua, localidad confrontada a límites semejantes a Tolomosa y situada más cerca de Argentina (a una hora)? Se trata de un tema fundamental en el que conviene profundizar, ya que los datos producidos sólo permiten explicarlo parcialmente. Nos limitaremos aquí a señalar el vínculo primordial entre migración internacional y redes (Domenach, 2001), que explicaría (por lo menos parcialmente) que los habitantes de Tolomosa (valle con poblamiento viejo y prácticas migratorias tradicionales hacia Argentina) emigren más que aquellos de Caigua (comunidad con un tejido social recientemente formado y de emigración nueva). 


\section{DOS PERSPECTIVAS: INERCIA DE UNA AGRICULTURA SUBVENCIONADA Y RECOLONIZACIÓN AGRÍCOLA}

Después de constatar los límites del sector agrícola y las estrategias migratorias puestas en marcha en las zonas rurales del departamento de Tarija, se puede cuestionar sobre el futuro de una población rural que todavía concentra 40\% del efectivo del departamento. ${ }^{4}$ Porque, aunque la emigración de los jóvenes tiene y tendrá efectos sobre la dinámica demográfica, ${ }^{5}$ sólo unas cuantas regiones remotas se ven actualmente afectadas por las señales de la despoblación. ${ }^{6}$ Del mismo modo, hay pocos ejemplos de abandono de la actividad agrícola y hasta vemos surgir signos de nueva ruralidad que muestran una cierta adaptación del medio (actividad migratoria, diversificación de los ingresos). Por lo tanto, las zonas rurales tarijeñas, incluso occidentales, no parecen tan afectadas por un sector agrario deprimido. Se puede cuestionar entonces si esta situación es el resultado de las estrategias migratorias y si puede perdurar. En general, chay un lugar para la agricultura artesanal en Bolivia? ¿Los sistemas de producción aún pueden evolucionar? ${ }^{77}$ Veamos cuáles elementos de respuesta puede aportar nuestros análisis.

La emigración hacia Tolomosa, ya sea estacional o de larga duración, debe ser considerada como una actividad en el valle. De hecho, tiene un impacto financiero directo sobre casi la mitad de los hogares encuestados. En este sentido, nuestro ejemplo se une al de Geneviève Cortes (2004), quien señala que la mitad de los ingresos de las familias de Pampa Churigua se perciben fuera de la explotación agrícola del hogar de origen y principalmente a través de estrategias migratorias. Sin embargo, distingue dos tipos de impactos: durante las emigraciones de contratación temporal (el caso de nuestros

\footnotetext{
${ }^{4}$ Según el censo INE 2001, no se dispone en las estimaciones más recientes de una diferenciación entre los ámbitos urbanos y rurales (INE, 2011).

${ }^{5}$ Como lo destacan Hervé Domenach y Michel Picouet, los desplazamientos no sólo implican transferencias de población sino que también son la causa de transferencias de potencialidades de crecimiento (o decrecimiento) algunas veces muy importantes, y de reestructuración del espacio y de las demandas sociales. Esto se nota por cambios directos en la estructura de la población (sexo y edad, en los lugares de origen y de destino) y a través de transferencias y modificaciones en el comportamiento reproductivo y social de la población emigrante al contacto con la población del lugar de destino (Domenach y Picouet, 1995, p. 43).

${ }^{6}$ Disminución absoluta de la población (Brunet, Ferras et al., 1993, p. 149).

${ }^{7}$ Sobre esta temática a nivel nacional, consultar el trabajo de Anaïs Toral (2011) sobre la agricultura familiar de exportación que se desarrolló alrededor de la quínoa, y las formas de movilidad que acompañan estos cambios en el sistema productivo.
} 
desplazamientos estacionales) es mucho menos importante el ingreso que cuando se trata de migraciones de familias (la emigración de los descendientes para nosotros), que generalmente permiten la acumulación monetaria. En este último caso, el ahorro puede ser invertido en la comunidad de origen (compra de nuevas tierras, de un tractor, la introducción de cultivos comerciales, el uso de fertilizantes, pesticidas...). En este punto, el ejemplo de Cortes difiere del nuestro: en Tolomosa, el impacto financiero de la migración parece reducirse a un modelo tradicional de actividad de sustitución, sin implicar inversiones significativas en el lugar de origen. ¿Por qué tal diferencia? ¿Las tierras agrícolas de Tolomosa hubieran conseguido su valorización óptima? Es difícil afirmarlo, porque este punto óptimo no existe en virtud de que las técnicas y los sistemas de producción evolucionan (Mesclier, 1993, p. 770). Sin embargo, las perspectivas de desarrollo del valle son limitadas (suelos pedregosos, relieves, erosión, recursos hídricos ampliamente utilizados), especialmente en el contexto de las pequeñas explotaciones familiares. Sólo una importante reorganización del sistema productivo (como la introducción de la vid, que tiene un cierto éxito en la cuenca vecina) podría asegurar el futuro de la agricultura en Tolomosa. ¿Existe realmente la intención de los agricultores de proceder a tal evolución? Como lo destaca Danilo Paz Ballivián, podrían conformarse con "subsidiar" su agricultura y satisfacer sus necesidades monetarias con los retornos financieros de la emigración, y así conservar un equilibrio tradicional en las áreas de partida. Este comportamiento, irracional para la mentalidad empresarial, es comprensible en el mundo de los pequeños productores quienes están más motivados por la satisfacción de las necesidades de la familia que por las ganancias (Paz Ballivián, 1995, p. 95).

Pero sin duda son las inversiones en los lugares de emigración las que mejor explican el escaso interés en la mejora del sistema productivo de Tolomosa. Porque, incluso si no se expresa en su valle de origen, muchos son los emigrantes que tienen una mentalidad de empresario en el sector agrícola argentino. Después de ser contratados como jornaleros, se especializan (como embaladores), luego capitalizan conocimiento y dinero, entonces compran herramientas, lo que los hace acceder a la condición de aparcero y les da los medios para adquirir tierras, incluso algunos terminan como jefes de explotaciones intensivas de alta tecnología (cultivos en invernaderos o hidropónicos). Para adaptarse al mercado, los emigrantes no dudan en revisar su práctica del espacio tradicional, algunos abandonan las provincias septentrionales de Salta o Jujuy para llegar a los suburbios agrícolas de las principales ciudades argentinas y acceder a los mercados. El resultado es una verdadera 
movilidad social, llamada "escalera boliviana” por Roberto Benencia. ${ }^{8}$ Por último, aunque en menor medida, destaquemos que esta evolución no se limita al sector agrícola sino que se reproduce también en los servicios y la industria ligera. En este sentido, una de las rutas clásicas es la transición de vendedores ambulantes o trabajadoras domésticas (las mujeres) a la fabricación o la comercialización de ropa de contrabando, fenómeno especialmente notable en las ciudades del norte de Argentina.

Estas inversiones ayudan a fortalecer la red de la emigración, y favorecen así el empleo de mano de obra temporal o la inserción de los recién llegados provenientes de las mismas comunidades. Así, en lugar de sufrir la competencia argentina, el originario de Tolomosa participa en el desarrollo agrícola del país vecino y mantiene el delicado equilibrio de un valle con su población en pleno envejecimiento. Las estrategias familiares de uso de los territorios hacen pensar que los lugares practicados por los Tolomosino constituyen un "archipiélago" de la familia (o de la comunidad) ${ }^{9}$ donde adaptan la valorización de los espacios a sus necesidades. En cierto modo se trata de "ir para quedarse" (Cortes, 2004), y la ausencia de signos de retorno, de reducción de la migración estacional o de evolución tecnológica de la agricultura en la cuenca sugieren que esta situación se mantendrá.

A diferencia de Tolomosa, las migraciones tienen muy poco impacto financiero en Caigua: la emigración estacional es inexistente y las remesas de los descendientes a la comunidad sólo concierne a una minoría de los hogares. Así, si las estrategias migratorias contribuyen fuertemente a reducir la presión antrópica sobre el minifundio y por lo tanto a limitar el impacto de las dificultades del sistema productivo, sólo constituyen un remedio parcial. Por el contrario, a través de una mejor valoración de la tierra (la producción de fruta) y la diversificación de las actividades (aparición de servicios), la gente de Caigua se distingue por una economía más dinámica que atiende sus necesidades monetarias. Y, a pesar de las dificultades encontradas, este sistema parece funcionar mejor; para prueba la distribución del índice de equipamiento más favorable en Caigua que en Tolomosa. Sin embargo, ¿este equilibrio puede mantenerse? Uno puede preguntarse sobre el futuro de la

\footnotetext{
${ }^{8}$ Recomendamos los numerosos trabajos de Roberto Benencia sobre los migrantes bolivianos en Argentina, entre otros: Benencia, 1997; Benencia, 2005; Benencia \& Geymonat, 2005, y Benencia \& Quaranta, 2006.

${ }^{9}$ Ver trabajos producidos en México sobre el concepto de los “archipiélagos” (Léonard, Quesnel et al., 2004, y Quesnel y Del Rey, 2005).
} 
población de Caigua, cuyos jóvenes inducen una cierta vitalidad, pero cuyo poblamiento actual se ve desafiado a causa de la emigración.

Paradójicamente es en Caigua donde los emigrantes optan por intercambios intersectoriales de actividad y el desarrollo agrícola es aún posible gracias a tres elementos: la creación de una represa de agua arriba de la comunidad; la reapertura, aunque sea parcial, de la refinería de aceite de Villamontes (y la demanda de soja que acompaña), y la disponibilidad de grandes extensiones de tierras vírgenes (debido a su baja fertilidad sin riego). La combinación de estos tres factores contribuye a mejorar las explotaciones y relanzar la colonización agrícola. Por lo tanto, será interesante constatar si las partidas disminuyen y si estamos viendo nuevas olas de inmigración desde los Valles Andinos o Subandinos. Es dudosa la intensidad de estos cambios, ya que estas nuevas explotaciones favorecerán una agricultura mecanizada, como sucede en los alrededores de Santa Cruz. Sin embargo, esta renovación agrícola relacionada con la ubicación privilegiada de Caigua sobre el eje asfaltado Santa CruzArgentina, estimulará el sector de servicios, y con ello la diversificación de las actividades. Esta evolución podría afectar el futuro de la comunidad. La difusión de las actividades comerciales y de transporte modifica los criterios por los cuales la población rural decide permanecer o partir. Así, es importante no sólo la disponibilidad de tierras, sino también el potencial de realización de actividades no agrícolas, lo cual no implica necesariamente una ubicación en zonas rurales cercanas a las ciudades, pero sin duda sí cerca de ejes de comunicación (Mesclier, 1993, p. 788).

Los factores que provocan las dificultades de nuestros dos modelos convergen, pero las estrategias migratorias y las perspectivas difieren mucho. En el Occidente, Tolomosa parece perpetrar la inmovilidad de una agricultura tradicional poco rentable y de una población en pleno envejecimiento debido a la emigración de los jóvenes hacia Argentina. En el Oriente, el desarrollo agrícola de Caigua está en decadencia por lo que es poco atractivo para los hijos que deciden emigrar hacia la ciudad, aunque las familias jóvenes que permanecen podrían beneficiarse de importantes mejoras. Esta oposición entre la inercia de estancamiento de las zonas rurales occidentales (con excepciones) y el dinamismo oriental (no general e inconsistente), sugiere que el futuro del medio rural del departamento de Tarija, tanto económica como demográficamente, se decidirá en el Oriente. 


\section{LA EXPANSIÓN NECESARIA DEL ÁREA DE ANÁLISIS}

Sin embargo, dada la gran diversidad del departamento, otras investigaciones permitirán detectar otras prácticas del espacio que podrían precisar estas conclusiones. En el Occidente, el estudio de un Valle Andino aislado sería necesario para evaluar mejor el impacto de la lejanía de la capital departamental y de las vías de comunicación. De manera complementaria, una unidad de análisis en la alta montaña (altiplano y valle del Río San Juan de Oro) permitiría tomar en cuenta las especificidades de esta región, marcada por la dureza del clima, y considerar los riesgos reales de la despoblación. ${ }^{10}$ En el Oriente, diversas dinámicas merecen ser exploradas. En primer lugar la del Piedemonte Sur, que requeriría la investigación de al menos dos localidades: una con poblamiento antiguo (por ejemplo Caiza), y la otra compuesta principalmente por inmigrantes (especialmente Tierras Nuevas). Enseguida, el estudio de la recomposición de los Valles Subandinos del Sur, alrededor de Bermejo, resultaría útil para aclarar las estrategias de adaptación a la crisis azucarera. Por último, los Valles Subandinos del centro serían un buen campo de observación de aislamiento oriental, provisional en una comunidad cerca de Entre Ríos o aún más anclado, al límite de la reserva de Tariquía por ejemplo. Para estas encuestas rurales, se recomienda la inclusión de un módulo adicional suplementario que abarque específicamente los desplazamientos estacionales hacia y desde las localidades, así como variables que ilustren la influencia de las redes en la migración, ${ }^{11}$ tema clave especialmente para los agricultores de Occidente a partir de sus desplazamientos hacia Argentina. En este sentido, y como complemento de nuestro trabajo, una investigación sobre los principales destinos ${ }^{12}$ aportaría interesantes elementos sobre las prácticas transnacionales del espacio. Esta investigación determinaría en qué medida estas redes constituyen "recursos migratorios" en el sentido de Emmanuel Ma Mung, que facilitan la movilidad de las personas mediante el trazado de canales de circulación, designando destinos y los posibles puntos de unión, proporcionando una logística de circulación y de medios de instalación (Ma Mung, 2002, p. 129).

\footnotetext{
${ }^{10}$ Ver Beck, Paniagua et al., 2001 así como Martin, 2010 para más detalle sobre esta región.

11 Podrían tratarse las siguientes preguntas: "Durante la migración, ¿ha trabajado para un miembro de su familia? ¿de su comunidad? Si no, ¿era originario de su valle?, ¿de Tarija?, ¿de otras partes en Bolivia?".

${ }^{12}$ Especialmente las localidades de Fraile Pintado y Santa Rosa, ubicadas cerca de la frontera.
} 
Finalmente, en el contexto actual, la restitución de las dinámicas rurales del departamento de Tarija también pasa por el estudio de sus centros urbanos. De hecho, las interacciones urbano-rurales son numerosas. El reciente y sostenido crecimiento de las aglomeraciones se explica (al menos en parte) por la atracción que ejercen sobre las poblaciones rurales, una tendencia marcada en gran medida en el caso de Caigua, y mucho menos en Tolomosa. ¿Por qué tal diferencia? ¿Por qué para algunos será menos interesante ir a Argentina en lugar de las ciudades bolivianas? Otro aspecto a considerar es el desarrollo urbano que puede influir en el sistema de producción de las zonas rurales de los alrededores, constituyendo así mercados potenciales. Es el caso de Caigua, que sin duda se benefició de la epopeya de Camiri o Yacuiba antes de someterse a la crisis, y que hoy depende del crecimiento de Villamontes. En cuanto a Tolomosa, la proximidad de Tarija facilita el flujo de algunas producciones comerciales. También en las ciudades se está desarrollando la industria agroalimentaria del departamento, reflejada en los alrededores: el Piedemonte ha proporcionado y proporcionará la soja a la refinería de Villamontes, y la presencia de vacas lecheras en el norte del valle de Tolomosa se relaciona con la fábrica PIL de Tarija. Además, las aglomeraciones podrían extenderse a las localidades rurales (lo que ya está ocurriendo en la cuenca de Tolomosa), y los agricultores podrán vivir en la ciudad, debido al desahogo de los territorios urbanos, principalmente permitido para la mejora de vías de comunicación y de medios de transporte, que hace posible trabajar cada vez más lejos de casa (Levy \& Lussault, 2003, p. 711).

La evolución de esta relación campo-ciudad corresponde sin duda a una transformación fundamental del espacio rural en las últimas décadas y va mucho más allá de la dinámica emigratoria de campesinos hacia los centros urbanos. De hecho, los cambios son tan fuertes y complejos que interrogan cada vez más sobre la validez de la categorización tradicional entre zonas urbanas y rurales. Este cuestionamiento genera actualmente muchas discusiones científicas en África y Asia. Como lo señala Anthony Riggs (2012) para introducir su estudio de la evolución de zonas rurales de Tailandia, durante los 25 últimos años, no todos los agricultores habitan los pueblos, ni los habitantes de pueblos son agricultores; no todo el espacio rural se dedica a la agricultura, ni la agricultura se desarrolla sólo en el campo; no todos los miembros de un hogar rural viven en el campo, y no necesariamente trabajan en zonas rurales. Los conceptos de espacio rural, de asentamiento rural, de pueblo rural y de actividad agrícola tendrán que redefinirse. 



\section{Anexo metodológico}

\section{ENTol 2002 (CuenCa De Tolomosa)}

La encuesta Entol 2002 se desarrolló en varias fases. La primera ocurrió desde principios del año 2002 y hasta el 5 de febrero: misiones exploratorias, entrevistas, y recopilación y análisis de los datos disponibles sobre el valle, permitieron seleccionar las localidades a investigar y entonces adaptar el cuestionario de Entar $2001^{13}$ a las necesidades de nuestro trabajo en las zonas rurales. Después, del 5 al 15 de febrero, la prioridad fue contactar con las autoridades locales, preparar los planes de sondeo y asegurar el apoyo logístico de la encuesta. Así, del 15 al 20 de febrero, nos concentramos en la selección y formación de los encuestadores. Finalmente, la encuesta se realizó entre el 20 de febrero y 1 de marzo, en las localidades de Pampa Redonda, Pinos Sur, Tolomosa Norte, San Andrés y Turumayo [ubicados en el Mapa A-1].

Estas comunidades ${ }^{14}$ debían proporcionar una muestra para ilustrar la diversidad de los asentamientos humanos en el valle (este argumento se desarrolla en el primer capítulo de este libro). Dada la falta de cartografía de las zonas a encuestar, hicimos ${ }^{15}$ planos de las localidades seleccionadas [ver Mapa

\footnotetext{
${ }^{13}$ El cuestionario de Entar 2001, encuesta del programa Frontarbol realizada en septiembre del año anterior, fue la base para la preparación de Entol 2002.

${ }^{14}$ Se llevó a cabo la recopilación y el análisis de los datos necesarios para la selección entre enero y febrero del mismo año. Durante esta etapa, nos hemos beneficiado de la valiosa colaboración (voluntario) de Ramiro Flores Cruz, estudiante de sociología de la Universidad de Buenos Aires (UBA), así como la de Hugo Arze, profesor de economía en la Universidad Juan Misael Saracho, Freddy Oreillana, ingeniero agrónomo que trabajó en varias localidades del valle, y de Liz Pérez, socióloga que realiza su tesis de maestría sobre la comunidad de Pampa Redonda.

${ }^{15}$ En colaboración con Armando Coyo y Rocío Méndez, dos estudiantes de la Universidad Juan Misael Saracho.
} 
Entol 2002 - Valle de Tolomosa - Plan de las localidades encuestadas

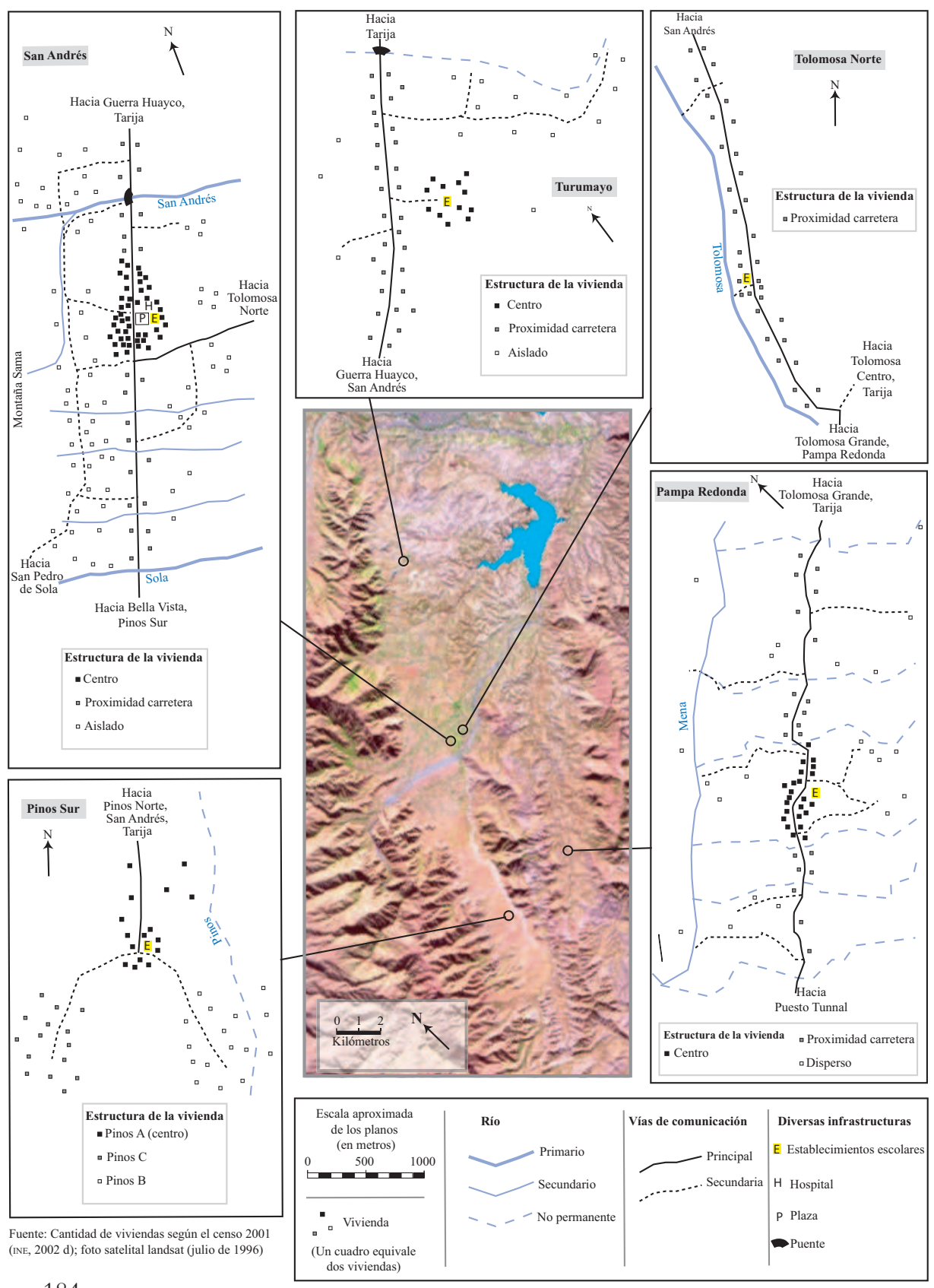

184 
Entol 2002 - Recursos humanos

\begin{tabular}{|ll|}
\hline & Preparación \\
Arming Coyo & Liz Pérez \\
Ceydric Martin & Philippe Hamelin \\
Freddy Orellana & Ramiro Florez Cruz \\
Hugo Arze & Rocío Méndez \\
\hline
\end{tabular}

\begin{tabular}{|ll|}
\hline \multicolumn{2}{|c|}{ Encuestadores } \\
Adriana Astorga & María Nelly Morales (3) \\
Arming Coyo & Ramiro Flores Cruz (4) \\
Blanca Arce & Rocío Méndez (4) \\
Ceydric Martin (6) & Seleni Velarde (5) \\
Dubeyza Benítez (1) & Siney Ichazo (6) \\
Gabriela Aracena & Vanessa Tocary \\
Horacio Gallardo & Veroska Acebey \\
Liz Pérez (2) & \\
\hline
\end{tabular}
(1) Salvo San Andrés
(4) Salvo Turumayo
(2) Salvo Pampa Redonda y Turumayo
(5) Salvo Tolomosa y Turumayo
(3) Salvo San Andrés y Turumayo
(6) Sólo Turumayo

\section{Supervisores}

Ceydric Martin Ramiro Flores Cruz Hugo Arze

\section{Codificación/Vaciado/Limpieza de datos}

Ceydric Martin

Maria Nelly Morales

Hortensia Fernández

Verónica Peralta

A-1], lo que permitió identificar las estructuras de las comunidades y así —-teniendo en cuenta las limitaciones logísticas como el número de encuestadores disponibles, ${ }^{16}$ la accesibilidad de las zonas a encuestar y los límites financie-

${ }^{16}$ La encuesta Entol 2002 tuvo lugar durante el verano, justo después del carnaval. En estas condiciones, la contratación de encuestadores voluntarios, la mayoría entre los estudiantes 
Entol 2002 - Hogares encuestados según las comunidades y sus estructuras

\begin{tabular}{|c|c|c|c|c|c|}
\hline Comunidad & Fecha & hog & $\begin{array}{l}\text { Cantidad de } \\
\text { ares encuestad }\end{array}$ & & $\begin{array}{l}\text { Cantidad de } \\
\text { encuestadores }\end{array}$ \\
\hline \multirow{4}{*}{ Pampa Redonda } & \multirow{4}{*}{$\begin{array}{l}20 \text { febrero, día } \\
\text { entero }\end{array}$} & \multirow{3}{*}{ Zona } & Centro & 18 & \multirow{4}{*}{11} \\
\hline & & & Carretera cerca & 16 & \\
\hline & & & Dispersado & 16 & \\
\hline & & Total & & 50 & \\
\hline \multirow{4}{*}{ Pinos Sur } & \multirow{4}{*}{$\begin{array}{l}21 \text { febrero, } \\
\text { mañana }\end{array}$} & \multirow{3}{*}{ Zona } & Pinos A & 10 & \multirow{4}{*}{12} \\
\hline & & & Pinos B & 11 & \\
\hline & & & Pinos C & 10 & \\
\hline & & Total & & 31 & \\
\hline Tolomosa Norte & 21 febrero, tarde & Total & & 30 & 11 \\
\hline \multirow{4}{*}{ San Andrés } & \multirow{4}{*}{$\begin{array}{l}22 \text { febrero, día } \\
\text { entero }\end{array}$} & \multirow{3}{*}{ Zona } & Centro & 28 & \multirow{4}{*}{12} \\
\hline & & & Carretera cerca & 12 & \\
\hline & & & Dispersado & 36 & \\
\hline & & Total & & 76 & \\
\hline \multirow{4}{*}{ Turumayo } & \multirow{4}{*}{$\begin{array}{l}\text { 1ero marzo, } \\
\text { mañana }\end{array}$} & \multirow{3}{*}{ Zona } & Centro & 5 & \multirow{4}{*}{11} \\
\hline & & & Carretera cerca & 16 & \\
\hline & & & Aislado & 5 & \\
\hline & & Total & & 26 & \\
\hline
\end{tabular}

Fuente: Entol 2002.

ros- establecer nuestro plan de sondeo sobre un muestro subjetivo por decisión razonada. Se previó encuestar al menos $25 \%$ de los hogares registrados por el INE [ver tabla abajo], que se encuentran en zonas representativas de las diversas formas de implantación del hábitat en las comunidades.

- Decidimos dedicar un día entero a la comunidad de Pampa Redonda con el fin de acceder a algunas viviendas alejadas (fuera del centro y del largo de la pista principal, las viviendas de la comunidad están muy dispersas y se ubican en un relieve altamente accidentado). Además, como nuestro objetivo es encuestar por lo menos una cuarta parte de los 129 hogares

de la universidad Juan Misael Caracho, fue laboriosa [ver anexo metodológico para la lista de participantes]. 
Entol 2002/INE 2001 -Individuos y hogares

\begin{tabular}{lc|c}
\hline \hline & \multicolumn{2}{c}{ Censo INE 2001 } \\
& Individuos & Hogares \\
\hline Tolomosa Norte & 245 & 52 \\
Pampa Redonda & 418 & 129 \\
San Andrés & 1,204 & 274 \\
Pinos Sur & 374 & 99 \\
Turumayo & 556 & 113 \\
\hline \hline
\end{tabular}

\begin{tabular}{lc|c}
\hline & \multicolumn{2}{c}{ Entol 2002 } \\
& Individuos & Hogares \\
\hline Tolomosa Norte & 141 & 27 \\
Pampa Redonda & 209 & 46 \\
San Andrés & 390 & 75 \\
Pinos Sur & 135 & 27 \\
Turumayo & 132 & 26 \\
\hline \hline & & \\
\hline \hline & \% encuestado por Entol 2002 \\
\hline Tolomosa Norte & 57.6 & Hogares \\
Pampa Redonda & 50.0 & 51.9 \\
San Andrés & 32.4 & 35.7 \\
Pinos Sur & 36.1 & 27.4 \\
Turumayo & 23.7 & 23.0 \\
\hline \hline
\end{tabular}

Fuente: Censo INE, 2001 (INE, 2002 b), Entol 2002.

censados por el INE (mínimo 32 familias), los 11 estudiantes que trabajaron ese día debían completar de tres a cuatro formularios en promedio, ${ }^{17}$

\footnotetext{
${ }^{17} \mathrm{El}$ tiempo de la encuesta varía considerablemente según el tamaño del hogar: en el caso de Entol 2002, osciló entre 10 y 50 minutos. Sin embargo, suponemos que la encuesta promedio toma aproximadamente media hora.
} 
Entol 2002 - Varios momentos de la encuesta

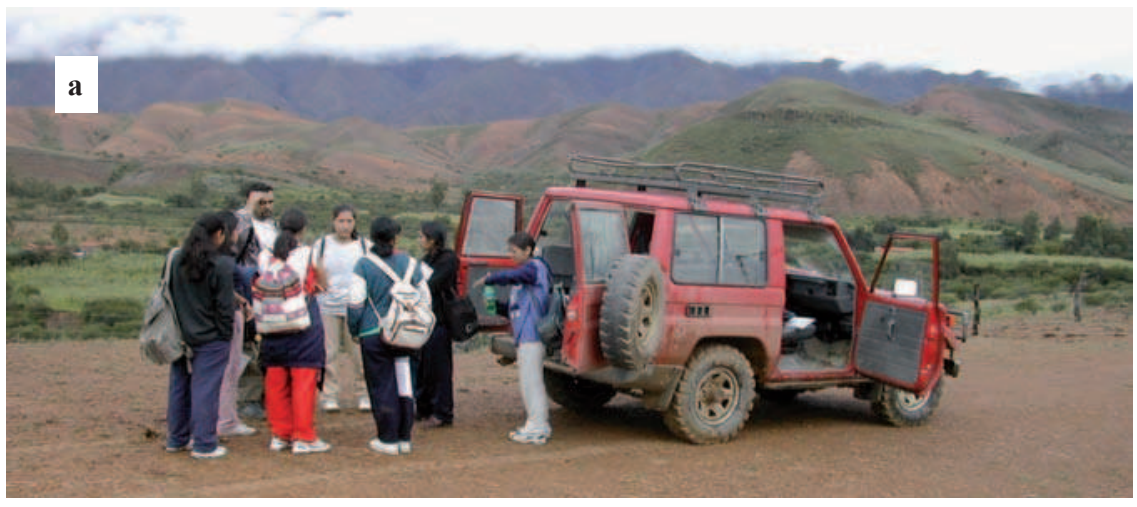

Imagen a: agrupamiento para la reco-lección de datos de hogares aislados de la comunidad de Pampa Redonda. Se pueden ver las cuencas erosionadas.

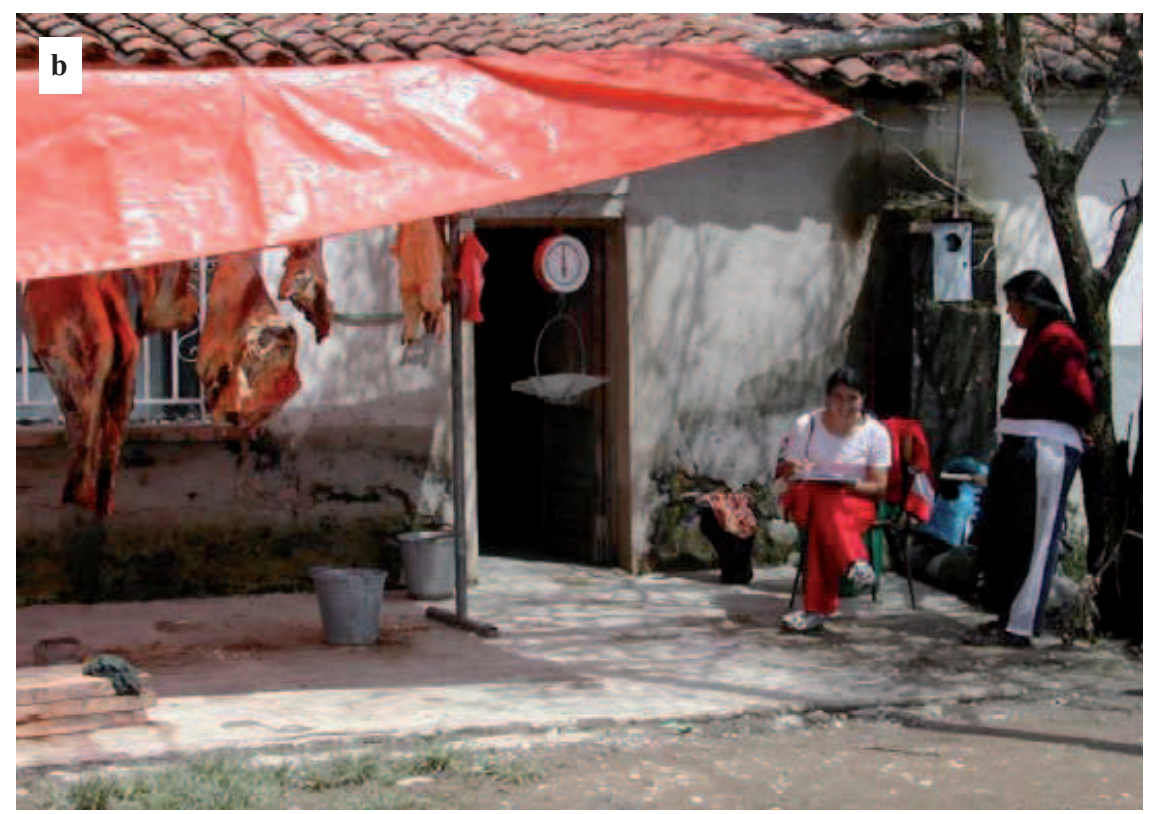

Imagen b: encuesta a una de las dos carnicerías del centro de San Andrés. 


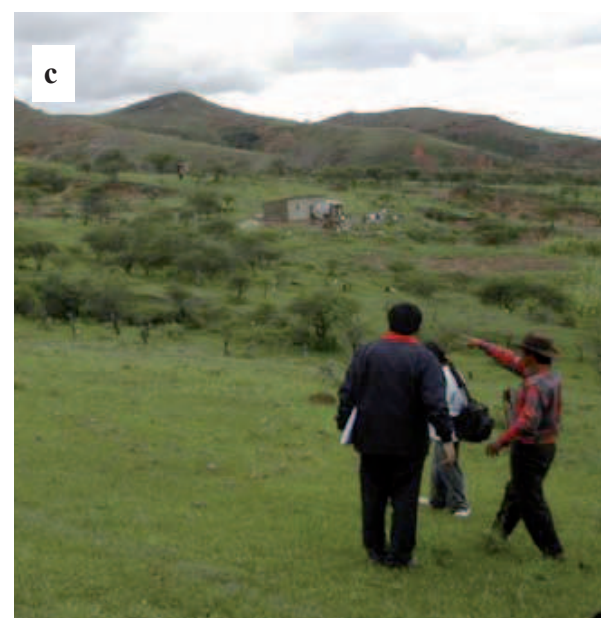

Imagen c: en Pampa Redonda, un campesino indica al estudiante como acceder al hogar que se visualiza en segundo plano.

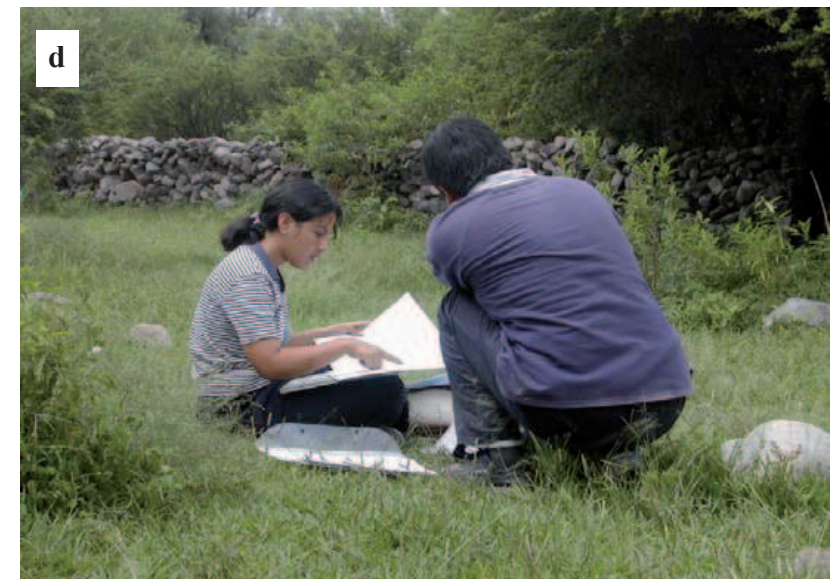

Imagen d: en Turumayo, entre dos encuestas se revisa el cuestionario. En segundo plano se nota el muro de piedra levantado para cuidar las zonas cultivadas de los animales.

Fotos a, b, c y d: Ceydric Martin, febrero de 2002. 
lo que nos permitió dedicar tiempo a los ajustes del cuestionario y al mejoramiento de su comprensión. Finalmente, la meta inicial fue superada y logramos encuestar 50 hogares: 18 en la zona central, 16 cerca de la pista que une a Tarija con Pampa Redonda y 16 en áreas remotas. Según nuestras observaciones y las autoridades de la comunidad, esta muestra respeta la distribución de la población en la localidad.

- Al día siguiente pasamos la mañana encuestando habitantes de la comunidad de Pinos Sur. La simplicidad de la distribución de las viviendas (concentradas en tres zonas de tamaño similar, y relativamente bien accesibles) nos permitió realizar nuestro trabajo en medio día. Así, con 12 encuestadores, estudiamos 10 familias en Pinos A, 11 en Pinos B y 10 en Pinos C, para un total de 31 hogares encuestados (27\% del total registrado por el INE).

- Durante la tarde, el levantamiento de datos se realizó en la localidad de Tolomosa Norte (cuyo hábitat se encuentra en su mayor parte alineado a la carretera transversal que une San Andrés con Tolomosa Grande). Los encuestadores se repartieron a lo largo de este eje de comunicación y sondearon una de cada dos casas. Así se entrevistaron a 30 familias que representan más de la mitad de las viviendas de acuerdo con los datos del censo del INE.

- El día siguiente se dedicó por completo a la localidad de San Andrés, la más importante del valle. Aquí se identificaron tres estructuras principales: el centro (que agrupa alrededor de un tercio de los hogares encuestados), la periferia (viviendas dispersas alrededor de diversos ríos que cruzan la localidad, y que concentra aproximadamente la mitad de la población), y una zona intermedia (en los bordes de la pista que conecta el norte de la cuenca con Tarija). Se encuestaron 76 hogares (27\% de los registrados por el INE): 28 en la zona central, 12 cerca de la carretera y 36 en las periferias más o menos lejanas.

- Por razones prácticas tuvimos que esperar hasta el primero de marzo para completar Entol 2002 con el levantamiento de datos en Turumayo. De acuerdo con nuestras observaciones y con la información de las autoridades locales, la población de esta comunidad se concentra principalmente a lo largo de la carretera que va a Tarija, el resto se distribuye alrededor de un pequeño centro y en zonas remotas. Según esta distribución elegimos cinco hogares en la zona central, 16 cerca de la carretera 
principal y otros cinco en zonas remotas para un total de 26 (que significa $23 \%$ de los hogares registrados por el INE). ${ }^{18}$

Al final Entol 2002 encuestó 213 hogares para un total de 1055 personas.

\section{EnVIL 2002 (comunidad de Caigua)}

Se seleccionaron las unidades de análisis de la encuesta Envil 2002 durante una estadía de investigación, en mayo de 2002. Decidimos investigar la ciudad de Villamontes y queríamos completar nuestro estudio urbano con el enfoque rural, para comprender la dinámica reciente de la población del Piedemonte tarijeño (Martin, 2010). Por razones logísticas, nos vimos obligados a limitar la elección a una sola localidad ${ }^{19}$ de la zona. Durante nuestra visita a Villamontes, las autoridades locale ${ }^{20}$ nos aconsejaron ir a Caigua, una de las comunidades más importantes del Piedemonte Norte (708 habitantes según el censo de 2001, clasificada justo detrás de Tiguipa, 830 habitantes, cf. Mapa B-1), que tiene la notoriedad de ser una zona de recepción para los inmigrantes.

Acatamos la recomendación y visitamos Caigua, ubicada a 20 kilómetros al norte de Villamontes, y constatamos cierto dinamismo (creación reciente de la comunidad, agricultura innovadora, presencia de inmigrantes). Además, como no existía ningún estudio sobre el desarrollo de esta localidad, decidimos utilizarla como unidad de análisis del Piedemonte de Tarija.

De regreso a la capital departamental, nos dedicamos a la elaboración de un cuestionario común a las encuestas previstas en Villamontes o en zona rural, que incorporaba un módulo para la agricultura a detalle. Nuestro objetivo era simplificar los formularios utilizados en nuestras investigaciones anteriores (Entar 2001, Enyac 2002 y Entol 2002), por dos razones principales. Primera, evitar las confusiones surgidas en Enyac 2002, ya que la complejidad del cuestio-

\footnotetext{
${ }^{18}$ A destacar que Turumayo es el único caso en que no llegamos a nuestra meta mínima de $25 \%$ de los hogares encuestados.

${ }^{19}$ De hecho, el presupuesto de Envil 2002 debía esencialmente autorizar la encuesta de la ciudad de Villamontes, además de optimizar los recursos disponibles con el fin de permitirnos trabajar dentro del ámbito rural. La elección de Caraparí fue para tener un enfoque de los Valles Subandinos orientales. El establecimiento de un precronograma de la encuesta, teniendo en cuenta los recursos financieros, nos dejó muy poco espacio para estudiar el Piedemonte rural. ${ }^{20}$ Notablemente Guillermo Salazar Echart, corregidor mayor (representante directo del prefecto) del municipio de Villamontes.
} 
Envil 2002 (Comunidad Caigua) - Plan esquemático de la localidad

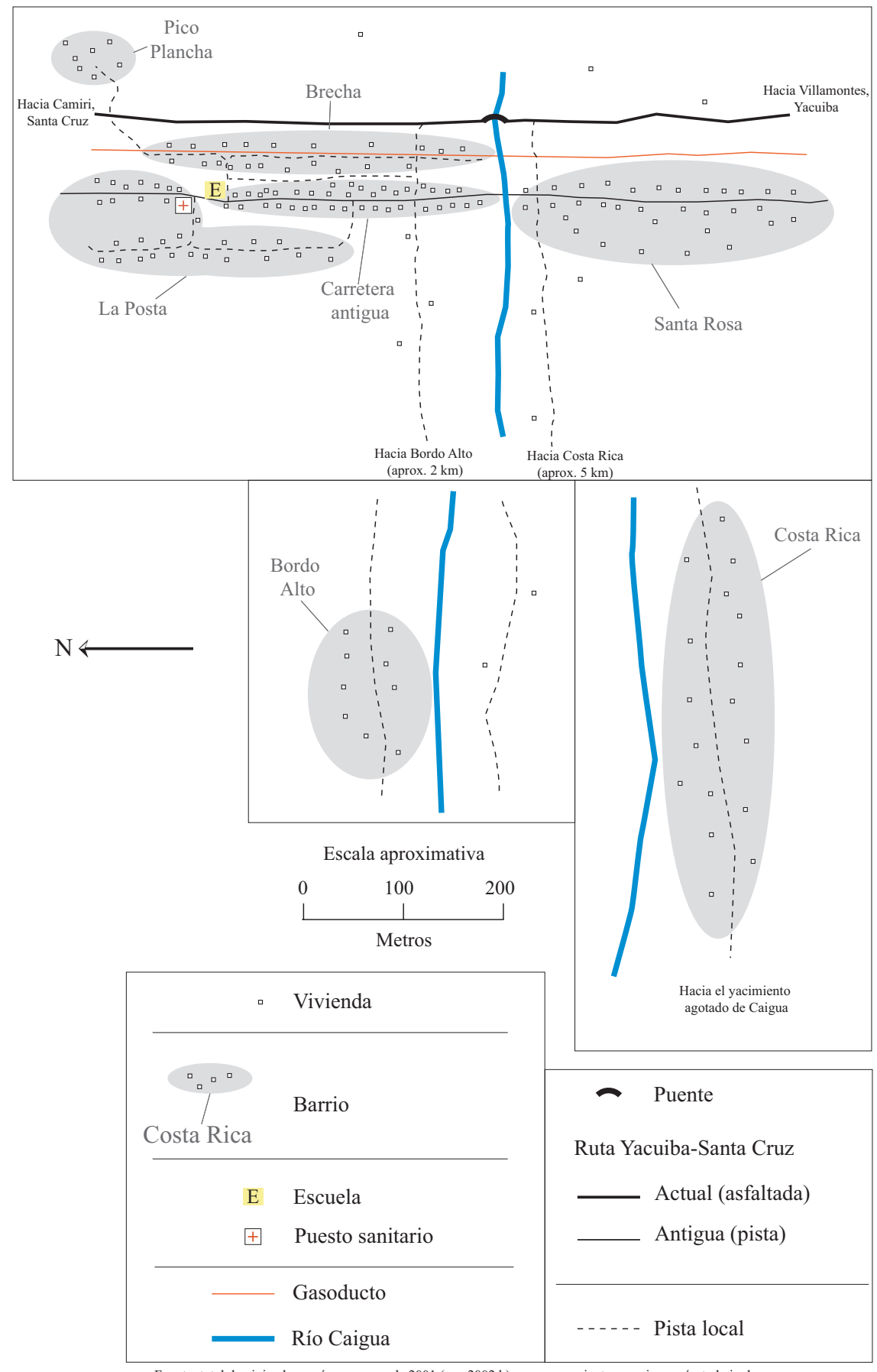

Fuente: total de viviendas según censo INE de 2001 (INE, 2002 b) y reagrupamientos propios según trabajo de campo. 
Envil 2002 (Comunidad Caigua) - Recursos humanos

\begin{tabular}{|l|}
\hline \multicolumn{2}{|c|}{ Misión exploratoria } \\
Ceydric Martin
\end{tabular}

\begin{tabular}{|lc|}
\hline & Cuestionario \\
Ceydric Martin & Philippe Hamelin \\
Hugo Arze & \\
\hline
\end{tabular}

\begin{tabular}{|l|l|}
\hline \multicolumn{2}{|c|}{ Encuestadores } \\
Caigua y Villamontes & Villamontes \\
Dalcy Camacho Arce & Gabriela Aracena \\
Gledia Castillo & Arming Coyo \\
Horacio Gallardo & Beimar Guerrero \\
Omar Jaramillo & Wilfredo Mamani \\
Daniela Jimena & Norma Nievez \\
Fabiana Sfarcich & Eloina Palacios \\
\hline
\end{tabular}

\begin{tabular}{|c|c|}
\hline Cevdric Martin & $\begin{array}{l}\text { Supervisores } \\
\text { Hugo Arze }\end{array}$ \\
\hline
\end{tabular}

\section{Codificación/captura/limpieza de base}

Ceydric Martin Verónica Peralta

Hortensia Fernández

nario había perturbado tanto al entrevistado como al encuestador, y segunda, para acortar el tiempo promedio de aplicación de las encuestas y con ello superar las limitaciones logísticas antes mencionadas. ${ }^{21}$ Los 14 encuestadores que participaron en Envil 2002 [cf. tabla abajo], todos ellos voluntarios, fueron seleccionados según la calidad de su participación anterior en nuestro programa de investigación. Teníamos un grupo particularmente calificado y motivado.

${ }^{21}$ En Enyac 2002, se estimó que los encuestadores podían completar de cuatro a cinco cuestionarios por medio día, para Villamontes el cálculo fue de cinco a seis. 


\begin{tabular}{|c|c|c|c|c|c|}
\hline & & $\begin{array}{l}\text { Cantidad de } \\
\text { vivienda* }\end{array}$ & $\%$ del total & $\begin{array}{l}\text { Cantidad de hoga- } \\
\text { ress encuestados }\end{array}$ & $\begin{array}{c}\% \text { del total de hogares } \\
\text { encuestados (según el INE) }\end{array}$ \\
\hline \multirow{4}{*}{ Centro } & La Posta & 30 & & 23 & \\
\hline & Brecha & 21 & & 8 & \\
\hline & Carretera antigua & 36 & & 7 & \\
\hline & subtotal & 87 & 53.7 & 38 & 43.7 \\
\hline \multirow{3}{*}{$\begin{array}{l}\text { Primera } \\
\text { periferia }\end{array}$} & Pico Plancha & 7 & & 5 & \\
\hline & Santa Rosa & 30 & & 20 & \\
\hline & Subtotal & 37 & 22.8 & 25 & 67.6 \\
\hline \multirow{3}{*}{$\begin{array}{l}\text { Zonas } \\
\text { alejadas }\end{array}$} & Costa Rica & 17 & & 9 & \\
\hline & Bordo Alto & 9 & & 0 & \\
\hline & Subtotal & 26 & 16.0 & 9 & 34.6 \\
\hline \multicolumn{2}{|c|}{ No ligados a unos barrios } & 12 & 7.4 & 0 & 0.0 \\
\hline \multicolumn{2}{|c|}{ Total general } & 162 & 100.0 & 72 & 44.4 \\
\hline
\end{tabular}

*: repartición por barrio según las informaciones aproximativas de las autoridades locales

Fuente: cantidad de vivienda total según el censo del INE de 2001 (INE, 2002 b), Envil 2002 y agrupaciones propias. 
Envil 2002 - Varios momentos de la encuesta
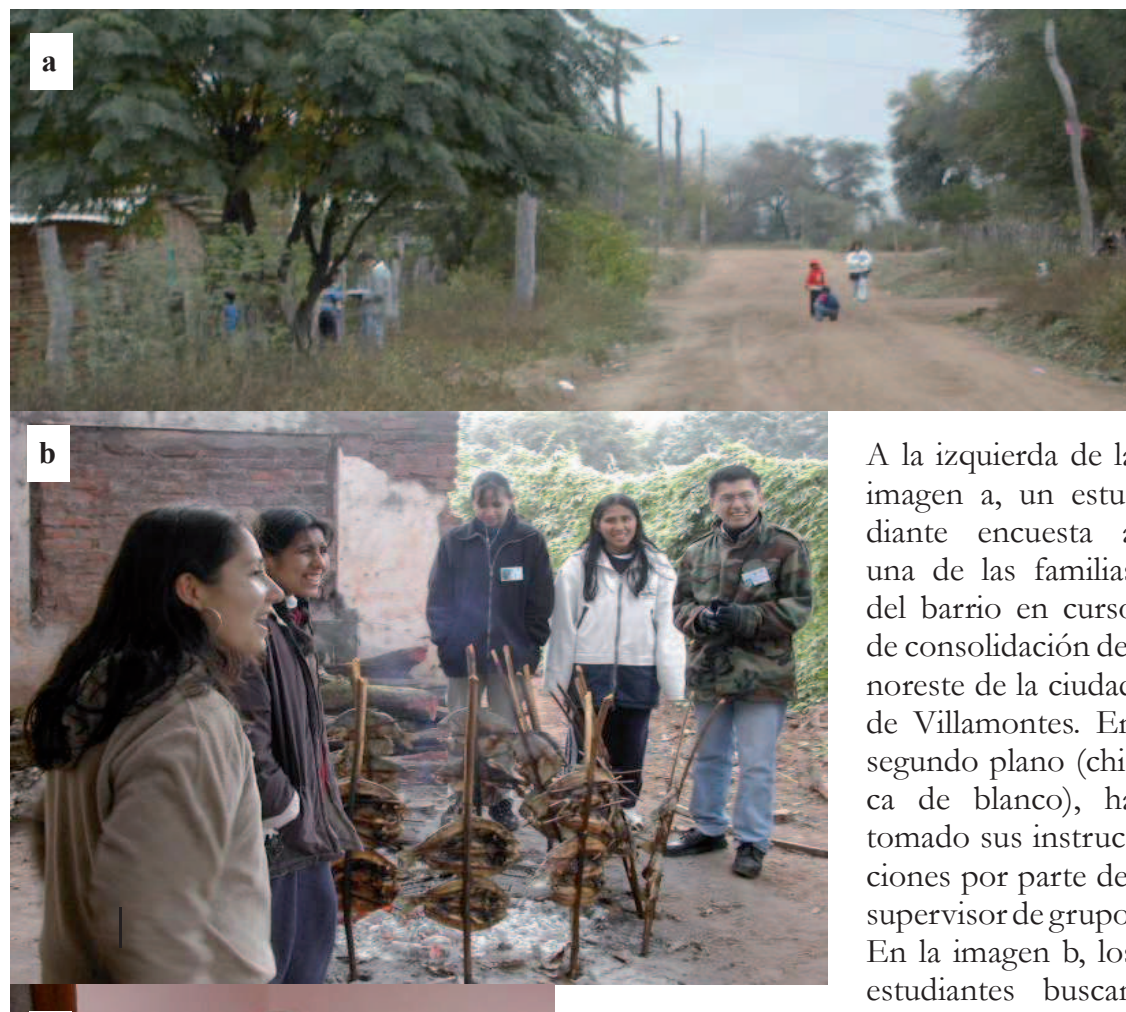

A la izquierda de la imagen a, un estudiante encuesta a una de las familias del barrio en curso de consolidación del noreste de la ciudad de Villamontes. En segundo plano (chica de blanco), ha tomado sus instrucciones por parte del supervisor de grupo. En la imagen b, los estudiantes buscan

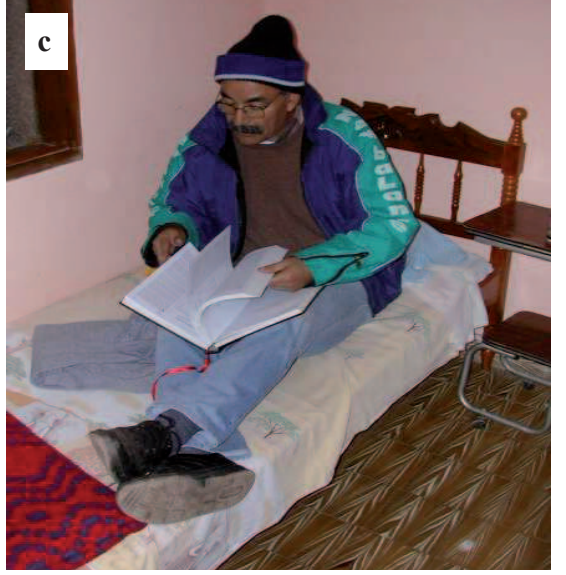
un poco de calor cerca de donde se prepara la comida ofrecida por la municipalidad (cocinado a la cruz del Surubi, pescado común en el Pilcomayo). Podemos notar las etiquetas de identificación en la ropa de los encuestadores, una novedad de Envil 2002, para mejorar la comunicación con la población local. Finalmente, de regreso al hotel después de la encuesta, el profesor Hugo Arze consulta el atlas municipal de Bolivia (INE, 1999) para conocer sobre la provincia de una localidad censada (imagen c). 


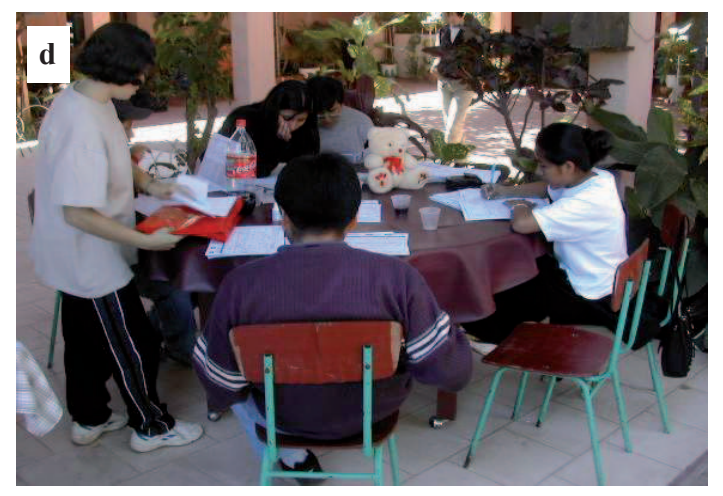

Los estudiantes revisan sus cuestionarios en la imagen $\mathrm{d}$. Fotos a, b, c y d: Ceydric Martin, julio de 2002.

Con el fin de preparar el estudio de Caigua, analizamos previamente la estructura del hábitat de la comunidad, ${ }^{22}$ cuyo desenvolvimiento parece haber sido condicionado por diferentes lógicas. Históricamente, esta localidad se ha desarrollado a lo largo del antiguo camino entre Yacuiba y Santa Cruz, a la orilla izquierda del río (que corresponde al barrio Carretera Central, cf. Mapa en el anexo metodológico). Es alrededor de estos primeros asentamientos que se desarrolló el centro de la comunidad; al Norte, el barrio de La Posta y al Este, el de la Brecha (sus orígenes se remontan a los trabajos de tubería del gaseoducto de Yabog en 1972 que resultó en la remoción de una amplia banda de unos veinte metros). La repartición de las viviendas es densa en los tres barrios que conforman el centro de Caigua y que concentran más de la mitad de los hogares en la comunidad (87 de un total de 162, cf. tabla abajo).

Enseguida distinguimos dos periferias: el barrio de Santa Rosa, situado también a lo largo de la antigua pista pero sobre la otra orilla del río Caigua, y aquella de Pico Plancha, al otro lado de la ruta pavimentada que une Yacuiba con Santa Cruz. Estos dos conjuntos, cuya repartición de las viviendas está más dispersa, concentran casi una cuarta parte de los hogares en la comunidad (37 de 162). Finalmente, el tercer grupo está conformado por dos barrios aislados de Caigua, ubicados en los primeros relieves de las montañas de Aguaragüe, en cada lado del río Sola: Bordo Alto situado a unos $2 \mathrm{~km}$ del centro y Costa Rica a unos $5 \mathrm{~km}$, cuyo desarrollo se explica por la apertura de un pista en los años setenta que permitía el acceso al depósito del petróleo local. Las zonas remotas de Caigua, donde las viviendas están muy dispersas,

\footnotetext{
${ }^{22}$ Como en el caso de Tolomosa, no hemos podido apoyarnos sobre una cartografía de la localidad.
} 
albergan cerca de 15\% de los hogares en la comunidad (26 de 162). Completamos el recuento señalando la presencia de 12 hogares dispersos que no se adjuntan a ningún barrio.

Enseguida, procedimos a un sondeo de cada estructura detectada. Dispusimos de siete encuestadores y de un día completo (5 de julio de 2002) para llevar a cabo nuestro censo. Se lograron completar de ocho a nueve cuestionarios, en promedio, por investigador. ${ }^{23}$ Esta media superó nuestras propias expectativas ya que encuestamos 72 hogares, es decir 44,4\% de los registrados por el INE (exactamente $42,5 \%$ en el centro, $67,6 \%$ en la primera periferia y $34,6 \%$ para los barrios remotos, cf. tabla abajo). ${ }^{24}$ La sobrerrepresentación de los hogares encuestados en la primera periferia no parece problemática, ya que el conjunto intermedio se compone de dos casas cerca del centro remoto. Finalmente, la tasa del sondeo global nos permite concluir una buena representación de las personas en la comunidad de Caigua.

${ }^{23}$ Es decir entre cuatro y 4.5 cuestionarios por encuestador por cada medio día, estimación ligeramente inferior a aquella de Villamontes (entre cinco y seis). El acceso a los hogares en el medio rural es más complejo.

${ }^{24} \mathrm{Al}$ no disponer de un vehículo el trabajo se dificultó y no pudimos encuestar a la minoría de los hogares dispersos no incorporados a los barrios. 



\section{Bibliografía}

Amilhat Szary, Anne-Laure (2007). "Are Borders More Easily Crossed Today? The Paradox of Contemporary Trans-Border Mobility in the Andes". Geopolitics, 12(1), pp. 1-18.

Baby-Collin, Virginie, Cortes, Geneviève \& Miret, Naïk (2009). "Migrants andins en Espagne: ruptures et continuités d'une géographie économique de l'immigration". (V. Baby-Colin, A. Bensaâd, \& P. Sintès, Éd.) Méditerranée, Migrations et territoires de la mobilité en Méditerranée, (113), pp. 41-53.

Beck, Stephan, Paniagua, Narel, Preston, David (2001). Historia, Ambiente y sociedad en Tarija, La Paz, Instituto de Ecología, 278 pp.

Benencia, Roberto (1997). "De peones a patrones quinteros. Movilidad social de familias bolivianas en la periferia bonaerense", Estudios Migratorios Latinoamericanos (35), Buenos Aires, Centro de Estudios Migratorios Latinoamericanos, pp. 63-102.

Benencia, Roberto (2005). Bolivianización de la borticultura en la Argentina. Procesos de migración transnacional y construcción de territorios productivos. Conicet, Buenos Aires.

Benencia, Roberto; Geymonat, Marcela (2005). "Migración transnacional y redes sociales en la creación de territorios productivos en la Argentina. Río Cuarto, Córdoba" Cuadernos de Desarrollo rural, (55), Pontificia Universidad Javeriana, Bogotá, Colombia, pp. 9-28.

Benencia, Roberto, Quaranta, German (2006). "Mercados de trabajo y economías de enclave. La 'escalera boliviana' en la actualidad", Estudios Migratorios Latinoamericanos (60), Buenos Aires, Centro de Estudios Migratorios Latinoamericanos, pp. 413-432. 
Blanchard, Sophie (2006). "Les migrants andins dans les Basses Terres boliviennes : mondialisation des stratégies migratoires". La mondialisation côté Sud: acteurset territoires. IRD Editions, pp. 163-179.

Bologna, Eduardo (2010). "Migraciones entre países del sur: los cambios y las continuidades en los flujos limítrofes hacia Argentina”, Migraciones Internacionales, (5, 3), enero-junio, Colegio de la Frontera Norte, México, pp. 175-209.

Brunet, Roger, Ferras, Robert, Théry, Hervé (1993). "Les mots de la géographie: dictionnaire critique", Montpellier - Paris, Reclus - La Documentation française, $520 \mathrm{pp}$.

Cambrézy, Luc (1996). "Chercher ailleurs...: droit d'ingérence scientifique ou partenariat partagé?", Les sciences hors d'Occident an 20e siècle, París, Instituto Francés de Investigación Científica para el Desarrollo en Cooperación (Orstom), pp. 147-153.

Cebián, Mar (2008). "Los diferentes determinantes del flujo de inmigrantes latinoamericanos en España: 1995-2006”. Dans N. C. Meichtry, A. Pellegrino, \& E. L. Bologna (Éd.), Migrantes latinoamericanos. El estado de las investigaciones en la región. Córdoba, Argentina: UNFPA: ALAP: Universidad Nacional de Córdoba.

CEDLA (1988). "Tenencia y uso de la tierra en el departamento de Tarija", La Paz, Centro de Estudios para el Desarrollo Laboral y Agrario, p. 245.

Celton, Dora (1995) "Plus d'un siècle d'immigration internationale en Argentine", Revue Européenne des Migrations Internationales (11, 2), Poitiers, Association pour l'Etude des Migrations Internationales, pp. 145-165.

Cortes, Geneviève (2002a). "L'accès aux ressources foncières, enjeu de l'émigration rurale andine". (H. Domenach \& P. Gonin, Éd.) Revue européenne des migrations internationales, Migrations et environnement, 18(2), pp. 83-104.

Cortes, Geneviève (2002b). "Migrations et mobilités circulatoires dans les Andes boliviennes. La face cachée d'une ruralité en résistance". Cabiers du monde bispanique et luso-brésilien (79), pp. 93-115.

Cortes, Geneviève (2004). "Ir para quedarse. Sobrevivencia y mutaciones de las sociedades campesinas andinas" (Bolivia), La Paz, Institut de re- 
cherche pour le développement, Instituto Francés de Estudios Andinos, Plural, 474 pp.

D’Andréa, Nicolas (2004) "Effets de frontière, migrations et redistribution du peuplement en Bolivie: les dynamiques territoriales dans le département du Tarija", Aix-en-Provence, Universidad Paul Cezanne AixMarseille III - Instituto de Ordenamiento Regional, tesis de doctorado en Ordenamiento territorial, urbanismo, p. 425.

D’Andréa, Nicolas (2007) "Recomposition régionale dans le Sud bolivien et migrations vers l'Argentine", Revue Européenne des Migrations Internationales, (23, 2). Poitier, Francia, pp. 173-198.

D’Andréa, Nicolas y Martin, Ceydric (2007). "La ciudad de Tarija: análisis de los factores de estabilidad del crecimiento demográfico", in Domenach, Hervé, Arze, Hugo, Celton, Dora, Hamelin, Philippe, Movilidad y procesos migratorios en el espacio de frontera argentino-boliviana, Prensa Universitaria de Córdoba, Córdoba, Argentina, pp. 39-54.

De Grammont, Hubert (2004) “'La nueva ruralidad en America Latina”. Revista Mexicana de Sociología, 66 (octubre), pp. 279-300. doi:10.2307/3541454

Domenach, Hervé y Picouet, Michel (1995). "Les migrations", Paris, Presses Universitaires de France, col. Que sais-je ?, 128 pp.

Domenach, Hervé (2001) "Les migrations internationales", Les Documents et Manuels du Ceped (12), París, Centro Población y Desarrollo, pp. 5158.

Domenach, Hervé, Arze, Hugo, Celton, Dora y Hamelin, Philippe (2007). "Movilidad y procesos migratorios en el espacio de frontera argentino boliviana", Prensa Universitaria de Córdoba, Córdoba, Argentina, p. 274.

Eastwood, D. A., \& Pollard, H. J. (1986). Colonisation and Coca in the Chapare, Bolvia: A Development Paradox for Colonisation Theory. Tijdschrift voor economische en sociale geografie, 77(4), pp. 258-268.

Franqueville, André (2000). "La Bolivie, d'un pillage à l'autre”, París, Institut de recherche pour le développement, p. 292.

Godard, Henri, \& Sandoval, Godofredo (2008). Migración transnacional de los Andes a Europa y Estados Unidos. IPEA, Instituto Francés de Estudios Andinos. 
Guibert, Martine, \& Velut, Sebastien (2011). Les agriculteurs latino-américains: dynamiques et enjeux de développement. L'Amérique latine est bien partie (édition 2011, pp. 99-104). La Documentation française.

Guilmoto, Christophe Z. y Sandron, Frédéric (2003) "Migration et développement", París, La documentation française, p. 142.

Hamelin, P. (2007). “El Tarija rural: un espacio en mutación”. Dans H. Domenach, H. Arze, D. Celton, \& P. Hamelin (Éd.), Movilidad y procesos migratorios en el espacio de frontera argentino boliviana Cordoba, Argentine: Prensa Universitaria de Córdoba, (p. 163-174)

Hamelin, Philippe; Martin, Ceydric y Bologna, Eduardo (2007) "Anexo 1: Metodología de la encuesta", Movilidady procesos migratorios en el espacio de frontera argentino-boliviana, Prensa Universitaria de Córdoba, Córdoba, Argentina, pp. 219-270.

Hinojosa Gordonova, Alfonso y Cortez Franco, Guido (1999). "Estrategias migratorias: entre la subsistencia y la búsqueda de oportunidades en el valle tarijeño", Estudios Migratorios Latinoamericanos (40-41), Buenos Aires, Centro de Estudios Migratorios Latinoamericanos, pp. 595-622.

Hinojosa Gordonova, Alfonso; Pérez, Liz y Cortez Franco, Guido (2000). "Idas y venidas: Campesinos tarijeños en el norte argentino", La Paz, Programa de Investigación Estratégica en Bolivia, 105 pp.

Hinojosa Gordonava, Alfonso (2009). Migración boliviana a España: antecedentes, caracterización y perspectivas. Dans H. Mazurek (Éd.), Migraciones contemporáneas: contribución al debate (pp. 157-180). Postgrado en Ciencias del Desarrollo CIDES-UMSA.

INE (2002a). "Censo nacional de población y vivienda 2001. Tarija: resultados departamentales”, La Paz, Instituto Nacional de Estadística, p. 174.

INE (2002b). "Bases de datos. Censo nacional de población y vivienda 2001.

Departamento de Tarija", La Paz, Instituto Nacional de Estadística, cd-rom.

INE (2002c). "Bases de datos. Censo nacional de población y vivienda 2001. Bolivia", La Paz, Instituto Nacional de Estadística, cd-rom.

INE (2002d). "Bolivia: Distribución de la Población", La Paz, Instituto Nacional de Estadística, p. 81. 
INE (2002e). "El proceso de urbanización en Bolivia, 1992-2001”, La Paz, Instituto Nacional de Estadística, p. 56.

INE (2003). “Anuario Estadístico 2002", La Paz, Instituto Nacional de Estadística, cd-rom.

INE (2011). “Tarija”. Instituto Nacional de Estadística.pdf.

Insua, Luis Llambí, \& Correa, Edelmira Pérez (2007). Nuevas ruralidades y viejos campesinismos. Agenda para una nueva sociología rural latinoamericana. Cuadernos de Desarrollo Rural (059), pp. 37-61.

Kay, Cristóbal. (2009), "Estudios rurales en América Latina en el periodo de globalización neoliberal: ¿una nueva ruralidad?" Revista Mexicana de Sociología, 4(4), pp. 607-645.

Léonard, Éric, Quesnel, André, \& Rey, Alberto del Rey (2004). "De la comunidad territorial al archipiélago familiar. Movilidad, contractualización de las relaciones intergeneracionales y desarrollo local en el sur del estado de Veracruz". Estudios Sociológicos (003), pp. 557-589.

Ma Mung, Emmanuel (2002). "Les mutations des migrations chinoises", Ville-Ecole-Intégration, enjeux - (131), París, Centre National de Documentation Pédagogique, pp. 129-145.

Martin, Ceydric (2010). "Dynamiques migratoires en Bolivie: Perspective géographique sur le peuplement du Sud frontalier (département du Tarija)". Editions universitaires européennes, Sarrebruck, Alemania, 612 pp.

Martin, Ceydric (2011). "Estrategias migratorias fronterizas y crisis rural en los valles andinos. Migraciones internacionales de los bolivianos a Argentina”, Estudios Migratorios Latinoamericanos, (71), julio-diciembre, CEMLA (Centro de Estudios Migratorios Latinoamericanos), Buenos Aires, Argentina

Martin Ceydric. (2012). "Migraciones, pluriactividad y recomposición del espacio rural. Las dinámicas múltiples del sur boliviano", Espacialidades, $(2,2)$, julio-diciembre, Universidad Autonoma Metropolitana, Mexico.

Martínez, María José (2010). "Nueva ruralidad: la remake del término pluriactividad”. Nómadas (26).

Mazurek, Hubert, \& Arréghini, Louis (2006). "Structuration des territoires et logiques divergentes de l'économie bolivienne". Espaces et Sociétés (1-2), pp. 73-91. 
Mazurek, Hubert (2007). "Tres preconceptos sobre migración interna en Bolivia”. Revista de Humanidades y Ciencias Sociales, 3 (núm. special), pp. 203-227.

Mazurek, Hubert (2009). Migraciones contemporáneas: contribución al debate. Postgrado en Ciencias del Desarrollo, CIDES-UMSA.

Meichtry, Norma, Pellegrino, Adela, \& Bologna, Eduardo (2008). Migrantes latinoamericanos. El estado de las investigaciones en la región. Córdoba, Argentine: UNFPA: ALAP: Universidad Nacional de Córdoba.

Mesclier, Evelyne (1993), "Pérou: vers une redistribution des populations rurales andines? Changements dans la société paysanne et évolution de l'organisation de l'espace", Boletín del Instituto Francés de Estudios Andinos (22, 3), Lima, IFEA, pp. 763-789.

Paz Ballivián, Danilo (1995). "Lecciones de sociología rural", La Paz, Plural, p. 126.

Presta, Ana María (2001). "Hermosos, fértiles y abundantes. Los valles centrales de Tarija y su población en el siglo XVI”. In S. Beck, P. Narel, \& D. Preston (Éd.), Historia, Ambiente y Sociedad en Tarija, Bolivia Instituto de Ecología. La Paz.

Preston, David (2001). "La osilación del sur y la pluviosidad en el sudoeste de Tarija". In S. Beck, P. Narel, \& D. Preston (Éd.), Historia, Ambiente y Sociedad en Tarija, Bolivia. Instituto de Ecología. La Paz.

Preston, David, Macklin, Mark \& Warburton, Jeff (1997). "Fewer People, Less Erosion: The Twentieth Century in Southern Bolivia". The Geographical Journal, 163(2), 198-205. doi:10.2307/3060183

Preston, David (1999). "La emigración dentro de las estrategias de vida en el valle del río Camacho: la transnacionalización de campesinos posmodernos", Proyecto Ambiente y Sociedad en los Andes: estrategias y políticas, Leeds, University of Leeds, School of Geography <www. geog.leeds.ac.uk>, p. 5.

Punch, Samantha (2001). "La emigración como estrategia para jóvenes: escape o expulsión", Historia, ambiente y sociedad en Tarija, Bolivia, La Paz, Instituto de Ecología, pp. 123-144.

Quesnel, André \& Del Rey, Alberto (2005). "La construccion de una economía familiar de archipielago: movilidad y recomposicion de las relacio- 
nes intergeneracionales en el medio rural mexicano". Estudios Demograficos y Urbanos, 20(2), pp. 197-228.

Quesnel, André (2004). "Dynamique de peuplement, appropriation de l'espace rural et environnement", Environnement et populations: la durabilité en question, París, L'Harmattan, col. Population, pp. 53-75.

Rigg, Jonathan, Salamanca, Albert \& Parnwell, Michael (2012). "Joining the Dots of Agrarian Change in Asia: A 25 Year View from Thailand”. World. Development, 40(7), 1469-1481. doi:10.1016/j.worlddev.2012.03.001

Rodríguez Vignoli, Jorge (2002). Distribución territorial de la población de América Latina y el Caribe: tendencias, interpretaciones y desafios para las políticas públicas. Santiago. Naciones Unidas; CEPAL, CELADE, División de Población.

Roux, Jean Claude (2000). La Bolivie orientale: confins inexplorés, battues aux indiens et économie de pillage, París, L'Harmattan, p. 317.

Sánchez Albarrán, A. (2011). "Sociología rural: el nuevo campesino entre la globalización y la tierra prometida". Espacio Abierto, (4), pp. 561-577.

Simmons, Alan (1985). "Contrôle institutionnel, migration et offre de maind'oeuvre: application aux mouvements historiques en Amérique latine", Les changements ou les transitions démographiques dans le monde contemporain en développement, París, Institut Français de Recherche Scientifique pour le Développement en Coopération (Orstom), pp. 285-320.

Souchaud, Souchaud \& Martin, Ceydric (2007). "Yacuiba: un islote de la mundialización en el Chaco boliviano". Dans H. Domenach, H. Arze, D. Celton, \& P. Hamelin (Éd.), Movilidad y procesos migratorios en el espacio de frontera argentino boliviana (pp. 55-93). Cordoba, Argentine: Prensa Universitaria de Córdoba.

Steward, Julian (1978). Handbook of South American Indians. Bureau of American Ethnology (3, The tropical Forest Tribes). Washington. United States Goverment Printing Office.

Toral, Anaïs Vassas (2011). Ruralité et agriculture au prisme des mobilités spatiales. L'Altiplano Sud de la Bolivie à l'heure du boom de la quinoa, tesis de doctorado de la Universidad Montpellier III

Whiteford, Scott (1981). "Workers from the north. Plantations, Bolivian Labor, and the City in Northwest Argentina", Austin, University of Texas Press, 189 pp. 
Zonisig (2001). "Zonificación Agroecológica y Socioeconómica - Departamento de Tarija", Tarija, Ministerio de Desarrollo Sostenible y Planificación, Prefectura de Tarija, 266 pp. + cd-rom.

Zonisig-APDS (2000). "Diagnóstico Integral, Municipio de Villa Montes", Villamontes, Ministerio de Desarrollo Sostenible y Planificación, p. 110.

Zoomers, Annelies (Éd.) (1998). Estrategias Campesinas en el Surandino de Bolivia - Intervenciones y desarrollo rural en el norte de Chuquisaca y Potosí. La Paz: Plural Editores/Centro de Información para el Desarrollo - CID. 
Migración en el Sur boliviano, de Ceydric Martin, se terminó de imprimir el 17 de diciembre de 2012, en los talleres de SM gráficos, tel. (0155) 53417480 